\title{
Redução no esforço de interação em segmentação de imagens digitais através de aprendizagem computacional
}

\author{
Bruno Klava
}

TESE APRESENTADA

$\mathrm{AO}$

Instituto DE MATEMÁtica E EstatísticA

DA

Universidade De SÃo Paulo

PARA

OBTENÇÃO DO TÍTULO

$\mathrm{DE}$

DOUTOR EM CIÊNCIAS

Programa: Ciência da Computação

Orientadora: Prof ${ }^{a}$. Dr ${ }^{a}$. Nina S. T. Hirata

Durante parte do desenvolvimento deste trabalho o autor recebeu auxílio financeiro do CNPq e da FAPESP

São Paulo, dezembro de 2014 



\section{Redução no esforço de interação em segmentação de imagens digitais através de aprendizagem computacional}

Esta versão da dissertação/tese contém as correções e alterações sugeridas pela Comissão Julgadora durante a defesa da versão original do trabalho, realizada em 08/10/2014. Uma cópia da versão original está disponível no Instituto de Matemática e Estatística da Universidade de São Paulo.

Comissão Julgadora:

- Prof ${ }^{\mathrm{a}}$. Dr ${ }^{\mathrm{a}}$. Nina Sumiko Tomita Hirata (orientadora) - IME-USP

- Prof. Dr. Alexandre Noma - UFABC

- Prof. Dr. Carlos Hitoshi Morimoto - IME-USP

- Prof. Dr. Paulo André Vecchiato de Miranda - IME-USP

- Prof. Dr. Roberto de Alencar Lotufo - UNICAMP 



\section{Agradecimentos}

Esta tese de doutorado é o fruto de muita dedicação. Ao longo do doutorado pude exercitar e aprimorar meus conhecimentos e habilidades desenvolvidos na excelente formação que tive na USP, completando 12 anos que tenho o privilégio de estudar nesta instituição. Tal privilégio não é mérito exclusivo meu, mas também de todos que me apoiaram e colaboraram para que eu pudesse trilhar este caminho.

Agradeço aos meus pais, Rita e Nelson, que nunca pouparam esforços para que eu tivesse as melhores oportunidades na minha vida. O melhor do Bruno é simplesmente o reflexo de todo o amor que vocês dedicaram a mim.

Aos meus amigos, que sempre me apoiaram e deram forças para eu vencer cada desafio a que me propus.

À professora Nina, com quem tive o privilégio de aprender muito ao longo dos últimos 9 anos. Pela sua paciência e competência a me ensinar sempre como melhorar.

Aos demais membros da banca do exame de qualificação e da banca de doutorado, professores Alexandre Noma, Carlos Hitoshi Morimoto, Junior Barrera, Paulo André Vecchiato de Miranda e Roberto de Alencar Lotufo, pelas valiosas discussões que contribuíram para a qualidade desta tese e com ideias para trabalhos futuros.

Aos demais professores e funcionários do Instituto de Matemática e Estatística da Universidade de São Paulo, pelo ensino de qualidade e pela excelente formação que proporci- 
onam aos alunos.

Aos coloradores André Victor Lucci Freitas (UNICAMP), Leonardo Ré (UNICAMP), Rubens Mendes Lopes (Instituto Oceanográfico - USP) e Jayaram K. Udupa (MIPG UPENN), pelas imagens cedidas para serem utilizadas nos experimentos. Aos voluntários que participaram dos experimentos e a todos que, de uma forma ou outra, contribuíram para a realização deste trabalho.

Finalmente, ao CNPq e à FAPESP (Processo 2009/16852-0), pelo auxílio financeiro concedido, permitindo minha dedicação ao programa de doutorado e ao desenvolvimento deste trabalho de pesquisa. 


\section{Resumo}

KLAVA, B. Redução no esforço de interação em segmentação de imagens digitais através de aprendizagem computacional. 2014. 123 p. Tese (Doutorado) - Instituto de Matemática e Estatística, Universidade de São Paulo, São Paulo, 2014.

A segmentação é um passo importante em praticamente todas as tarefas que envolvem processamento de imagens digitais. Devido à variedade de imagens e diferentes necessidades da segmentação, a automação da segmentação não é uma tarefa trivial. Em muitas situações, abordagens interativas, nas quais o usuário pode intervir para guiar o processo de segmentação, são bastante úteis. Abordagens baseadas na transformação watershed mostram-se adequadas para a segmentação interativa de imagens: o watershed a partir de marcadores possibilita que o usuário marque as regiões de interesse na imagem; o watershed hierárquico gera uma hierarquia de partições da imagem sendo analisada, hierarquia na qual o usuário pode navegar facilmente e selecionar uma particular partição (segmentação). Em um trabalho prévio, propomos um método que integra as duas abordagens de forma que o usuário possa combinar os pontos fortes dessas duas formas de interação intercaladamente. Apesar da versatilidade obtida ao se integrar as duas abordagens, as hierarquias construídas dificilmente contêm partições interessantes e o esforço de interação necessário para se obter um resultado desejado pode ser muito elevado. Nesta tese propomos um método, baseado em aprendizagem computacional, que utiliza imagens previamente segmentadas para tentar adaptar uma dada hierarquia 
de forma que esta contenha partições mais próximas de uma partição de interesse. Na formulação de aprendizagem computacional, diferentes características da imagem são associadas a possíveis contornos de regiões, e esses são classificados como contornos que devem ou não estar presentes na partição final por uma máquina de suporte vetorial previamente treinada. A hierarquia dada é adaptada de forma a conter uma partição que seja consistente com a classificação obtida. Essa abordagem é particularmente interessante em cenários nos quais lotes de imagens similares ou sequências de imagens, como frames em sequências de vídeo ou cortes produzidas por exames de diagnóstico por imagem, precisam ser segmentadas. Nesses casos, é esperado que, a cada nova imagem a ser segmentada, o esforço de interação necessário para se obter a segmentação desejada seja reduzido em relação ao esforço que seria necessário com o uso da hierarquia original. Para não dependermos de experimentos com usuários na avaliação da redução no esforço de interação, propomos e utilizamos um modelo de interação que simula usuários humanos no contexto de segmentação hierárquica. Simulações deste modelo foram comparadas com sequências de interação observadas em experimentos com usuários humanos. Experimentos com diferentes lotes e sequências de imagens mostram que o método é capaz de reduzir o esforço de interação.

Palavras-chave: watershed hierárquico, segmentação interativa de imagens, hierarquia de partições, aprendizado computacional. 
KLAVA, B. Reducing the interaction effort in digital image segmentation through machine learning. 2014. 123 p. Tese (Doutorado) - Instituto de Matemática e Estatística, Universidade de São Paulo, São Paulo, 2014.

Segmentation is an important step in nearly all tasks involving digital image processing. Due to the variety of images and segmentation needs, automation of segmentation is not a trivial task. In many situations, interactive approaches in which the user can intervene to guide the segmentation process, are quite useful. Watershed transformation based approaches are suitable for interactive image segmentation: the watershed from markers allows the user to mark the regions of interest in the image; the hierarchical watershed generates a hierarchy of partitions of the image being analyzed, hierarchy in which the user can easily navigate and select a particular partition (segmentation). In a previous work, we have proposed a method that integrates the two approaches so that the user can combine the strong points of these two forms of interaction interchangeably. Despite the versatility obtained by integrating the two approaches, the built hierarchies hardly contain interesting partitions and the interaction effort needed to obtain a desired outcome can be very high. In this thesis we propose a method, based on machine learning, that uses images previously segmented to try to adapt a given hierarchy so that it contains partitions closer to the partition of interest. In the machine learning formulation, different image features are associated to the possible region contours, and these are classified as ones 
that must or must not be present in the final partition by a previously trained support vector machine. The given hierarchy is adapted to contain a partition that is consistent with the obtained classification. This approach is particularly interesting in scenarios where batches of similar images or sequences of images, such as frames in video sequences or cuts produced by imaging diagnosis procedures, need to be segmented. In such cases, it is expected that for each new image to be segmented, the interaction effort required to achieve the desired segmentation is reduced relative to the effort that would be required when using the original hierarchy. In order to do not depend on experiments with users in assessing the reduction in interaction effort, we propose and use an interaction model that simulates human users in the context of hierarchical segmentation. Simulations of this model were compared with interaction sequences observed in experiments with humans users. Experiments with different bacthes and image sequences show that the method is able to reduce the interaction effort.

Keywords: hierarchical watershed, interactive image segmentation, hierarchy of partitions, machine learning. 
1 Introdução 1

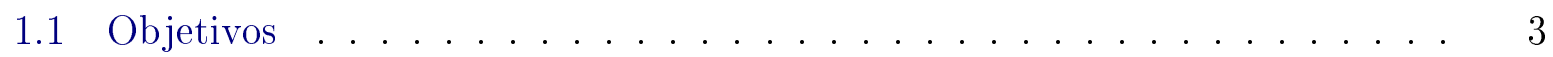

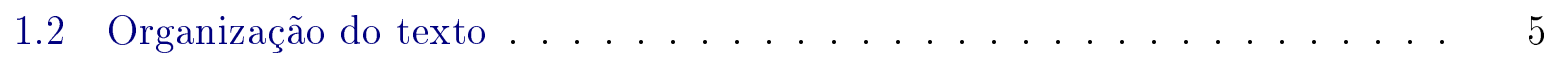

2 Fundamentos $\quad 7$

2.1 Transformação watershed . . . . . . . . . . . . . . 7

2.1.1 Watershed clássico .................. 7

2.1.2 Watershed a partir de marcadores ............ 9

2.1.3 Watershed hierárquico .................. 11

2.1.4 Alternando entre as abordagens do watershed . . . . . . . . . 14

2.2 Avaliação do resultado de segmentações . . . . . . . . . . . . . . . 15

3 Incorporação de resultados de segmentações anteriores $\quad 19$ 
3.1 Modelagem do problema de aprendizado . . . . . . . . . . . . . 19

3.1.1 Completar as bordas obtidas por um classificador . . . . . . . . . 21

3.1.2 Filtragem de bordas pouco confiáveis . . . . . . . . . . . . . 21

3.1.3 Remoção de bordas desnecessárias via fusão de regiões . . . . . . . 23

3.2 Definição do vetor de características . . . . . . . . . . . . . 25

3.3 Utilização de múltiplos classificadores . . . . . . . . . . . . . . . . 27

4 Simulação de interação no watershed hierárquico 29

4.1 Descrição do modelo de interação . . . . . . . . . . . . . . . . . 29

4.2 Experimentos com usuários . . . . . . . . . . . . . . . . . 34

4.3 Simulação . . . . . . . . . . . . . . . . . . . . 37

4.4 Análise dos resultados $\ldots \ldots \ldots \ldots$

4.5 Discussão . . . . . . . . . . . . . . . . . . . . 43

$\begin{array}{lll}5 & \text { Experimentos } & 49\end{array}$

5.1 Medida do esforço de interação . . . . . . . . . . . . . . 49

5.2 Descrição dos experimentos . . . . . . . . . . . . . . 51

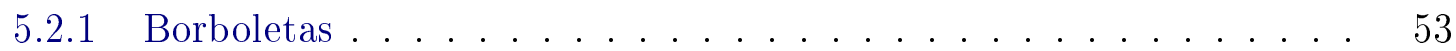

5.2 .2 Fitoplâncton . . . . . . . . . . . . . . 56

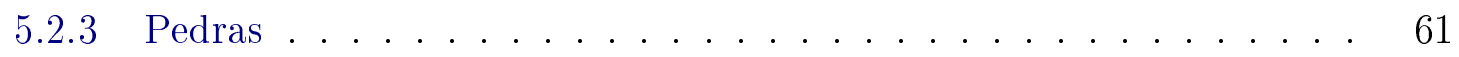

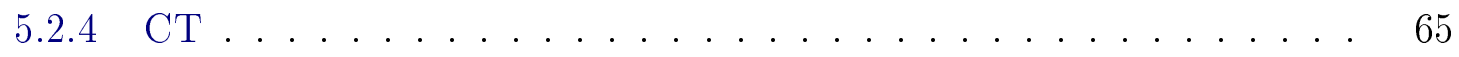

5.3 Discussão sobre o resultado dos experimentos . . . . . . . . . . . . 67

6 Integração com sistemas interativos de segmentação $\quad 71$

6.1 Treinamento online $\times$ offline ................... 71

6.2 Coerência entre operações global e locais . . . . . . . . . . . 73 
6.2.1 Representação de hierarquias através de dendrogramas . . . . . . 76

6.2.2 Adaptação dos pesos da hierarquia . . . . . . . . . . . . . 76

$\begin{array}{llr}7 & \text { Considerações finais } & 81\end{array}$

$\begin{array}{ll}\text { Apêndices } & 82\end{array}$

A Tarefas de segmentação dos experimentos $\quad 83$

$\begin{array}{ll}\text { B Hierarquia de valor médio } & 95\end{array}$

$\begin{array}{ll}\text { Referências Bibliográficas } & 99\end{array}$ 



\section{Lista de Abreviaturas}

AGM Árvore geradora mínima

ALC Árvore dos lagos críticos

PAG Grafo de adjacência de pixels (pixel adjacency graph)

RAG Grafo de adjacência de regiões (region adjacency graph)

SVM Máquina de suporte vetorial (support vector machine) 



\section{Lista de Figuras}

2.1 Inundação de uma superfície topográfica. . . . . . . . . . . . . . 8

2.2 Watershed clássico. . . . . . . . . . . . . . . . . . 9

2.3 Watershed a partir de marcadores. . . . . . . . . . . . 10

2.4 Localização de partições através de operações sobre a hierarquia. . . . . . . 12

2.5 Limitação de partições devido à estrutura da hierarquia. . . . . . . . . . . 14

2.6 Alternando entre as abordagens do watershed. . . . . . . . . . . 16

3.1 Efeito de erros de classificação de arestas entre ativas e inativas. . . . . . . 22

3.2 Utilização da hierarquia para obter bordas que delimitam regiões numa partição. . . . . . . . . . . . . . . . . . . 23

3.3 Efeito da fusão de regiões adjacentes sem arestas inativas. . . . . . . . . . 24

3.4 Banco de filtros. . . . . . . . . . . . . . . . . . 26

3.5 Combinação de diversos classificadores. . . . . . . . . . . . . . . . 28

4.1 Modelo de simulação de interação no watershed hierárquico. . . . . . . . . 31

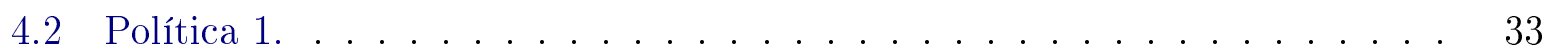




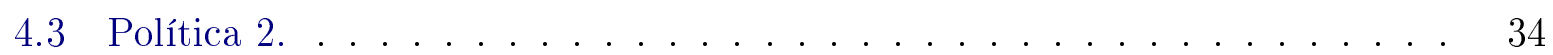

4.4 Captura de tela da execução do SegmentIt nos experimentos com usuários. 36

4.5 Perfis médios de evolução das medidas de qualidade nos experimentos. . . . 40

4.6 Exemplo de execução de uma mesma tarefa de segmentação dos experimentos por um voluntário e por uma simulação com a política 3. . . . . . .

4.7 Correlação entre os perfis médios dos experimentos com usuários e cada uma

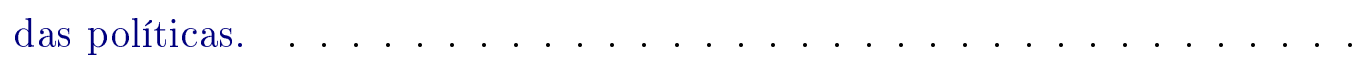

4.8 Perfis médios de evolução das medidas de qualidade nos experimentos sobrepostos à variabilidade das séries médias dos usuários humanos. . . . . .

4.9 Séries médias das medidas de qualidade nos experimentos com cada um dos usuários humanos que colaboraram nos experimentos. . . . . . . . . .

4.10 Perfis médios de evolução das medidas de qualidade nos experimentos para diversos valores constantes para $\mathcal{P}$. . . . . . . . . . . 46

4.11 Correlação entre os perfis médios dos experimentos com usuários e cada uma das políticas e diversos valores constantes para $\mathcal{P}$. . . . . . . . .

5.1 Exemplos de imagens e ground truths do lote "Borboletas". . . . . . . . . 53

5.2 Esforço para segmentar o lote "Borboletas" sem o método proposto. . . . . 54

5.3 Esforço para segmentar o lote "Borboletas" sem as heurísticas. . . . . . . . 54

5.4 Esforço para segmentar o lote "Borboletas" com a heurística de filtragem. . 55

5.5 Esforço para segmentar o lote "Borboletas" com a heurística de fusão. . . . 55

5.6 Esforço para segmentar o lote "Borboletas" com ambas as heurísticas. . . . 56

5.7 Esforço total para segmentar o lote "Borboletas". . . . . . . . . . . . 57

5.8 Exemplos de imagens e ground truths do lote "Fitoplâncton". . . . . . . . . 57

5.9 Esforço para segmentar o lote "Fitoplâncton" sem o método proposto. . . . 58

5.10 Esforço para segmentar o lote "Fitoplâncton" sem as heurísticas. . . . . . . 59

5.11 Esforço para segmentar o lote "Fitoplâncton" com a heurística de filtragem. 59 
5.12 Esforço para segmentar o lote "Fitoplâncton" com a heurística de fusão. . . 60

5.13 Esforço para segmentar o lote "Fitoplâncton" com ambas as heurísticas. . . 60

5.14 Esforço total para segmentar o lote "Fitoplâncton". . . . . . . . . . . . . 61

5.15 Exemplos de imagens e ground truths da sequência "Pedras". . . . . . . . . 62

5.16 Esforço para segmentar a sequência "Pedras" sem o método proposto. . . . 62

5.17 Esforço para segmentar a sequência "Pedras" sem as heurísticas. . . . . . . 63

5.18 Esforço para segmentar a sequência "Pedras" com a heurística de filtragem. 63

5.19 Esforço para segmentar a sequência "Pedras" com a heurística de fusão. 64

5.20 Esforço para segmentar a sequência "Pedras" com ambas as heurísticas. . . 64

5.21 Esforço total para segmentar a sequência "Pedras". . . . . . . . . . . . 65

5.22 Exemplos de imagens e ground truths da sequência "CT". . . . . . . . . . 66

5.23 Esforço para segmentar a sequência "CT" sem o método proposto. . . . . . 67

5.24 Esforço para segmentar a sequência "CT" sem as heurísticas. . . . . . . . . 68

5.25 Esforço para segmentar a sequência "CT" com a heurística de filtragem. . . 68

5.26 Esforço para segmentar a sequência "CT" com a heurística de fusão. . . . . 69

5.27 Esforço para segmentar a sequência "CT" com ambas as heurísticas. . . . . 69

5.28 Esforço total para segmentar a sequência "CT". . . . . . . . . . . . 70

6.1 Tempo de processamento para o lote "Borboletas". . . . . . . . . . . 73

6.2 Tempo de processamento para o lote "Fitoplâncton". . . . . . . . . . . . . 74

6.3 Tempo de processamento para a sequência "Pedras". . . . . . . . . . . . 74

6.4 Tempo de processamento para a sequência "CT". . . . . . . . . . . . . 75

6.5 Uma hierarquia de partições representada por um dendrograma. . . . . . . 77

6.6 Partições obtidas através de operações hierárquicas. . . . . . . . . . . 78

6.7 Adaptação dos pesos do dendograma. . . . . . . . . . . . . 79 


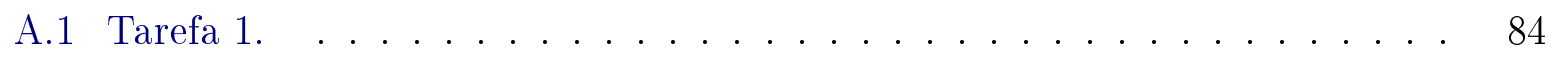

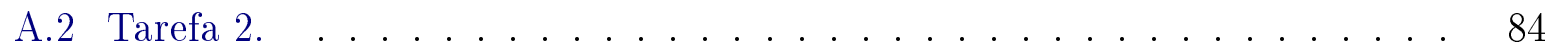

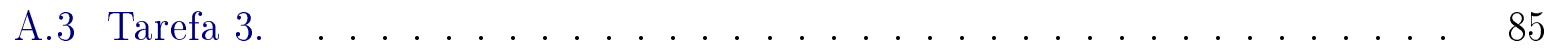

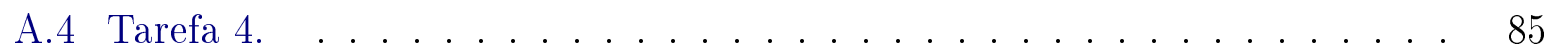

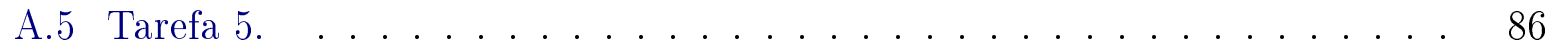

A.6 Tarefa $6 . \ldots \ldots \ldots \ldots \ldots \ldots \ldots$

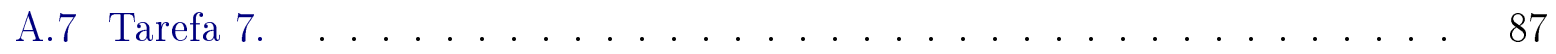

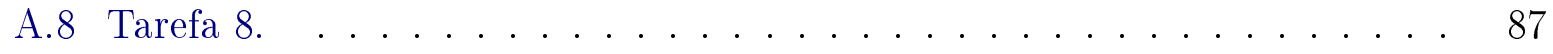

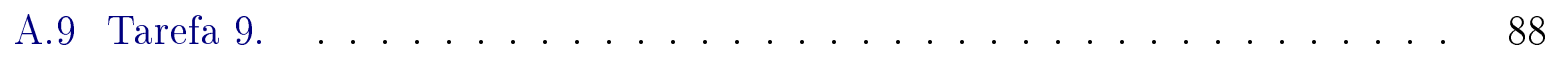

A.10 Tarefa $10 \ldots \ldots \ldots \ldots \ldots \ldots \ldots$

A.11 Tarefa 11. . . . . . . . . . . . . . . . . . 89

A.12 Tarefa 12. . . . . . . . . . . . . . . . . 89

A.13 Tarefa 13. . . . . . . . . . . . . . . . . . 90

A.14 Tarefa 14. . . . . . . . . . . . . . . . . . 90

A.15 Tarefa 15. . . . . . . . . . . . . . . . . . 91

A.16 Tarefa 16. . . . . . . . . . . . . . . . . . 91

A.17 Tarefa 17. . . . . . . . . . . . . . . . . . . . 92

A.18 Tarefa 18. . . . . . . . . . . . . . . . . . . . . 92

A.19 Tarefa 19. . . . . . . . . . . . . . . . . . . 93

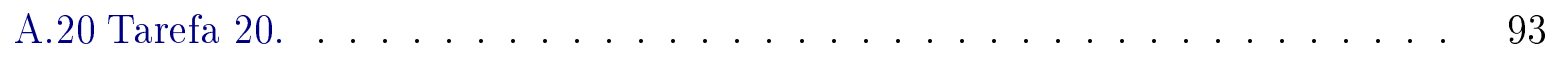

B.1 Imagem segmentada mais facilmente usando a hierarquia de valor médio. 96 


\section{Introdução}

Tarefas de segmentação são necessárias em muitos problemas que envolvem análise e processamento de imagens digitais. A segmentação consiste em delimitar, no domínio espacial da imagem, os contornos dos objetos alvos da análise em questão. Após a segmentação ser feita, medidas podem ser extraídas de tais objetos para então serem utilizadas em tarefas posteriores, como classificação e reconhecimento de objetos, por exemplo. Por se tratar de uma das tarefas iniciais em diversos sistemas de análise de imagens, a qualidade do resultado do processo de segmentação é de extrema importância, tendo efeitos sobre todas as tarefas subsequentes ao processo.

Em geral, não existe um mapeamento satisfatório entre atributos de baixo nível de imagens digitais com o conteúdo dessas, salvo alguns casos bem específicos. Dentre esses casos, podemos citar: o uso de substâncias de contraste, utilizados em alguns processos médicos para ressaltar determinados tecidos ou estruturas; a aquisição de imagens multiespectrais, em que determinados objetos podem ser diferenciados dos demais por seus materiais terem diferentes propriedades de absorção ou reflexão de comprimento de ondas específicos; uso de técnicas como chroma keying na produção de vídeos, onde uma cor que não aparece nos objetos do primeiro plano da imagem é utilizada no fundo, de forma que tal fundo é facilmente subtraído das imagens adquiridas. Os problemas de segmentação são bem resolvidos nos casos listados pois seus processos de aquisição das imagens foram gerenciados explicitamente para que a segmentação seja obtida de forma direta ou bem facilitada. Porém, nestes casos, a técnica de segmentação fica restrita ao processo de aquisição definido.

Não são raras as situações nas quais a segmentação de imagens precisa ser realizada manualmente, quer seja pela dificuldade de se projetar algoritmos que automaticamente produzam resultados satisfatórios, ou pela necessidade de segmentações com alta precisão.

Abordagens interativas para segmentação de imagens são um intermediário entre abordagens automáticas e manuais, tratando a inabilidade das abordagens automáticas gera- 
rem resultados sempre corretos e também reduzindo a carga de trabalho necessária nas abordagens puramente manuais. Numa abordagem interativa, usuários guiam o processo de segmentação através de um conjunto de operações interativas (semi-supervisionadas). Podemos dividir tais operações em dois principais grupos:

- um grupo de tais operações consiste em fazer marcações nos objetos de interesse ou seus contornos, que então são usados como sementes no interior das regiões de interesse ou como pontos de ancoragem para delinear os contornos de tais regiões (Beucher e Meyer, 1993; Blake et al., 2004; Falcão et al., 1998; Mortensen e Barrett, 1998);

- outro grupo de operações consiste em fundir e dividir regiões de forma a se obter um resultado desejado (Ning et al., 2010), operações comuns em segmentação hierárquica, abordagem na qual uma partição numa pilha de partições aninhadas pode ser selecionada rapidamente e regiões individuais podem ser fundidas ou divididas para refinar a partição selecionada (Cates et al., 2005; Gerstmayer et al., 2011; Hahn e Peitgen, 2003; Klava e Hirata, 2009; Zanoguera et al., 1999). Hierarquias são particularmente adequadas quando segmentações com diversos níveis de detalhes são desejados ou quando há muito objetos a serem segmentados.

A transformação watershed (Meyer e Beucher, 1990) é utilizada amplamente em diversos sistemas para segmentação de imagens digitais. Existem duas abordagens de segmentação interativa baseadas na transformação watershed, que utilizam os dois tipos de operações citados acima:

- watershed a partir de marcadores: abordagem na qual o problema de segmentação é reduzido ao problema de se criar marcadores adequados para os objetos em análise. Nesta abordagem, cada um dos marcadores dá origem a uma região da partição. Editando interativamente o conjunto de marcadores, o usuário tem controle sobre o processo de segmentação e a partição obtida.

- watershed hierárquico: determina um conjunto hierárquico de partições, no qual partições mais finas estão aninhadas sob partições mais grossas. A ordem na qual as regiões dos níveis mais finos são fundidas em regiões de níveis mais grossos é determinada por métricas bem definidas sobre tais regiões. O problema de segmentação é, então, reduzido ao problema de se navegar pela hierarquia de partições para se localizar uma partição desejada.

No watershed a partir de marcadores, há a necessidade de se marcar cada um do objetos da cena individualmente, porém o usuário tem controle total sobre o número de regiões e a 
forma dessas na partição obtida. Já no watershed hierárquico, é possível segmentar diversos objetos conjuntamente, porém as partições que podem ser obtidas são limitadas pela estrutura da hierarquia construída, determinada pela métrica utilizada em sua construção.

Em um trabalho anterior (Klava, 2009), foi proposta a integração das duas abordagens supracitadas, de forma que o usuário possa alternar entre elas, usufruindo dos pontos positivos de cada uma delas. Tal integração foi implementada na ferramenta SegmentIt, disponível em http://segmentit. sourceforge.net/. Essa abordagem integrada permite o uso de diferentes métricas de construção de hierarquias para segmentar diferentes regiões de uma mesma imagem, o que torna o sistema mais versátil e facilita a segmentação de diferentes tipos de imagens. Porém, seu uso é limitado, uma vez que pode ser necessário muito esforço de interação para se localizar uma partição próxima da desejada numa hierarquia de partições. Além disso, geralmente é necessário realizar muitas operações que alteram a estrutura de tais hierarquias. Esse esforço de interação torna-se crítico quando desejamos segmentar um conjunto grande de imagens.

Uma característica importante em segmentação interativa é permitir que os usuários obtenham os resultados desejados com o mínimo de esforço possível. Portanto, tanto os resultados das segmentações (Pont-Tuset e Marqués, 2013; Unnikrishnan et al., 2007) quanto questões relativas aos esforço de interação (Kohli et al., 2012; McGuinness e O'Connor, 2010, 2011) devem ser levadas em consideração para a avaliação desses métodos.

\section{$1.1 \quad$ Objetivos}

Este trabalho foi iniciado tendo como motivação a criação de hierarquias mais representativas, isto é, hierarquias que contenham partições que melhor reflitam o conteúdo das imagens e portanto sejam mais próximas das possíveis segmentações desejadas. Supomos que, no contexto de segmentação interativa, o esforço de interação para a segmentação de uma imagem será consideravelmente reduzido se a hierarquia contiver uma partição que seja próxima da segmentação desejada. Quando muitas imagens devem ser segmentadas e quando não existe um protocolo de aquisição que possibilite sua segmentação automática, o esforço de interação necessário para realizar tal tarefa torna-se crítico, justamente pelo grande número de imagens. Neste caso, é desejado que o resultado de segmentações previamente realizadas sirvam como base para facilitar a segmentação de novas imagens. Técnicas de aprendizagem computacional, mais especificamente técnicas de aprendizado supervisionado, são adequadas para atender este cenário.

A partir dessa motivação, foram formulados os seguintes objetivos:

- investigar formas para utilizar, no contexto de segmentação hierárquica, informações relativas a segmentações prévias para facilitar a segmentação de novas imagens 
semelhantes;

- elaborar um método baseado em aprendizagem computacional para facilitar a segmentação de novas imagens a partir de segmentações prévias de imagens semelhantes;

- implementar, testar e validar o método proposto.

No caso da segmentação hierárquica, considerando-se o grafo de adjacência de regiões da partição mais fina na hierarquia, uma particular segmentação pode ser vista como um conjunto de subgrafos disjuntos. Arestas do grafo que não fazem parte de nenhum dos subgrafos correspondem a arestas que cruzam fronteiras entre duas regiões da segmentação. Desta forma, as arestas podem ser classificadas como correspondendo a fronteiras ou não. Apoiado nesse fato, neste trabalho propomos uma formulação do problema de segmentação como um problema de classificar quais arestas são ou não de fronteira.

Uma vez de posse de um classificador desses, deve-se de alguma forma utilizar os resultados de classificação na segmentação hierárquica. Em nossa proposta isto é feito adaptandose uma hierarquia existente, de forma que partições mais compatíveis com a classificação obtida apareçam próximo ao topo da hierarquia.

Para verificar se as hierarquias adaptadas reduzem de fato o esforço de interação, é necessário definir de forma clara o que é esse esforço e como estimá-lo em uma sessão de segmentação interativa. O esforço de interação, considerando todos os seus espectros, inclui por exemplo aspectos de percepção cognitiva. Neste trabalho, o esforço de interação refere-se ao número de operações interativas.

Mesmo considerando este escopo simplificado para o esforço de interação, ainda assim seriam necessários experimentos com usuários para estimar o esforço. Uma vez que experimentos que envolvem a participação de usuários são extremamente difíceis de serem executados, uma abordagem frequentemente utilizada é avaliar métodos interativos através de simulações com usuários robôs que simulem o comportamento de usuários reais. Apesar do uso de usuário robôs permitirem a avaliação automática de métodos de segmentação interativa, há a necessidade de uma prévia validação do modelo de interação dos usuários robôs.

Em McGuinness e O'Connor (2011) um modelo para simulação de usuários no contexto de algoritmos de segmentação baseados em marcadores foi proposto e validado. Em tal modelo, marcadores são sucessivamente criados e refinados de acordo com uma distribuição de probabilidades, baseada no erro de segmentação a cada passo do processo. O uso de simulações com usuários-robôs na avaliação de algoritmos interativos de segmentação baseados em marcadores parece ser já uma prática comum na literatura (Moschidis e Graham, 2010; Zhao et al., 2011).

Neste trabalho propomos um novo modelo de simulação de interação no contexto de 
segmentação hierárquica. Esse modelo foi comparado com experimentos realizados com usuários e é adotado para avaliar o método de aprendizagem proposto.

\subsection{Organização do texto}

No Capítulo 2 são revisados os conceito importantes para o desenvolvimento do trabalho. Em especial são revisadas a transformação watershed a partir de marcadores e o watershed hierárquico, as operações de interação sobre uma hierarquia de partições, e métricas para avaliação de resultados de segmentações. No Capítulo 3 é apresentada a proposta central desta tese: um método que utiliza informação de segmentações prévias para reduzir o esforço de interação em novas segmentações, no contexto de segmentação hierárquica. O modelo de simulação de interação, utilizado para avaliar o método proposto, é descrito no Capítulo 4. As tarefas de segmentação utilizadas em experimentos com usuários visando a validação desse modelo são apresentadas no Apêndice A. No Capítulo 5 são descritos os experimentos realizados para validar o método proposto, juntamente com os resultados obtidos e discussões. O Apêndice B apresenta a hierarquia de valor médio utilizada em alguns dos experimentos. No Capítulo 6 são consideradas questões práticas para a integração do método proposto em sistemas interativos de segmentação. Por fim, no Capítulo 7 são apresentadas as conclusões desta tese de doutorado e as possibilidades de trabalhos futuros. 



\section{Fundamentos}

Neste capítulo são apresentados os fundamentos das áreas correlatas a este trabalho, juntamente com uma revisão do trabalho anterior (Klava, 2009), cujas limitações serão exploradas nesta tese de doutorado.

\subsection{Transformação watershed}

A transformação watershed foi inspirada no estudo de linhas de partição de águas, um clássico na área de topologia. O uso de watersheds em problemas de segmentação de imagens foi introduzido por Serge Beucher e Christian Lantuejoul (Beucher e Lantuejoul, 1979). Posteriormente, Fernand Meyer introduziu o uso de marcadores (Meyer, 1986), solucionando o problema de supersegmentação da abordagem clássica. Em Meyer e Beucher (1990) e Meyer (2001a) é revisada a transformação watershed e seu uso na área de morfologia matemática para segmentação de imagens digitais.

\subsubsection{Watershed clássico}

Watersheds, ou linhas de partições de águas, representam as linhas que dividem as bacias hidrográficas num relevo. Uma bacia hidrográfica, associada a um rio, é formada por todas as regiões tais que, se uma gota de chuva precipita sobre tal região, então, tal gota de água irá escoar até o rio em questão ou um de seus afluentes. As linhas de partições de águas, então, são formadas pelos pontos nos quais, se uma gota de chuva precipita sobre tal ponto, é indeterminado para qual das bacias hidrográficas adjacentes ela irá escoar.

Imagens digitais em níveis de cinza podem ser interpretadas como relevos. O nível de cinza de um pixel é interpretado como sendo sua altitude. Uma zona plana é um 
componente conexo maximal cujos pixels têm a mesma altitude. Um mínimo regional é uma zona plana não adjacente a nenhuma outra zona plana com menor altitude. Watersheds em imagens digitais, então, são definidos pelos pixels sobre os quais não está definido para qual mínimo regional irá escoar uma gota de água que precipite sobre tal pixel.

Algoritmos para a determinação dos watersheds de imagens digitais a partir da simulação de chuva podem não ser muito eficientes pois, ao determinar o caminho que uma gota de água segue, se for encontrado um planalto (zona plana que não é um mínimo regional) devem ser analisados diversos caminhos que podem levar a diferentes mínimos regionais.

Algoritmos mais eficientes podem ser implementados baseados na simulação de imersão ou inundação: considere o relevo como uma superfície e faça um furo em cada um dos mínimos regionais; submergindo a superfície a uma velocidade constante faz com que a água inunde a superfície a partir dos diferentes mínimos regionais; quando duas ou mais frentes de águas, oriundas de diferentes mínimos regionais, estão prestes a se encontrar, uma barreira é construída pra evitar tal encontro; o processo de imersão termina quando toda a superfície está submersa, restando visível na superfície de água somente as barreiras construídas, barreiras que definem as linhas de watershed. Esse processo de inundação é ilustrado na Figura 2.1. Cada mínimo regional fica, então, associado a uma região, chamada de bacia primitiva.
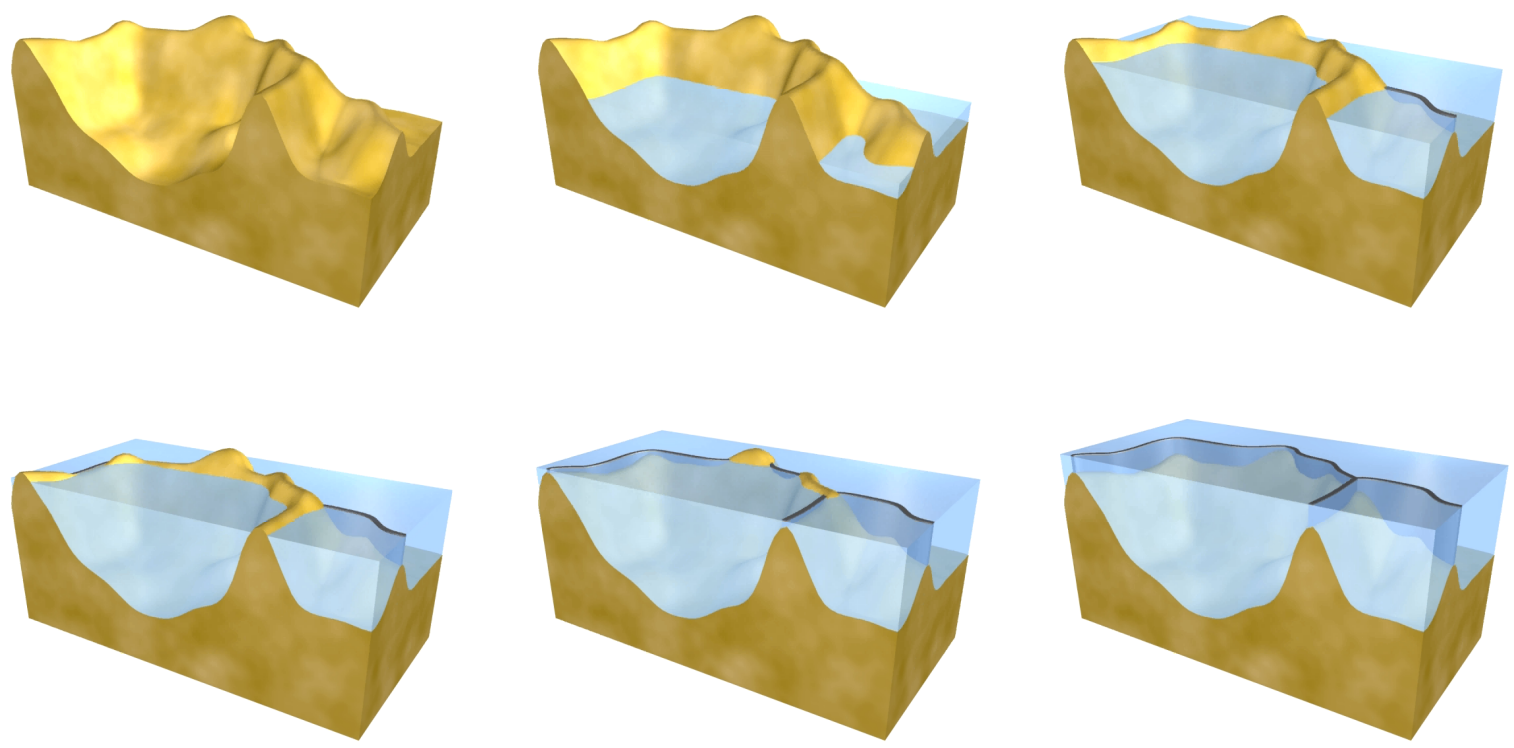

Figura 2.1: Inundação de uma superfície topográfica a partir de seus mínimos regionais e construção das barreiras (em cinza) que representam as linhas de watershed. 
As linhas de watershed ficam sobre as regiões mais altas do relevo. Como desejamos aplicar o watershed para obter as bordas que delimitam os objetos de interesse, tais bordas devem ter maiores níveis de cinza que o restante da imagem. Essa não é uma característica geral das imagens, mas é uma característica comum às imagens do tipo gradiente, como o gradiente morfológico. Por esse motivo, ao invés de aplicar a transformação watershed diretamente sobre a imagem original, é comum que se aplique tal transformação sobre o gradiente da imagem sendo analisada. Na Figura 2.2 é exibida o resultado da aplicação do watershed sobre o gradiente morfológico de uma imagem.

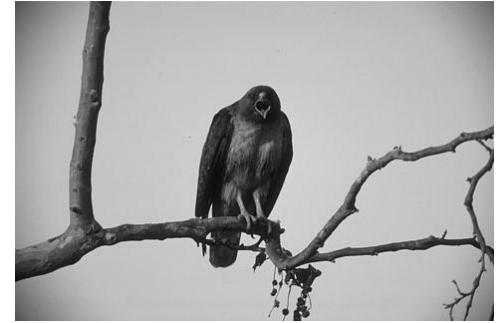

(a) Imagem original

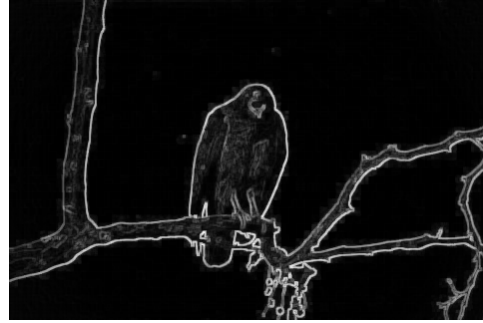

(b) Gradiente morfológico

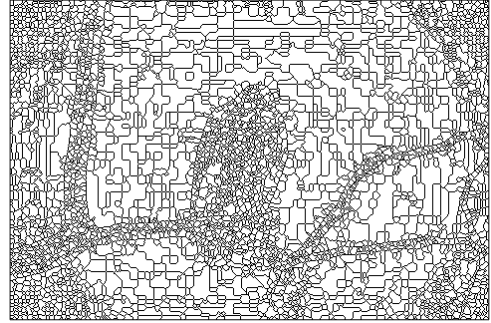

(c) Watershed clássico

Figura 2.2: Watershed clássico.

O problema do watershed clássico é que o resultado é, em geral, supersegmentado, uma vez que as imagens (ou seus gradientes) geralmente apresentam muitos mínimos regionais, principalmente pela textura dos objetos das imagens, ruídos inerentes aos processos de aquisição ou mesmo por processos de compressão utilizados no armazenamento de imagens digitais em determinados formatos.

\subsubsection{Watershed a partir de marcadores}

Para solucionar o problema de supersegmentação supracitado, foi proposto o uso de marcadores (Meyer, 1986): na simulação de inundação, ao invés de fazer um furo em cada um dos mínimos regionais, um furo é feito em cada um dos marcadores; o processo segue como descrito anteriormente, resultando em uma bacia de retenção para cada um dos marcadores. Cada bacia de retenção, então, corresponde a uma região de interesse da partição. Desta forma, o problema de segmentação é reduzido ao problema de criar marcadores adequados para cada um dos objetos alvos da análise. A localização, formato e tamanho exato dos marcadores não é importante, o que torna essa abordagem bastante robusta: os marcadores podem ser movidos dentro de determinadas regiões, chamadas de regiões receptivas não redundantes (Audigier e Lotufo, 2007), de forma que o resultado não seja alterado. Através da manipulação dos marcadores de forma interativa, um sistema de segmentação baseado nesta abordagem permite que o usuário guie o processo de segmentação, tendo 
pleno controle sobre o número de regiões de interesse, suas formas e os níveis de detalhes de cada região. Na Figura 2.3 é ilustrada a segmentação por marcadores da imagem da Figura 2.2(a).

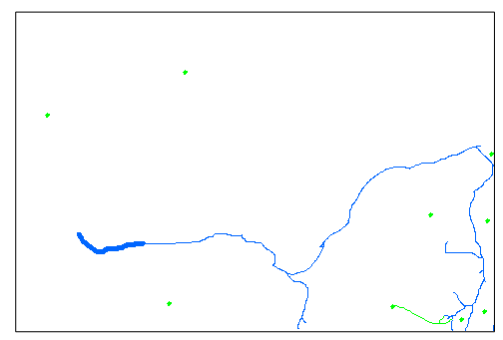

(a) Marcadores

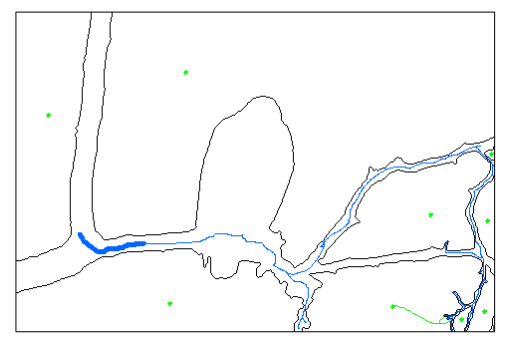

(b) Marcadores e resultado sobrepostos

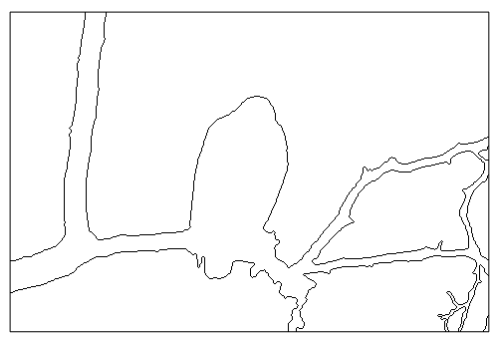

(c) Resultado

Figura 2.3: Watershed a partir de marcadores.

Uma implementação eficiente da simulação de inundação a partir de marcadores é por meio do algoritmo da IFT (Falcão et al., 2004), uma generalização do algoritmo de Djikstra para múltiplas fontes e funções de custo mais gerais. Nessa abordagem, uma partição é obtida através da rotulação dos vértices do grafo que representa a imagem: uma rotulação inicial (de um subconjunto de vértices) é derivada a partir dos marcadores; tal rotulação é propagada para os demais vértices do grafo através de caminhos de custo mínimos. Uma vantagem da utilização desse algoritmo é a possibilidade de utilizar grafos que representam a imagem em diferentes granularidades:

- Grafo de adjacência de pixels, ou $\mathrm{PAG}^{1}$ : grafo cujos vértices são os pixels da imagem considerada;

- Grafo de adjacência de regiões, ou $\mathrm{RAG}^{2}$ : grafo cujos vértices são as bacias primitivas da imagem considerada.

Com a utilização do PAG é possível que se obtenha partições com qualquer nível de detalhe no nível dos pixels, sendo possível, por exemplo, separar uma bacia primitiva em mais de uma região. Já com a utilização do RAG, as bacias primitivas são unidades atômicas, o que limita a precisão das partições que podem ser obtidas. Porém, a execução da transformação watershed sobre o RAG é feita de forma mais rápida, uma vez que esse grafo possui um número de vértices bem menor que o PAG.

\footnotetext{
${ }^{1}$ PAG: do inglês Pixel Adjacency Graph.

${ }^{2}$ RAG: do inglês Region Adjacency Graph.
} 


\subsubsection{Watershed hierárquico}

No watershed hierárquico, uma hierarquia de partições é construída de forma que partições mais finas fiquem aninhadas sob partições mais grossas.

A hierarquia é representada por uma árvore binária, chamada de árvore dos lagos críticos (ALC), descrita em Meyer (1996), construída com base na simulação de inundação utilizada no watershed clássico: iniciamos o nível mais baixo da hierarquia com a partição mais fina da imagem, dada pelo resultado do watershed clássico (as bacias primitivas são as folhas da ALC); ao longo do processo de inundação, quando duas bacias de retenção se fundem, há a formação do que chamamos de lago crítico; cada lago crítico é armazenado em um novo nó na hierarquia, nó que é definido como pai dos dois nós correspondentes às bacias de retenção que foram fundidas em tal lago crítico, sejam elas duas bacias primitivas, uma bacia primitiva e um lago crítico ou dois lagos críticos; o processo segue até que todas as bacias de retenção estejam aninhadas sob um único lago crítico, que corresponde à raiz da ALC e engloba todo o domínio espacial da imagem.

A ALC pode ser obtida rapidamente a partir de uma árvore geradora mínima (AGM) do RAG, uma vez que as arestas da AGM do RAG e seus pesos indicam quais bacias de retenção são fundidas e em qual ordem tais fusões ocorrem. O peso de uma aresta pode corresponder, por exemplo, ao nível de água no momento da fusão das regiões conectadas por ela, como no processo descrito acima.

No contexto do watershed hierárquico, o problema de segmentação é reduzido ao problema de se navegar pela estrutura hierárquica para localizar a partição de interesse. Tal navegação pode ser feita através das operações propostas em Zanoguera et al. (1999):

- seleção de limiar - permite escolher um limiar para selecionar uma partição dentro da hierarquia através da supressão de todas as arestas com peso maior que o dado limiar, correspondendo a um corte por toda a estrutura hierárquica, como ilustrado na Figura 2.4(c);

- divisão local - divide a região selecionada em outras duas, correspondentes aos nós filhos da região selecionada, como ilustrado na Figura 2.4(d);

- fusão local - funde a região selecionada com uma ou mais regiões na região correspondente ao nó pai da região originalmente selecionada, como ilustrado na Figura 2.4(e).

As operações sobre a ALC funcionam como remoção/inclusão de arestas na AGM do RAG:

- a partição mais fina da hierarquia corresponde a todos os vértices desconectados, ou seja, cada bacia primitiva é uma região da partição; 


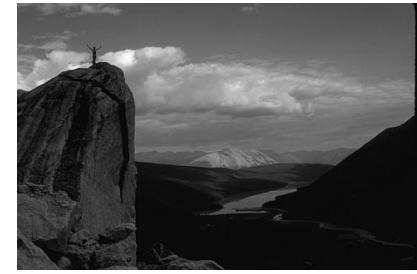

(a) Imagem original

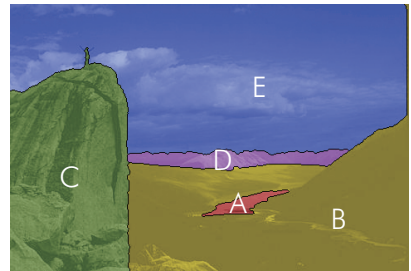

(b) Partição mais fina
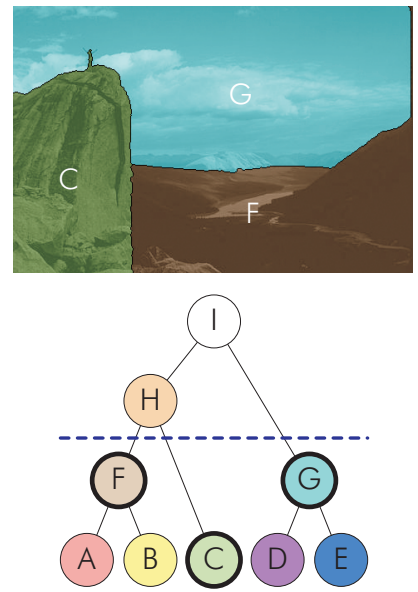

(c) Seleção de limiar
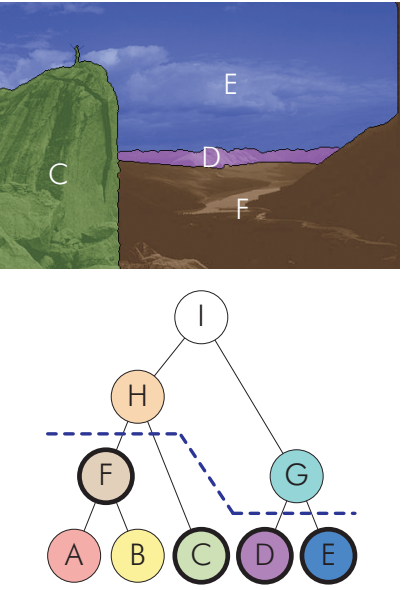

(d) Divisão local
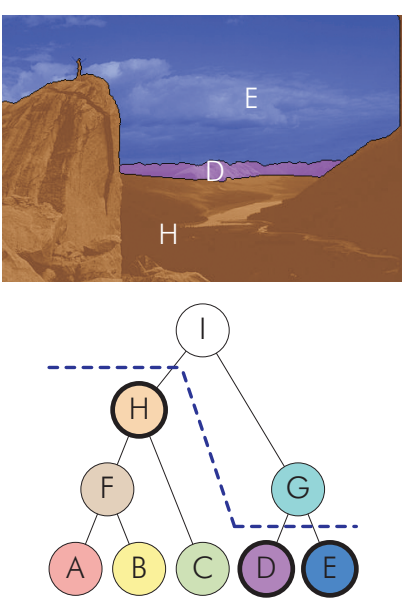

(e) Fusão local

Figura 2.4: Localização de partições através de operações sobre a hierarquia: (c) 3 regiões (F, C e G) selecionadas por um limiar. (d) Região G dividida em D e E. (e) Regiões F e $\mathrm{C}$ fundidas em $\mathrm{H}$.

- a partição mais grossa da hierarquia corresponde a todos os vértices conectados, ou seja, a única região da partição é formada por toda a imagem;

- as partições intermediárias são dadas por um subconjunto de arestas da AGM do RAG: cada componente conexo dos vértices do RAG e do dado subconjunto de arestas corresponde a uma região da partição. Ao remover uma aresta, uma região é dividida em duas; ao incluir uma aresta, duas regiões são fundidas.

A remoção de uma aresta da AGM corresponde a um corte no grafo, que por sua vez corresponde a uma borda (uma linha de partição) na imagem.

O processo de inundação descrito anteriormente, denominado de inundação uniforme, resulta numa hierarquia cujas partições geralmente não evidenciam nenhuma característica importante na imagem. Hierarquias mais interessantes são obtidas através do processo de inundação síncrona, similar à inundação uniforme, mas com as seguintes diferenças: 
- Ao invés de fazer um furo em cada mínimo regional da imagem, uma fonte de água é criada sobre cada um deles;

- ao invés de submergir a superfície a uma velocidade constante, a vazão das fontes de água é controlada de forma que uma métrica bem definida sobre as bacias de retenção fique constante.

A métrica utilizada no processo de inundação síncrona pode ser:

- Profundidade: resulta numa hierarquia que diferencia regiões de acordo com seus contrastes;

- Área: resulta numa hierarquia que diferencia regiões de acordo com seus tamanhos;

- Volume: resulta numa hierarquia que combina as características das duas outras métricas, diferenciando regiões de acordo com seus contrastes e tamanhos.

Com a utilização dessas métricas, a operação de limiar sobre a hierarquia obtida determina a característica das regiões da partição selecionada. Se utilizarmos, por exemplo, a métrica de área e selecionarmos um limiar igual a $A$, todas as regiões da partição obtida terão área maior que o valor $A$ selecionado.

Como descrito em Meyer (2001b), o processo de inundação síncrona a partir de qualquer uma das métricas supracitadas pode ser feito a partir da AGM do RAG obtida no processo de inundação uniforme. Isso se deve ao fato de que as arestas da AGM do RAG e seus pesos contêm toda a informação necessária para determinar quais bacias de retenção são fundidas entre si e qual a ordem que tais fusões ocorrem.

Apesar da inundação síncrona gerar hierarquias com partições que evidenciam características interessantes na imagem, nem todas as partições possíveis da imagem podem ser obtidas diretamente da ALC, uma vez que a estrutura da hierarquia define quais partições podem ser obtidas. Para resolver tal problema, em Klava e Hirata (2009) foi proposta uma nova operação sobre a hierarquia:

- fusão manual - permite fundir regiões adjacentes na imagem independentemente da estrutura original da hierarquia, como ilustrado na Figura 2.5.

Na operação de fusão manual, pode ser necessário a inclusão de arestas que não estão numa AGM do RAG, ou mesmo a utilização de arestas do RAG em ordens que não seguem os pesos dados pela métrica utilizada para gerar a hierarquia original. Por este motivo, pode ser necessário a reconstrução da hierarquia para que esta contenha a partição desejada. Tal reconstrução pode ser implementada de forma eficiente ao se aproveitar as subárvores que 

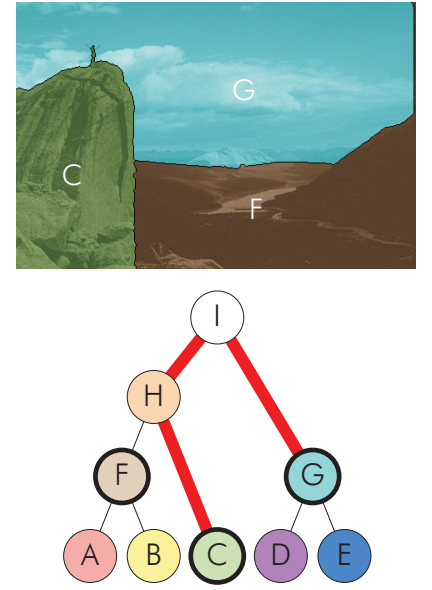

(a) Hierarquia incompatível com a partição desejada
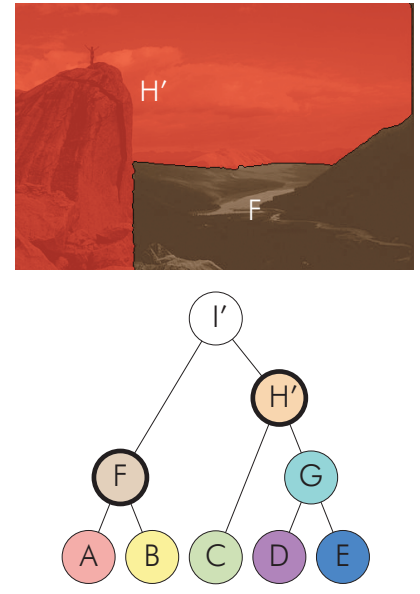

(b) Hierarquia compatível com a partição desejada

Figura 2.5: Limitação de partições devido à estrutura da hierarquia: (a) Se desejamos fundir as regiões $\mathrm{C}$ e $\mathrm{G}$ da Figura 2.4(c), o menor ancestral comum delas (que corresponde à raiz da hierarquia, caminhos destacados em vermelho) deve ser selecionado, o que implica que a região $\mathrm{F}$ também deve ser fundida com $\mathrm{C}$ e G. (b) Hierarquia modificada, contendo a partição desejada.

representam as regiões da partição selecionada antes da operação de fusão: o processo de inundação se inicia com as bacias de retenção correspondentes às subárvores citadas, sendo necessário reconstruir a hierarquia somente deste nível até a raiz da ALC, reaproveitando as subestruturas da hierarquia original que permanecem comuns à nova hierarquia desejada. Como exemplo, na Figura 2.5 as subárvores enraizadas em F, C e G são reaproveitadas da hierarquia original, sendo necessário reconstruir somente os níveis superiores (nós H' e I') para se obter a partição desejada.

Com essa operação de fusão manual, em que o usuário especifica quais regiões devem ser fundidas, qualquer partição da imagem com nível de precisão do RAG podem ser obtidas através da abordagem hierárquica.

\subsubsection{Alternando entre as abordagens do watershed}

Tendo as duas abordagens da transformação watershed, um sistema de segmentação pode facilitar tarefas de segmentação ao possibilitar que se utilize ambas as abordagens alternadamente:

- uma segmentação realizada inicialmente através da hierarquia pode ser refi- 
nada/corrigida com o uso de marcadores;

- uma região selecionada através de marcadores pode ser subsegmentada através da abordagem hierárquica, o que permite que diferentes métricas para construção de hierarquias possam ser utilizadas para segmentar diferentes objetos de uma mesma imagem.

Para se alternar da abordagem hierárquica para a abordagem de marcadores, podemos calcular os marcadores mínimos (Audigier e Lotufo, 2007). O objetivo do problema de marcadores mínimos é o inverso do watershed a partir de marcadores: dada uma partição de uma imagem, consiste em achar um conjunto mínimo de marcadores que é suficiente para se obter a mesma partição através da transformação watershed.

Para se alternar da abordagem de marcadores para a abordagem hierárquica, utilizamos a mesma técnica da operação de fusão manual na hierarquia:

- consideramos inicialmente cada uma das regiões da partição selecionada por marcadores e construímos uma hierarquia restrita a cada uma dessas regiões, obtendo, assim, uma subárvore da ALC para cada uma dessas regiões;

- construímos o restante da hierarquia tendo como regiões iniciais as bacias de retenção associadas às subárvores criadas no passo anterior.

No diagrama da Figura 2.6 são relacionadas as transições possíveis entre as abordagens interativas do watershed e representações de partições através do RAG ou do PAG.

\subsection{Avaliação do resultado de segmentações}

A avaliação de abordagens para segmentação geralmente é feita através da comparação dos resultados obtidos com uma segmentação ideal, chamada de ground truth. No contexto do watershed formulado como um problema em grafos, podemos comparar uma segmentação com um ground truth verificando, para cada aresta do grafo, se os vértices ligados por esta aresta estão ou não conectados. Com base nessa comparação, definimos quatro classes:

- Verdadeiros positivos (VP): pares conectados tanto na segmentação avaliada quanto no ground truth;

- Verdadeiros negativos (VN): pares desconectados tanto na segmentação avaliada quanto no ground truth; 


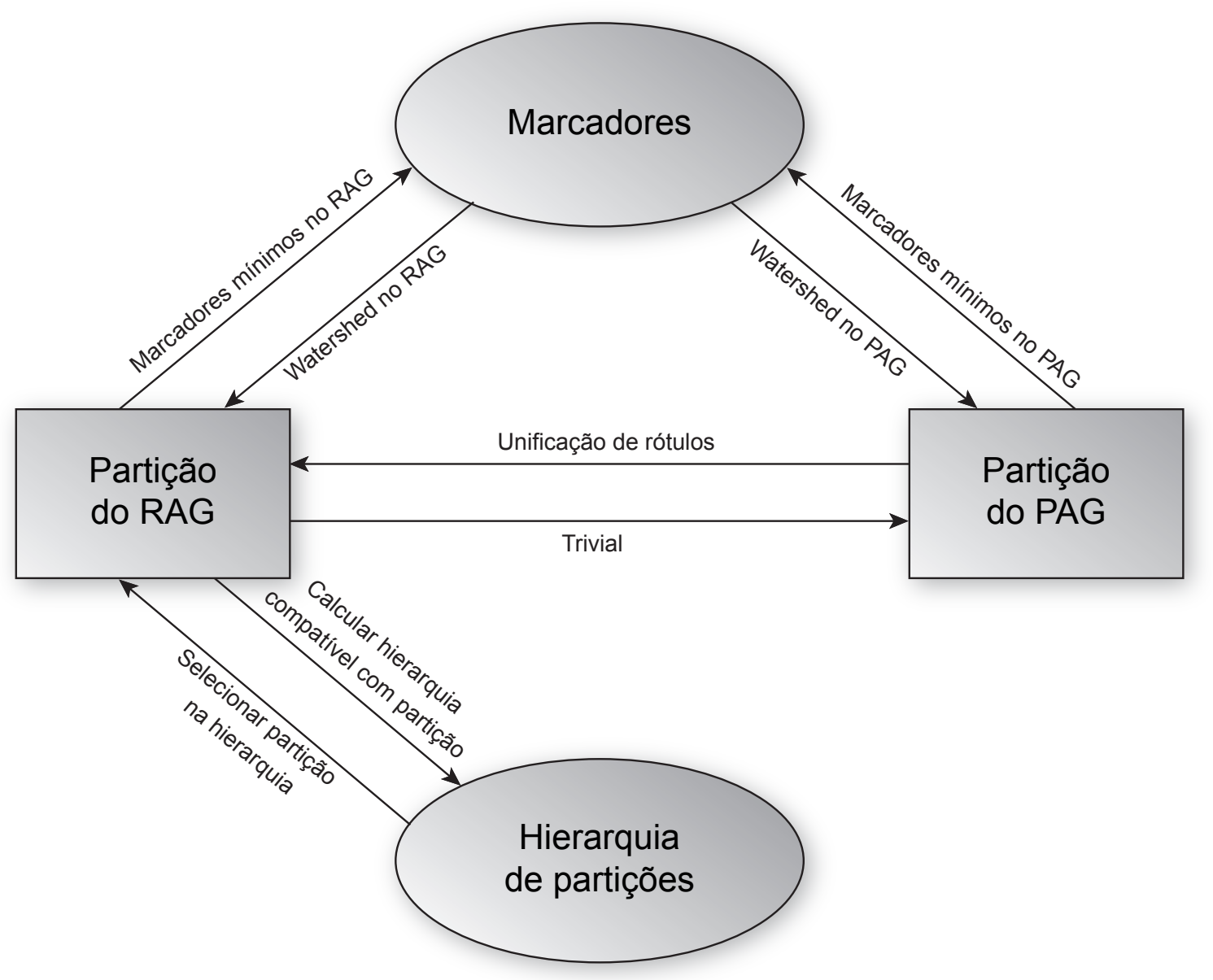

Figura 2.6: Alternando entre as abordagens do watershed. Uma análise detalhada desse diagrama está disponível em Klava (2009).

- Falsos positivos (FP): pares conectados na segmentação avaliada mas desconectados no ground truth;

- Falsos negativos (FN): pares desconectados na segmentação avaliada mas conectados no ground truth.

Com a quantidade de elementos em cada uma dessas classes, definimos três medidas que podem ser utilizadas para se comparar quantitativamente o resultado de diferentes abordagens:

$$
\text { Acurácia }=\frac{|V P|+|V N|}{|V P|+|V N|+|F P|+|F N|}
$$




\begin{tabular}{|c|c|c|c|}
\hline & \multicolumn{2}{|c|}{ Ground truth } \\
\hline & & $\begin{array}{c}\text { Vértices } \\
\text { conectados }\end{array}$ & $\begin{array}{c}\text { Vértices } \\
\text { desconectados }\end{array}$ \\
\hline \multirow{2}{*}{$\begin{array}{c}\text { Segmentação } \\
\text { avaliada }\end{array}$} & $\begin{array}{c}\text { Vértices } \\
\text { conectados }\end{array}$ & $\begin{array}{c}\text { Verdadeiros } \\
\text { positivos (VP) }\end{array}$ & $\begin{array}{c}\text { Falsos } \\
\text { positivos }(\mathrm{FP})\end{array}$ \\
\hline & $\begin{array}{c}\text { Vértices } \\
\text { desconectados }\end{array}$ & $\begin{array}{c}\text { Falsos } \\
\text { negativos }(\mathrm{FN})\end{array}$ & $\begin{array}{c}\text { Verdadeiros } \\
\text { negativos (VN) }\end{array}$ \\
\hline
\end{tabular}

Tabela 2.1: Classes dos pares de vértices do grafo.

$$
\begin{aligned}
\text { Precisão } & =\frac{|V P|}{|V P|+|F P|} \\
\text { Exatidão } & =\frac{|V P|}{|V P|+|F N|}
\end{aligned}
$$

As medidas de qualidade definidas acima, acurácia (Rand index), precisão e exatidão, são comumente utilizadas para comparar partições (Meilă, 2007). No contexto de segmentação de imagens, essas medidas geralmente são utilizadas examinando pares de pixels (Pont-Tuset e Marqués, 2013). Neste trabalho, tais medidas serão utilizadas para comparações de pares de bacias primitivas, que são as unidades atômicas no RAG. 



\section{Incorporação de resultados de segmentações anteriores}

As hierarquias derivadas a partir de inundações síncronas, descritas na Subseção 2.1.3, geram partições que diferenciam regiões de acordo com métricas bem definidas: contraste entre regiões, tamanho das regiões ou uma combinação entre esses dois critérios. Entretanto, essas hierarquias, e qualquer outro tipo de hierarquia definida a partir de métricas de baixo nível, geralmente exigem um esforço de interação considerável para se obter os resultados desejados.

Neste capítulo apresentamos a proposta central desta tese: uma formulação baseada em aprendizagem computacional para integrar informação de segmentações prévias no processo de segmentação hierárquica. Conforme mencionado na introdução desta tese, o objetivo é a redução no esforço de interação necessário para segmentar novas imagens.

\subsection{Modelagem do problema de aprendizado}

Um problema de aprendizado supervisionado corresponde à tarefa de inferir uma função ou classificador a partir de um conjunto de exemplos. Cada exemplo é composto por dados de entrada, geralmente representados por um vetor de características, e o respectivo valor de saída desejado (o resultado do processo para os dados de entrada é conhecido). O problema de aprendizado supervisionado é, então, gerar um classificador, criado com base no conjunto de exemplos, que sirva para classificar novos vetores de características, cujos valores de saída são desconhecidos.

No contexto de aprendizado supervisionado para nosso problema de segmentação interativa, imagens previamente segmentadas, junto com as respectivas partições, formam o conjunto de exemplos. 
No contexto do watershed hierárquico, uma partição de uma imagem é dada por uma partição dos vértices do RAG da imagem. Se duas bacias primitivas pertencem à mesma região da partição selecionada, dizemos que a aresta que liga as duas bacias primitivas está ativa na partição. Caso contrário, quando duas bacias primitivas pertencem a regiões distintas da partição selecionada, dizemos que a aresta que liga as duas bacias primitivas está inativa na partição. Uma partição de uma imagem corresponde, então, a uma divisão das arestas do respectivo RAG em dois conjuntos: arestas ativas e arestas inativas.

Qualquer partição do RAG de uma imagem pode ser definida em termos de arestas ativas e inativas. Esta formulação é adequada para qualquer tipo de partição, sejam partições binárias, nas quais é desejado separar o conteúdo da imagem em dois grupos (objetos e fundo) ou partições com múltiplas classes, em que se deseja separar as diversas partes de um objeto ou separar diferentes objetos entre si. Com isso, um classificador binário, capaz de diferenciar arestas em duas classes, é adequado para atender aos requisitos do problema de segmentação.

A classificação das arestas de um RAG em dois conjuntos, arestas ativas e arestas inativas, porém, não resulta necessariamente numa partição da imagem. Seja $G_{I}=(V, E)$ o RAG de uma imagem $I$, onde $V$ é o conjunto de vértices (bacias primitivas de $I$ ) e $E$ é o conjunto de arestas. Uma partição de $I$ em $n$ regiões corresponde a uma partição de $V$ em $n$ conjuntos $V_{i}, 1 \leq i \leq n$, tais que: $V=\bigcup_{i=1}^{n} V_{i}$ e $V_{i} \cap V_{j}=\emptyset, \forall i \neq j$. Todas as arestas que ligam vértices pertencentes a uma mesma região $V_{i}$ devem estar ativas. Além disso, todas as arestas que ligam vértices pertencentes a diferentes regiões devem estar inativas. Dessa forma, todas as arestas na borda entre diferentes regiões da partição devem estar inativas. Em outras palavras, as arestas correspondentes às bordas que separam duas regiões diferentes de uma partição devem estar todas inativas, isto é, tais arestas devem fechar totalmente a borda entre tais regiões.

Considere um classificador que seja capaz de classificar arestas de um RAG entre arestas ativas e arestas inativas. Um classificador que não comete erros iria classificar as arestas de um RAG nesses dois conjuntos de forma a satisfazer as restrições descritas acima. Porém, como os classificadores estão sujeitos a erros, bastaria uma única aresta na borda entre duas regiões diferentes de uma partição ser classificada de forma errada (como ativa) para que a partição não fosse obtida corretamente, pois corresponderia a um buraco na borda entre as regiões em questão. Essa situação é ilustrada na Figura 3.1.

Para obter um resultado que corresponda a uma partição da imagem em questão, descrevemos a seguir um método que completa as bordas obtidas por um classificador. A ideia básica do método consiste em utilizar informações das partições contidas em uma dada hierarquia de partições da imagem (por exemplo, qualquer uma das hierarquias citadas no Capítulo 2). Sob outro ponto de vista, podemos dizer também que a hierarquia dada é adaptada de forma a conter partições que sejam fortemente compatíveis com a classificação das bordas obtida. Uma vez que as bordas tenham sido completas, algumas heurísticas 
para remover bordas de regiões espúrias são também propostas nas seções 3.1.2 e 3.1.3.

\subsubsection{Completar as bordas obtidas por um classificador}

Uma borda numa partição separa duas regiões. Numa hierarquia de partições, se uma borda aparece em um certo nível, essa borda necessariamente aparece em todos os níveis abaixo deste, uma vez que qualquer nível da hierarquia é formado a partir da fusão de regiões de partições dos níveis abaixo. Seja $b$ a borda correspondente a uma aresta $\left\{P_{1}, P_{2}\right\}$ classificada como inativa por um classificador. A aresta $\left\{P_{1}, P_{2}\right\}$ liga as bacias primitivas $P_{1}$ e $P_{2}$ no RAG da imagem. Seja $x$ o nível mais alto da hierarquia cuja partição correspondente contém $b$ como uma de suas bordas. No nível exatamente acima, $x+1$, tal borda não está presente na partição correspondente. De fato, a partição do nível $x+1$ foi gerada a partir da fusão de regiões da partição do nível $x$. Em particular, um nó $R$ do nível $x+1$ foi gerado pela fusão dos nós $R_{1}$ e $R_{2}$ do nível $x$, nós que correspondem às regiões mais altas na hierarquia que têm $b$ como borda entre elas. Se selecionarmos somente as bordas que dividem as regiões $R_{1}$ e $R_{2}$ entre si, tais bordas podem não delimitar uma região fechada numa partição, condição necessária como descrito anteriormente. Para garantir que essa condição seja satisfeita, podemos selecionar todas as bordas que separam $R_{1}$ e $R_{2}$ entre si e também as bordas que separam $R_{1}$ e $R_{2}$ das demais regiões da partição do nível $x$, como ilustrado na Figura 3.2, resultando no conjunto de bordas $B$.

Considere que a borda $b$ de fato corresponda a uma aresta inativa, ou seja, o classificador acertou o rótulo da aresta. Para obter tal borda interativamente, manipulando a hierarquia correspondente através das operações disponíveis, um usuário necessariamente selecionaria as bordas $B$, uma vez que essas bordas correspondem aos contornos das regiões mais altas que contém $b$. Partindo da raiz da hierarquia, por exemplo, um usuário poderia utilizar uma série de operações de divisão local até obter a borda desejada $b$. Como resultado, todas as bordas de $B$ são obtidas, uma vez que tais bordas correspondem aos contornos das regiões mais altas que contém $b$. Dessa forma, o processo automático que foi proposto para seleção de bordas corresponde ao resultado que seria obtido de forma interativa, utilizando as operações hierárquicas. Podemos obter facilmente $B$ a partir de $b: b$ corresponde à aresta $\left\{P_{1}, P_{2}\right\}$, classificada como inativa; na ALC, $R$ é o menor ancestral comum entre $P_{1}$ e $P_{2}$; $B$ corresponde às bordas de $R_{1}$ e $R_{2}$, os filhos de $R$.

\subsubsection{Filtragem de bordas pouco confiáveis}

Se muitas arestas classificadas como inativas pertencerem ao mesmo conjunto de bordas $B$, como obtido no processo descrito acima, maior a certeza de que tal conjunto de bordas $B$ sejam bordas pertences à segmentação desejada. Da mesma forma, se poucas arestas classificadas como inativas pertencerem a um conjunto de bordas $B^{\prime}$, menor a certeza que 


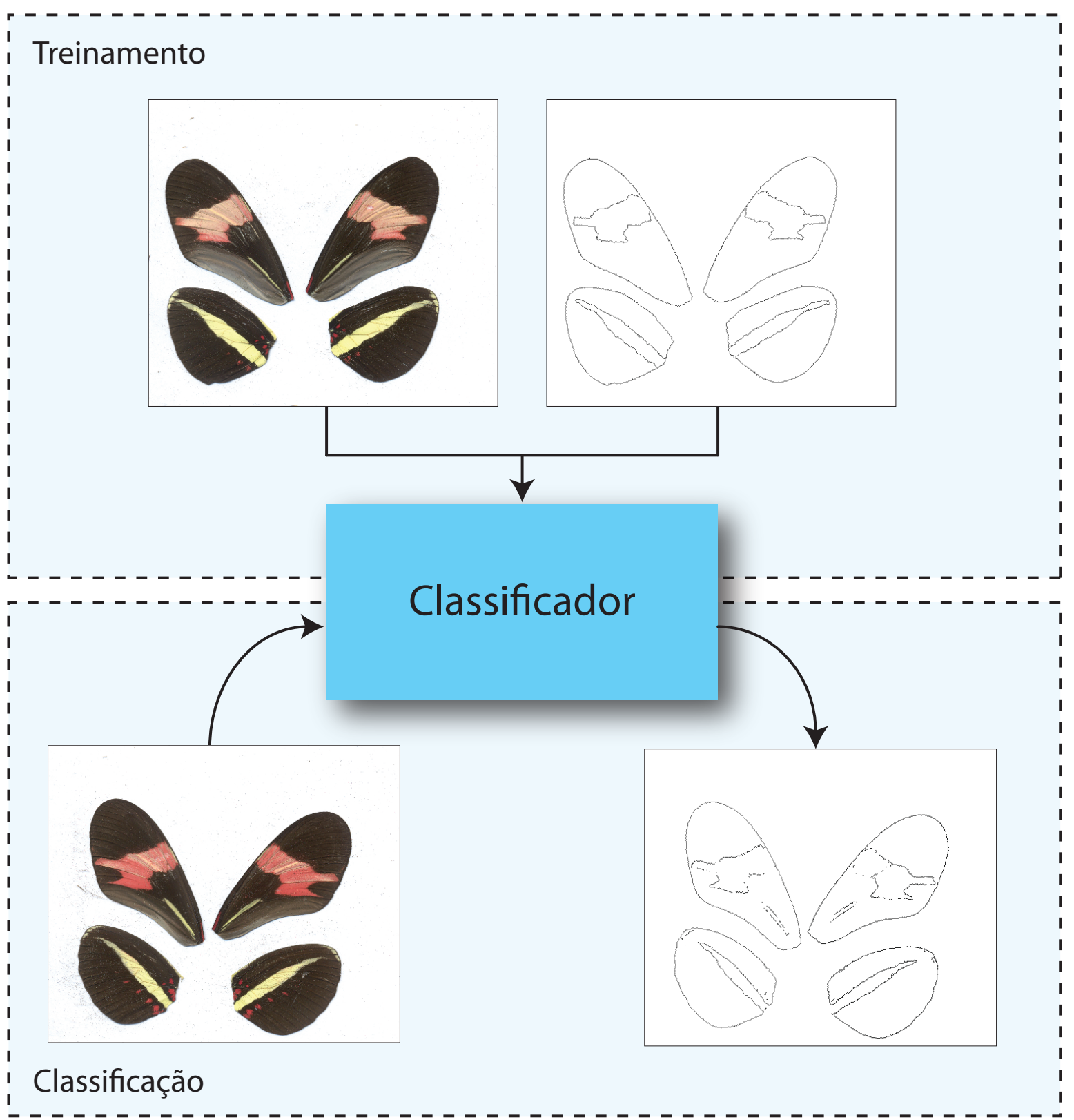

Figura 3.1: Efeito de erros de classificação de arestas entre ativas e inativas. Durante o treinamento, partições de imagens determinam uma rotulação das arestas dos respectivos RAGs entre ativas e inativas. Ao classificar arestas de um RAG que não foi utilizado no treinamento, um classificador pode cometer erros. Erros de classificação, mesmo que poucos, resultam numa rotulação de arestas do RAG que não correspondem a uma partição da respectiva imagem, uma vez que erros de classificação geram buracos nas bordas de regiões da partição desejada. 

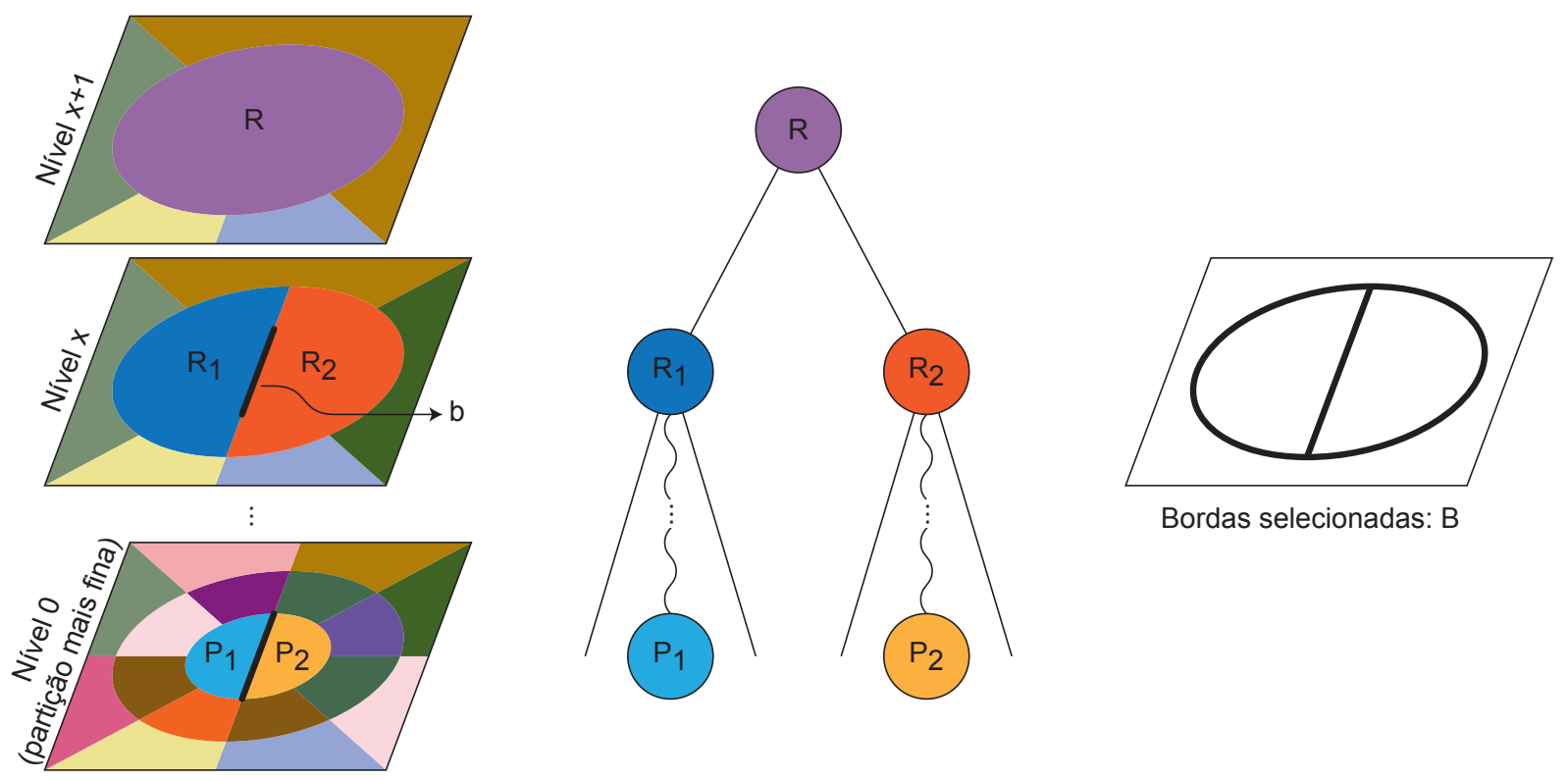

Figura 3.2: Utilização da hierarquia para obter bordas que delimitam regiões numa partição. Seja $b$ uma borda classificada como inativa por um classificador. Para garantir que tal borda esteja presente como borda numa partição, é necessário que outras bordas, juntamente com $b$, delimitem alguma região. Podemos selecionar as bordas $B$ das regiões mais altas na hierarquia, $R_{1}$ e $R_{2}$, que contém $b$ nos limites entre elas. $R_{1}$ e $R_{2}$ correspondem aos filhos de $R$ na hierarquia, onde $R$ é o menor ancestral comum de $P_{1}$ e $P_{2}$, que são as bacias primitivas ligadas pela aresta que corresponde à borda $b$.

$B^{\prime}$ é um conjunto de bordas pertences à segmentação desejada. Para garantir um mínimo de certeza em relação a um conjunto de bordas $B$, podemos levar em consideração tal conjunto $B$ somente se este foi selecionado por um número mínimo de arestas classificadas como inativas. Essa filtragem de conjunto de bordas pode ser adequada para excluir da partição obtida bordas indesejadas geradas devido a erros de classificação de arestas.

\subsubsection{Remoção de bordas desnecessárias via fusão de regiões}

Num processo interativo, utilizamos as operações de seleção de limiar e operações de divisão local para obter as bordas desejadas. Neste processo, bordas além das desejadas também podem ser selecionadas. Para remover essas bordas indesejadas, podemos usar a operação de fusão manual. Da mesma forma, as bordas selecionadas automaticamente no processo descrito anteriormente também podem resultar em bordas desnecessárias, como no exemplo da Figura 3.3. Para remover tais bordas, podemos fazer a fusão de regiões adjacentes que não têm nenhuma aresta classificada como inativa na borda entre elas. 


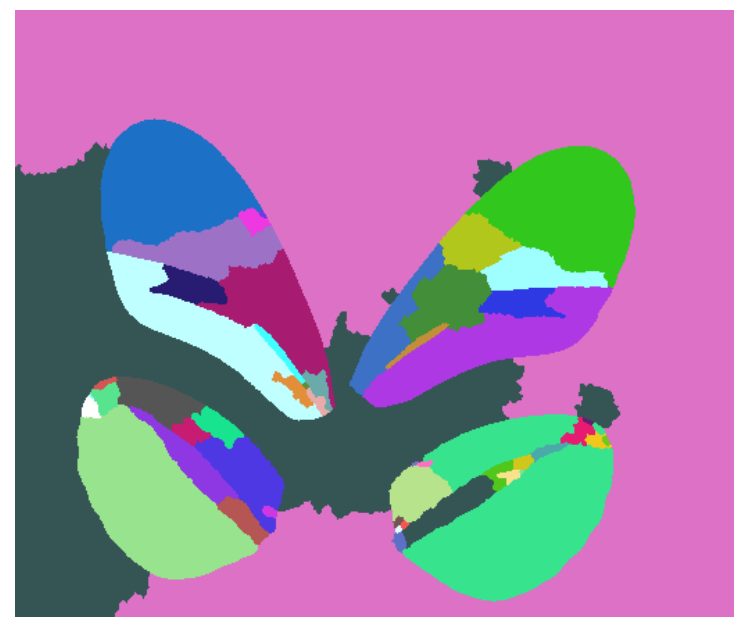

(a) Partição com bordas completadas

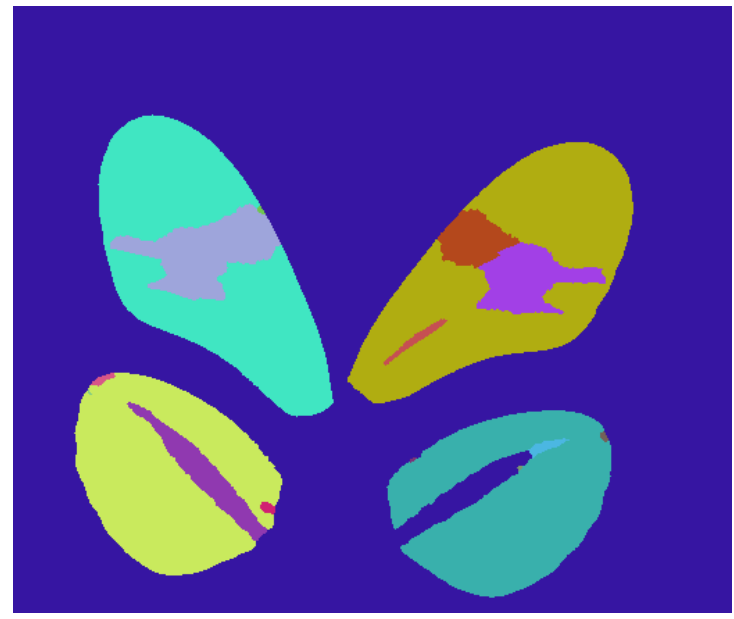

(c) Partição obtida após fusão

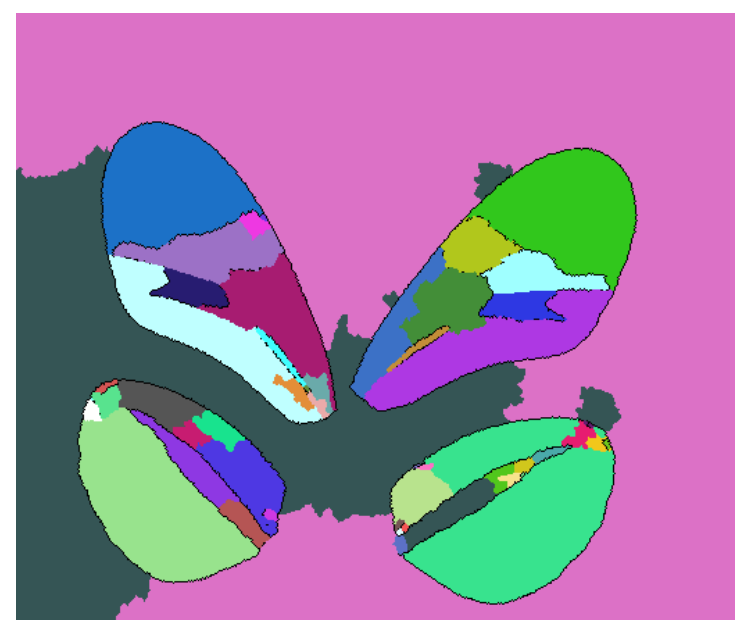

(b) Bordas correspondentes às arestas classificadas como inativas sobrepostas à imagem anterior

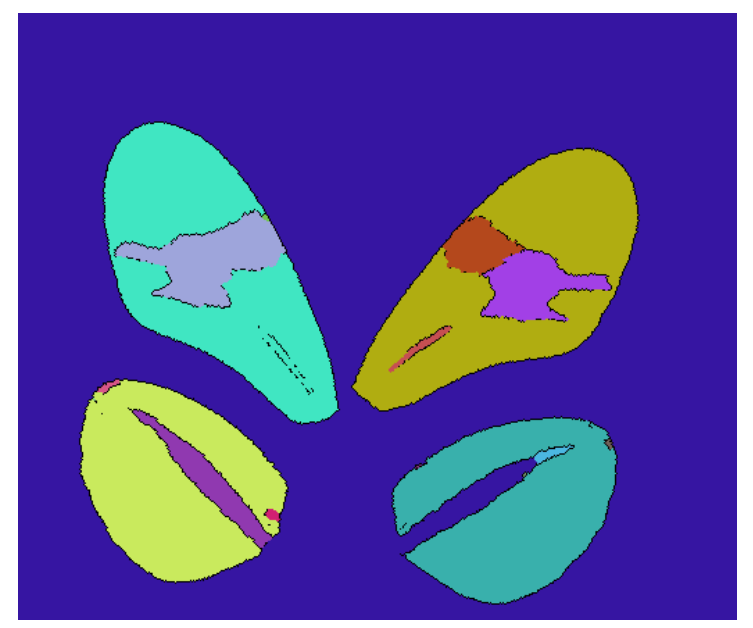

(d) Bordas correspondentes às arestas classificadas como inativas sobrepostas à imagem anterior

Figura 3.3: Ao selecionar as regiões mais altas da hierarquia que contêm as bordas desejadas, bordas indesejadas também são criadas. Para reduzir esse problema, é possível fazer a fusão de regiões adjacentes que não têm nenhuma aresta classificada como inativa na borda entre elas. 


\subsection{Definição do vetor de características}

Para que seja possível utilizar um classificador para resolver o problema de aprendizado definido na Seção 3.1, é necessário definir um vetor de características que represente os dados de entrada. O problema de aprendizado foi definido em termos de arestas a serem classificadas entre ativas e inativas. Um vetor de características deve, então, associar características a arestas de RAGs.

As hierarquias do watershed hierárquico definem pesos para cada nó interno da hierarquia (lago crítico), que por sua vez correspondem a arestas de uma AGM do RAG. Para utilizar tais pesos como características para arestas do RAG de uma imagem, é necessário definir os pesos para todas as arestas do RAG, e não somente para as arestas associadas aos lagos críticos da hierarquia, que são arestas de uma AGM do RAG da imagem em questão. No processo de inundação descrito na Subseção 2.1.3, a criação de um lago crítico corresponde ao processamento de uma das arestas do RAG da imagem, aresta $\left\{p_{1}, p_{2}\right\}$ que liga os dois nós, $C_{1}$ e $C_{2}$, que foram fundidos para a criação do novo lago crítico. $p_{1}$ é uma das bacias primitivas pertencentes ao nó $C_{1}$ e $p_{2}$ é uma das bacias primitivas pertencentes ao nó $C_{2}$. Seja $\left\{p_{1}^{\prime}, p_{2}^{\prime}\right\}$ uma outra aresta do RAG, diferente da aresta $\left\{p_{1}, p_{2}\right\}$, que liga uma bacia primitiva $p_{1}^{\prime}$ de $C_{1}$ a uma bacia primitiva $p_{2}^{\prime}$ de $C_{2}$. Se a aresta $\left\{p_{1}^{\prime}, p_{2}^{\prime}\right\}$ tivesse o mesmo peso que a aresta $\left\{p_{1}, p_{2}\right\},\left\{p_{1}^{\prime}, p_{2}^{\prime}\right\}$ poderia substituir $\left\{p_{1}, p_{2}\right\}$ na AGM do RAG e a hierarquia correspondente seria a mesma. Dessa forma, podemos propagar o peso dado pelo processo de inundação para a aresta $\left\{p_{1}, p_{2}\right\}$ para todas as arestas $\left\{p_{1}^{\prime}, p_{2}^{\prime}\right\}$. Tal propagação de pesos pode ser implementada eficientemente:

- Seja $\{a, b\}$ uma aresta do RAG que não foi utilizada no processo de inundação para a construção de uma hierarquia $\mathscr{H}$;

- seja $C$ o lago crítico que é o menor ancestral comum entre $a$ e $b$ em $\mathscr{H}$;

- seja $p$ o peso associado a $C$ em $\mathscr{H}$;

- atribua o peso $p$ à aresta $\{a, b\}$.

Dessa forma, para cada métrica definida nos processos de inundação síncrona (profundidade, área e volume), podemos associar uma característica às arestas do RAG da imagem a ser segmentada.

Outra característica que podemos associar a uma aresta $\{a, b\}$ é a diferença entre medidas feitas sobre as respectivas bacias primitivas, $a$ e $b$. Podemos, por exemplo, utilizar a diferença entre o nível de cinza médio dos pixels pertencentes a a com o nível de cinza médio dos pixels pertencentes a $b$. Essa característica corresponde aos pesos dados às arestas do RAG na partição mais fina da hierarquia descrita no Apêndice B. 
A característica descrita acima é definida somente em função dos pixels dentro de cada bacia primitiva, ou seja, uma informação local. É de interesse que se incorpore informação contextual, de modo que informações de pixels fora das bacias primitivas em questão (mas que estejam próximos destas) sejam levados em consideração. Uma forma de incorporarmos informação contextual é fazendo a convolução da imagem de entrada com um banco de filtros, como feito em Shotton et al. (2009). Filtros com diferentes disposições, como os exibidos na Figura 3.4, podem ser utilizados para incorporar informações de diferentes vizinhanças. Desta forma, através de diferentes filtros podemos gerar características que codificam diferentes relações espaciais entre os objetos contidos na imagem de interesse. Podemos, então, utilizar como característica para uma aresta $\{a, b\}$, a diferença entre os níveis de cinza médios dos pixels das bacias primitivas $a$ e $b$, porém não considerando o nível de cinza original de tais pixels, mas o valor que tais pixels apresentam na convolução da imagem original com um filtro do banco considerado. Vale ressaltar que a convolução pode ser implementada eficientemente no domínio de Fourier (Gonzalez e Woods, 2002).

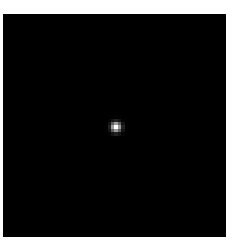

(a)

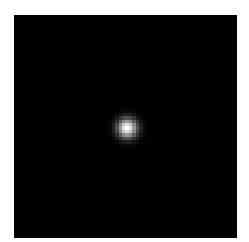

(b)

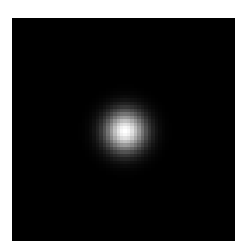

(c)

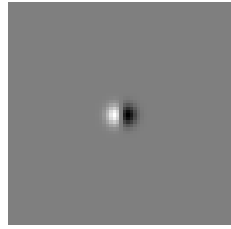

(d)

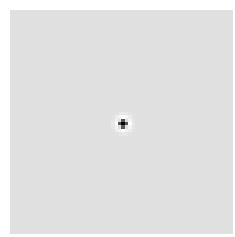

(h)

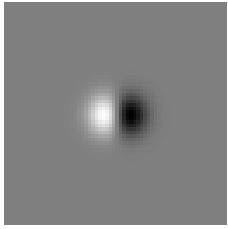

(e)

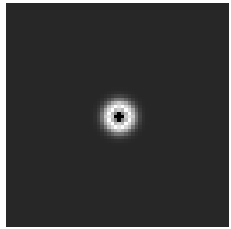

(i)

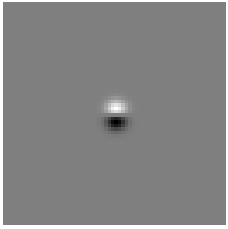

(f)

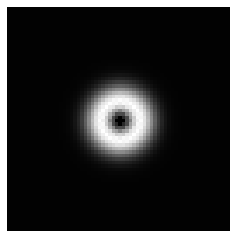

(j)

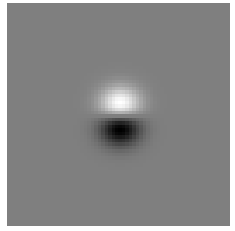

(g)

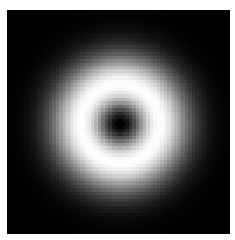

(k)

Figura 3.4: Banco de filtros: (a-c) gaussianas, (d-g) derivadas de gaussianas e (h-k) laplacianos de gaussianas. 


\subsection{Utilização de múltiplos classificadores}

O problema de aprendizado descrito propõe a utilização de segmentações previamente realizadas para segmentar novas imagens.

Se temos a segmentação de várias imagens, uma possibilidade seria gerar um conjunto de treinamento com todas essas imagens/partições e gerar um único classificador com esse conjunto de treinamento. Dessa forma, o classificador desejado deverá otimizar uma função que considere todas as imagens/partições, o que pode resultar em um grande tempo de processamento, devido ao grande número de exemplos utilizados no treinamento do classificador.

Uma abordagem alternativa é considerar cada par imagem/partição individualmente para treinar um classificador, gerando um classificador para cada segmentação previamente realizada. Dessa forma, os diversos classificadores obtidos podem ser gerados mais rapidamente, uma vez que o conjunto de treinamento de cada classificador é menor. Em contrapartida, cada classificador obtido deve ser utilizado separadamente e, portanto, o tempo total de classificação de um novo exemplo é proporcional ao número de classificadores utilizados.

Na Figura 3.5 é exibido o resultado da classificação utilizando 5 classificadores independentes, cada um treinado com um par imagem/partição de uma segmentação previamente realizada. Cada classificador pode cometer erros, alguns classificadores cometendo mais erros que outros. Para combinar o resultado dos diferentes classificadores, podemos atribuir a uma aresta o rótulo que corresponde a maioria entre os rótulos dados pelos diferentes classificadores, como numa técnica de votação ou boosting. Dessa forma, se um classificador não é adequado para segmentar uma imagem, tal classificador tem efeito minimizado pela combinação dos diversos classificadores. O problema de aprendizado para inferir um único classificador que utilizasse todos os exemplos seria computacionalmente mais complexo, comparando-se com o custo computacional total do problema de inferir um classificador para cada par imagem/partição separadamente. 


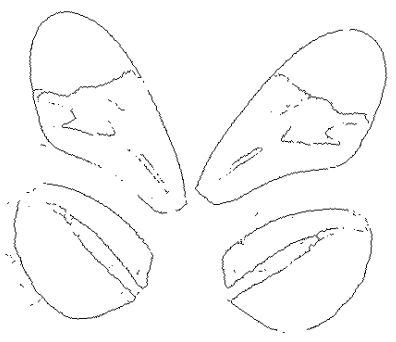

(a) Classificador 1

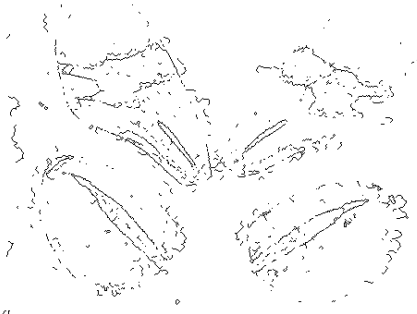

(d) Classificador 4

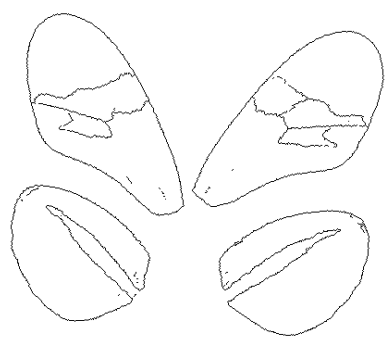

(b) Classificador 2

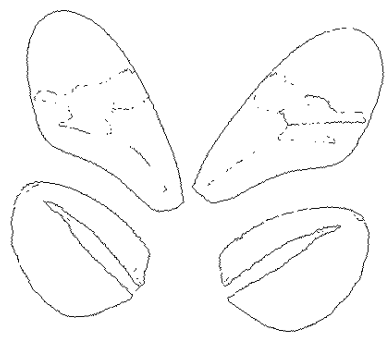

(e) Classificador 5

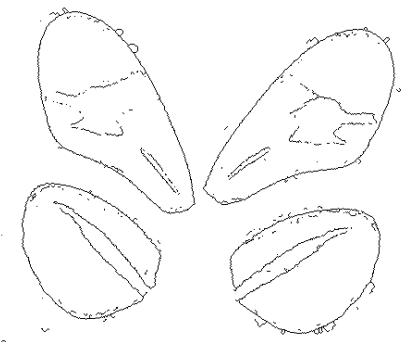

(c) Classificador 3

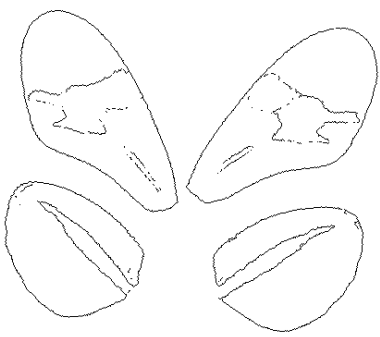

(f) Combinação das classificações

Figura 3.5: Para utilizar o resultado de diversas segmentações feitas anteriormente, podemos treinar um classificador para cada par imagem/partição. O resultado dos diversos classificadores pode ser combinado como numa votação: uma aresta é classificada como inativa se foi classificada como tal pela maioria dos classificadores utilizados. Nas imagens (a) a (e) é exibido o resultado da classificação das arestas do RAG de uma mesma imagem utilizando 5 diferentes classificadores, cada um treinado com um par imagem/partição diferente. Note que existe muito ruído devido a erros de classificação. Em particular, note que o classificador utilizado em (d) não é adequado para segmentar a imagem em questão. Em (f) é exibido o modelo resultante da combinação da votação dos classificadores utilizados. 


\section{Simulação de interação no watershed hierárquico}

Experimentos com sistemas interativos podem ser inviáveis por demandarem muita interação de usuários. Uma solução possível para contornar esse problema e viabilizar tal tipo de experimentos é através de simulações.

Um modelo de simulação deve ser capaz de simular o mais próximo possível o comportamento de usuários numa dada tarefa. Uma vez criado e validado tal tipo de modelo, experimentos que seriam inviáveis podem ser simulados de forma automatizada, sem a necessidade de intervenção humana.

Em McGuinness e O'Connor (2011) é proposto e validado um modelo de simulação de interação para algoritmos de segmentação baseados em marcações (o watershed a partir de marcadores é um algoritmo deste tipo), nos quais o processo é direcionado a partir de marcações feitas sobre os objetos alvos da análise em questão. Nesse trabalho, o modelo de simulação proposto direciona o processo de segmentação gerando uma sequência de operações de interação. Tal sequência de operações é gerada a partir de medidas de erro entre a segmentação em cada passo da simulação e a segmentação ideal definida em um ground truth. Especificamente, o modelo é capaz de gerar, a cada passo da simulação, novos marcadores para as regiões da partição desejada.

Neste capítulo descrevemos uma proposta de modelo de interação para o watershed hierárquico, seguindo uma formulação inspirada em McGuinness e O’Connor (2011).

\subsection{Descrição do modelo de interação}

Conforme descrito na Subseção 2.1.3, no watershed hierárquico são possíveis quatro operações: seleção de limiar, divisão local, fusão local e fusão manual. O usuário pode aplicar 
essas operações sequencialmente até obter a partição desejada. Um modelo que simule tal processo deve, então, ser capaz de gerar uma sequência das operações supracitadas sobre a hierarquia de partições, de forma que seja obtida a partição correspondente a uma segmentação ideal (ground truth) previamente estabelecida.

Em cada passo do processo de segmentação, a imagem é separada em diversas regiões. Cada região pode:

1. corresponder a exatamente uma região do ground truth e, portanto, não deve ser afetada por operações posteriores;

2. ter intersecção com mais de uma região do ground truth e, portanto, deve ser subdividida em alguma operação posterior;

3. estar propriamente contida em uma única região do ground truth e, portanto, deve ser fundida em alguma operação posterior com outras regiões adjacentes e que também estão propriamente contidas em tal região do ground truth.

A cada passo da simulação devemos classificar as regiões da partição atual nos três tipos citados acima e realizar alguma operação levando em consideração a existência de regiões de cada um dos tipos:

- se existirem somente regiões do tipo 1 , a partição do passo atual corresponde ao ground truth e, portanto, chegamos ao fim da simulação;

- se existir alguma região do tipo 2, ela pode ser dividida em duas outras regiões através da operação de divisão local;

- se existirem duas ou mais regiões do tipo 3 que são adjacentes e estão contidas na mesma região do ground truth, elas podem ser fundidas através da operação de fusão manual.

A operação de fusão local, ao contrário da operação de fusão manual, não permite escolher com quais regiões a região selecionada será fundida (estas regiões são determinadas pela estrutura da hierarquia, como ilustrado na Figura 2.5). Por esse motivo, essa operação não será considerada no modelo de simulação proposto.

A operação de seleção de limiar atua de forma global sobre a estrutura da hierarquia e, portanto, pode desfazer o efeito de operações anteriores. Por esse motivo, tal operação deve ser utilizada somente no passo inicial da simulação, se utilizada. Com isso, podemos iniciar a simulação de uma das seguintes formas: 
- realizar uma operação de seleção de limiar para selecionar uma partição inicial e classificar as regiões resultantes nos tipos 1, 2 ou 3; ou

- classificar a região formada pela imagem inteira como do tipo 2 (partimos do princípio de que a partição do ground truth é formada por mais de uma região).

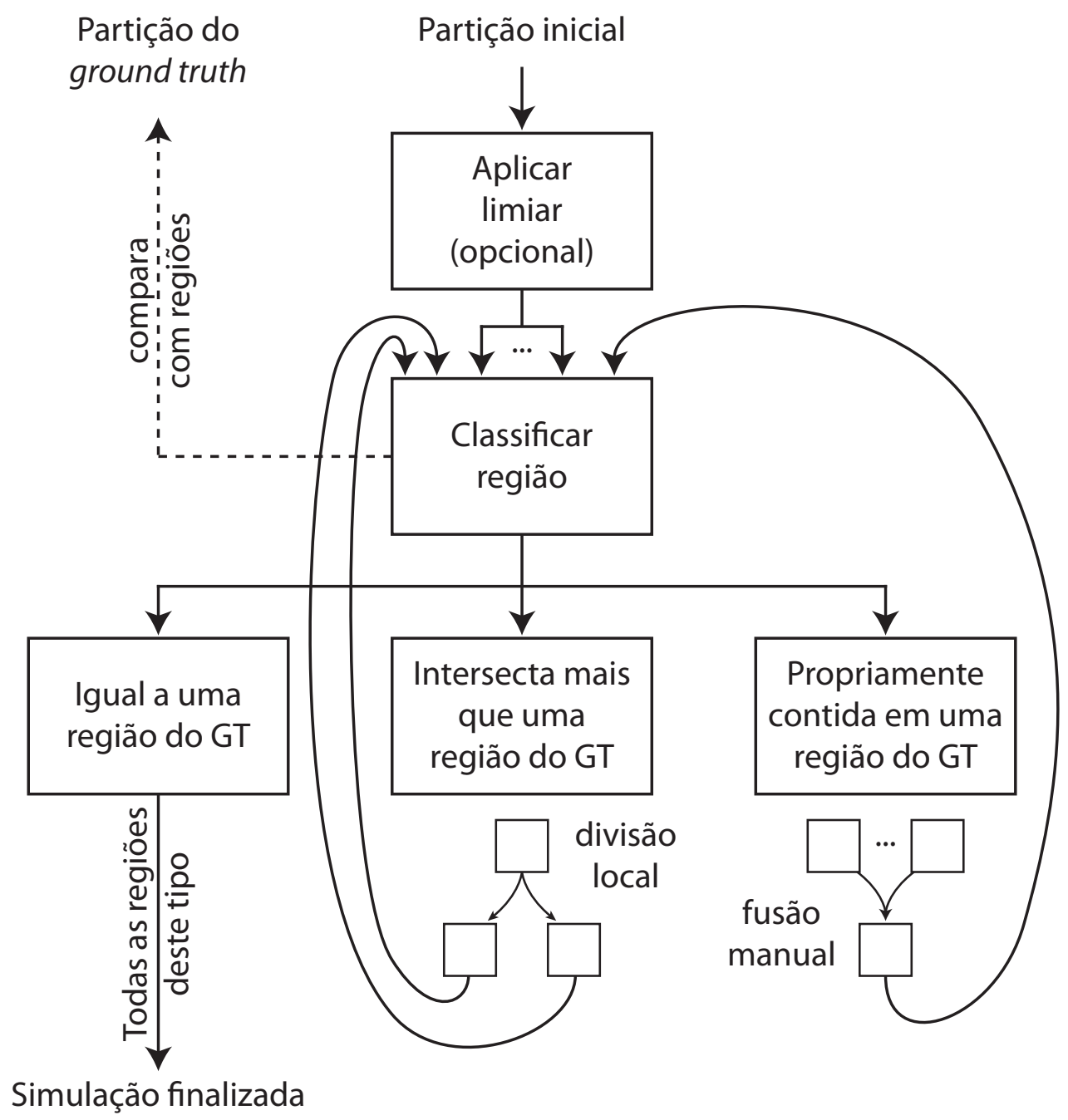

Figura 4.1: Modelo de simulação de interação no watershed hierárquico.

Na Figura 4.1 é exibido um diagrama que ilustra o processo de simulação descrito anteriormente. Para que tal processo fique completamente definido, resta determinar em que ordem as operações de divisão local e fusão manual serão realizadas. Propomos três políticas para tal: 
- Política 1: realizar primeiro todas as operações de divisão local, deixando as operações de fusão manual para serem realizadas somente no final do processo;

- Política 2: realizar uma operação de fusão manual sempre que for possível, executando operações de divisão local somente enquanto não existir uma operação de fusão manual possível;

- Política 3: sempre que uma operação de fusão manual for possível, executar tal operação de acordo com uma função de probabilidade $\mathcal{P}$.

Na política 1 é minimizado o número de operações de fusão manual no processo todo, sendo necessário realizar, no máximo, $N$ tais operações, onde $N$ é o número de regiões da partição do ground truth. Apesar do número de operações de fusão manual ser minimizado, tais operações podem demandar um alto esforço de interação, uma vez que muitas regiões devem ser marcadas ou selecionadas para executar essas operações. Na Figura 4.2 é ilustrada a obtenção de uma partição com o uso da política 1.

Na política 2 é maximizado o número de operações de fusão manual. Porém, cada uma dessas operações demanda um menor esforço de interação, pois poucas regiões devem ser marcadas ou selecionadas para serem fundidas a cada passo. Na Figura 4.3 é ilustrada a obtenção da mesma partição da Figura 4.2, mas com o uso da política 2.

A política 3 é um meio termo entre as políticas 1 e 2, possivelmente representando melhor o comportamento geral dos usuários, que não é determinístico. Nesta política, é necessário associar, para cada operação de fusão manual possível, uma probabilidade $\mathcal{P}$ da mesma ser executada no passo atual da simulação. Definimos a seguinte função de probabilidade:

- a probabilidade $\mathcal{P}$ de executar uma operação de fusão manual é definida como a razão entre o tamanho (em pixels) das regiões a serem fundidas e o tamanho total da imagem.

Com o uso desta função de probabilidade o processo de simulação tende a privilegiar a formação de estruturas mais gerais, postergando o refinamento de detalhes na partição desejada, como numa abordagem coarse to fine.

Note que as políticas 1 e 2 podem ser vistas como casos particulares da política 3, para $\mathcal{P}=0$ e $\mathcal{P}=1$, respectivamente. Além disso, o número de operações de divisão local é sempre o mesmo, independentemente da política adotada. Tal número depende somente do número de nós do grafo que representa a imagem, da estrutura do ground truth e do valor do limiar que foi utilizado, se utilizado, no passo inicial. 


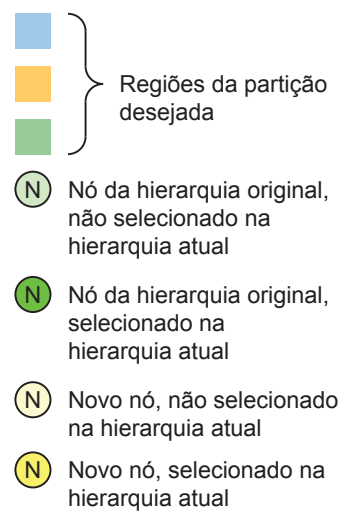

(a) Legenda
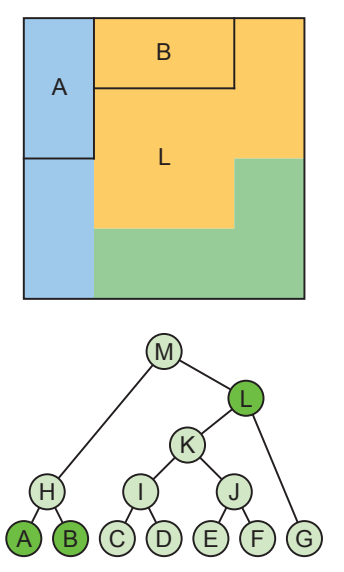

(e) $\mathrm{H}$ dividido em $\mathrm{A}$ e $\mathrm{B}$
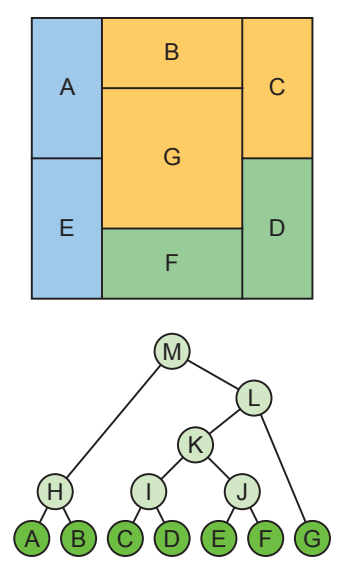

(i) $\mathrm{J}$ dividido em $\mathrm{E}$ e $\mathrm{F}$
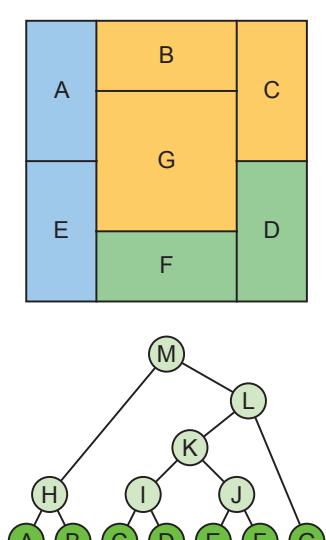

A B (C) (D) EE (F)

(b) Partição mais fina
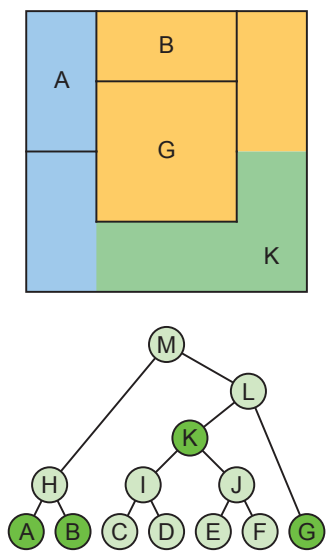
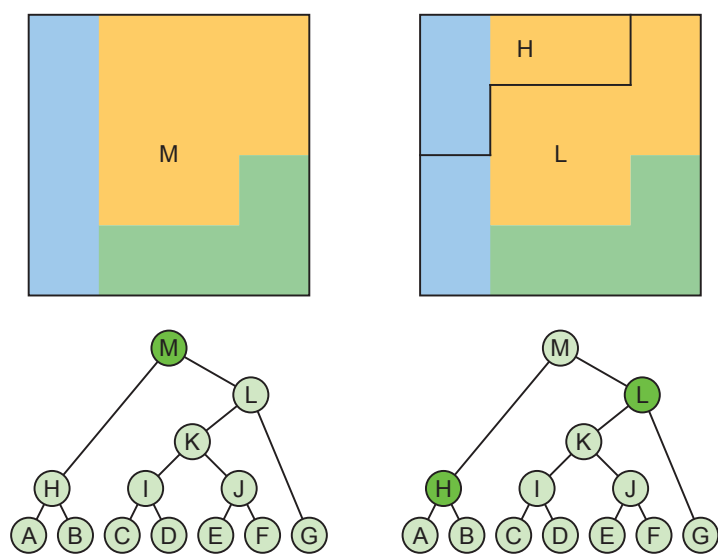

(c) Partição mais grossa (d) $\mathrm{M}$ dividido em $\mathrm{H}$ e L (inicial) M
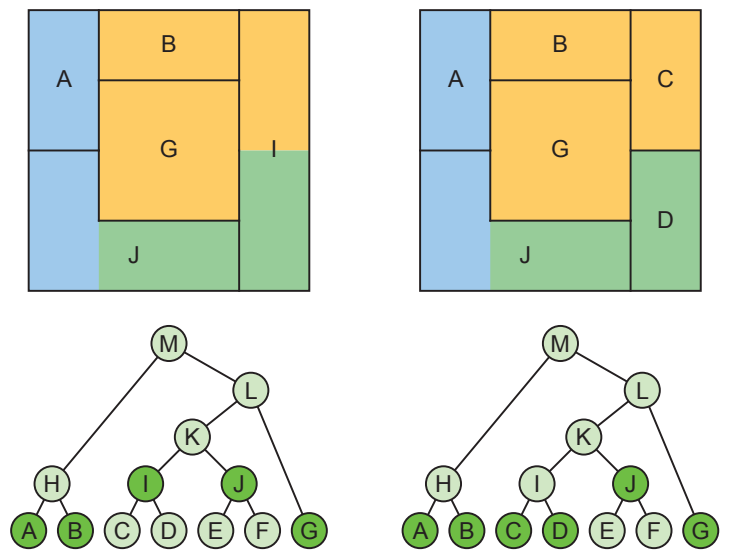

(f) $\mathrm{L}$ dividido em $\mathrm{K}$ e $\mathrm{G}$

(g) K dividido em I e J

(h) I dividido em $\mathrm{C}$ e $\mathrm{D}$
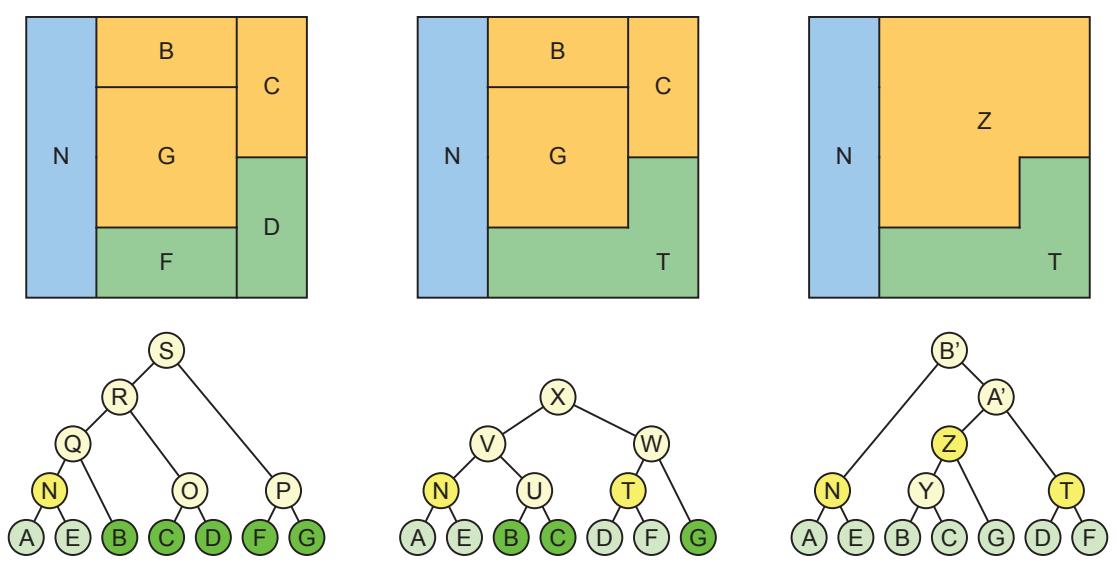

(j) A e E fundido em N (k) D e F fundidos em T (l) $\mathrm{B}, \mathrm{C}$ e G fundidos em

Figura 4.2: Usando a política 1, 3 fusões manuais foram realizadas para se obter a partição desejada com 3 regiões. 

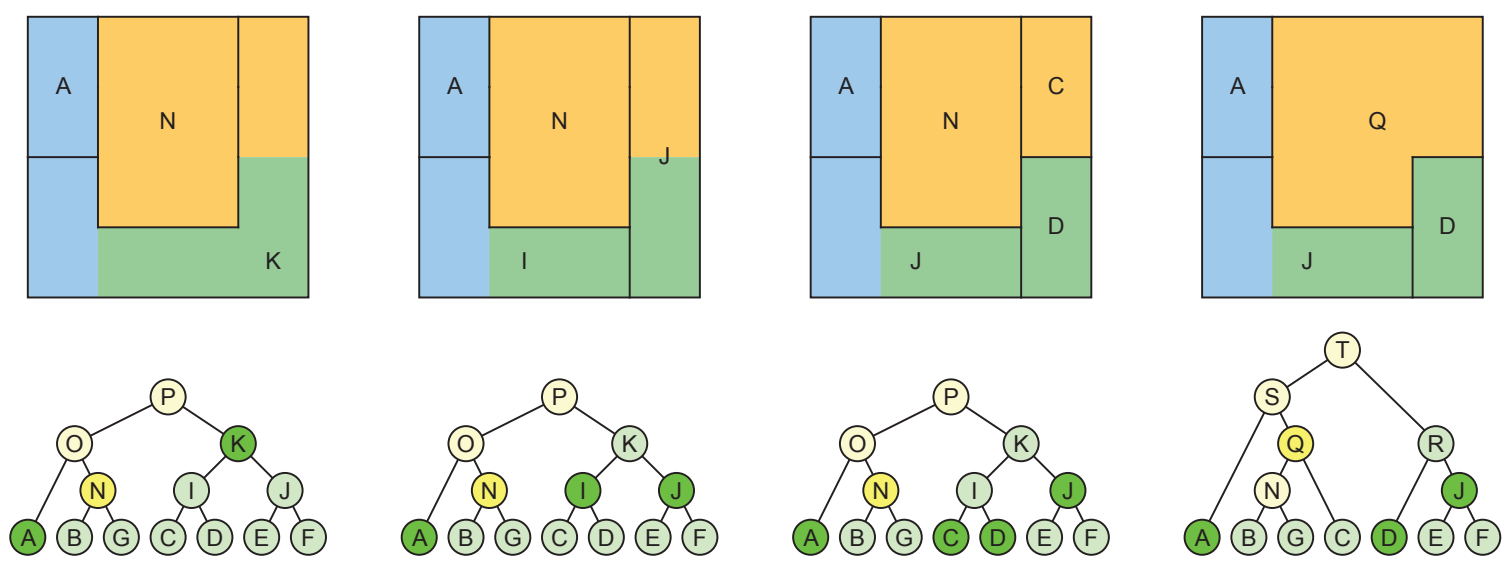

(g) B e G fundidos em $\mathrm{N}$

(h) $\mathrm{K}$ dividido em I e $\mathrm{J}$

(i) I dividido em $\mathrm{C}$ e $\mathrm{D}$

(j) $\mathrm{N}$ e $\mathrm{C}$ fundidos em $\mathrm{Q}$
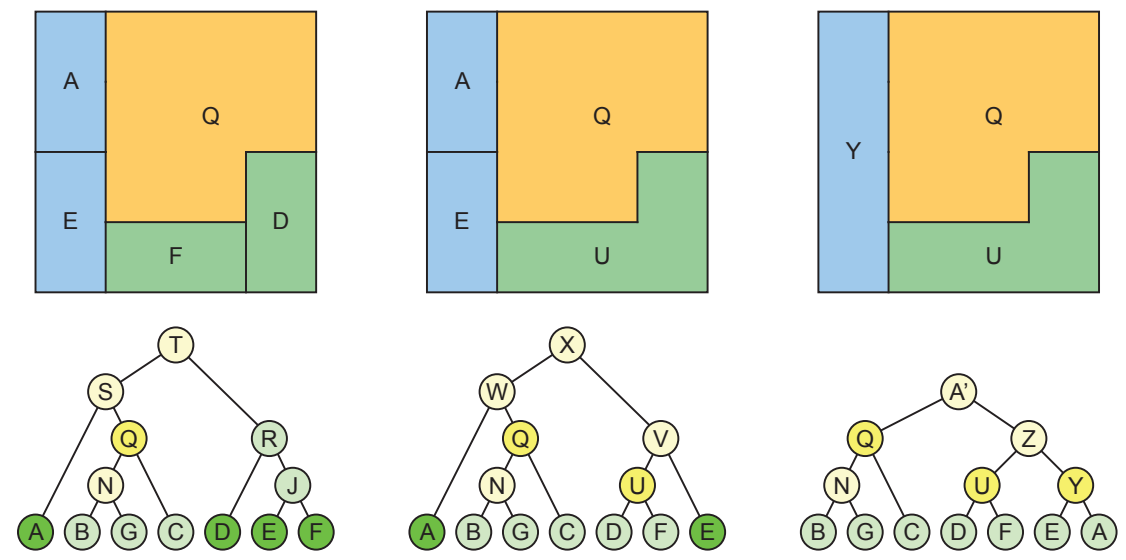

(k) J dividido em E e F

(1) D e F fundidos em U (m) A e E fundidos em $\mathrm{Y}$

Figura 4.3: Política 2. Até o passo (f), os passos são iguais aos da Figura 4.2. 4 fusões manuais foram realizadas para se obter a partição desejada com 3 regiões.

\subsection{Experimentos com usuários}

Para validar o modelo proposto, são necessários experimentos com usuários de verdade. Tais experimentos servem como base para analisar se o processo de segmentação através da simulação proposta se aproxima do processo realizado por usuários humanos.

Para realizar os experimentos necessários, foi criado um conjunto de 20 tarefas de segmentação, exibido no Apêndice A. Cada tarefa de segmentação é composta por uma imagem de entrada, uma descrição textual explicando quais objetos devem ser segmentados 
na imagem e um ground truth que corresponde ao resultado esperado.

Para cobrir diversos níveis de complexidade encontrados em tarefas de segmentação, o conjunto de tarefas criado não foi restrito a um domínio específico, contendo imagens desde microscopia até fotografia de cenas naturais. As imagens selecionadas foram restritas a um tamanho máximo de $800 \times 600$ pixels, tamanho suficiente para requerer diversos passos de interação, mas sem demandar um tempo excessivo para se obter os resultados desejados.

Os ground truths não foram criados usando o watershed hierárquico, de forma que não sejam obtidos muito facilmente utilizando tal abordagem. Porém, os ground truths foram criados utilizando o watershed a partir de marcadores com o nível de precisão do RAG e, portanto, podem ser localizados nas hierarquias derivadas do watershed hierárquico com a utilização das operações disponíveis.

Dependendo da estrutura da imagem, a métrica utilizada na construção da hierarquia pode favorecer ou não a obtenção da partição desejada. Além disso, algumas partições podem ser obtidas mais facilmente com o uso de marcadores, como é caso de algumas das tarefas do conjunto criado para os experimentos. Apesar desses fatos, como o objetivo dos experimentos é avaliar aspectos relativos à interação dos usuários para executar as tarefas de segmentação, e não avaliar as hierarquias existentes, utilizamos o watershed hierárquico com a métrica de volume em todas as tarefas dos experimentos descritos neste capítulo.

Os experimentos foram executados com uma versão do SegmentIt com os seguintes elementos adicionais para apoiar os experimentos:

- um vídeo demonstrando as operações disponíveis e uma imagem de teste para que os usuários pudessem testar e se familiarizar com as operações hierárquicas;

- um sistema online de escalonamento que seleciona qual a próxima tarefa a ser executada pelo usuário, de forma que cada tarefa de segmentação fosse executada por aproximadamente o mesmo número de usuários;

- possibilidade do usuário interromper o experimento após executar uma tarefa de segmentação, voltando a executar novas tarefas em um momento mais oportuno;

- tempo ilimitado para executar cada tarefa;

- a cada tarefa executada, envio automático dos dados relacionados a execução da tarefa para um servidor para serem analisados posteriormente;

- exibição de uma descrição textual do resultado esperado, junto com uma miniatura do ground truth, para esclarecer qualquer dúvida a respeito do objetivo da tarefa.

Na Figura 4.4 exibimos uma captura de tela da execução da versão do SegmentIt utilizada nos experimentos, com as funcionalidades descritas acima. A exibição da miniatura 
do ground truth não compromete os experimentos, uma vez que o objetivo não é avaliar o resultado final da segmentação obtida pelos usuários, mas sim avaliar como o processo de segmentação é realizado.

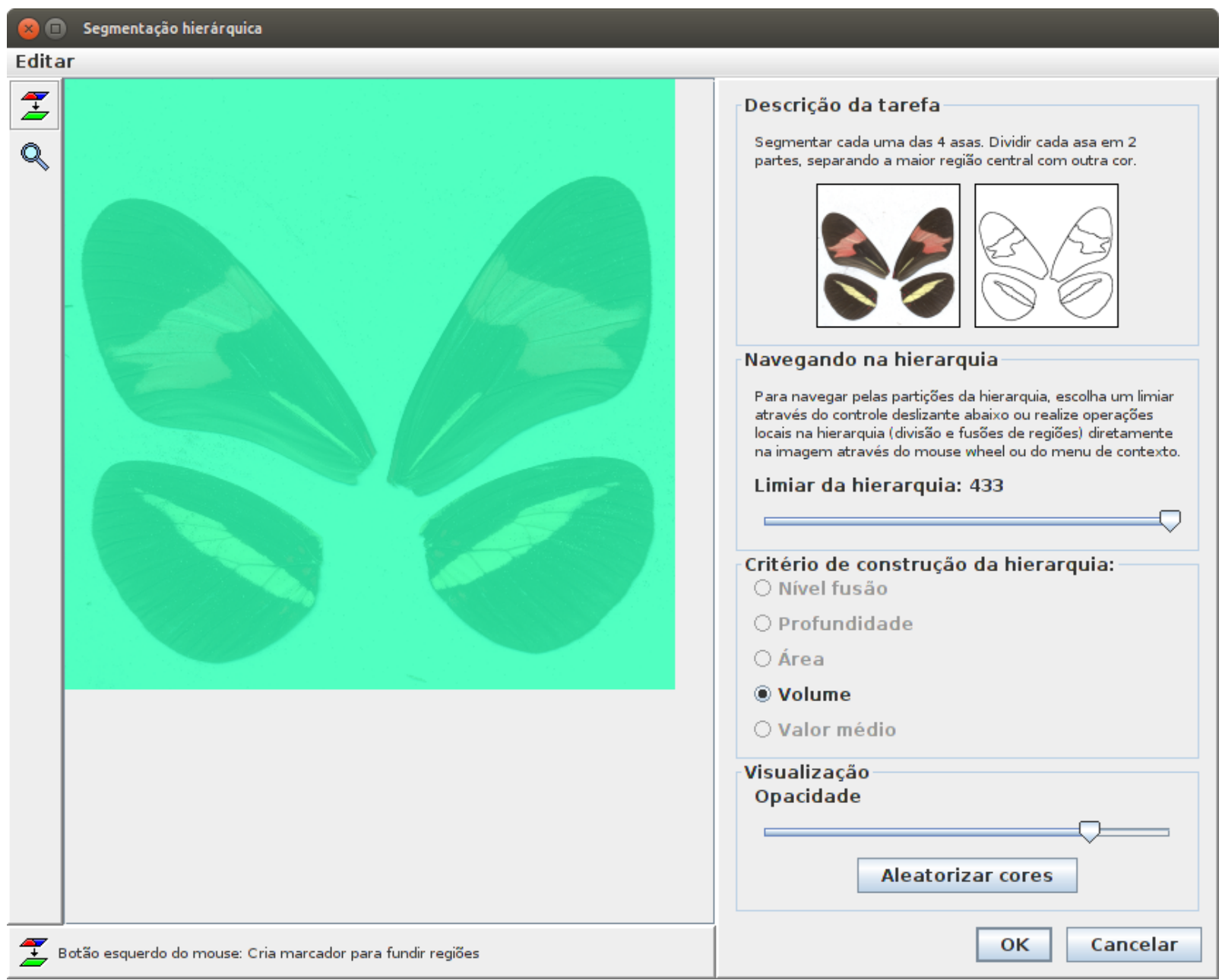

Figura 4.4: Captura de tela da execução do SegmentIt nos experimentos com usuários. A métrica de volume foi mantida como única métrica disponível. Uma descrição textual e uma miniatura do resultado esperado são exibidas para o usuário executar cada tarefa.

Voluntários foram convidados a participar dos experimentos e foram instruídos a executar quantas tarefas pudessem, não sendo necessário executar todas as 20 tarefas. Um total de 15 voluntários participaram dos experimentos, conforme apresentado na Tabela 4.1, resultando num total de 200 execuções de tarefas de segmentação. 


\begin{tabular}{|c|c|c|c|c|c|c|c|c|c|c|c|c|c|c|c|c|}
\hline & \multicolumn{15}{|c|}{ Voluntário } & \\
\hline Tarefa & 1 & 2 & 3 & 4 & 5 & 6 & 7 & 8 & 9 & 10 & 11 & 12 & 13 & 14 & 15 & Total \\
\hline 1 & OK & OK & $\mathrm{OK}$ & OK & OK & - & OK & OK & OK & - & OK & - & OK & - & - & 10 \\
\hline 2 & OK & OK & $\mathrm{OK}$ & OK & OK & - & OK & OK & OK & - & OK & - & - & OK & - & 10 \\
\hline 3 & OK & OK & $\mathrm{OK}$ & OK & OK & $\mathrm{OK}$ & OK & OK & OK & - & OK & - & - & - & - & 10 \\
\hline 4 & OK & OK & $\mathrm{OK}$ & OK & OK & $\mathrm{OK}$ & OK & OK & OK & - & OK & - & - & - & - & 10 \\
\hline 5 & OK & OK & - & OK & OK & - & OK & OK & OK & - & OK & - & OK & OK & - & 10 \\
\hline 6 & OK & OK & - & OK & OK & - & OK & OK & OK & - & OK & OK & - & OK & - & 10 \\
\hline 7 & $\mathrm{OK}$ & OK & - & $\mathrm{OK}$ & $\mathrm{OK}$ & - & OK & OK & OK & - & OK & OK & - & $\mathrm{OK}$ & - & 10 \\
\hline 8 & OK & OK & - & $\mathrm{OK}$ & OK & - & OK & OK & OK & - & OK & OK & - & OK & - & 10 \\
\hline 9 & OK & OK & - & OK & OK & - & OK & OK & OK & - & OK & OK & - & OK & - & 10 \\
\hline 10 & OK & OK & - & $\mathrm{OK}$ & OK & - & OK & OK & OK & OK & OK & OK & - & - & - & 10 \\
\hline 11 & OK & OK & - & OK & OK & - & OK & OK & OK & OK & OK & - & OK & - & - & 10 \\
\hline 12 & OK & OK & - & OK & OK & - & OK & OK & $\mathrm{OK}$ & OK & OK & - & OK & - & - & 10 \\
\hline 13 & OK & OK & - & OK & OK & - & OK & OK & OK & OK & OK & - & OK & - & - & 10 \\
\hline 14 & OK & OK & - & OK & OK & - & OK & OK & OK & OK & OK & - & OK & - & - & 10 \\
\hline 15 & OK & OK & - & OK & OK & - & OK & OK & OK & OK & OK & - & OK & - & OK & 11 \\
\hline 16 & OK & OK & - & OK & $\mathrm{OK}$ & - & OK & OK & OK & OK & OK & - & OK & - & - & 10 \\
\hline 17 & OK & OK & - & $\mathrm{OK}$ & OK & - & OK & OK & OK & OK & OK & - & OK & - & - & 10 \\
\hline 18 & $\mathrm{OK}$ & $\mathrm{OK}$ & - & OK & $\mathrm{OK}$ & - & OK & OK & OK & OK & OK & - & OK & - & - & 10 \\
\hline 19 & OK & OK & - & $\mathrm{OK}$ & OK & - & OK & OK & OK & OK & OK & - & OK & - & - & 10 \\
\hline 20 & OK & OK & - & OK & OK & - & OK & $\mathrm{OK}$ & OK & - & OK & - & OK & - & - & 9 \\
\hline Total & 20 & 20 & 4 & 20 & 20 & 2 & 20 & 20 & 20 & 10 & 20 & 5 & 12 & 6 & 1 & 200 \\
\hline
\end{tabular}

Tabela 4.1: Colaboração dos voluntários no experimento. 15 voluntários participaram, executando 200 tarefas de segmentação ao total. 8 dos 15 voluntários executaram todas as 20 tarefas. O sistema de escalonamento de tarefas permitiu que cada tarefa fosse executada por aproximadamente o mesmo número (10) de voluntários.

\subsection{Simulação}

O modelo e as políticas descritas na Seção 4.1 permitem definir quais operações devem ser realizadas para executar uma tarefa de segmentação, dado seu ground truth. Para realizar a simulação, é importante definir a ordem em que as regiões da imagem serão processadas. Usuários geralmente adotam alguma estratégia, como segmentar um objeto de cada vez, uma abordagem coarse to fine ou outra estratégia que dependa do conteúdo da imagem. Portanto, a ordem em que as regiões são processadas não é arbitrária. Para a simulação do modelo com as políticas, devemos considerar uma ordem de processamento que reflita esse comportamento não arbitrário. Para tal propósito, as regiões do tipo 2 (que devem ser divididas) são processadas seguindo a ordem de uma fila. Usando uma fila, de certa forma as regiões são processadas na ordem em que aparecem na partição. Além disso, as regiões próximas a uma região já processada tendem a ser processadas antes das mais afastadas. Para as regiões do tipo 3 (regiões a serem fundidas), a ordem não é importante ou depende da política considerada: na política 1, a ordem de processamento das regiões é 
irrelevante, uma vez que todas as regiões são processadas nos últimos passos da simulação; na política 2, regiões são fundidas assim que tal fusão é possível; na política 3, a ordem em que as regiões são processadas depende da função de probabilidade considerada. Por esse motivo, as regiões do tipo 3 são armazenadas numa estrutura que não mantém uma ordem de processamento definida.

Nos experimentos com usuários, como exibimos uma miniatura do ground truth para o usuário, ele pode executar as operações desejadas até estar confiante de que obteve uma partição próxima da definida. Dessa forma, é esperado que o resultado final obtido pelos usuários seja bem próximo do ground truth. Por esse motivo, nas simulações não definimos um critério de parada, como por exemplo número máximo de operações e, portanto, as simulações são executadas até que se obtenha exatamente a partição definida no ground truth.

As políticas 1 e 2 são determinísticas e, portanto, foram executadas somente uma vez para cada tarefa de segmentação. Já a política 3 é probabilística e foi executada 10 vezes para cada tarefa, simulando diferentes usuários.

A operação de seleção de limiar não foi utilizada nas simulações, pois não existe um padrão único de utilização desta operação entre os usuários: alguns usuários preferem selecionar um limiar baixo o suficiente de forma que quase todas as bordas desejadas estejam presentes, precisando utilizar, após a seleção do limiar, apenas operações de fusão, predominantemente; outros usuários preferem selecionar um limiar tal que a partição obtida contenha as estruturas gerais da partição desejada, sendo necessário também executar operações de divisão local para segmentar determinadas regiões; outros usuários preferem nem utilizar a operação de seleção de limiar. Além disso, os usuários tendem a utilizar a operação de seleção de limiar para explorar a estrutura da hierarquia, diminuindo e aumentando o valor do limiar algumas vezes, para então selecionar um valor de limiar que considerem adequado. Porém, a exclusão desta operação nas simulações não compromete os experimentos, uma vez que o resultado de uma operação de seleção de limiar pode ser obtido com uma sequência de operações locais.

\subsection{Análise dos resultados}

Apesar de diversos aspectos relativos a interação serem importantes, a análise de aspectos cognitivos de interação estão além do escopo deste trabalho. Nosso interesse é a respeito das sequências de operações realizadas durante os processos de segmentação. Comparar explicitamente as sequências de operações realizadas por usuários humanos e pelas simulações seria impraticável, uma vez que tais sequências variam muito em termos da quantidade e tipos de operações executadas, seja por variações no conteúdo das imagens consideradas e por diferenças entre as decisões dos usuários. As decisões feitas por um usuário durante um 
processo de segmentação podem ser tão variáveis, que um mesmo usuário, segmentando uma mesma imagem em diferentes momentos, pode gerar sequências de operações bem diferentes entre si.

Dada a dificuldade em se relacionar diretamente as simulações com os experimentos realizados por usuários humanos, iremos fazer uma comparação indireta, isto é, não serão comparadas as sequências de operações em si, mas sim o reflexo das mesmas nos resultados obtidos: as medidas de qualidade definidas na Seção 2.2 são computadas para cada passo das simulações/execuções, comparando cada partição obtida com a definida no ground truth. Desta forma, cada execução de tarefa, seja realizada por um usuário humano ou simulada por um usuário robô, fica representada por uma série temporal para cada medida considerada, série que determina como tal medida evoluiu ao longo do processo de segmentação. Apesar da evolução contida nas séries temporais não definir diretamente quais operações foram executadas, de certa forma tais séries refletem as escolhas feitas pelos usuários. Portanto, a análise da evolução das medidas consideradas nos permite correlacionar as simulações com os experimentos realizados pelos voluntários.

Para correlacionar as diferentes séries temporais, primeiro é necessário que elas tenham o mesmo número de pontos. Como o número de operações executadas varia bastante, as séries temporais foram expandidas linearmente para conterem o mesmo número de pontos e preservarem a sua forma.

As diversas simulações e execuções das tarefas por usuários resultou num total de 440 séries temporais para cada medida, divididas em 4 grupos:

- 200 execuções por usuários humanos;

- 20 execuções (uma para cada tarefa) com a política 1;

- 20 execuções (uma para cada tarefa) com a política 2;

- 200 execuções (10 para cada tarefa) com a política 3.

Para cada medida e cada um dos grupos listados acima, foram calculadas as médias das séries temporais, resultando nos perfis de evolução, exibidos na Figura 4.5, que serão utilizados nesta análise.

Como descrito anteriormente, as operações de seleção de limiar e de fusão local não foram incluídas na simulação. Além disso, as operações de desfazer e refazer, disponíveis aos voluntários, não foram incluídas no modelo da simulação. Na Figura 4.6 é exibido um exemplo de execução de uma mesma tarefa de segmentação por um dos voluntários e da mesma tarefa através da simulação com a política 3. Como os voluntários podem executar mais tipos de operações, consideramos filtrar as séries temporais das tarefas executadas pelos voluntários para corresponderem ao resultado obtido sem a execução de tais operações. 


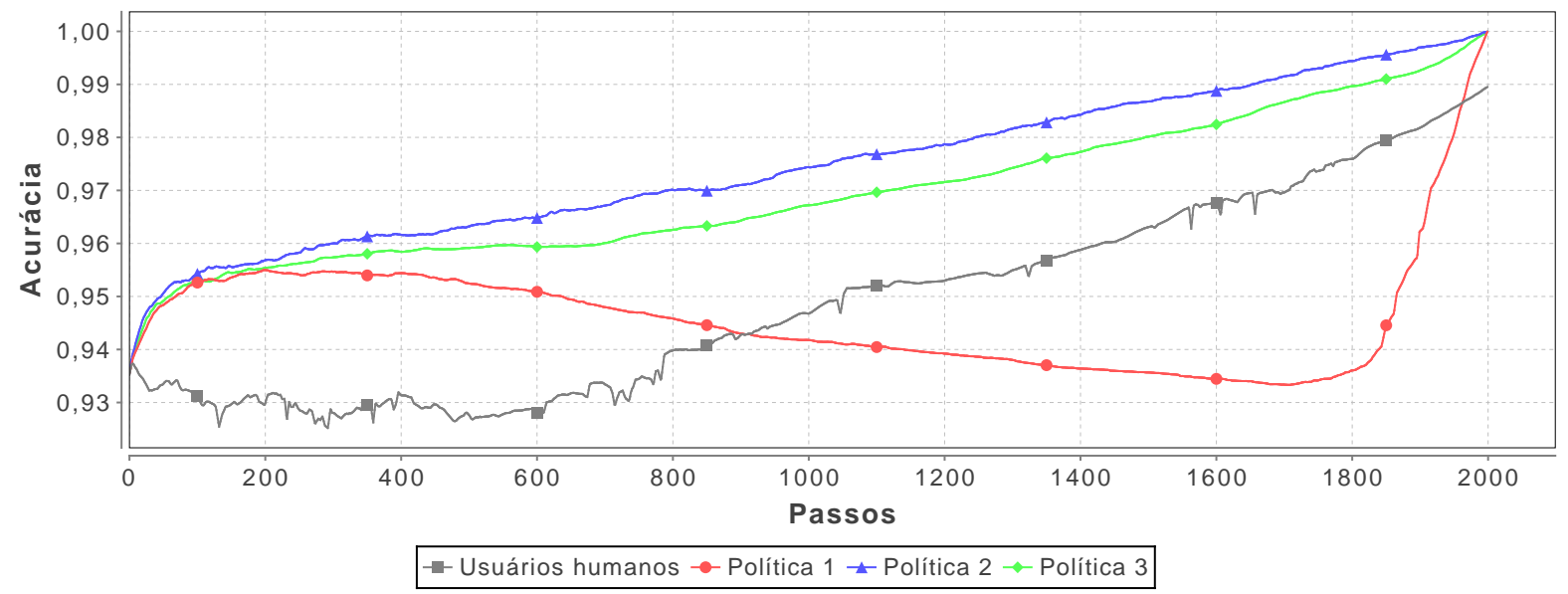

(a) Acurácia

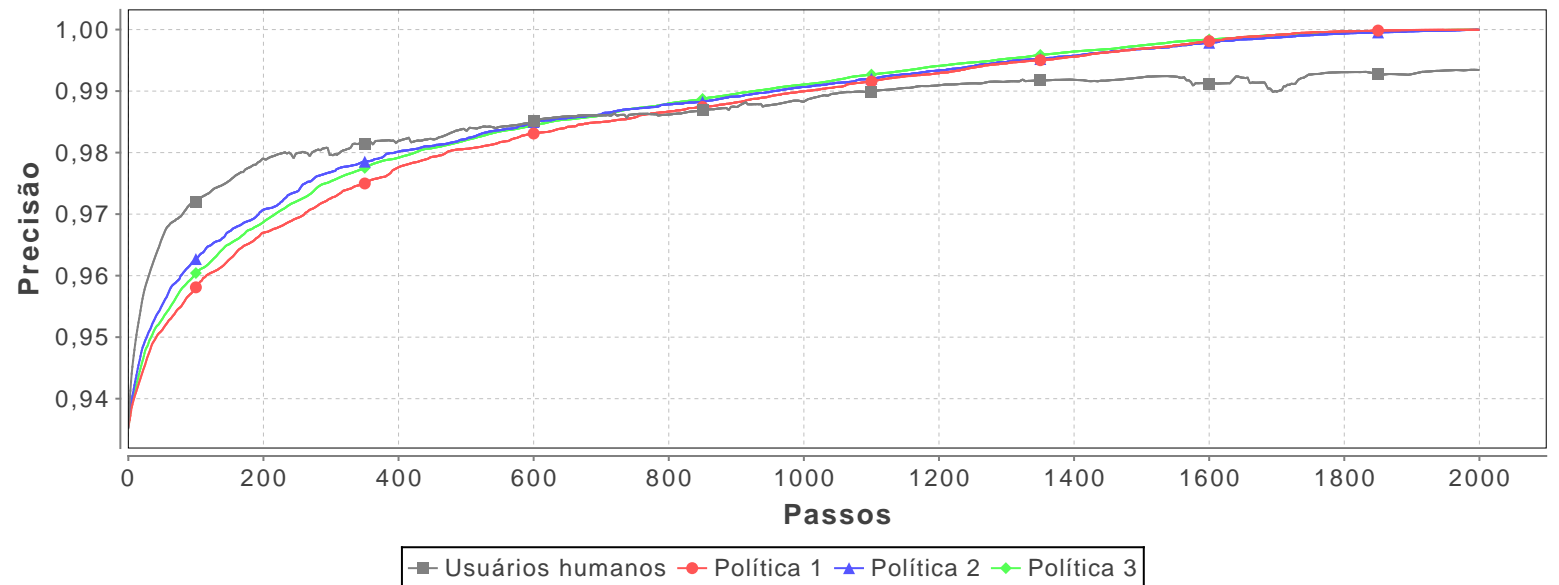

(b) Precisão

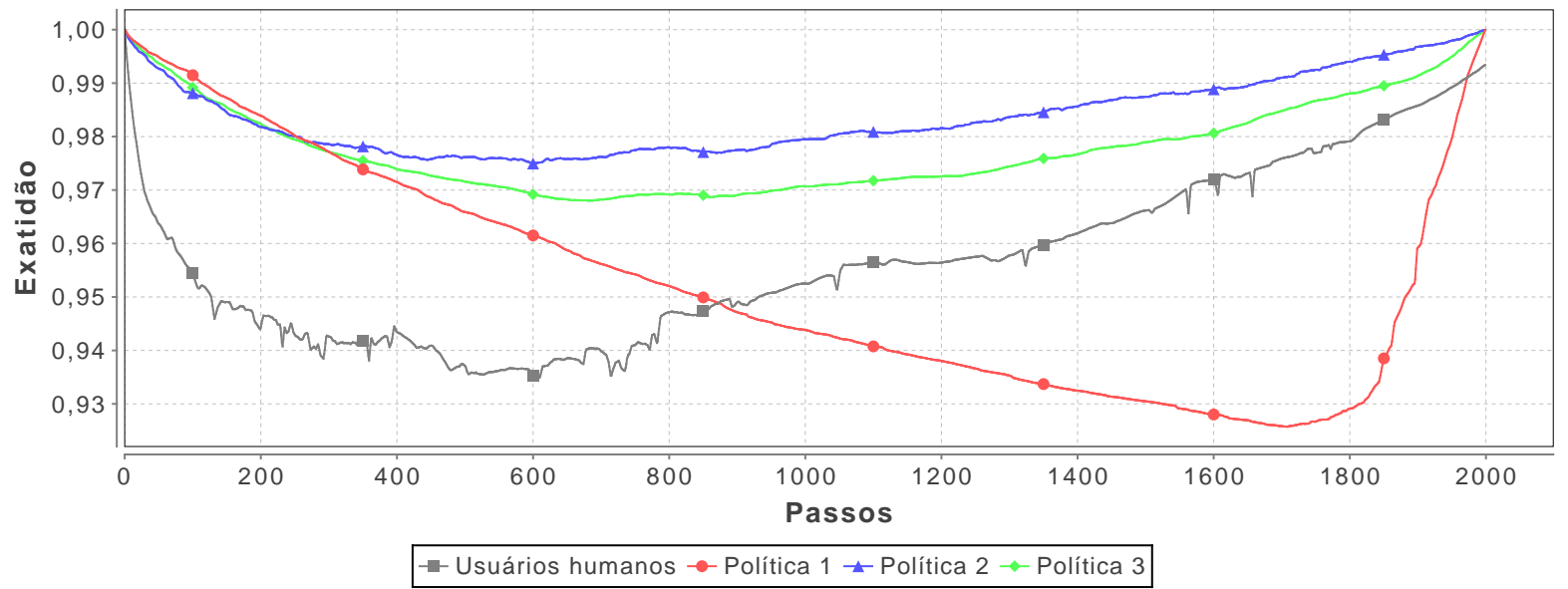

(c) Exatidão

Figura 4.5: Perfis médios de evolução das medidas de qualidade nos experimentos. 
Porém, os perfis médios das medidas consideradas obtidos foram praticamente os mesmos, somente um pouco menos ruidosos. Desta forma, os gráficos exibidos neste capítulo não consideram tal filtragem.

Note, nos gráficos da Figura 4.5, que as simulações sempre atingem o valor máximo das medidas consideradas, uma vez que a partição do ground truth correspondente sempre é obtida. Por esse mesmo motivo, as simulações geralmente resultam em um maior número de operações executadas, comparando-se com os experimentos realizados pelos voluntários.

Os perfis médios das medidas de acurácia e exatidão das simulações com a política 1 são os que mais se diferenciam dos demais. Isto se deve ao fato que, nesta política, as operações de fusão manual são realizadas somente nos últimos passos da simulações, o que resulta num grande número de falsos negativos e um pequeno número de verdadeiros positivos antes de tais operações serem executadas. Por este mesmo motivo, estes perfis médios crescem abruptamente no final do processo. Os demais perfis têm um comportamento mais suave. Em particular, os perfis das políticas 2 e 3 são visualmente bem similares entre si e os perfis dos usuários humanos também têm uma evolução geral próxima aos perfis dessas duas políticas.

Para quantificar a similaridade entre os experimentos executados pelos usuários com as simulações com cada um das políticas propostas, calculamos o coeficiente de correlação de Pearson (Rodgers e Nicewander, 1988) entre os perfis de cada uma das medidas, conforme exibido na Figura 4.7. A correlação entre o perfis médios da medida de precisão é bem alta; por outro lado, a correlação dos perfis médios das medidas de acurácia e exatidão não é muito alta. Porém, note que a correlação é positiva para as políticas 2 e 3, enquanto é negativa para a política 1 .

Apesar das correlações entre os perfis das políticas e dos usuários humanos não serem todas muito altas, os perfis das políticas propostas praticamente se encaixam dentro da variabilidade das séries do usuários humanos, exibidas nas áreas preenchidas da Figura 4.8. Cada uma dessas áreas é limitada pelas séries médias (referente a cada medida) de cada um dos 15 voluntários que colaboraram nos experimentos, conforme exibido na Figura 4.9.

Para verificar se a ordem das operações dada pela função de probabilidade $\mathcal{P}$ definida para a política 3 tem relevância no processo, simulamos tal política com diversos valores constantes para $\mathcal{P}$. Variando $\mathcal{P}$ de 0 a 1 faz os perfis médios resultantes se deslocarem dos perfis médios da política 1 para os perfis médios da política 2, conforme exibido na Figura 4.10. Na Figura 4.11 complementamos o gráfico da Figura 4.7 acrescentado a correlação entre essas novas simulações com os experimentos realizados por usuários humanos. As correlações obtidas são similares às correlações da política 3 com a função $\mathcal{P}$ originalmente proposta. No entanto, a função proposta é mais interessante, uma vez que seu valor não é constante, pois depende do conteúdo da imagem. 


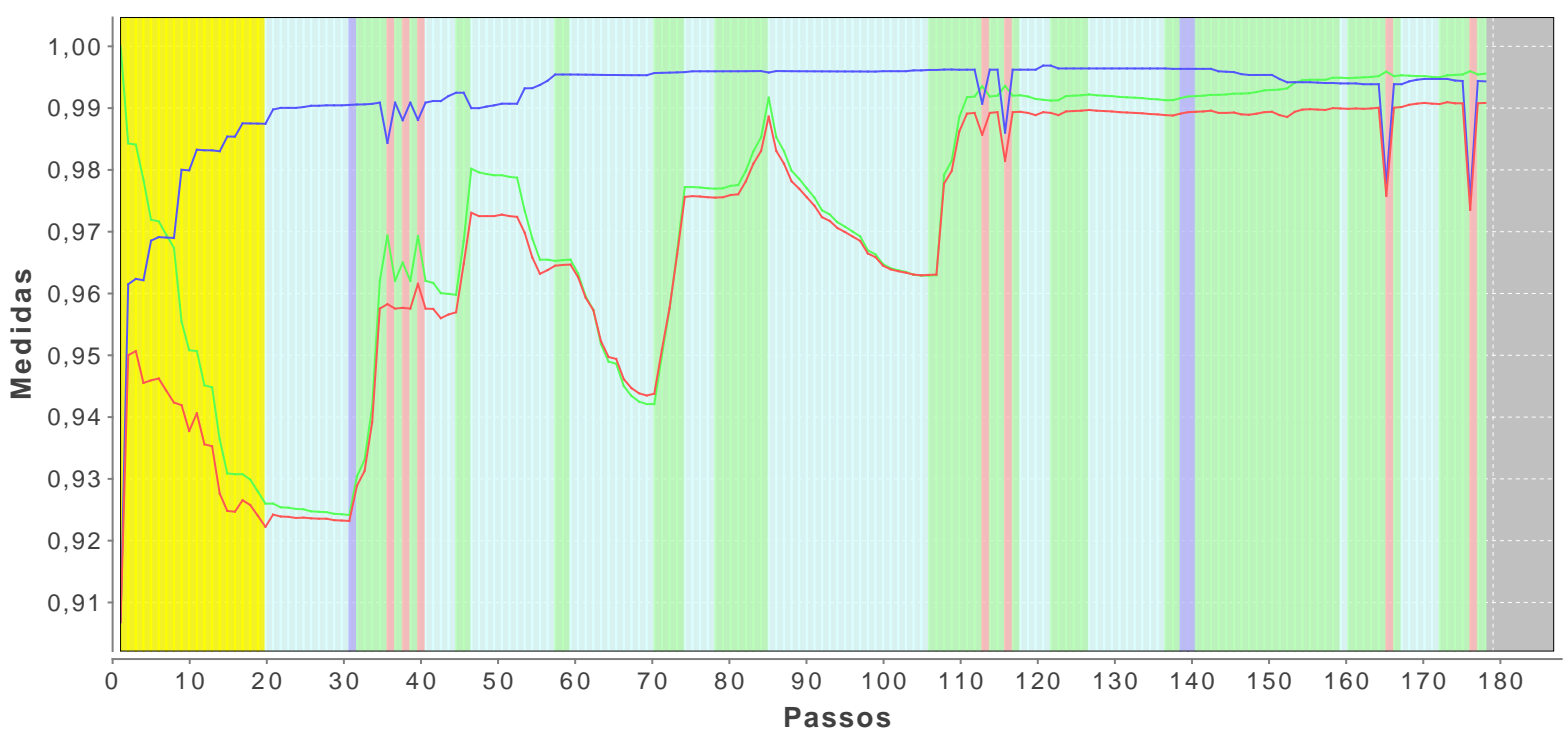

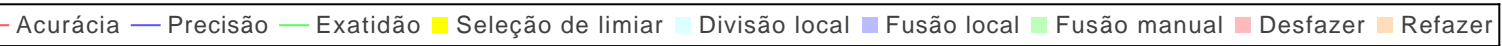

(a) Tarefa executada por um voluntário

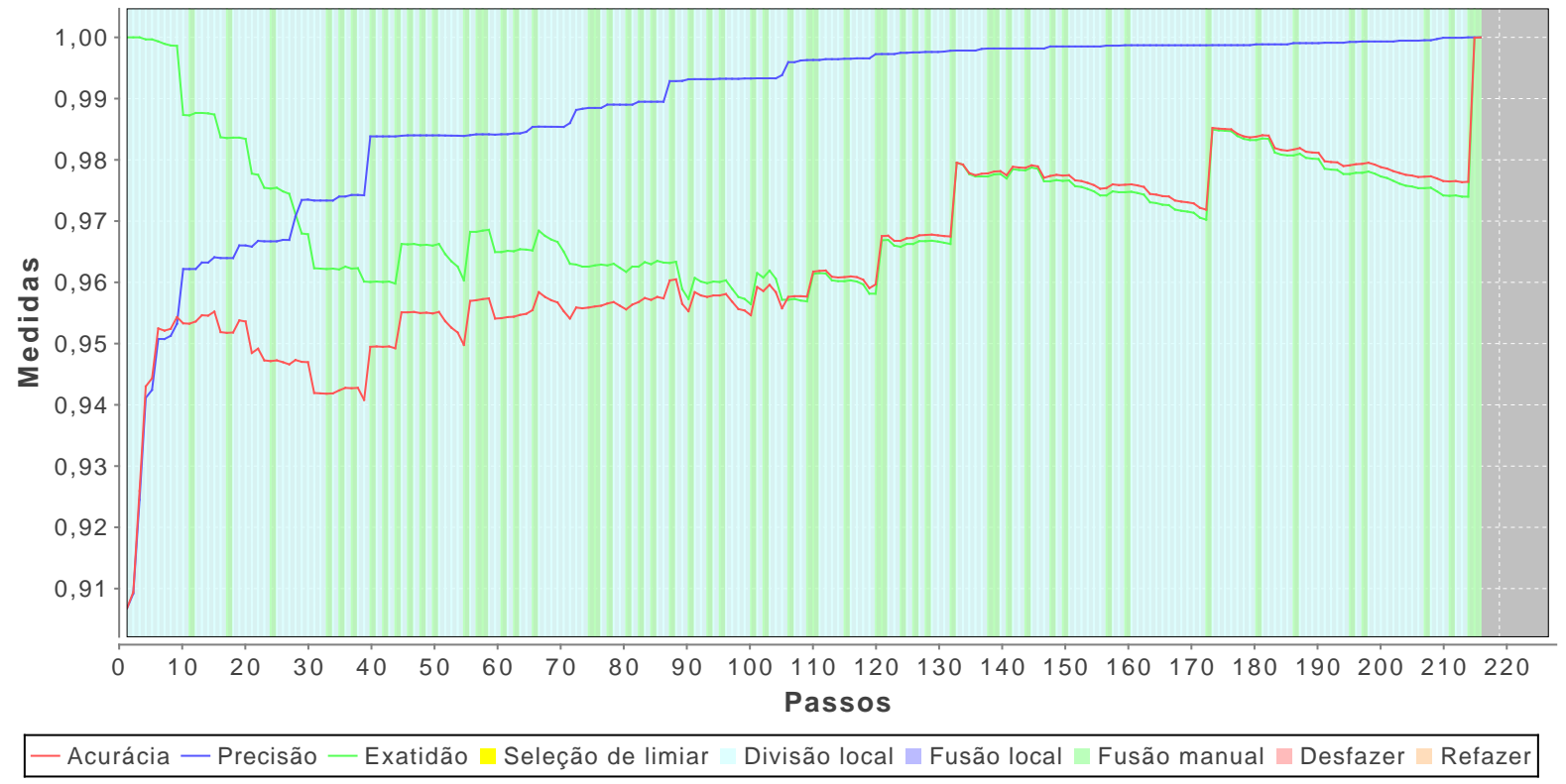

(b) Tarefa executada via simulação com a política 3

Figura 4.6: Exemplo de execução de uma mesma tarefa de segmentação dos experimentos por um voluntário e por uma simulação com a política 3. As operações utilizadas nas simulações são um subconjunto das operações disponíveis aos usuários humanos. 


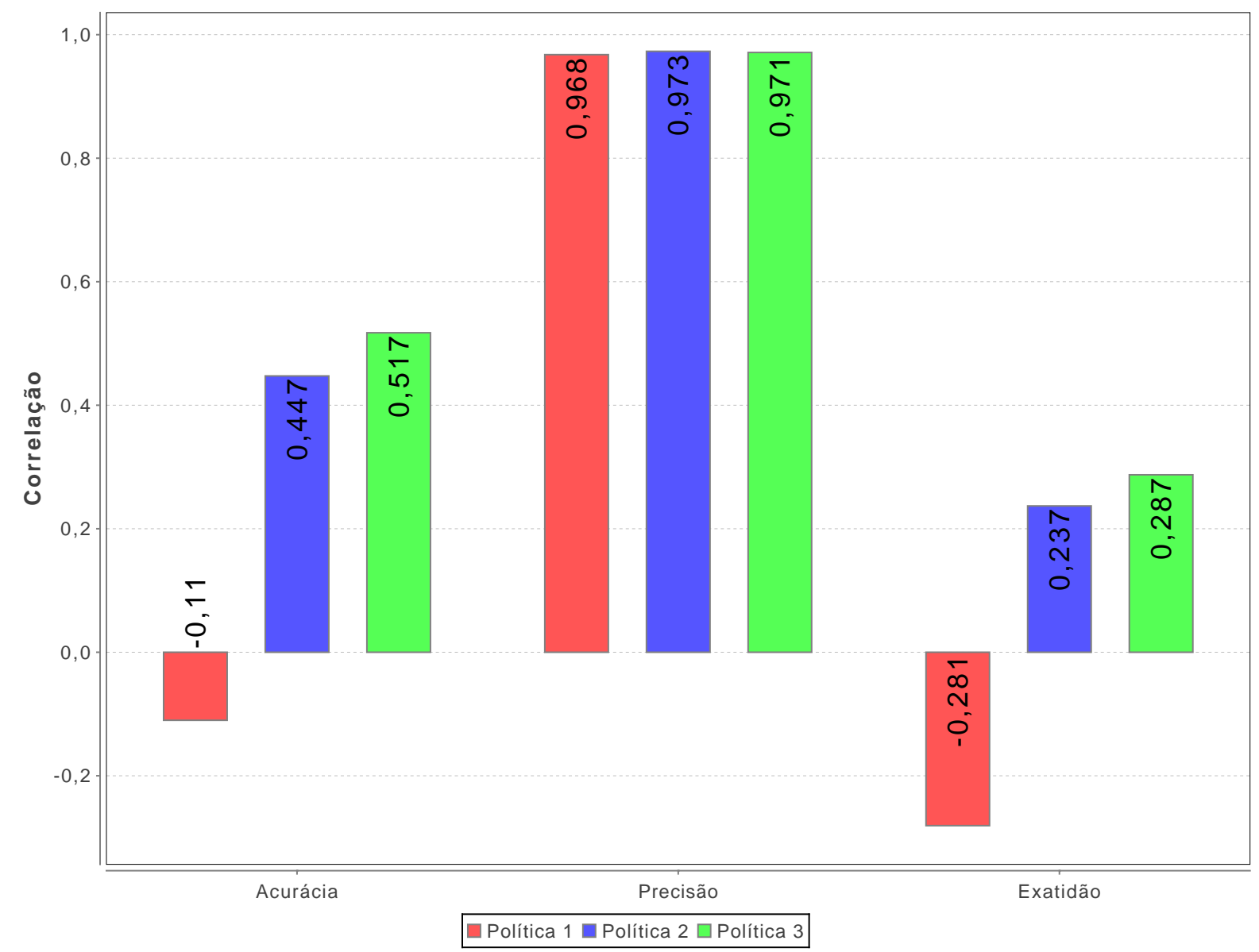

Figura 4.7: Correlação entre os perfis médios dos experimentos com usuários e cada uma das políticas.

\subsection{Discussão}

Com a análise feita na seção anterior, concluímos que as políticas 2 e 3 tem um comportamento mais parecido com os usuários humanos do que a política 1. Apesar do perfis médios das simulações com essas políticas não terem uma forte correlação com os perfis médios dos experimentos realizados com usuários humanos, tais perfis se encaixam na variabilidade desses e, portanto, podem ser utilizados para simular tal processo. Consideramos que a política 3 é a mais adequada por não ser determinística, refletindo melhor as escolhas feitas por usuários humanos ao longo de processos interativos de segmentação.

Com o modelo proposto, experimentos mais complexos (com imagens em alta resolução, com muitas imagens ou com muitas repetições) que seriam inviáveis de serem feitos com intervenção humana podem ser realizados de forma automática, bastando ter o ground 


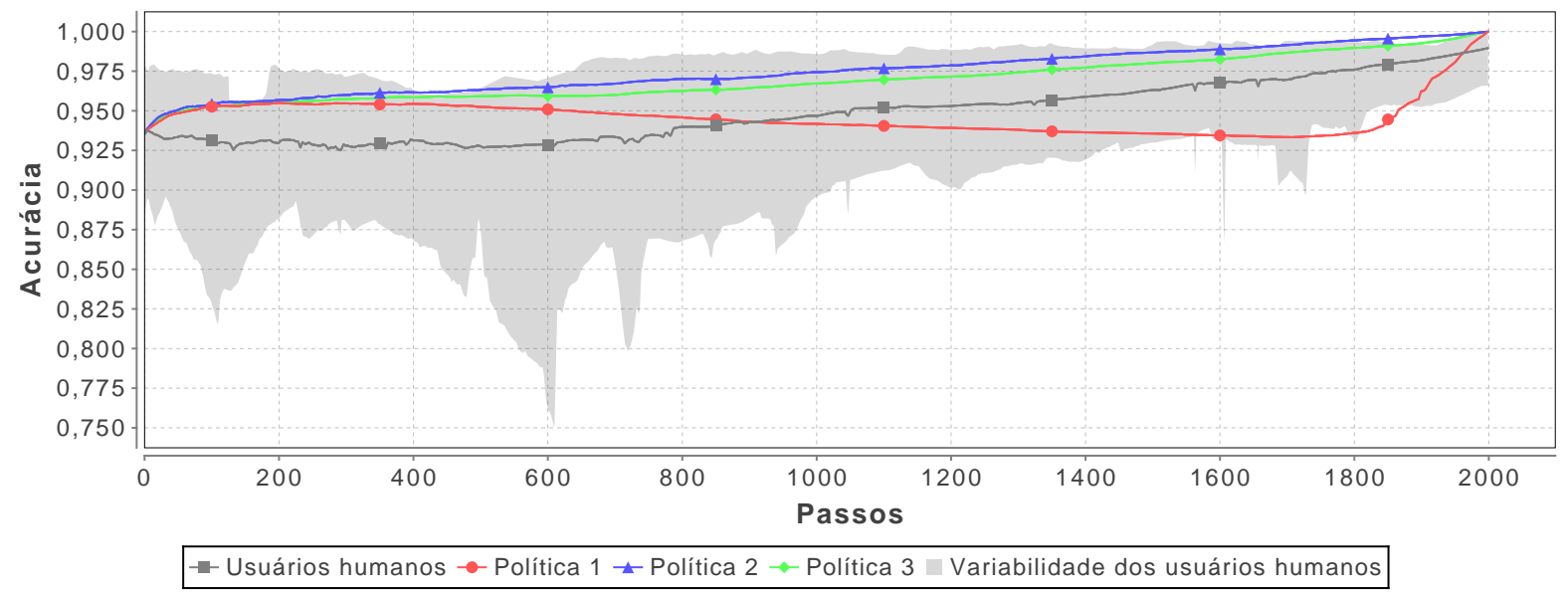

(a) Acurácia

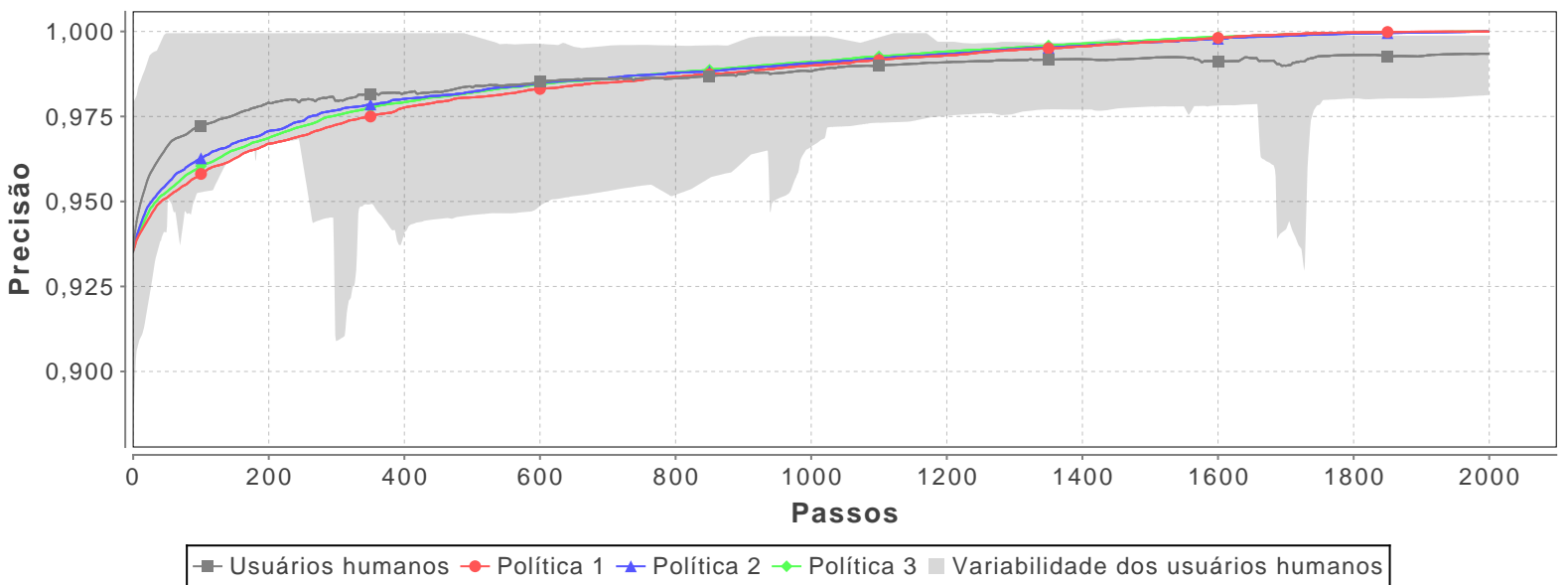

(b) Precisão

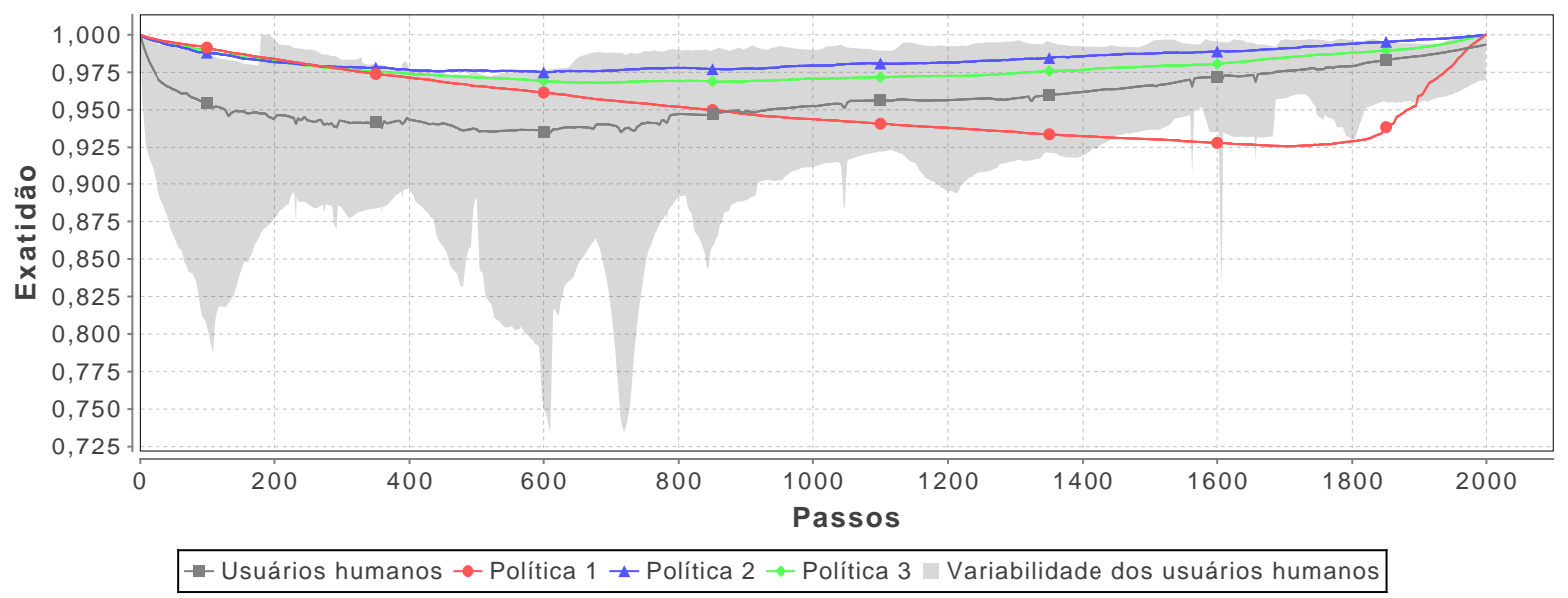

(c) Exatidão

Figura 4.8: Perfis médios de evolução das medidas de qualidade nos experimentos sobrepostos à variabilidade das séries médias dos usuários humanos. 


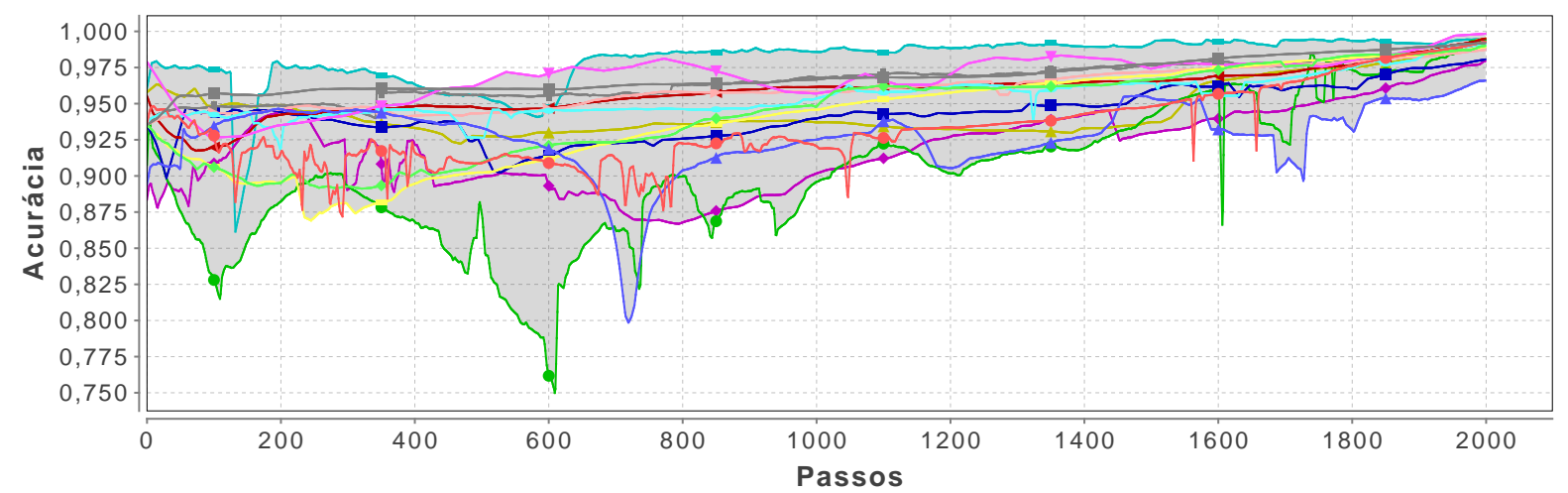

- Usuário $1-$ - Usuário $2 \uparrow$ Usuário $3 \rightarrow$ Usuário $4-$ Usuário $5 \rightarrow$ Usuário $6 \multimap$ Usuário $7 \rightarrow$ Usuário $8 \rightarrow$ - Usuário 9

— Usuário $10 \rightarrow$ Usuário $11 \rightarrow$ Usuário $12 \rightarrow$ Usuário $13 \rightarrow$ Usuário 14 - - Usuário $15 \square$ Variabilidade dos usuários humanos

(a) Acurácia

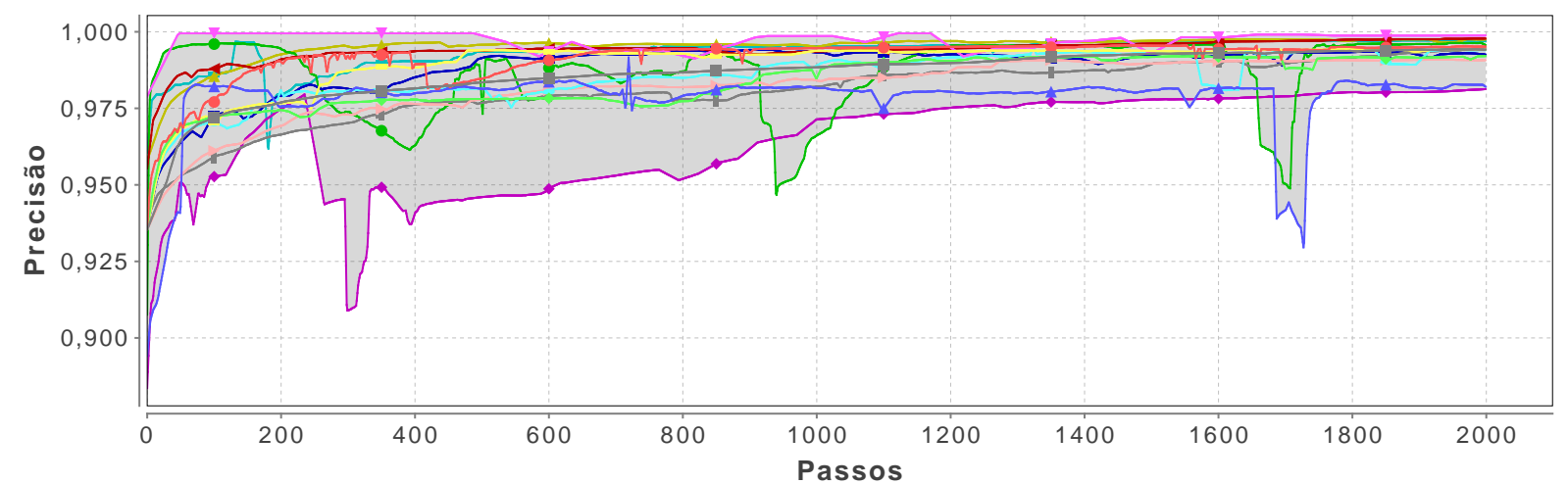

- Usuário $1 \rightarrow$ Usuário $2 \multimap$ Usuário $3 \rightarrow$ Usuário $4-$ Usuário $5 \rightarrow$ Usuário $6-$ Usuário $7 \rightarrow$ Usuário $8 \rightarrow$ Usuário 9

— Usuário 10 - Usuário $11-$ Usuário $12-$ - Usuário $13 \rightarrow$ Usuário 14 - Usuário 15 Variabilidade dos usuários humanos

(b) Precisão

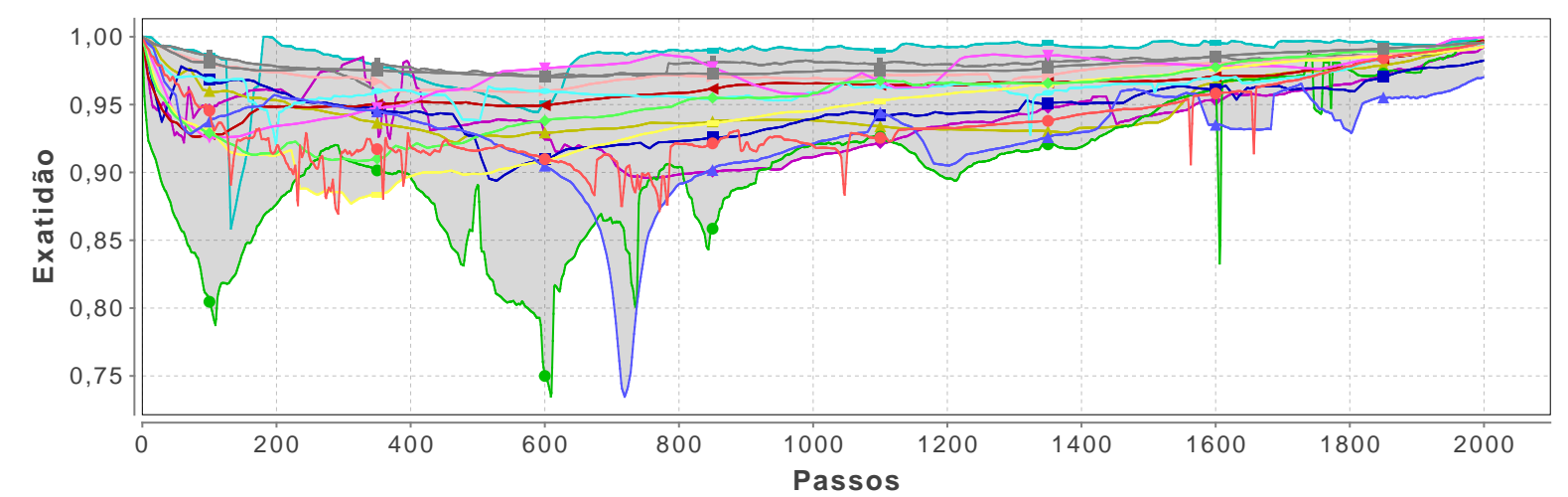

-- Usuário 1 - Usuário $2 ₫$ Usuário $3 \multimap$ Usuário $4-$ Usuário $5 \multimap$ Usuário $6 \multimap$ Usuário $7 \rightarrow$ Usuário $8 \multimap-$ Usuário 9

— Usuário $10 \rightarrow$ Usuário $11 \rightarrow$ Usuário 12 - Usuário $13 \multimap$ Usuário 14 -- Usuário 15 Variabilidade dos usuários humanos

(c) Exatidão

Figura 4.9: Séries médias das medidas de qualidade nos experimentos com cada um dos usuários humanos que colaboraram nos experimentos. A área definida por essas curvas médias define a variabilidade dos usuários humanos, exibida na Figura 4.8. 


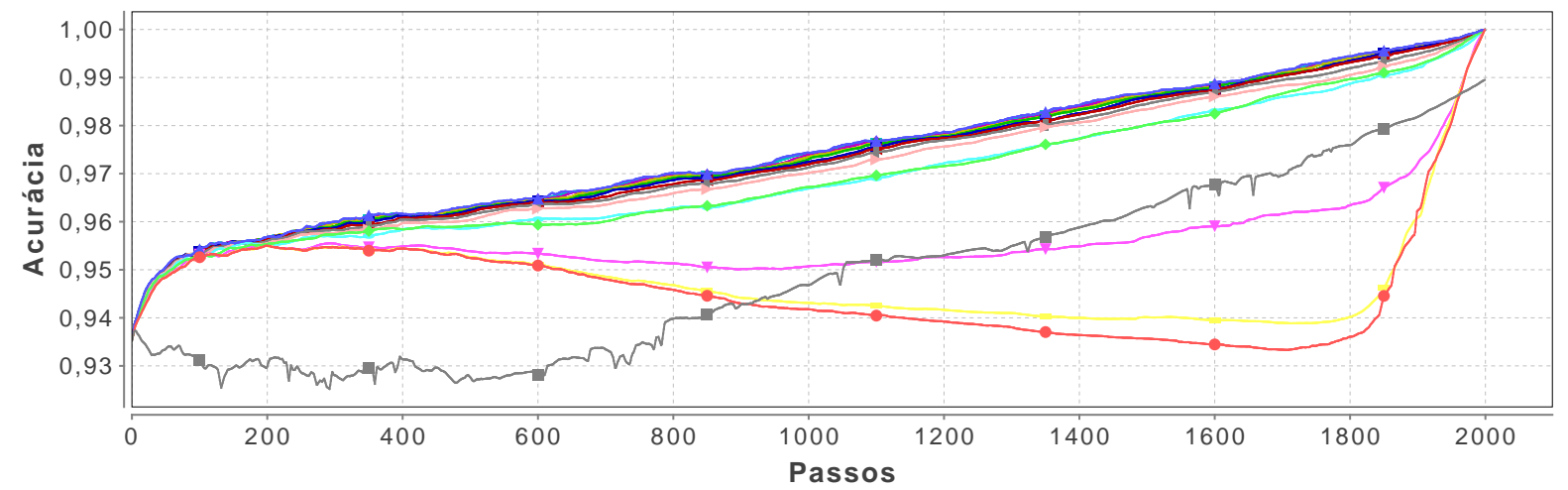

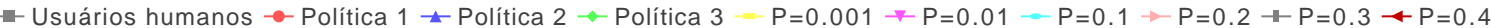

$\rightarrow P=0.5 \rightarrow P=0.6 \rightarrow P=0.7 \rightarrow P=0.8 \rightarrow P=0.9$

(a) Acurácia

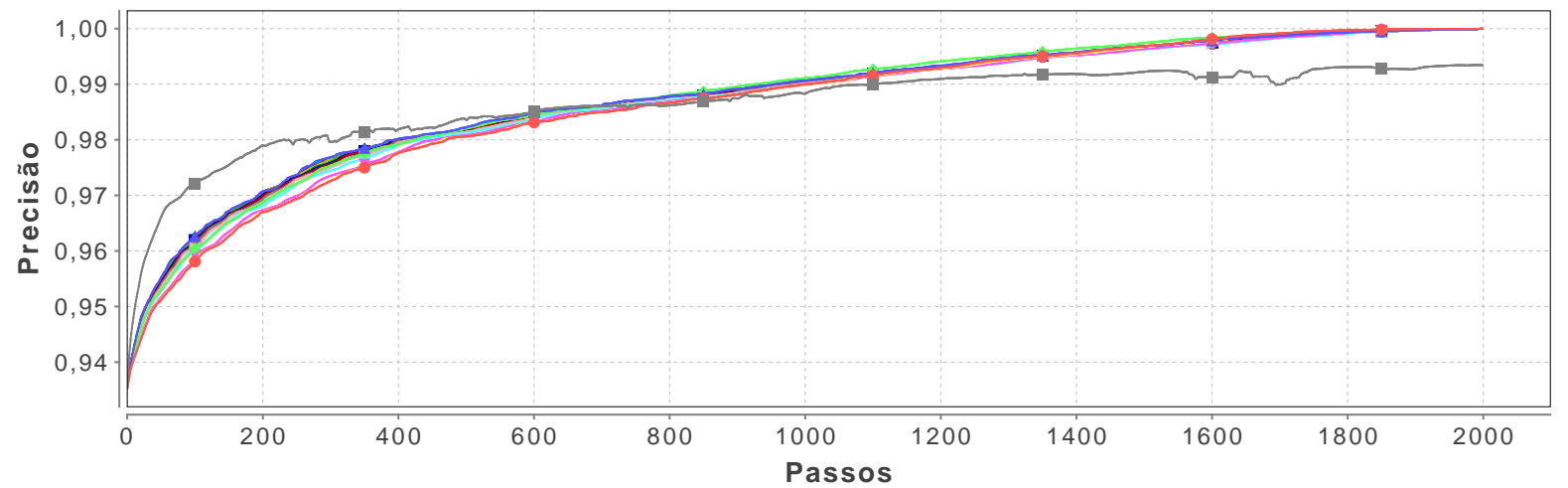

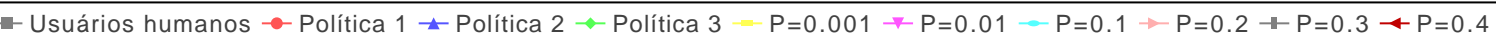

$\rightarrow \mathrm{P}=0.5 \rightarrow \mathrm{P}=0.6 \rightarrow \mathrm{P}=0.7 \rightarrow \mathrm{P}=0.8 \rightarrow \mathrm{P}=0.9$

(b) Precisão

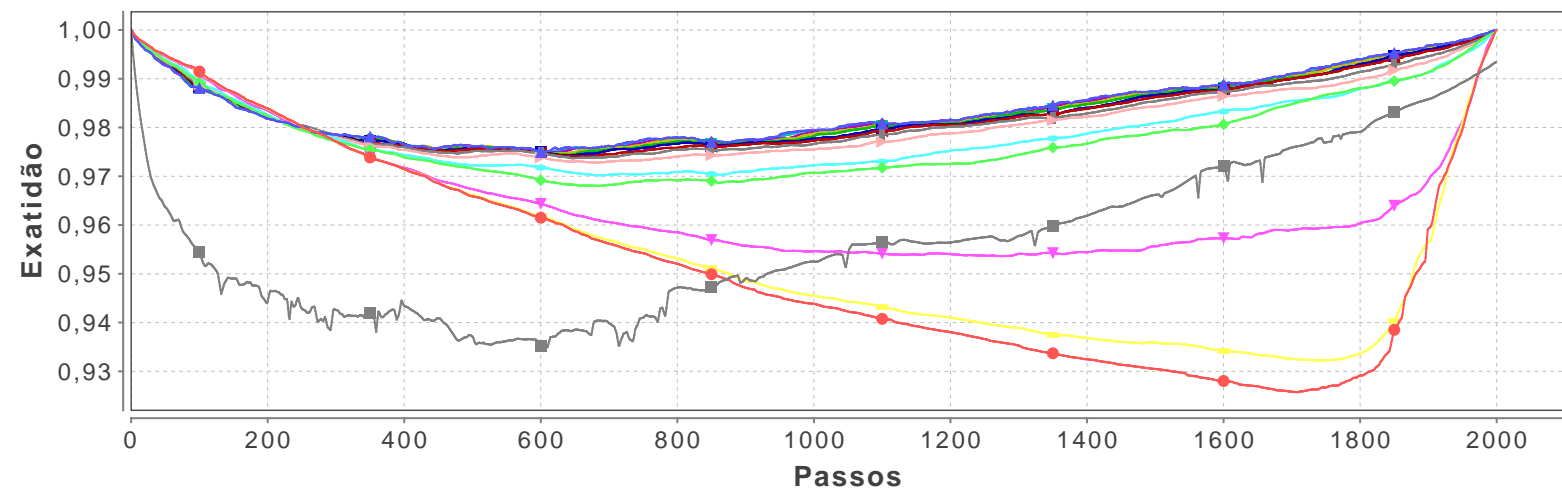

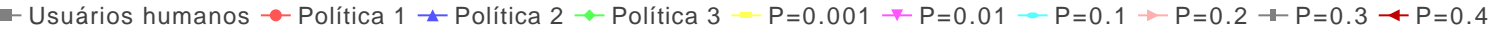

$\because P=0.5 \rightarrow P=0.6 \rightarrow P=0.7 \rightarrow P=0.8 \rightarrow P=0.9$

(c) Exatidão

Figura 4.10: Perfis médios de evolução das medidas de qualidade nos experimentos para diversos valores constantes para $\mathcal{P}$. 


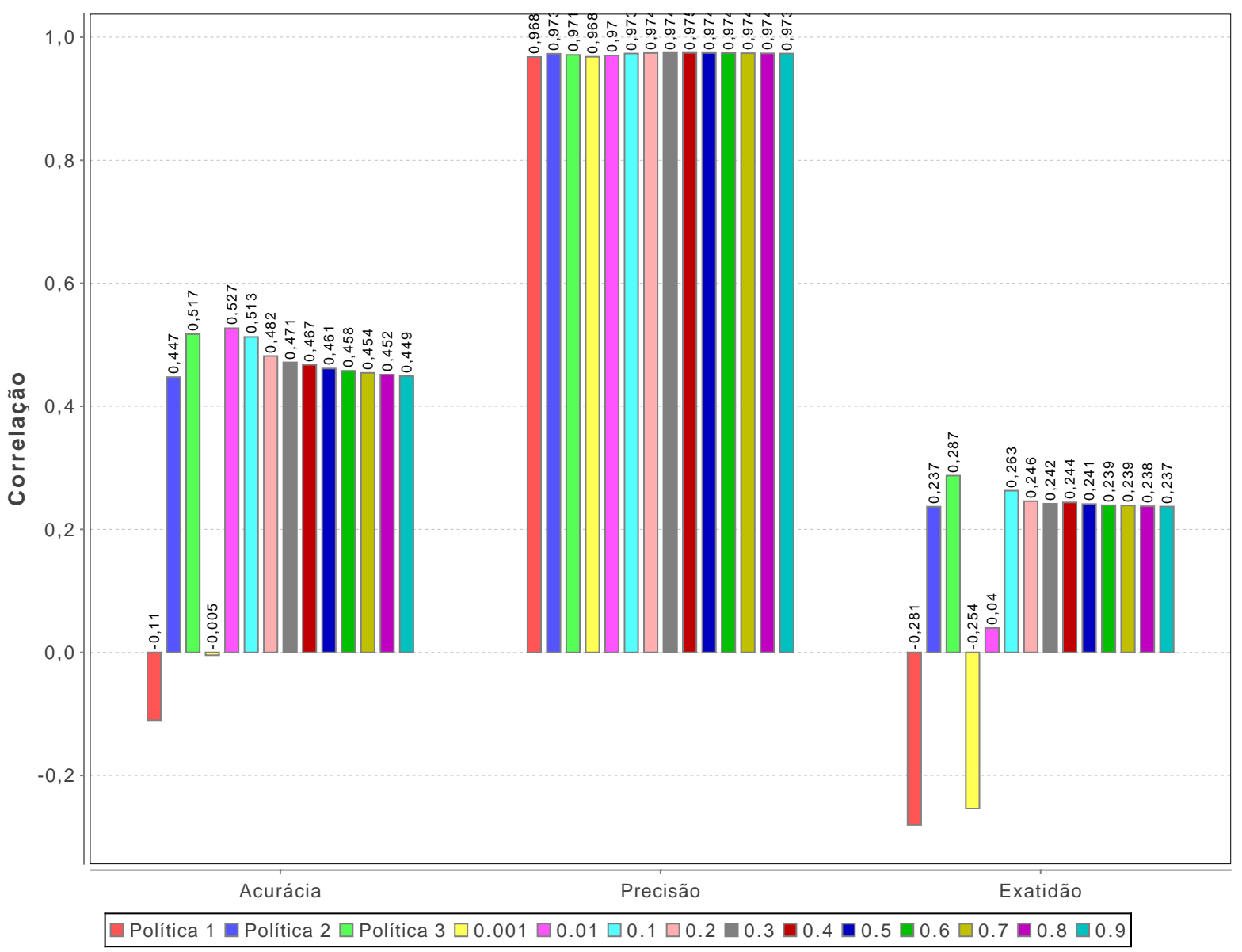

Figura 4.11: Correlação entre os perfis médios dos experimentos com usuários e cada uma das políticas e diversos valores constantes para $\mathcal{P}$.

truth para direcionar o processo.

Os experimentos descritos neste capítulo foram baseados no watershed hierárquico. Porém, o modelo pode ser utilizado com outras hierarquias e estendido para incluir outros tipos de operações. A metodologia utilizada nesses experimentos, seja com as medidas de qualidade aqui consideradas ou mesmo com outras medidas, permanece válida para novos cenários. No Apêndice B apresentamos uma hierarquia de partições diferentes das hierarquias geradas por processos de inundações síncronas para a qual o modelo de interação proposto nesse capítulo também é válido.

Uma crítica que pode ser feita em relação às medidas de qualidade utilizadas para avaliar o modelo proposto é que tais medidas começam com valores muito altos nos experimentos e simulações. Isso se deve às definições das classes de arestas feitas na Seção 2.2. Como a segmentação inicial é formada por todas as bacias primitivas pertencendo à mesma 
região, todas as arestas do RAG são inicialmente classificadas como verdadeiros positivos, o que determina o alto valor das medidas de qualidade no passo inicial dos experimentos e simulações. Uma melhor definição para as classes de arestas seria classificar todas as arestas como verdadeiros negativos no passo inicial, de forma que os verdadeiros positivos fossem selecionados ao longo do processo de segmentação. 


\section{Experimentos}

Neste capítulo descrevemos uma série de experimentos realizados para avaliar o método proposto no Capítulo 3. Tal método utiliza segmentações previamente realizadas para gerar classificadores binários. Tais classificadores, por sua vez, são utilizados para gerar uma partição para uma nova imagem.

Em geral, um classificador que não comete erros não existe. Por esse motivo, a abordagem adotada, então, é gerar um classificador que minimize alguma medida que compara os resultados obtidos pelo classificador com os resultados ideais esperados. No contexto do problema ao qual o método foi proposto, a medida que desejamos minimizar é o esforço de interação necessário para se obter uma partição. Dessa forma, desejamos que, ao se utilizar o método proposto, o esforço necessário para se obter uma partição seja menor que o esforço necessário para se obter a mesma partição sem a utilização do método.

Podemos definir o esforço de interação necessário para realizar uma tarefa a partir de uma sequência de passos que possibilite a execução de tal tarefa. Nesse contexto, o modelo de simulação de interação descrito no Capítulo 4 gera uma sequência de operações que pode ser utilizada para se realizar uma tarefa de segmentação.

\subsection{Medida do esforço de interação}

Podemos utilizar a sequência de operações obtidas usando o modelo proposto no Capítulo 4 para estimar o esforço de interação necessário para se realizar a tarefa de segmentação que foi simulada. Quanto maior for o número de operações necessárias para se obter uma partição, maior é o esforço de interação necessário para tal. O esforço de interação necessário para executar uma tarefa de segmentação, então, pode ser definido como a soma dos esforços de interação necessários para se executar cada uma das operações realizadas. 
Porém, cada operação pode ter um esforço de interação diferente, esforço que leva em consideração como o usuário deve interagir com o sistema que implementa tal operação.

A seguir, descrevemos o esforço de interação necessário para executar cada operação hierárquica implementada no SegmentIt. Tal esforço considera como cada um dos tipos de operações foi disponibilizada aos usuários através da interface gráfica da ferramenta:

- a operação de seleção de limiar demanda um esforço muito pequeno para ser executada, uma vez que basta mover o controle deslizante correspondente a essa operação para escolher o limiar desejado;

- as operações de fusão e divisão local também demandam um esforço muito pequeno, uma vez que, para serem executadas, basta: (1) selecionar a operação desejada no menu de contexto disponível ao clicar sobre a região que deve ser afetada ou (2) deixar o cursor do mouse sobre a região desejada e fazer um gesto de rotação na mouse wheel;

- na operação de fusão manual, o usuário deve indicar quais regiões devem ser fundidas, desenhando um marcador que passe por todas as regiões que se deseja fundir. Quanto maior for o número de regiões a serem fundidas em uma operação de fusão manual, maior o esforço de interação necessário para realizar tal operação.

Definimos o esforço de interação necessário para executar uma sequência de operações $\left\langle x_{1}, x_{2}, \ldots, x_{n}\right\rangle$ como:

$$
\mathscr{E}_{\text {total }}\left(\left\langle x_{1}, x_{2}, \ldots, x_{n}\right\rangle\right)=\sum_{i=1}^{n} \mathscr{E}\left(x_{i}\right)
$$

onde

$$
\mathscr{E}\left(x_{i}\right)= \begin{cases}\alpha & \text { se } x_{i} \text { é uma operação de seleção de limiar } \\ \beta & \text { se } x_{i} \text { é uma operação de divisão ou fusão local } \\ \gamma * \mathscr{E}_{\text {fusão }}(n) & \text { se } x_{i} \text { é uma operação de fusão manual de } n \text { regiões }\end{cases}
$$

Como descrito acima, quanto maior for o número de regiões a serem fundidas em uma operação de fusão manual, maior o esforço de interação necessário para realizar tal operação. De fato, para fundir $n$ regiões, é necessário fazer um marcador que passe pelas $n$ regiões, ou seja, é necessário cruzar pelo menos $n-1$ vezes as bordas que separam as $n$ diferentes regiões. Então, definimos que: 


$$
\mathscr{E}_{\text {fusão }}(n)=n-1
$$

Uma definição mais precisa para $\mathscr{E}_{\text {fusão }}(n)$ poderia levar em consideração o tamanho, estrutura e posição relativa entre as regiões a serem fundidas.

Nas análises feitas a respeito do esforço de interação ao longo desse capítulo, iremos considerar que $\alpha=\beta=\gamma=1$.

\subsection{Descrição dos experimentos}

Para a execução dos experimentos, utilizamos máquinas de suporte vetorial, ou SVMs ${ }^{1}$, para a classificação das arestas do RAG. Em particular, utilizamos a implementação de Chang e Lin (2011). Entretanto, note que o método proposto no Capítulo 3 é independente da técnica de aprendizado supervisionado utilizada.

Para compor o vetor de características, utilizamos 15 características, como descrito na Seção 3.2:

- 3 características derivadas das inundações síncronas;

- 1 característica derivada do nível de cinza médio das bacias primitivas;

- 11 características derivadas da convolução da imagem de entrada com um banco de filtros.

Após classificar as arestas de uma imagem entre ativas e inativas, o resultado obtido é processado de forma que corresponda a uma partição válida, conforme descrito na Subseção 3.1.1. Opcionalmente, é possível ainda utilizar dois pós-processamentos (heurísticas):

1. remover da partição obtida as bordas selecionadas por um pequeno número de arestas classificadas como inativas, como descrito na Subseção 3.1.2;

2. fundir regiões adjacentes na partição obtida que não têm arestas classificadas como inativas entre suas bordas, como descrito na Subseção 3.1.3.

Em relação a esses 2 pós-processamentos, serão avaliadas 4 configurações:

- Sem as heurísticas: sem a utilização dos 2 pós-processamentos;

\footnotetext{
${ }^{1}$ SVM: do inglês Support Vector Machine
} 
- Com a heurística de filtragem: com a utilização somente da filtragem de bordas que foram selecionadas por menos que 10 arestas;

- Com a heurística de fusão: com a utilização da fusão de regiões adjacentes que não têm arestas inativas nas bordas entre elas;

- Com ambas as heurísticas: com a utilização dos 2 pós-processamentos propostos.

Uma vez obtida uma partição inicial e dada uma hierarquia previamente construída para uma imagem, tal partição é utilizada por simulações com o modelo descrito no Capítulo 4 para então inferir o esforço de interação necessário para se obter a partição desejada. O mesmo modelo de interação pode ser utilizado para inferirmos o esforço de interação necessário para realizar a mesma tarefa de segmentação, mas sem a utilização do método proposto, ou seja, partindo da partição mais grosseira da imagem em questão, formada por uma única região.

No Capítulo 3 descrevemos que cada imagem previamente segmentada é utilizada para a geração de um classificador. Ao segmentar um conjunto de imagens, a cada nova imagem a ser segmentada, todas as imagens do conjunto que já foram segmentadas podem ser utilizadas para gerar uma partição inicial para a nova imagem. Devemos avaliar, então, o efeito de se utilizar mais ou menos classificadores para cada nova imagem a ser segmentada. Se um conjunto tem $n$ imagens, será avaliado e esforço necessário para se segmentar cada uma das imagens do conjunto usando de 0 a $n$ classificadores:

- as imagens do conjunto são segmentadas sempre na mesma ordem;

- ao utilizar 0 modelos, o que está sendo avaliado é o esforço de interação necessário para segmentar as imagens do conjunto sem a utilização do método proposto;

- ao utilizar $x$ modelos, $0<x<n$, para cada imagem a ser segmentada serão utilizados até $x$ modelos, correspondentes às $x$ imagens anteriores à imagem atual, para selecionar uma partição inicial para tal imagem.

Nas subseções a seguir, apresentamos os resultados dos experimentos para cada um dos 4 conjuntos de imagens selecionados. Os ground truths gerados para cada imagem dos conjuntos são utilizados de duas formas nos experimentos:

- quando simulamos a segmentação de uma imagem, o respectivo ground truth é utilizado para guiar o modelo de simulação descrito no Capítulo 4;

- quando uma imagem é utilizada para compor um classificador, o respectivo ground truth é utilizado junto com tal imagem para a geração desse classificador, de forma que tal classificador possa ser utilizado para gerar a partição inicial para outras imagens. 


\subsubsection{Borboletas}

Descrição do conjunto: Lote de imagens, cedida por colaborador, com 100 fotografias de asas de borboletas da espécie Heliconius erato. Em algumas das imagens há anotações feitas nos próprios espécimes.

Tarefa de segmentação: Segmentar cada uma das asas. Em cada asa, separar a maior região central com outra cor. Exemplos de imagens desse lote e seus respectivos ground truths são exibidos na Figura 5.1.

Tamanho das imagens: $442 \mathrm{px}$ a $738 \mathrm{px}$ de largura $\times 405 \mathrm{px}$ a $648 \mathrm{px}$ de altura.

Créditos das imagens: Prof. André Victor Lucci Freitas e Dr. Leonardo Ré Jorge (UNICAMP).
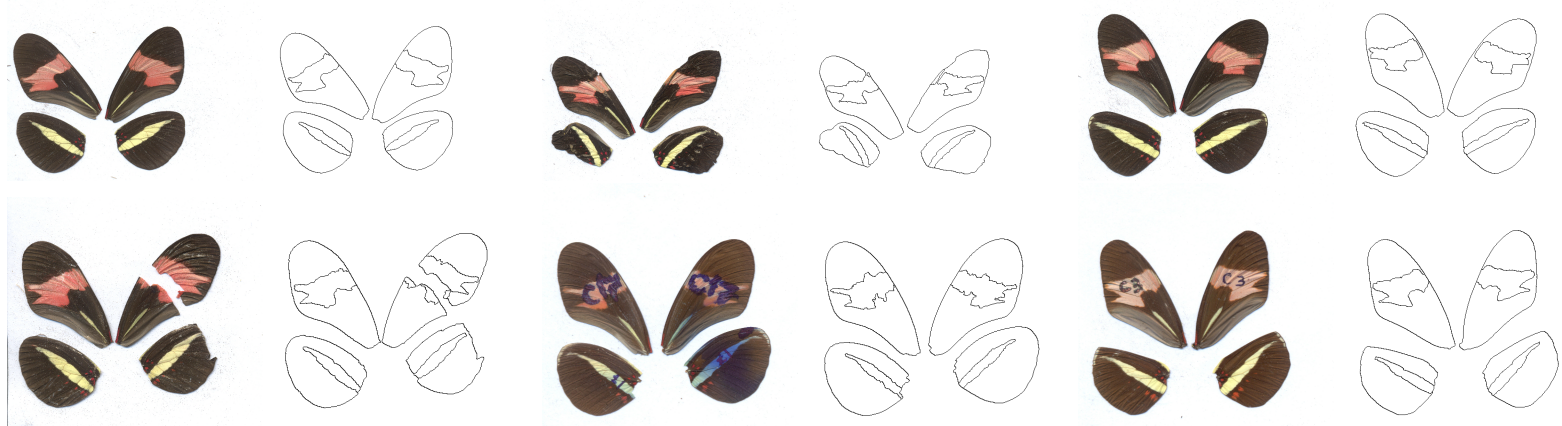

Figura 5.1: Exemplos de imagens e ground truths do lote "Borboletas".

Na Figura 5.2 exibimos o esforço necessário para segmentar, sem o método proposto, cada imagem do lote "Borboletas" utilizando o critério de inundação uniforme (nível fusão) e os 3 critérios de inundação síncrona (profundidade, área e volume). O esforço total para cada um dos critérios é exibido na Tabela 5.1. Como o esforço mínimo para este lote foi obtido usando o critério de volume, este será o critério utilizado para os demais experimentos com este lote de imagens.

\begin{tabular}{|r|c|}
\cline { 2 - 2 } \multicolumn{1}{c|}{} & Esforço total \\
\hline Nível fusão & 89576 \\
\hline Profundidade & 18911 \\
\hline Área & 19304 \\
\hline Volume & 15371 \\
\hline
\end{tabular}

Tabela 5.1: Esforço total para segmentar o lote "Borboletas" sem o método proposto.

Nas figuras 5.3 a 5.6 é exibido o esforço para segmentar cada uma das imagens do lote "Borboletas", com as 4 configurações de pós-processamento. Nesses gráficos, exibimos no 


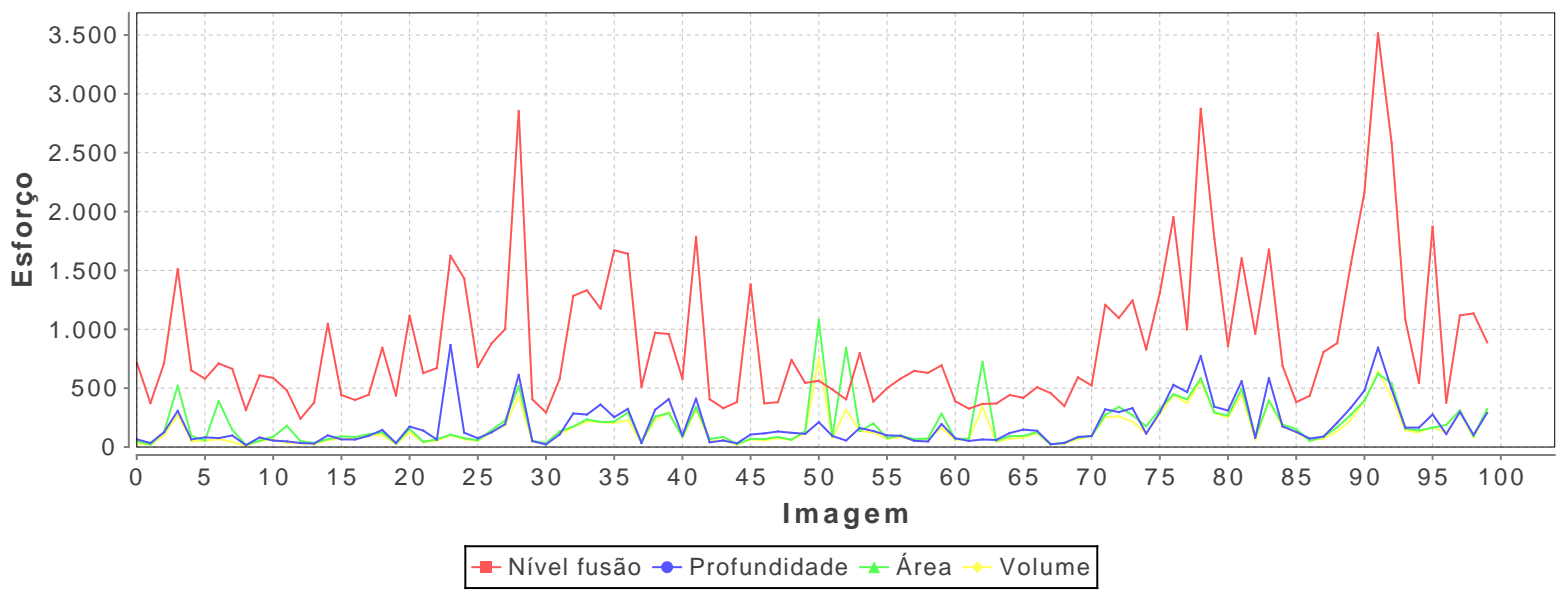

Figura 5.2: Esforço para segmentar o lote "Borboletas" sem o método proposto.

eixo horizontal o índice de cada imagem no conjunto. No eixo vertical, exibimos o esforço necessário para segmentar a imagem do respectivo índice (eixo horizontal) com a utilização de um certo número de classificadores, dado por cada uma das curvas exibidas. Note que o uso de poucos classificadores pode dificultar a segmentação das imagens.

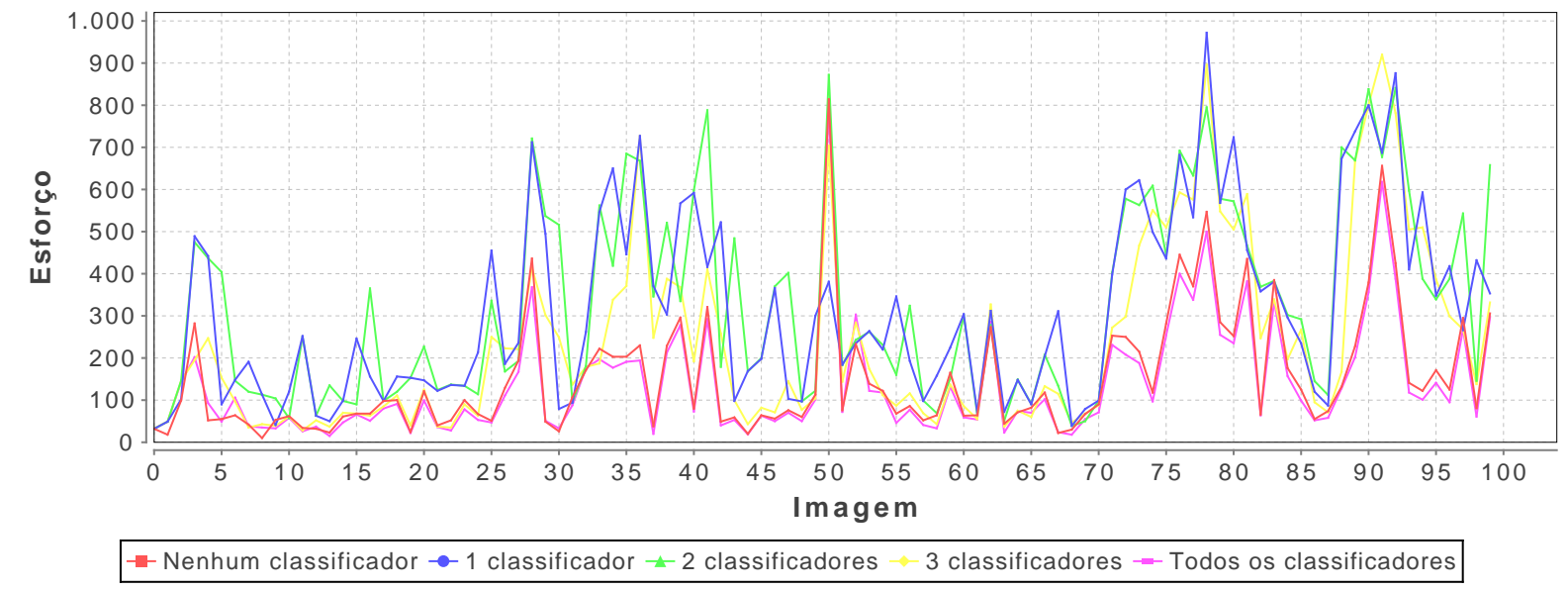

Figura 5.3: Esforço para segmentar o lote "Borboletas" sem as heurísticas.

Na Figura 5.7 é exibido o esforço total para segmentar todas as imagens do lote "Borboletas". O esforço total é dado pela soma dos esforços de interação para segmentar cada imagem do lote. Desta forma, exibimos no eixo horizontal o número de classificadores utilizados e, no eixo vertical, o esforço total para segmentar todas as imagens do conjunto em questão. Cada curva do gráfico corresponde a uma das 4 configurações de pós-processamento. A utilização de poucos classificadores dificulta o processo devido às 


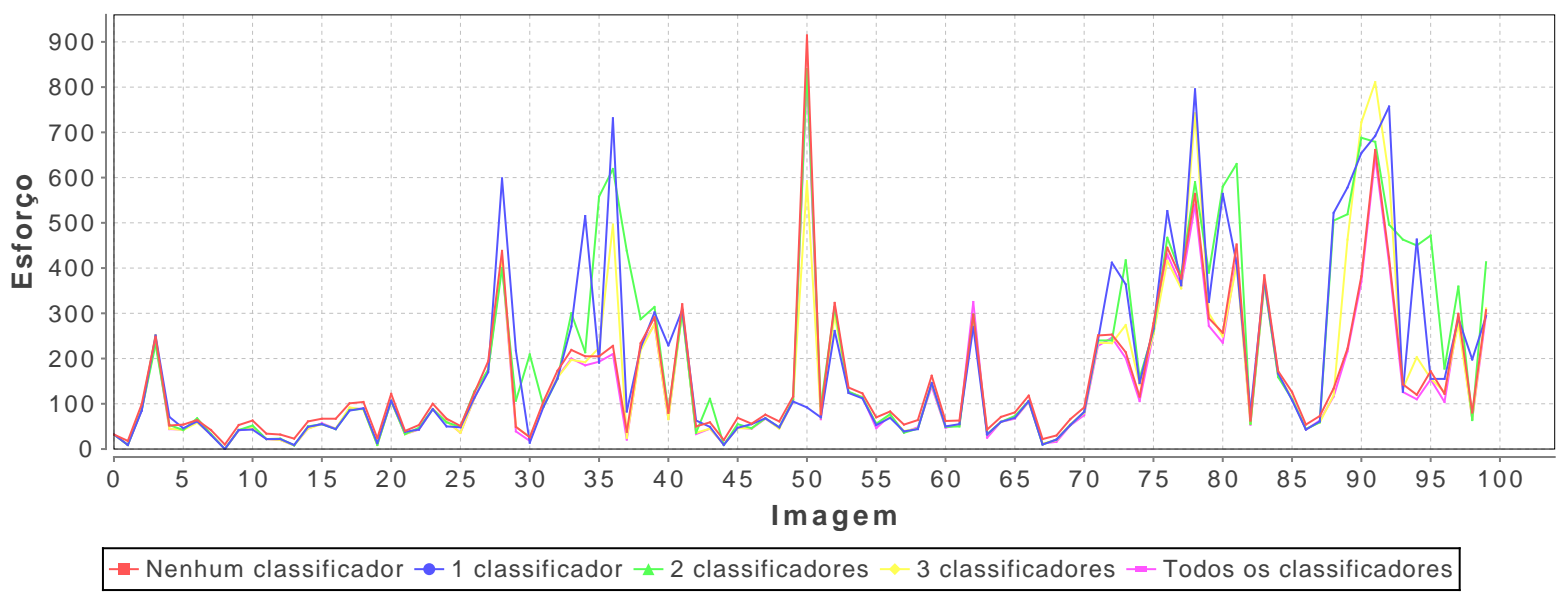

Figura 5.4: Esforço para segmentar o lote "Borboletas" com a heurística de filtragem.

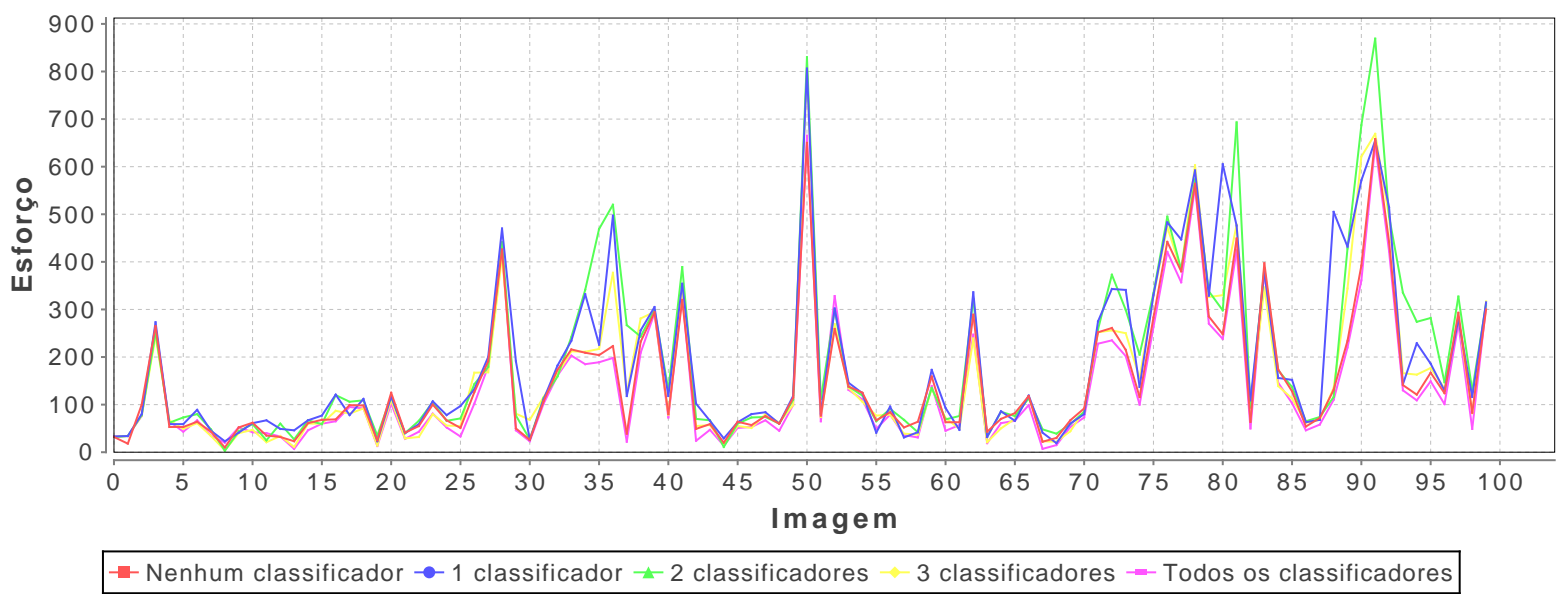

Figura 5.5: Esforço para segmentar o lote "Borboletas" com a heurística de fusão.

diferenças entre as características das imagens. Porém, com 10 a 20 classificadores, o esforço de interação total é levemente reduzido e não há ganho ao aumentar o número de classificadores. Note na Figura 5.7(b) que não há uma vantagem clara para nenhuma das configurações possíveis dos pós-processamentos. Na Tabela 5.2 comparamos o esforço original (sem o uso de classificadores) com o esforço mínimo para cada umas das configurações dos pós-processamentos. 


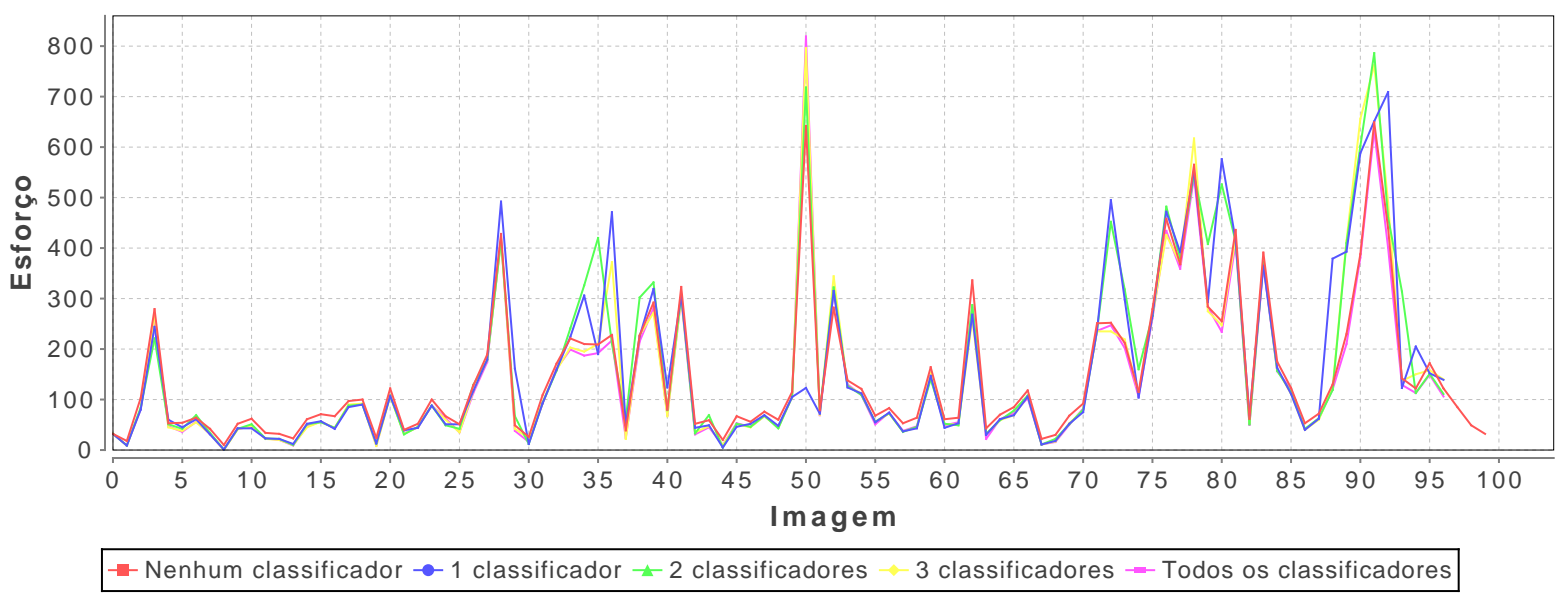

Figura 5.6: Esforço para segmentar o lote "Borboletas" com ambas as heurísticas.

\begin{tabular}{|r|c|c|c|}
\cline { 2 - 4 } \multicolumn{1}{c|}{} & $\begin{array}{c}\text { Esforço original } \\
\text { (sem classificadores })\end{array}$ & Esforço mínimo & $\begin{array}{c}\text { Razão entre esforço } \\
\text { mínimo e esforço original }\end{array}$ \\
\hline Sem as heurísticas & 15276 & $\begin{array}{c}13659 \\
(82 \text { classificadores })\end{array}$ & $89 \%$ \\
\hline Com a heurística de filtragem & 15503 & $\begin{array}{c}13610 \\
(87 \text { classificadores })\end{array}$ & $87 \%$ \\
\hline Com a heurística de fusão & 15200 & $\begin{array}{c}13654 \\
(51 \text { classificadores })\end{array}$ & $89 \%$ \\
\hline Com ambas as heurísticas & 14739 & $\begin{array}{c}13177 \\
\text { classificadores })\end{array}$ & $89 \%$ \\
\hline
\end{tabular}

Tabela 5.2: Redução do esforço de interação para segmentar o lote "Borboletas".

\subsubsection{Fitoplâncton}

Descrição do conjunto: Lote de imagens, cedida por colaborador, com 100 imagens de microscopia com amostras de fitoplâncton. Algumas imagens contém detritos e algumas imagens não apresentam nenhum fitoplâncton. Foram usadas substâncias corantes para realçar os indivíduos (não foi usado o mesmo corante em todas as amostras).

Tarefa de segmentação: Segmentar cada indivíduo de fitoplâncton. Exemplos de imagens desse lote e seus respectivos ground truths são exibidos na Figura 5.8.

Tamanho das imagens: $720 \mathrm{px}$ de largura $\times 480 \mathrm{px}$ de altura.

Créditos das imagens: Prof. Rubens Mendes Lopes (Instituto Oceanográfico - USP).

Na Figura 5.9 exibimos o esforço necessário para segmentar, sem o método proposto, cada imagem do lote "Fitoplâncton" utilizando o critério de inundação uniforme (nível fusão) e os 3 critérios de inundação síncrona (profundidade, área e volume). O esforço 


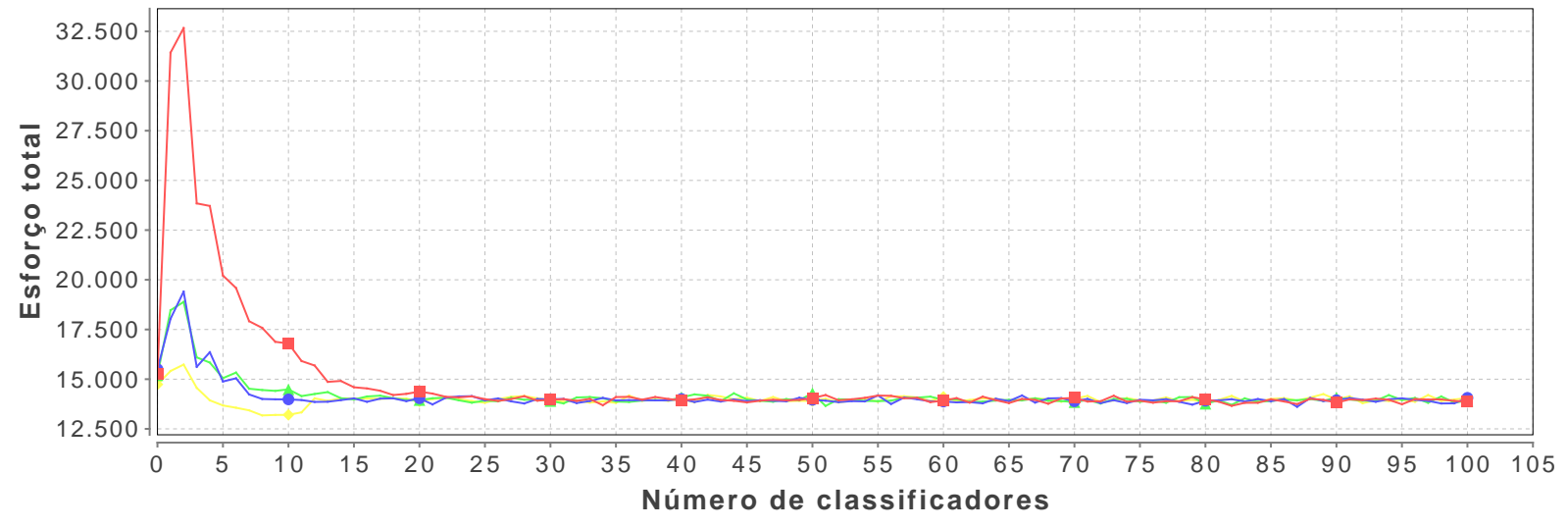

- Sem as heurísticas - - Com a heurística de filtragem - Com a heurística de fusão - Com ambas as heurísticas

(a)

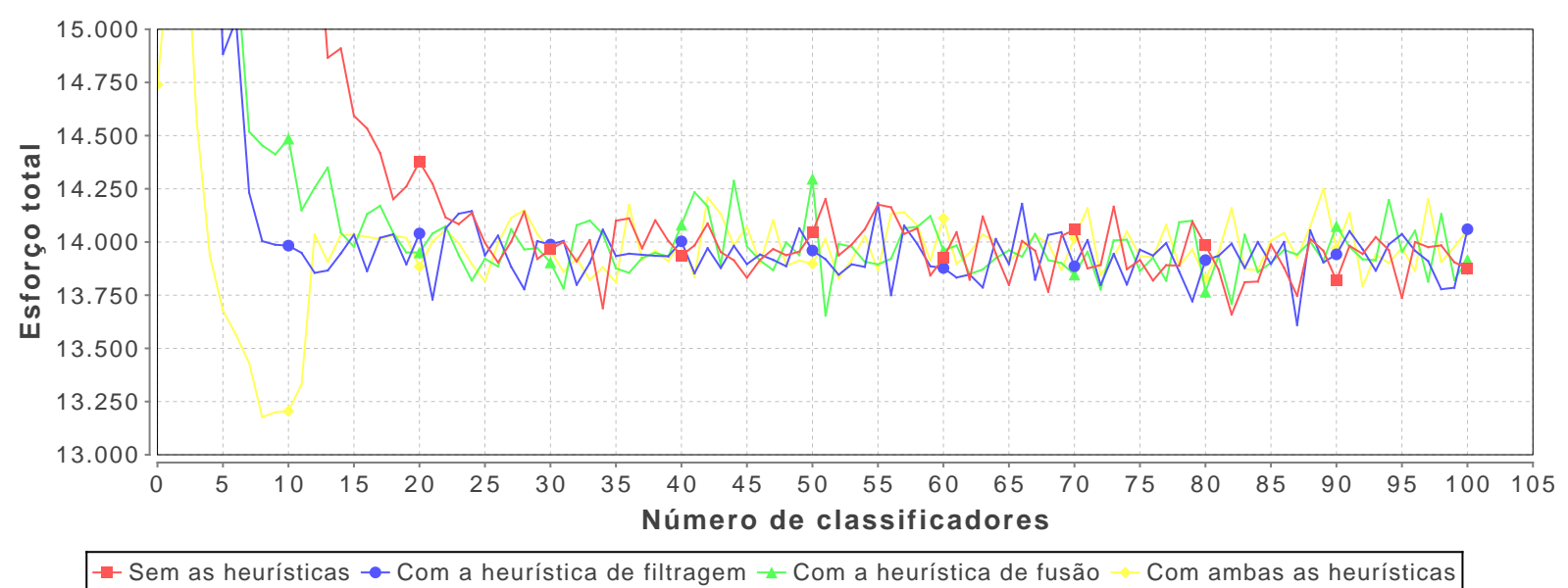

(b) Detalhe da medida de esforço no intervalo de 13000 a 15000

Figura 5.7: Esforço total para segmentar o lote "Borboletas".
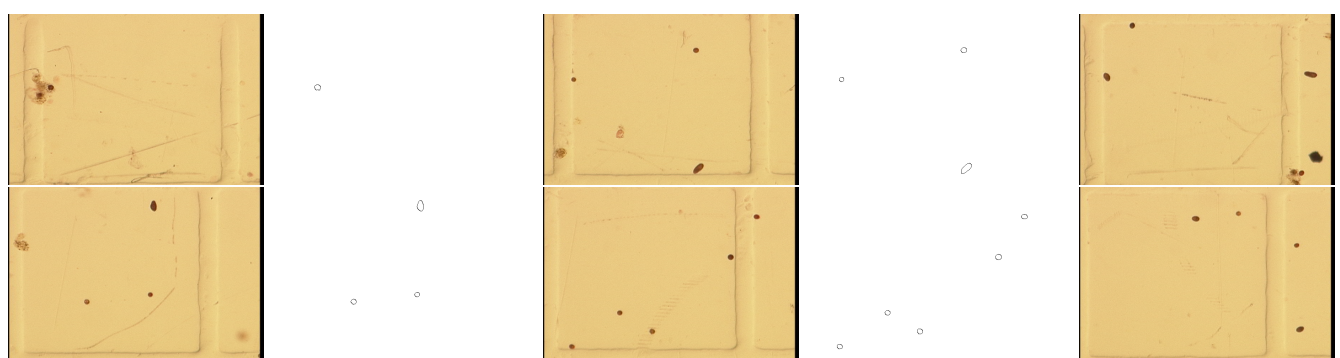

Figura 5.8: Exemplos de imagens e ground truths do lote "Fitoplâncton". 
total para cada um dos critérios é exibido na Tabela 5.3. Como o esforço mínimo para este lote foi obtido usando o critério de profundidade, este será o critério utilizado para os demais experimentos com este lote de imagens.

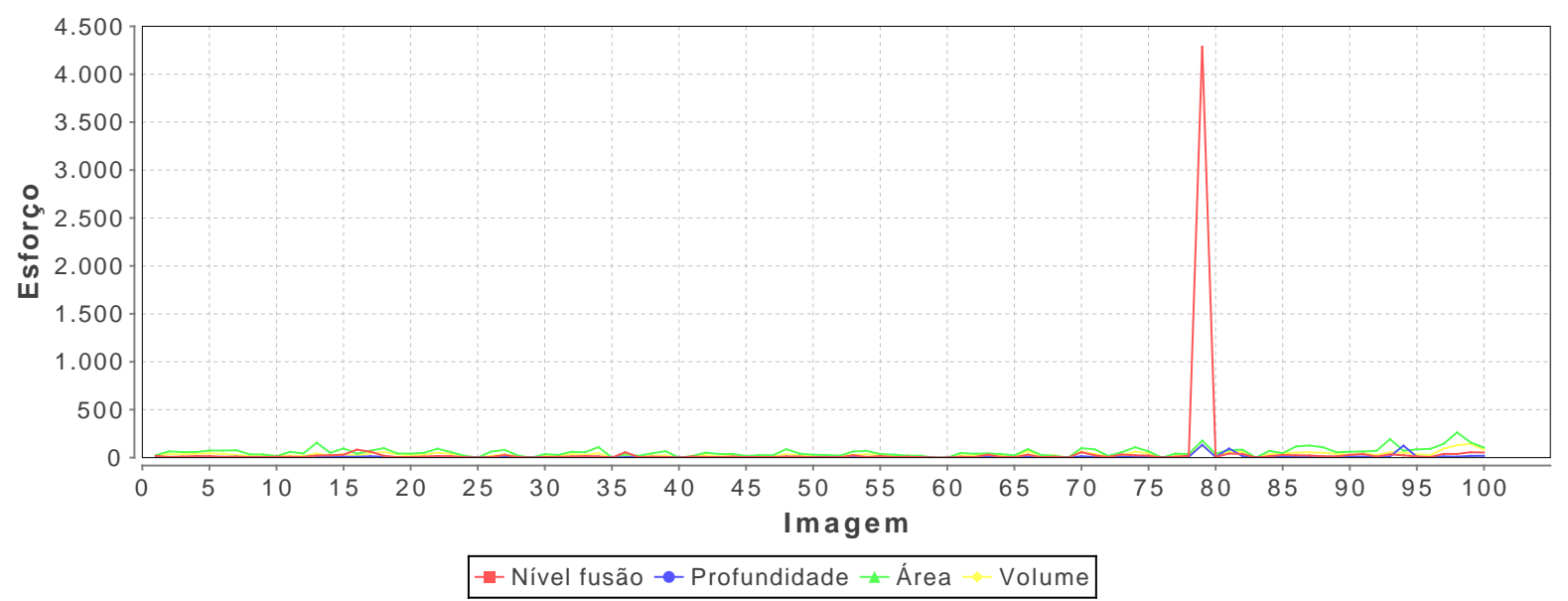

(a)

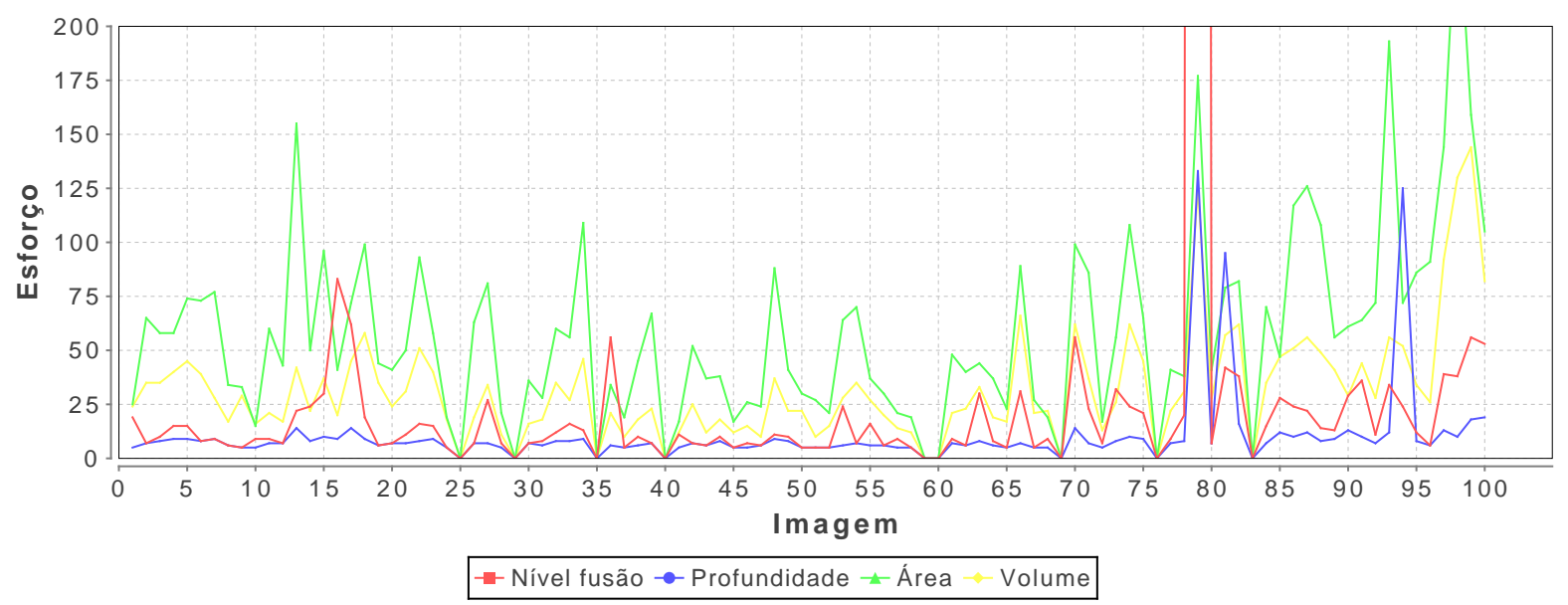

(b) Detalhe da medida de esforço no intervalo de 0 a 200

Figura 5.9: Esforço para segmentar o lote "Fitoplâncton" sem o método proposto.

Nas figuras 5.10 a 5.13 é exibido o esforço para segmentar cada uma das imagens do lote "Fitoplâncton", com as 4 configurações de pós-processamento. Note que, para algumas imagens, o uso de 1 ou 2 classificadores pode dificultar a tarefa. Nesses casos, os classificadores utilizados não são adequados para segmentar as imagens em questão. Observe os picos relativos às imagens de número 79, 81 e 94. Tais imagens não são facilmente segmentadas pela hierarquia de inundação síncrona com o critério selecionado (profundidade), conforme pode ser observado na Figura 5.9. 


\begin{tabular}{|r|c|}
\cline { 2 - 2 } \multicolumn{1}{c|}{} & Esforço total \\
\hline Nível fusão & 5871 \\
\hline Profundidade & 1048 \\
\hline Área & 5761 \\
\hline Volume & 3181 \\
\hline
\end{tabular}

Tabela 5.3: Esforço total para segmentar o lote "Fitoplâncton" sem o método proposto.

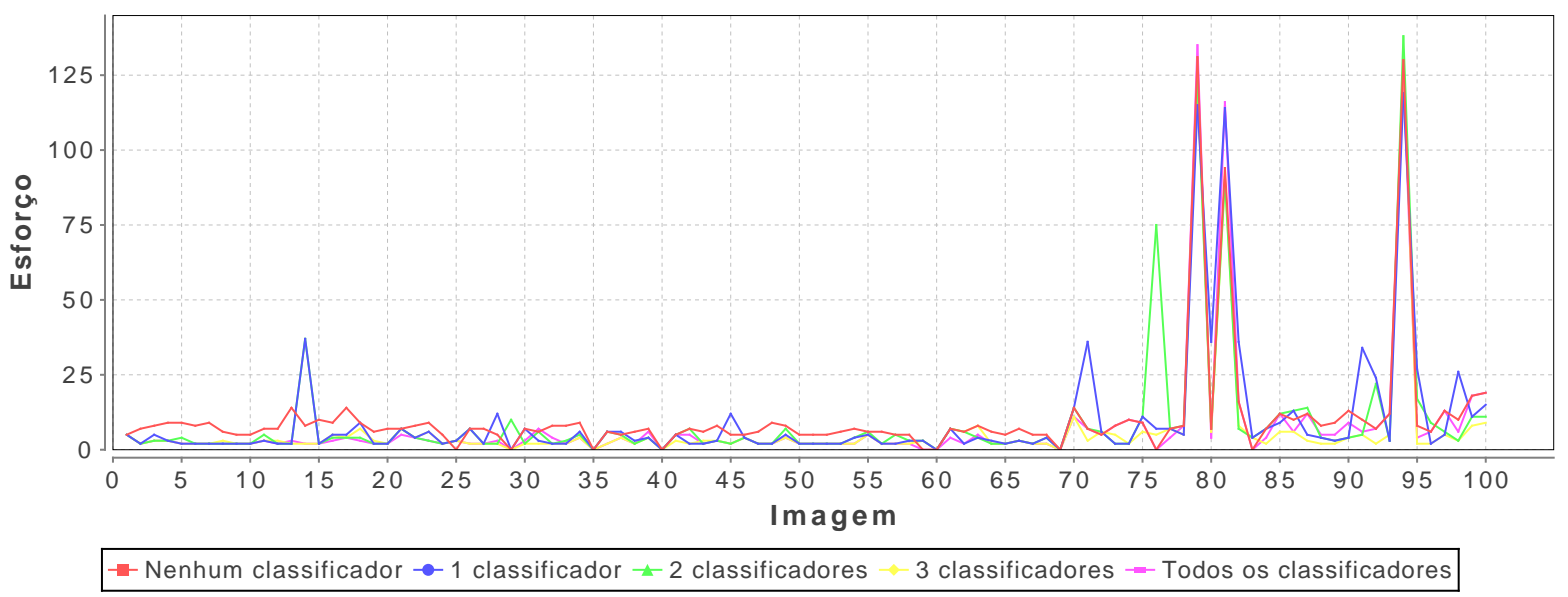

Figura 5.10: Esforço para segmentar o lote "Fitoplâncton" sem as heurísticas.

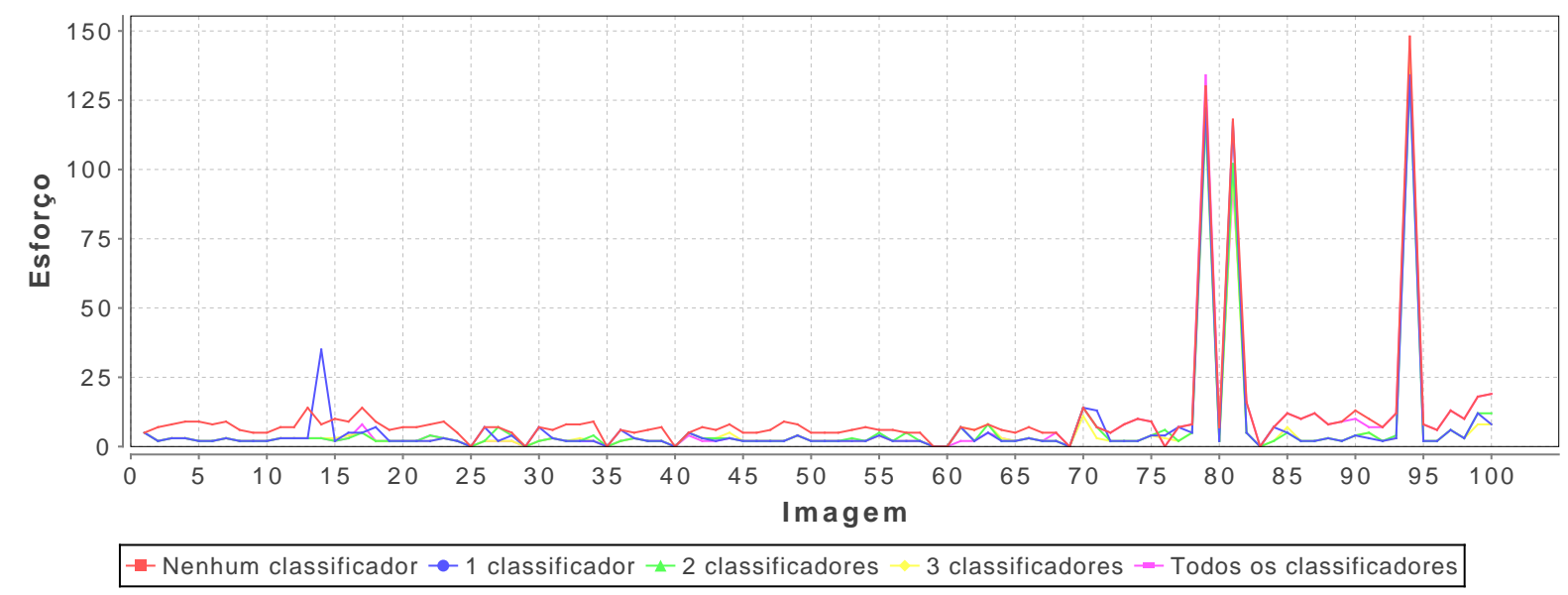

Figura 5.11: Esforço para segmentar o lote "Fitoplâncton" com a heurística de filtragem.

Na Figura 5.14 é exibido o esforço total para segmentar todas as imagens do lote "Fitoplâncton". O esforço total é dado pela soma dos esforços de interação para segmentar cada imagem do lote. Para este conjunto, o uso de classificadores reduz o esforço total, 


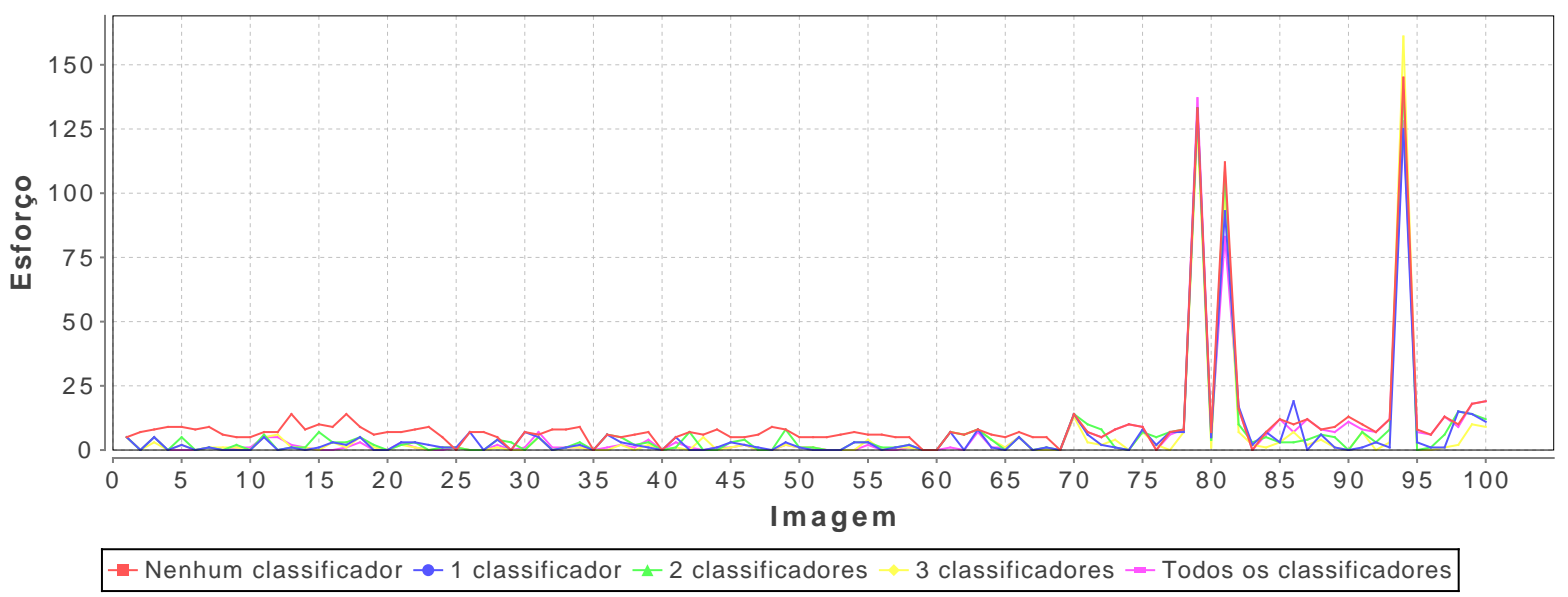

Figura 5.12: Esforço para segmentar o lote "Fitoplâncton" com a heurística de fusão.

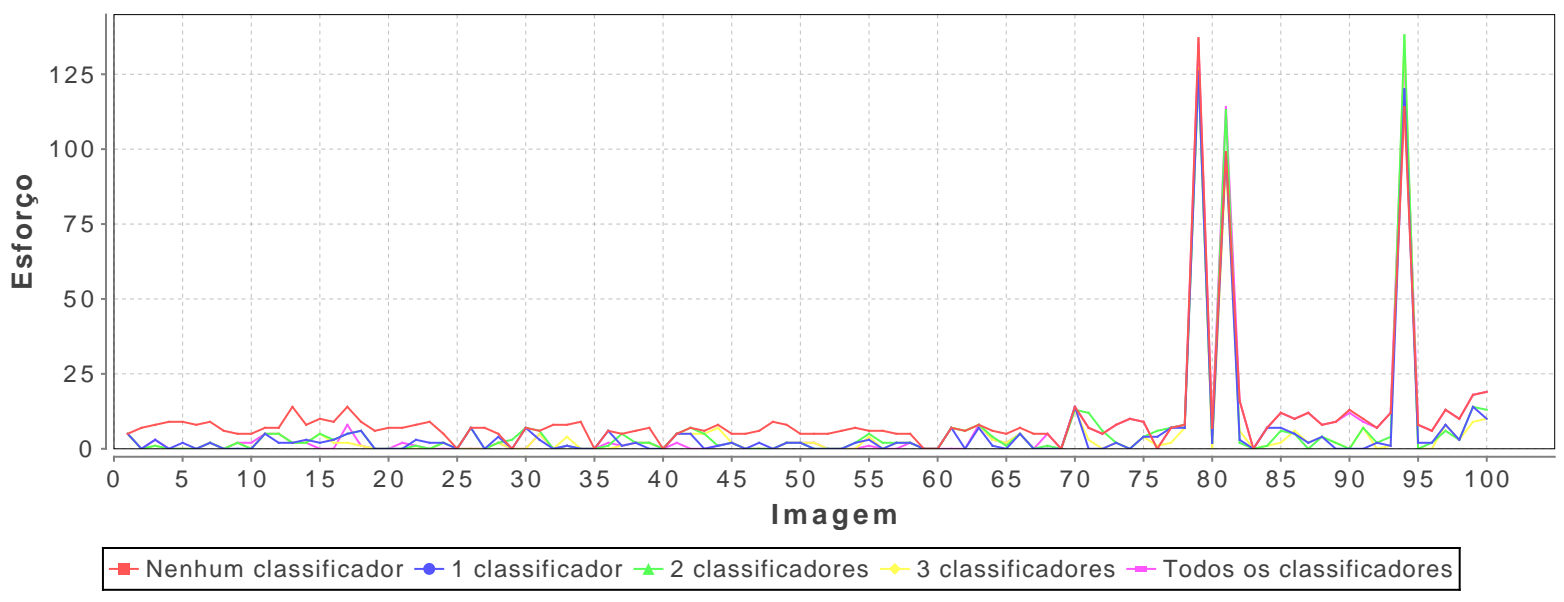

Figura 5.13: Esforço para segmentar o lote "Fitoplâncton" com ambas as heurísticas.

independentemente do número de classificadores utilizados. Quando utilizamos poucos classificadores, de 0 a 10 classificadores, maior é a redução do esforço total de interação conforme aumentamos o número de classificadores. Porém, quando aumentamos um pouco mais o número de classificadores, de 10 a 50 classificadores, o esforço total não é reduzido tanto. Aumentando bastante o número de classificadores, acima de 50 classificadores, o esforço de interação fica estável, ou seja, não há ganho ao se utilizar um grande número de classificadores. Em relação aos pós-processamentos, ao utilizarmos a heurística de fusão temos uma maior redução no esforço de interação em relação a não usar tal heurística. $O$ uso da heurística de filtragem não tem efeito significativo. Na Tabela 5.4 comparamos o esforço original (sem o uso de classificadores) com o esforço mínimo para cada umas das configurações dos pós-processamentos. 


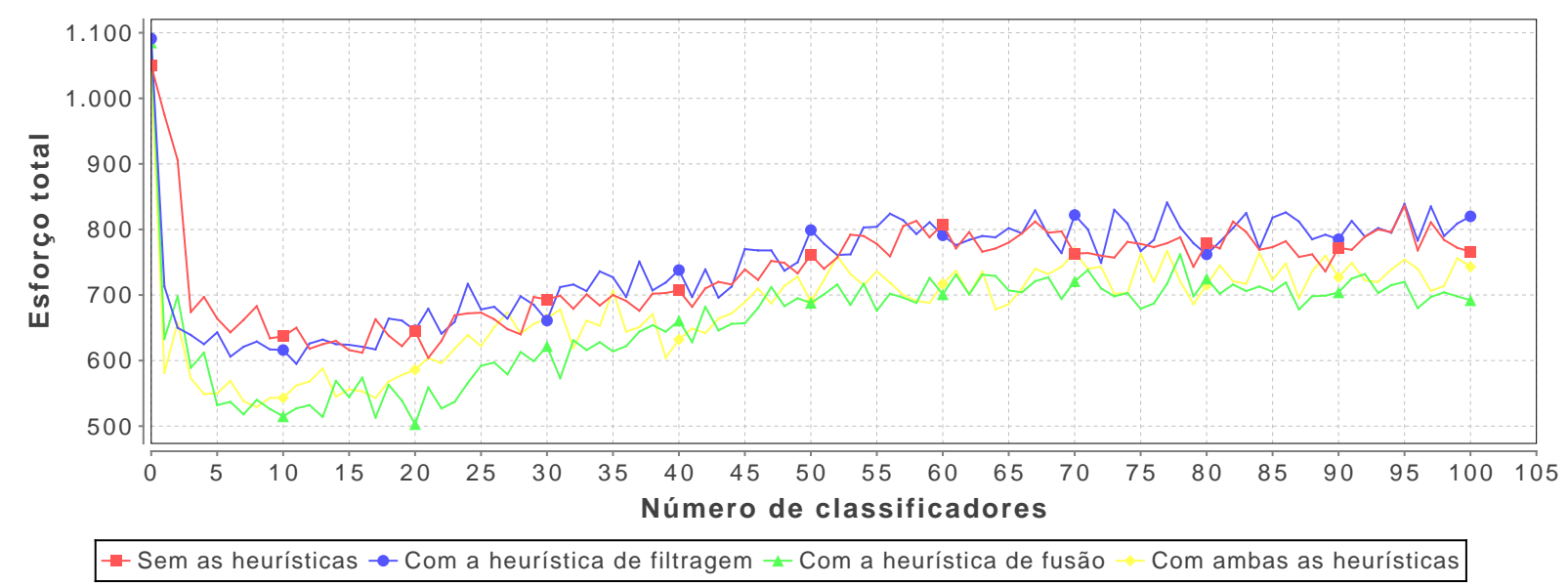

Figura 5.14: Esforço total para segmentar o lote "Fitoplâncton".

\begin{tabular}{|c|c|c|c|}
\hline & $\begin{array}{c}\text { Esforço original } \\
\text { (sem classificadores) }\end{array}$ & Esforço mínimo & $\begin{array}{c}\text { Razão entre esforço } \\
\text { mínimo e esforço original }\end{array}$ \\
\hline Sem as heurísticas & 1050 & $\begin{array}{c}604 \\
(21 \text { classificadores })\end{array}$ & $57 \%$ \\
\hline Com a heurística de filtragem & 1091 & $\begin{array}{c}595 \\
(11 \text { classificadores })\end{array}$ & $54 \%$ \\
\hline Com a heurística de fusão & 1085 & $\begin{array}{c}503 \\
(20 \text { classificadores })\end{array}$ & $46 \%$ \\
\hline Com ambas as heurísticas & 1045 & $\begin{array}{c}529 \\
(8 \text { classificadores })\end{array}$ & $50 \%$ \\
\hline
\end{tabular}

Tabela 5.4: Redução do esforço de interação para segmentar o lote "Fitoplâncton".

\subsubsection{Pedras}

Descrição do conjunto: Sequência de 461 frames de um vídeo gerado especificamente para os experimentos.

Tarefa de segmentação: Segmentar cada pedra. Exemplos de imagens dessa sequência e seus respectivos ground truths são exibidos na Figura 5.15.

Tamanho das imagens: 568px de largura $\times 320 \mathrm{px}$ de altura.

Na Figura 5.16 exibimos o esforço necessário para segmentar, sem o método proposto, cada imagem da sequência "Pedras" utilizando o critério de inundação uniforme (nível fusão) e os 3 critérios de inundação síncrona (profundidade, área e volume). O esforço total para cada um dos critérios é exibido na Tabela 5.5. Como o esforço mínimo para esta sequência foi obtido usando o critério de volume, este será o critério utilizado para os demais experimentos com esta sequência de imagens. 


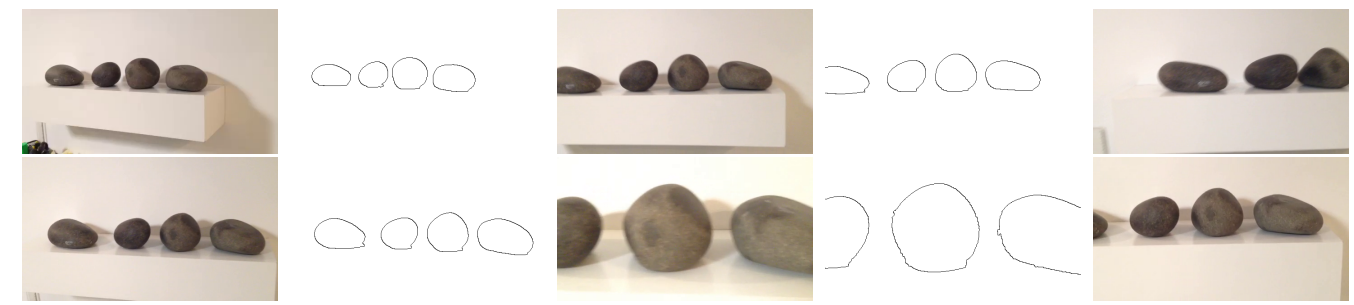

Figura 5.15: Exemplos de imagens e ground truths da sequência "Pedras".

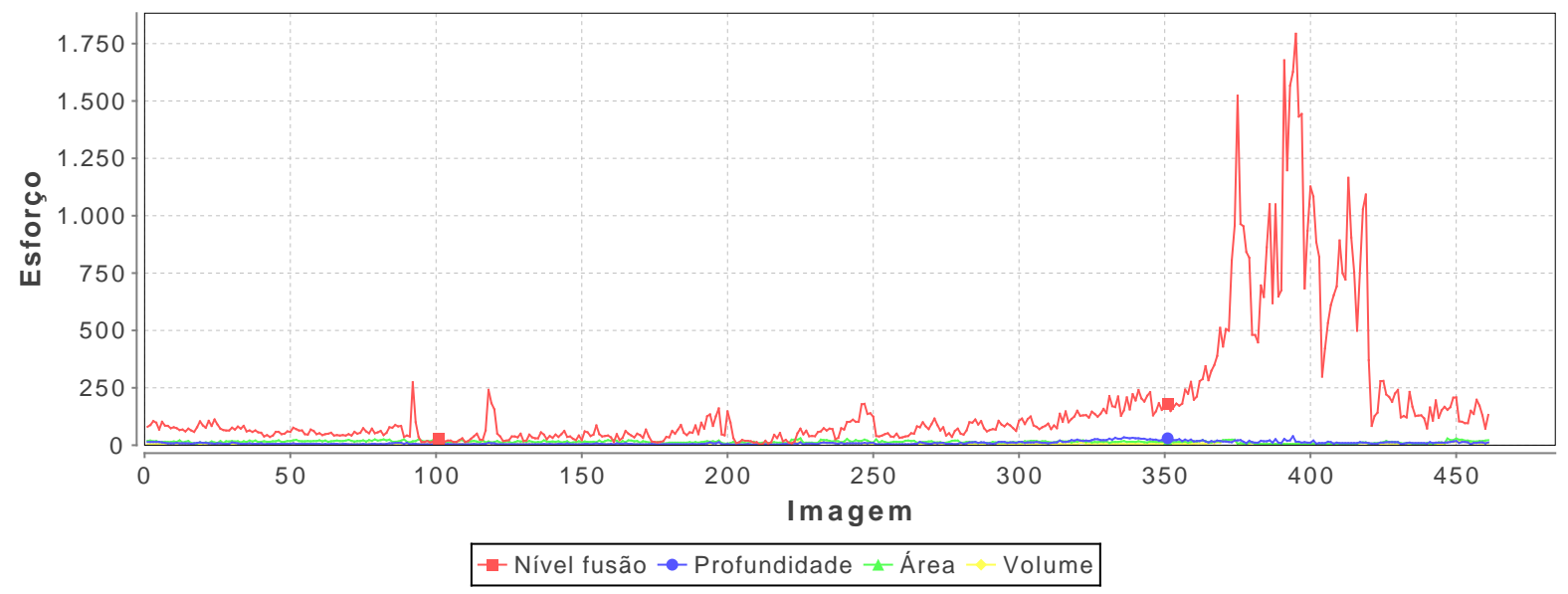

(a)

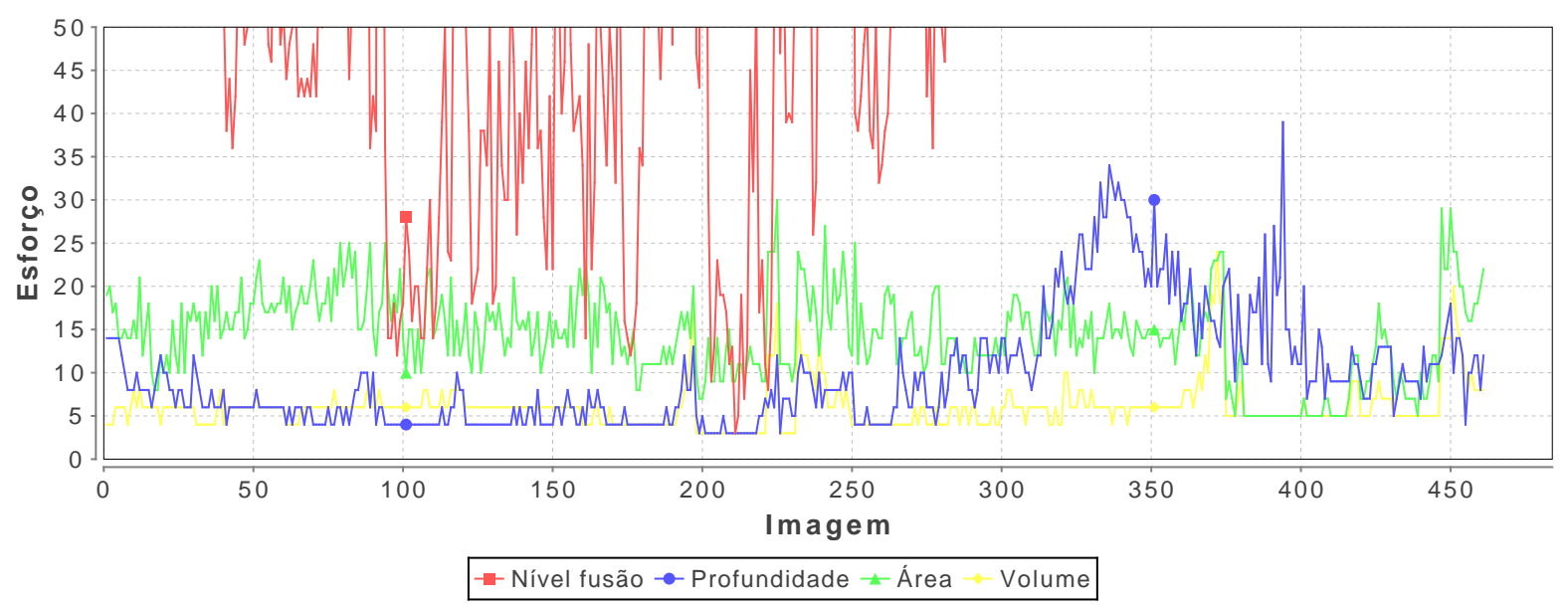

(b) Detalhe da medida de esforço no intervalo de 0 a 50

Figura 5.16: Esforço para segmentar a sequência "Pedras" sem o método proposto.

Nas figuras 5.17 a 5.20 é exibido o esforço para segmentar cada uma das imagens da sequência "Pedras", com as 4 configurações de pós-processamento. Note que, em geral, o 


\begin{tabular}{|r|c|}
\cline { 2 - 2 } \multicolumn{1}{c|}{} & Esforço total \\
\hline Nível fusão & 80188 \\
\hline Profundidade & 4474 \\
\hline Área & 6613 \\
\hline Volume & 2797 \\
\hline
\end{tabular}

Tabela 5.5: Esforço total para segmentar a sequência "Pedras" sem o método proposto.

uso de classificadores facilitou a segmentação de todas as imagens.

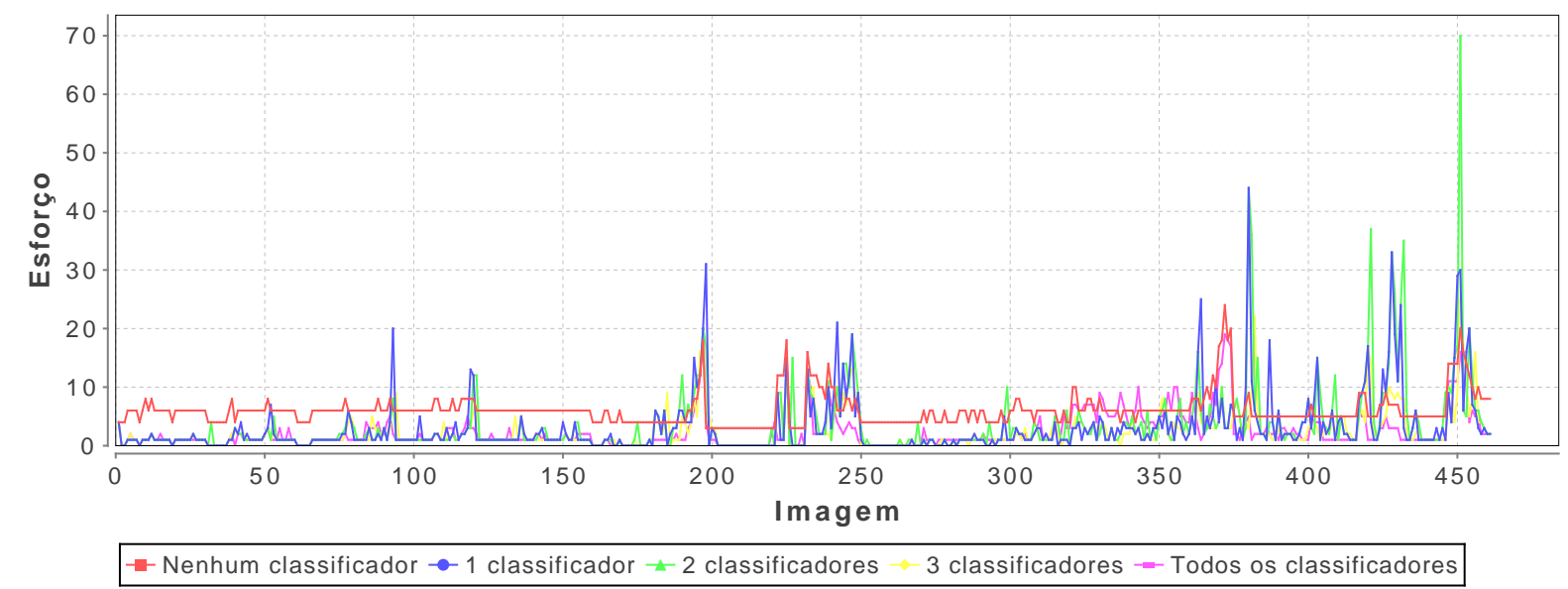

Figura 5.17: Esforço para segmentar a sequência "Pedras" sem as heurísticas.

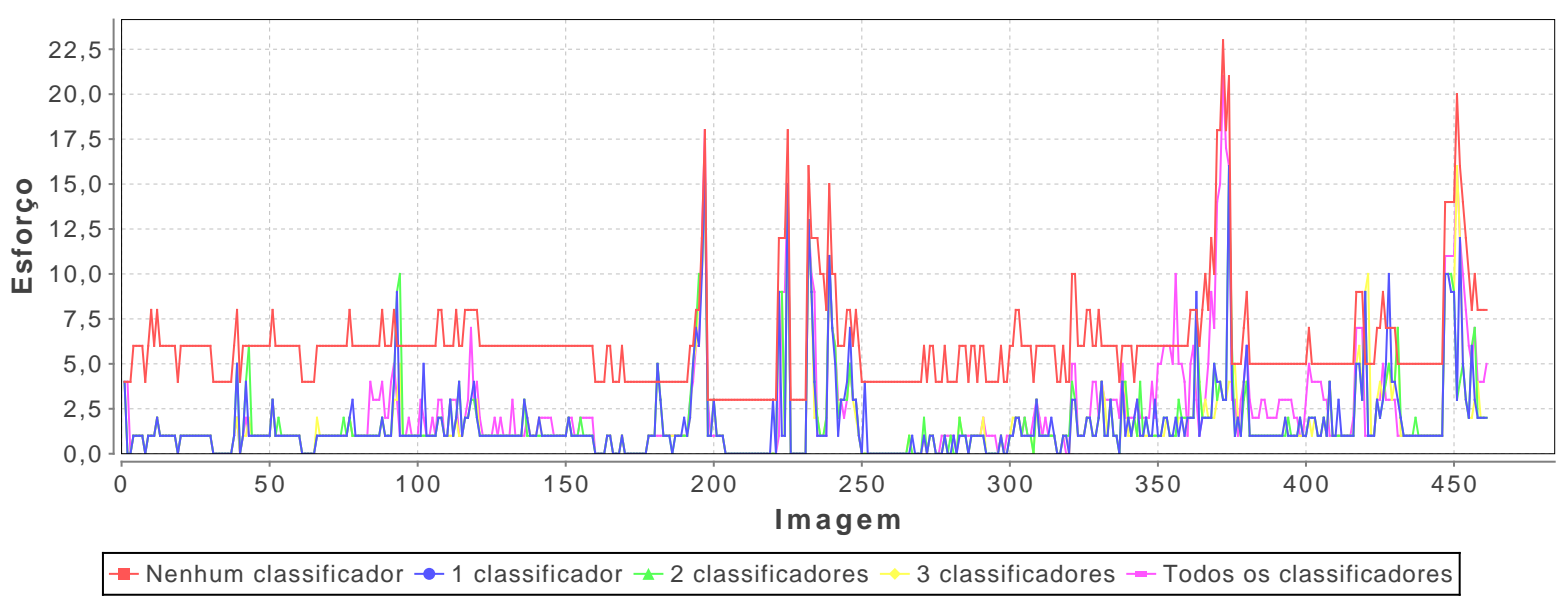

Figura 5.18: Esforço para segmentar a sequência "Pedras" com a heurística de filtragem.

Na Figura 5.21 é exibido o esforço total para segmentar todas as imagens da sequência "Pedras". O esforço total é dado pela soma dos esforços de interação para segmentar 


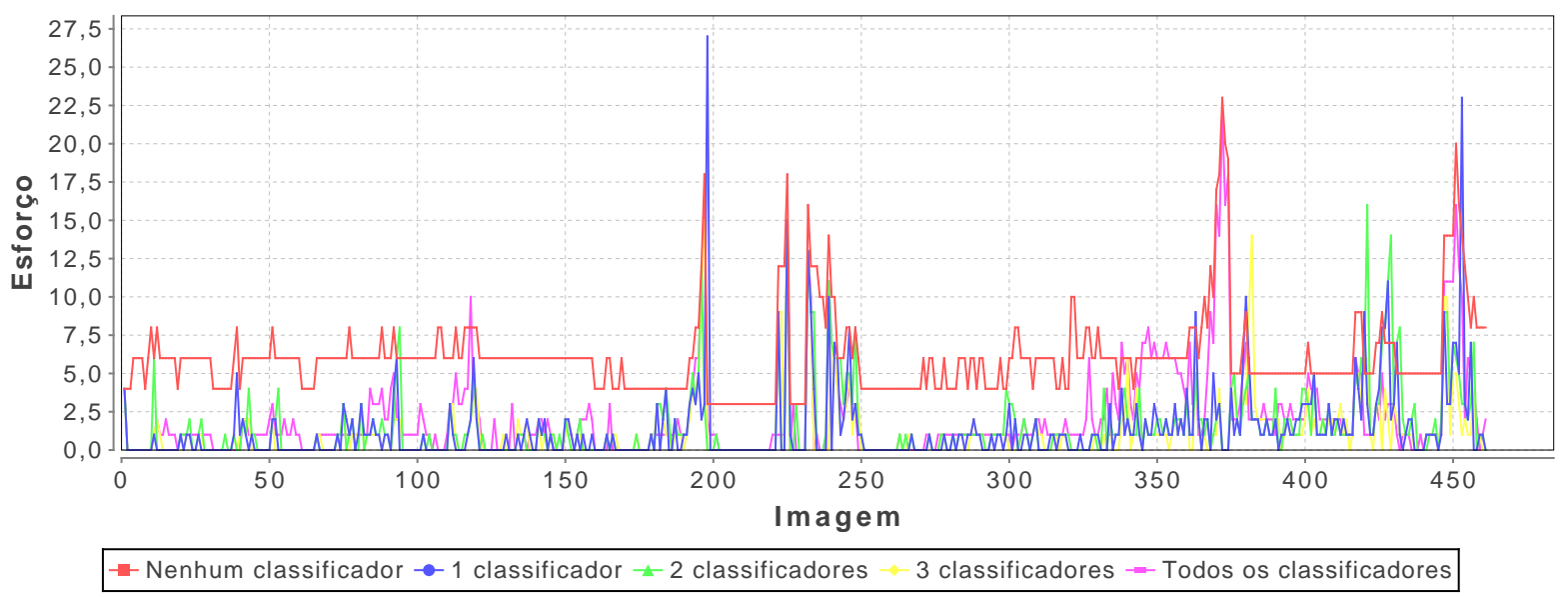

Figura 5.19: Esforço para segmentar a sequência "Pedras" com a heurística de fusão.

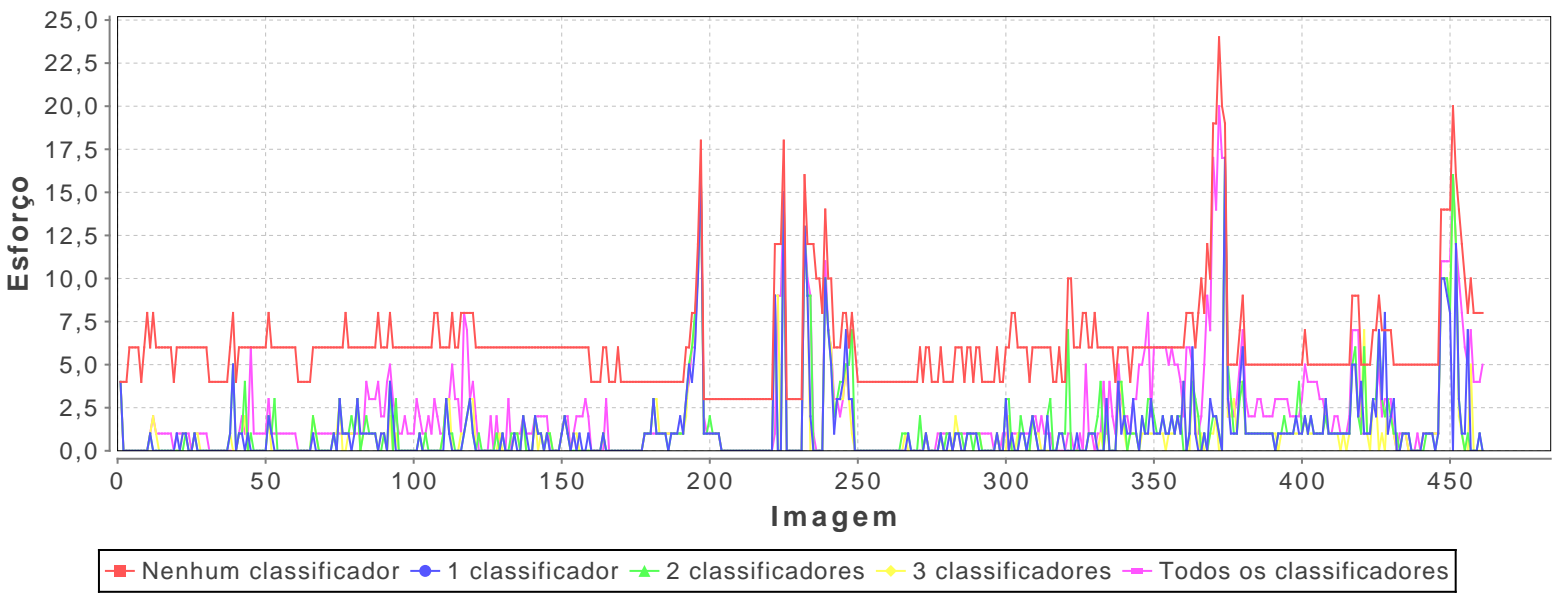

Figura 5.20: Esforço para segmentar a sequência "Pedras" com ambas as heurísticas.

cada imagem do lote. Para este conjunto, o uso de classificadores reduz o esforço total, independentemente do número de classificadores utilizados. Para um número pequeno de classificadores utilizados, de 0 a 10 classificadores, maior é a redução do esforço total de interação conforme aumentamos o número de classificadores. Porém, ao aumentar o número de classificadores utilizados, acima de 10 classificadores, o esforço total não é reduzido tanto. Podemos atribuir esse comportamento à coerência temporal existente entre os frames consecutivos da sequência. Se utilizamos um grande número de classificadores, estamos utilizando frames muito diferentes do atual, o que faz a redução do esforço não ser tão grande quanto a redução obtida quando usamos um pequeno número de classificadores, próximos ao frame atual e, portanto, mais semelhantes com este e mais adequados para serem utilizados. Os pós-processamentos reduzem o esforço em relação a não utilizá-los. 
A maior redução é obtida ao utilizarmos somente a heurística de fusão de regiões adjacentes que não têm arestas inativas nas bordas entre elas. Na Tabela 5.6 comparamos o esforço original (sem o uso de classificadores) com o esforço mínimo para cada umas das configurações dos pós-processamentos.

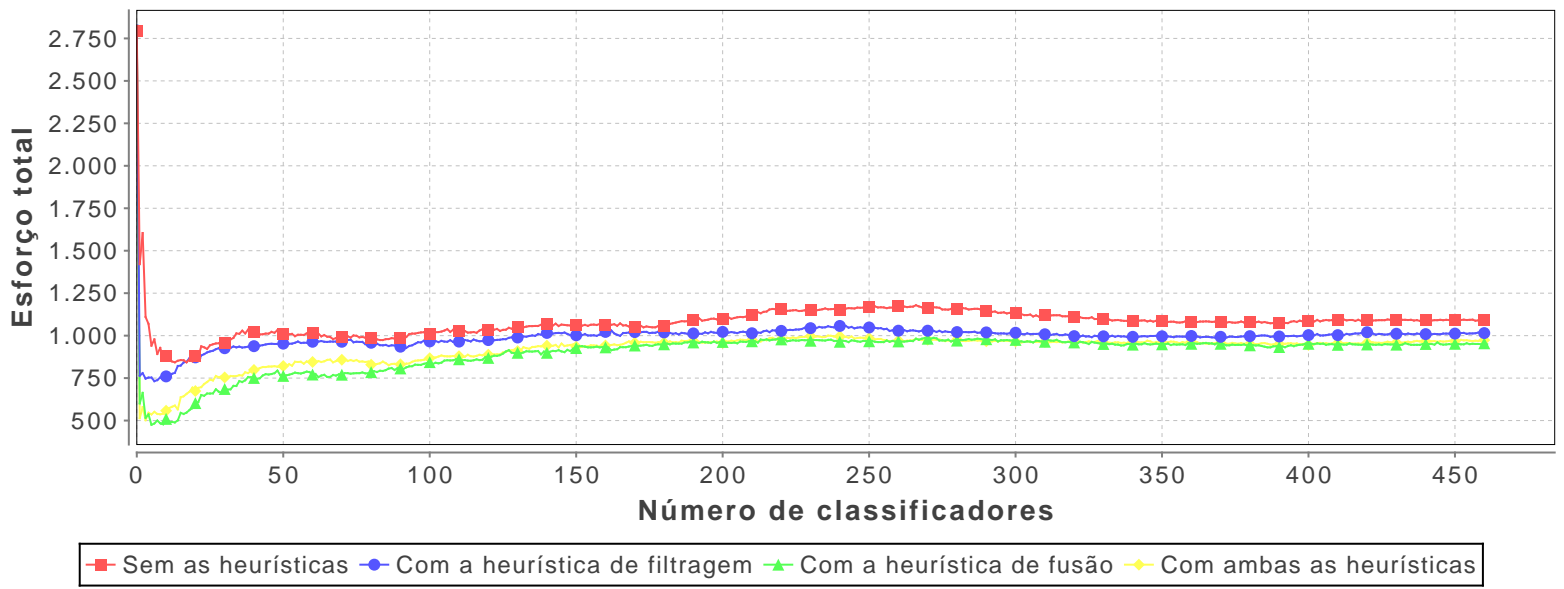

Figura 5.21: Esforço total para segmentar a sequência "Pedras".

\begin{tabular}{|c|c|c|c|}
\hline & $\begin{array}{c}\text { Esforço original } \\
\text { (sem classificadores) }\end{array}$ & Esforço mínimo & $\begin{array}{c}\text { Razão entre esforço } \\
\text { mínimo e esforço original }\end{array}$ \\
\hline Sem as heurísticas & 2795 & $\begin{array}{c}843 \\
(13 \text { classificadores })\end{array}$ & $30 \%$ \\
\hline Com a heurística de filtragem & 2797 & $\begin{array}{c}732 \\
\text { (6 classificadores) }\end{array}$ & $26 \%$ \\
\hline Com a heurística de fusão & 2795 & $\begin{array}{c}475 \\
\text { (5 classificadores })\end{array}$ & $16 \%$ \\
\hline Com ambas as heurísticas & 2799 & $\begin{array}{c}502 \\
\text { (3 classificadores) }\end{array}$ & $17 \%$ \\
\hline
\end{tabular}

Tabela 5.6: Redução do esforço de interação para segmentar a sequência "Pedras".

\subsubsection{CT}

Descrição do conjunto: Sequências de cortes de exames de tomografia computadorizada, cedida por colaborador. As primeiras 21 imagens formam uma sequência e as 19 restantes uma outra sequência.

Tarefa de segmentação: Segmentar os tecidos ósseos (não incluir cavidades). Exemplos de imagens dessa sequência e seus respectivos ground truths são exibidos na Figura 5.22. 
Tamanho das imagens: $512 \mathrm{px}$ de largura $\times 512 \mathrm{px}$ de altura.

Créditos das imagens: Prof. Jayaram K. Udupa (MIPG - UPENN).
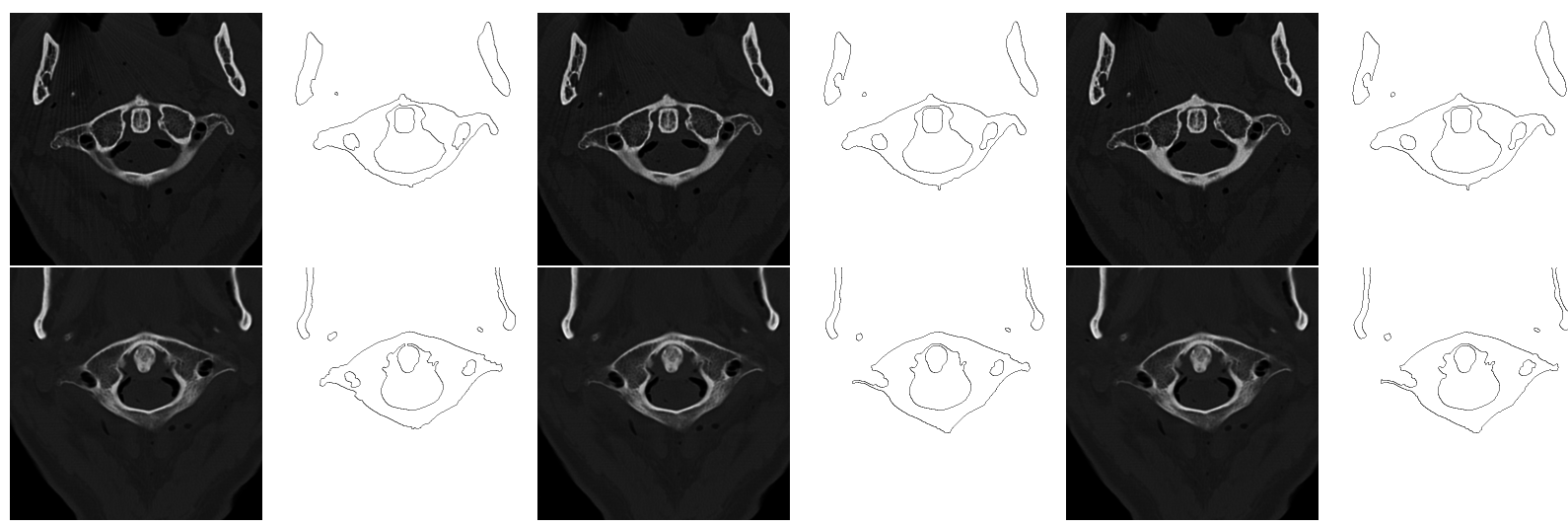

Figura 5.22: Exemplos de imagens e ground truths da sequência "CT".

Na Figura 5.23 exibimos o esforço necessário para segmentar, sem o método proposto, cada imagem da sequência "CT" utilizando o critério de inundação uniforme (nível fusão), os 3 critérios de inundação síncrona (profundidade, área e volume) e a hierarquia de valor médio (Apêndice B). O esforço total para cada um dos critérios é exibido na Tabela 5.7. Como o esforço mínimo para esta sequência foi obtido usando o critério de área, este será o critério utilizado para os demais experimentos com esta sequência de imagens.

\begin{tabular}{|r|c|}
\cline { 2 - 2 } \multicolumn{1}{c|}{} & Esforço total \\
\hline Nível fusão & 213182 \\
\hline Profundidade & 63805 \\
\hline Área & 11117 \\
\hline Volume & 11133 \\
\hline Valor médio & 49491 \\
\hline
\end{tabular}

Tabela 5.7: Esforço total para segmentar a sequência "CT" sem o método proposto.

Nas figuras 5.24 a 5.27 é exibido o esforço para segmentar cada uma das imagens da sequência "CT", com as 4 configurações de pós-processamento. Note que o uso de poucos classificadores pode dificultar a segmentação das imagens.

Na Figura 5.28 é exibido o esforço total para segmentar todas as imagens da sequência "CT". O esforço total é dado pela soma dos esforços de interação para segmentar cada imagem do lote. A utilização de poucos classificadores dificulta o processo devido às diferenças entre as características das imagens. Porém, com 10 a 20 classificadores, o esforço de interação total é levemente reduzido e não há ganho ao aumentar o número de classificadores. A maior redução de esforço é obtida ao não utilizarmos nenhum pós-processamento. 


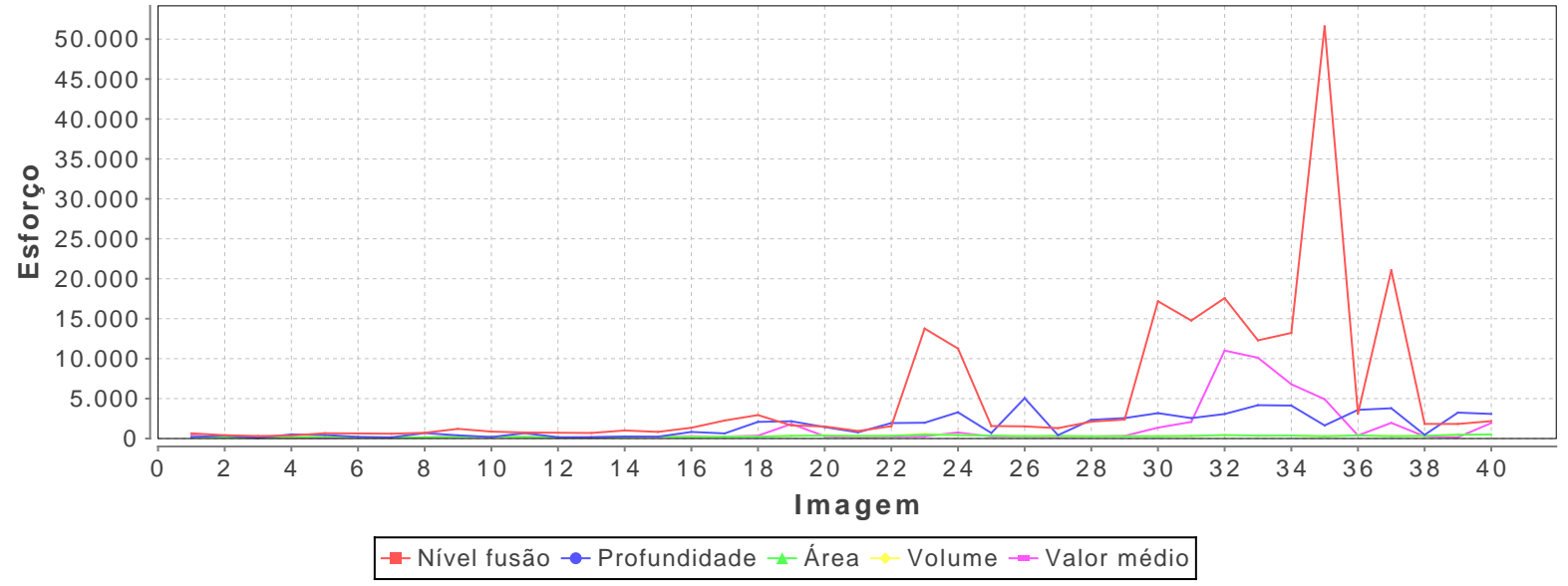

(a)

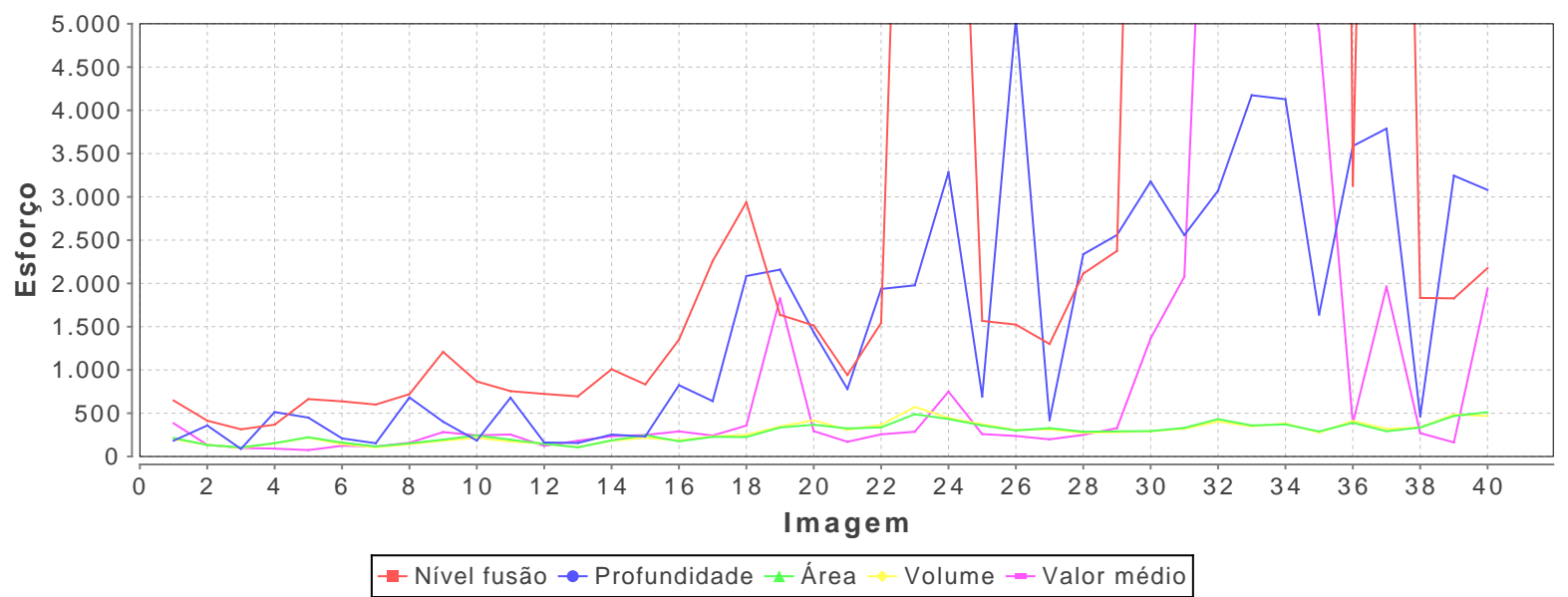

(b) Detalhe da medida de esforço no intervalo de 0 a 5000

Figura 5.23: Esforço para segmentar a sequência "CT" sem o método proposto.

Na Tabela 5.8 comparamos o esforço original (sem o uso de classificadores) com o esforço mínimo para cada umas das configurações dos pós-processamentos.

\subsection{Discussão sobre o resultado dos experimentos}

Na Tabela 5.9 exibimos um breve resumo comparando os resultados obtidos com cada um dos conjuntos testados na seção anterior.

Apesar do método proposto não considerar nenhuma particularidade do domínio de 


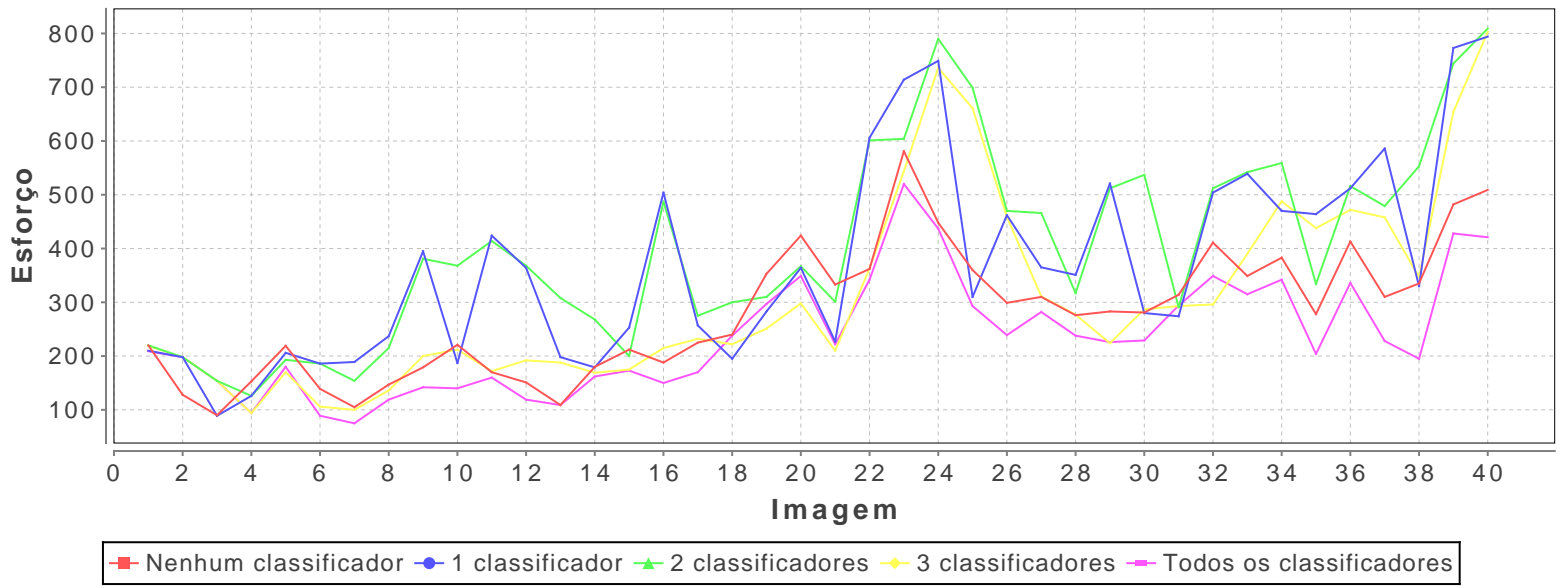

Figura 5.24: Esforço para segmentar a sequência "CT" sem as heurísticas.

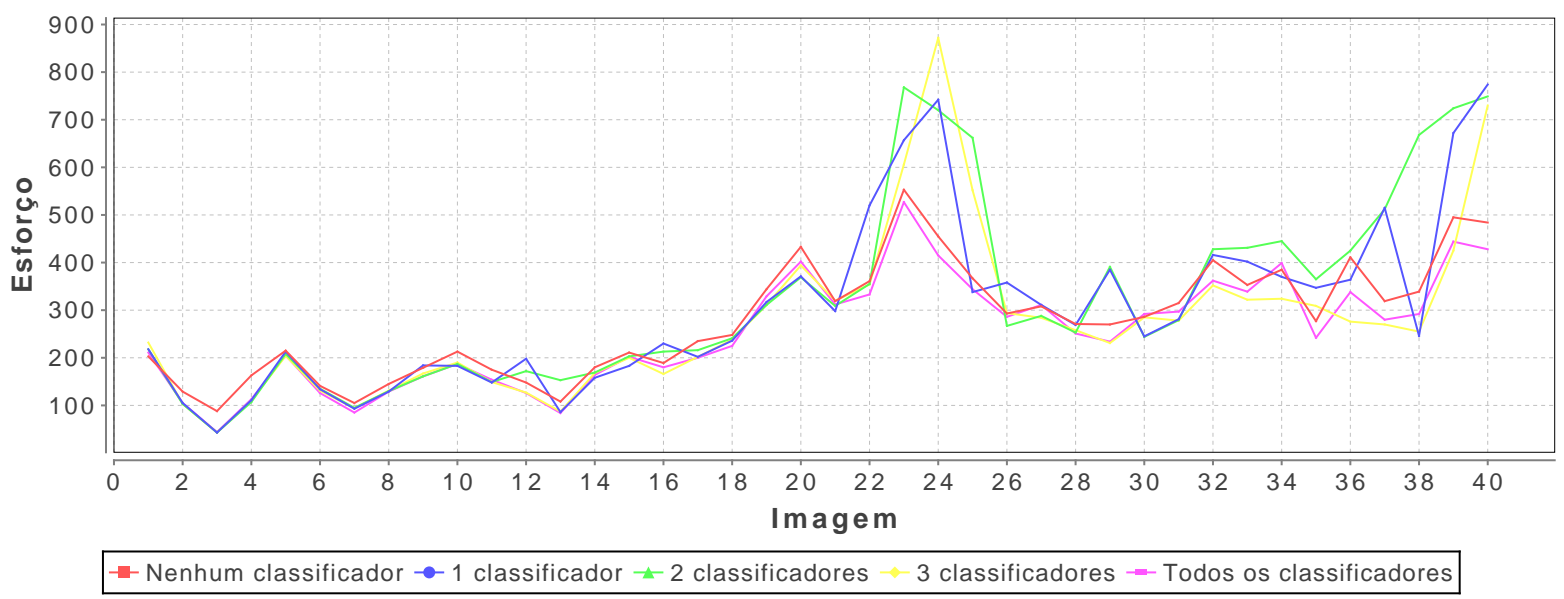

Figura 5.25: Esforço para segmentar a sequência "CT" com a heurística de filtragem.

\begin{tabular}{|r|c|c|c|}
\cline { 2 - 4 } \multicolumn{1}{c|}{} & $\begin{array}{c}\text { Esforço original } \\
\text { (sem classificadores })\end{array}$ & Esforço mínimo & $\begin{array}{c}\text { Razão entre esforço } \\
\text { mínimo e esforço original }\end{array}$ \\
\hline Sem as heurísticas & 11170 & $\begin{array}{c}9030 \\
(21 \text { classificadores })\end{array}$ & $80 \%$ \\
\hline Com a heurística de filtragem & 11118 & $\begin{array}{c}9823 \\
(8 \text { classificadores })\end{array}$ & $88 \%$ \\
\hline Com a heurística de fusão & 11129 & $\begin{array}{c}10590 \\
(9 \text { classificadores })\end{array}$ & $95 \%$ \\
\hline $\begin{array}{c}10404 \\
(7 \text { classificadores })\end{array}$ & $93 \%$ \\
\hline
\end{tabular}

Tabela 5.8: Redução do esforço de interação para segmentar a sequência "CT". 


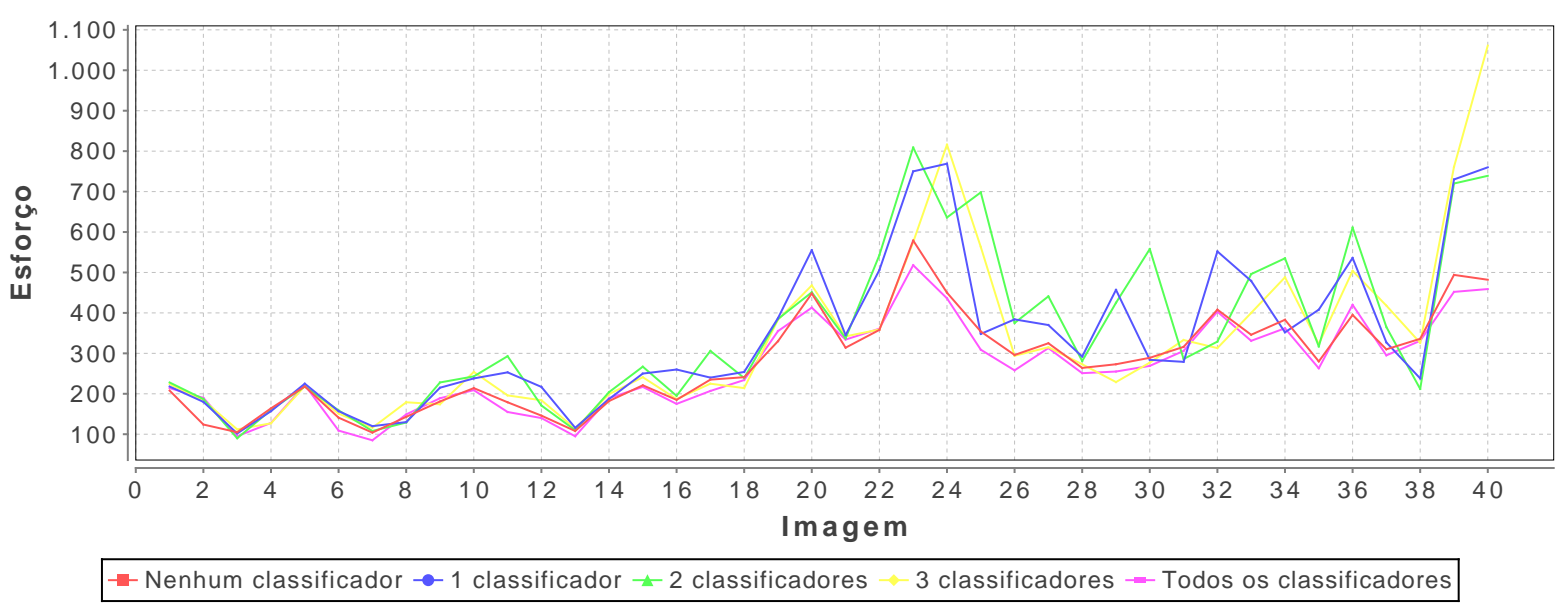

Figura 5.26: Esforço para segmentar a sequência "CT" com a heurística de fusão.

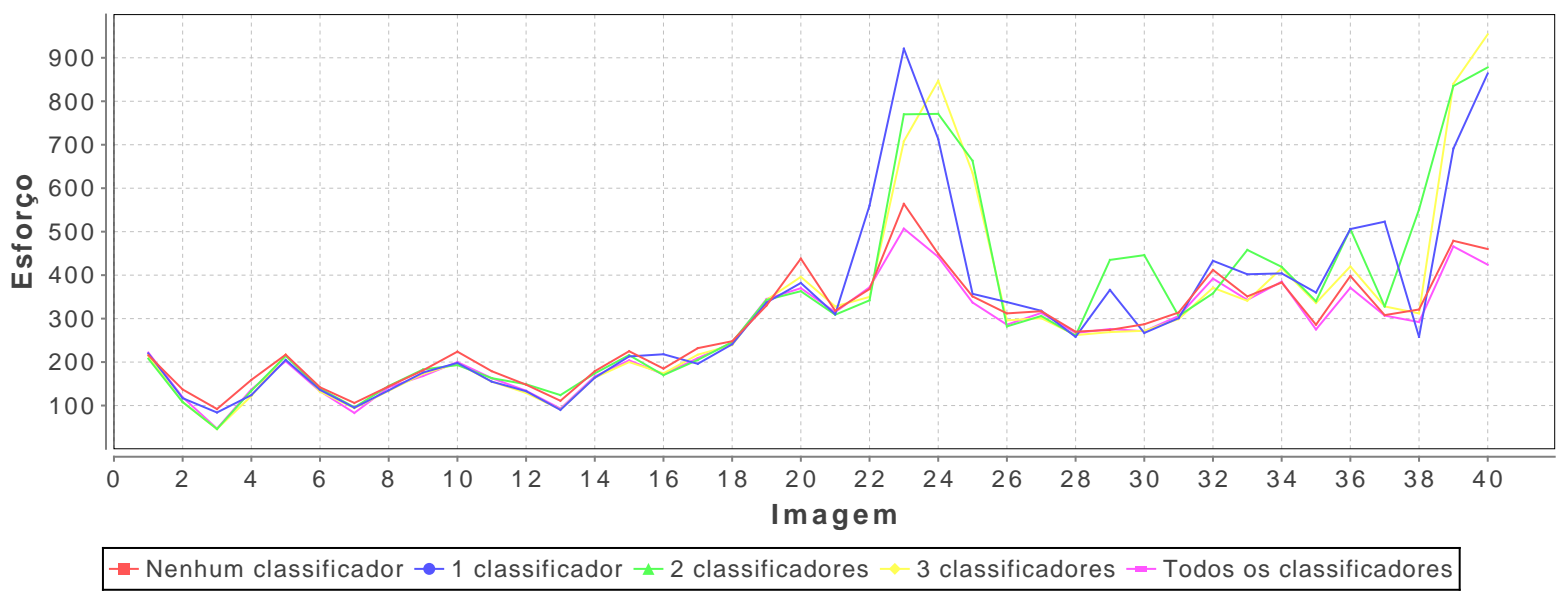

Figura 5.27: Esforço para segmentar a sequência "CT" com ambas as heurísticas.

\begin{tabular}{|c|c|c|c|}
\cline { 2 - 4 } \multicolumn{1}{c|}{} & $\begin{array}{c}\text { Métrica } \\
\text { utilizada }\end{array}$ & $\begin{array}{c}\text { Razão entre o } \\
\text { esforço mínimo e } \\
\text { o esforço original }\end{array}$ & $\begin{array}{c}\text { Configuração que em geral reduz } \\
\text { mais o esforço de interação }\end{array}$ \\
\hline Borboletas & Volume & $87 \%$ & Não há vantagem clara entre as 4 configurações \\
\hline Fitoplâncton & Profundidade & $46 \%$ & Remoção de bordas desnecessárias via fusão de regiões \\
\hline Pedras & Volume & $16 \%$ & Remoção de bordas desnecessárias via fusão de regiões \\
\hline CT & Área & $80 \%$ & Sem pós-processamento \\
\hline
\end{tabular}

Tabela 5.9: Comparação entre os resultados dos experimentos com os 4 conjuntos considerados.

aplicação, o conjunto de imagens a ser segmentado dever ser restrito a um domínio específico. Em particular, quanto mais específico for o domínio (quanto mais semelhantes entre 


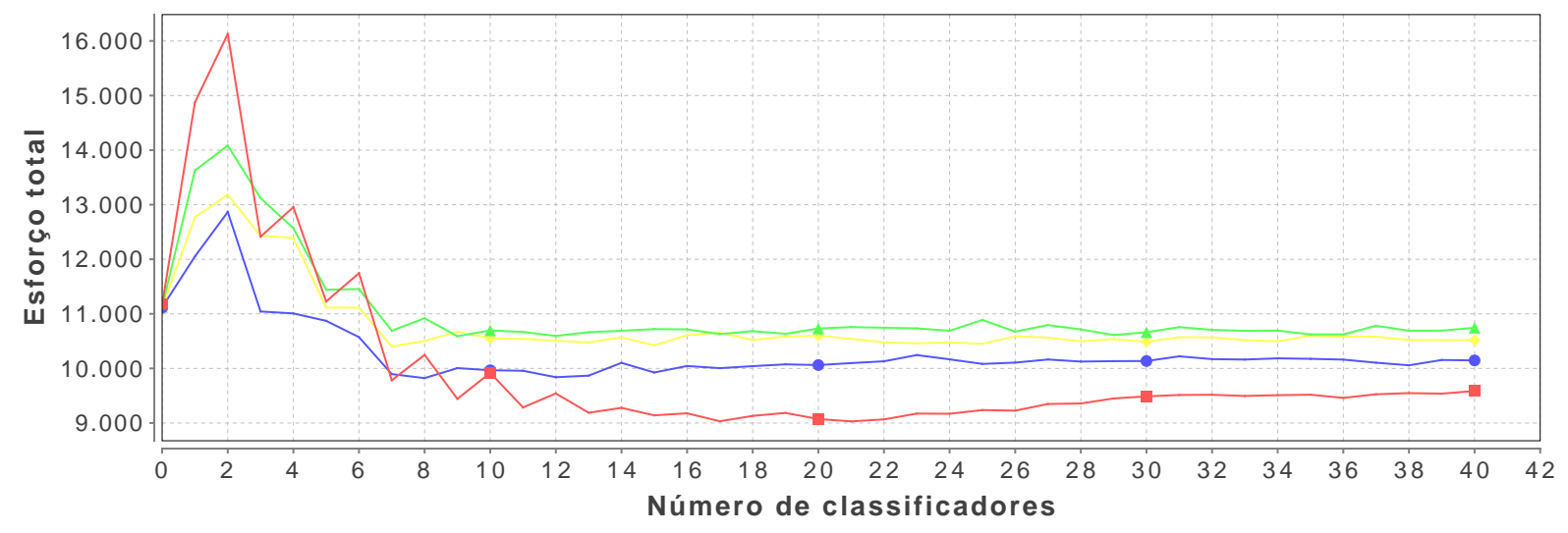

- Sem as heurísticas $\rightarrow$ Com a heurística de filtragem - Com a heurística de fusão - Com ambas as heurísticas

Figura 5.28: Esforço total para segmentar a sequência "CT".

si forem as imagens do conjunto), maior a qualidade da segmentação pelos classificadores e, portanto, maior a redução no esforço de interação necessário para segmentar tal conjunto. Este é o principal motivo pela maior redução obtida na sequência "Pedras", uma vez que frames consecutivos são geralmente muito semelhantes entre si.

Nos experimentos, utilizamos SVMs com kernels gaussianos e parâmetros fixos. Os resultados obtidos com essa configuração podem ser melhorados. Para tal é possível:

- fazer uma análise, restrita ao domínio de aplicação, sobre o efeito do tipo de kernel e parâmetros utilizados nas SVMs;

- avaliar o uso de outras características e técnicas de seleção de características;

- utilizar outra técnica de aprendizado supervisionado que seja mais adequada ou com menor tempo de processamento para o domínio de aplicação, comparando com o uso das SVMs.

Em relação aos pós-processamentos descritos nas seções 3.1.2 e 3.1.3, nem sempre existe vantagem em se utilizar as heurísticas propostas. Portanto, para cada domínio de aplicação, deve ser avaliado se cada uma dessas heurísticas reduzem o esforço de interação. Na heurística de filtragem de bordas pouco confiáveis, a seleção de conjunto em termos de um número fixo da arestas pode não ser adequado para partições com pequenos objetos, como na sequência "Fitoplâncton". Melhores resultados poderiam ser obtidos com tal heurística se, por exemplo, fosse considerada que uma porcentagem mínima de arestas de um dado conjunto selecionasse tal conjunto, ao invés de um número constante de arestas. 


\section{Integração com sistemas interativos de segmentação}

Neste capítulo são consideradas algumas questões práticas para a integração do método proposto no Capítulo 3 em sistemas interativos para segmentação de imagens digitais.

\subsection{Treinamento online $\times$ offline}

Os experimentos realizados no Capítulo 5 demostram que a utilização do método proposto é útil para reduzir o esforço da interação necessário para segmentar conjuntos com um grande número de imagens. No entanto, os experimentos não consideraram o tempo de processamento. O método proposto é baseado na utilização de classificadores, que utilizam imagens previamente segmentadas e suas respectivas partições como dados de treinamento. Como o treinamento pode ter um alto tempo de processamento, seu uso em um sistema interativo pode ser proibitivo.

Em cada uma das figuras 6.1 a 6.4, exibimos 3 curvas relativas ao tempo de processamento envolvido em 3 passos distintos do processo:

- calcular características: refere-se ao tempo necessário para calcular as 15 características, conforme descrito na Seção 5.2, de cada uma das imagens. Tais características compõe os vetores que representam cada aresta do RAG da respectiva imagem. Ao calcular as características para uma imagem, os vetores correspondentes são utilizados para inferir os rótulos das respectivas arestas. Tais vetores podem ser armazenados para serem utilizados posteriormente na geração de um classificador baseado na imagem em questão. Note que o tempo referente a esse processamento geralmente é baixo (de 1 a 2 segundos) para todas as imagens utilizadas nos experimentos. Por esse motivo, o tempo de tal processamento não é crítico ao considerarmos um processo interativo de segmentação. 
- prever usando modelo: refere-se ao tempo necessário para classificar as arestas de uma outra imagem com base em um classificador criado com a imagem do índice respectivo (eixo horizontal). Note que o tempo referente a esse processamento é bem baixo, o que permite o uso de vários modelos para classificar uma imagem, sem sobrecarregar o tempo de processamento neste ponto do processo (classificação).

- treinar modelo: refere-se ao tempo necessário para gerar um modelo a partir de uma imagem, dados os vetores de características e os rótulos associados a cada aresta do RAG da imagem. Note que tal tempo de processamento pode ser elevado, sendo crítico num processo interativo de segmentação. A seguir, discutimos como podemos lidar com os casos em que o tempo desse processamento é elevado.

Para conjuntos de imagens em que o treinamento é feito bem rápido, como o lote "Fitoplâncton" e a sequência "Pedras", esse não é um fator crítico: o treinamento de um classificador com uma imagem pode ser feito assim que tal imagem é segmentada e o classificador obtido pode ser utilizado para pré-segmentar a próxima imagem. Já no caso de conjuntos em que o tempo de treinamento não é muito pequeno, como é para o lote "Borboletas" e a sequência "CT", essa abordagem não é adequada: o usuário deveria aguardar o treinamento de um classificador antes de segmentar uma próxima imagem. Neste cenário, uma solução possível é realizar o treinamento de classificadores separadamente do fluxo principal de execução da tarefa de segmentação do conjunto de imagens. Assim, a cada imagem segmentada, o classificador criado com base nessa imagem deve ser treinado numa thread separada, de forma a não impedir que o usuário faça a segmentação de outras imagens enquanto aguarda o treinamento do classificador. A cada nova imagem que o usuário vai começar a segmentar, é possível utilizar os classificadores cujo treinamento já foi finalizado até o momento. Vale ressaltar que somente um subconjunto das imagens precisa ser utilizado no treinamento de classificadores para maximizar a redução no esforço de interação necessário. Outra possibilidade, mais adequada para casos em que o treinamento demora muito, é fazer a segmentação de um pequeno subconjunto de imagens, realizar o treinamento dos respectivos classificadores de forma offline e retomar a segmentação das outras imagens somente depois que todos os classificadores já tenham sido treinados. Alternativamente, é possível fazer uma amostragem das arestas utilizadas pra se treinar um classificador, de forma que o tempo de processamento seja reduzido e possibilite fazer o treinamento de forma online.

No caso de sequências de vídeo, caso os frames estejam separados em tomadas, o usuário pode segmentar alguns frames iniciais de uma tomada e, enquanto o treinamento estiver em andamento, pode prosseguir com a segmentação dos frames da próxima tomada. Imagens de lotes (tomadas) distintos podem ser segmentadas ciclicamente de forma que no momento em que o usuário está para iniciar a segmentação de um próximo frame de uma certa tomada, os treinamentos relativos aos frames anteriores na mesma tomada já tenham sido concluídos. 


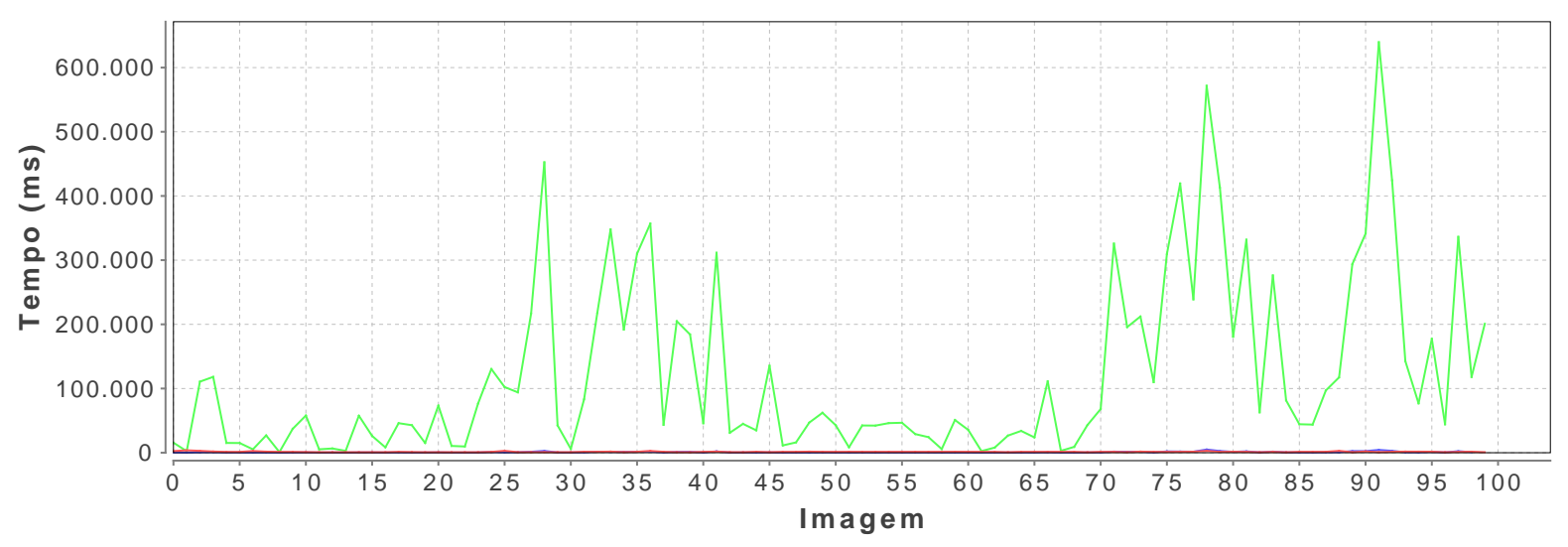

- - Calcular características $\rightarrow-$ Prever usando modelo - Treinar modelo

(a)

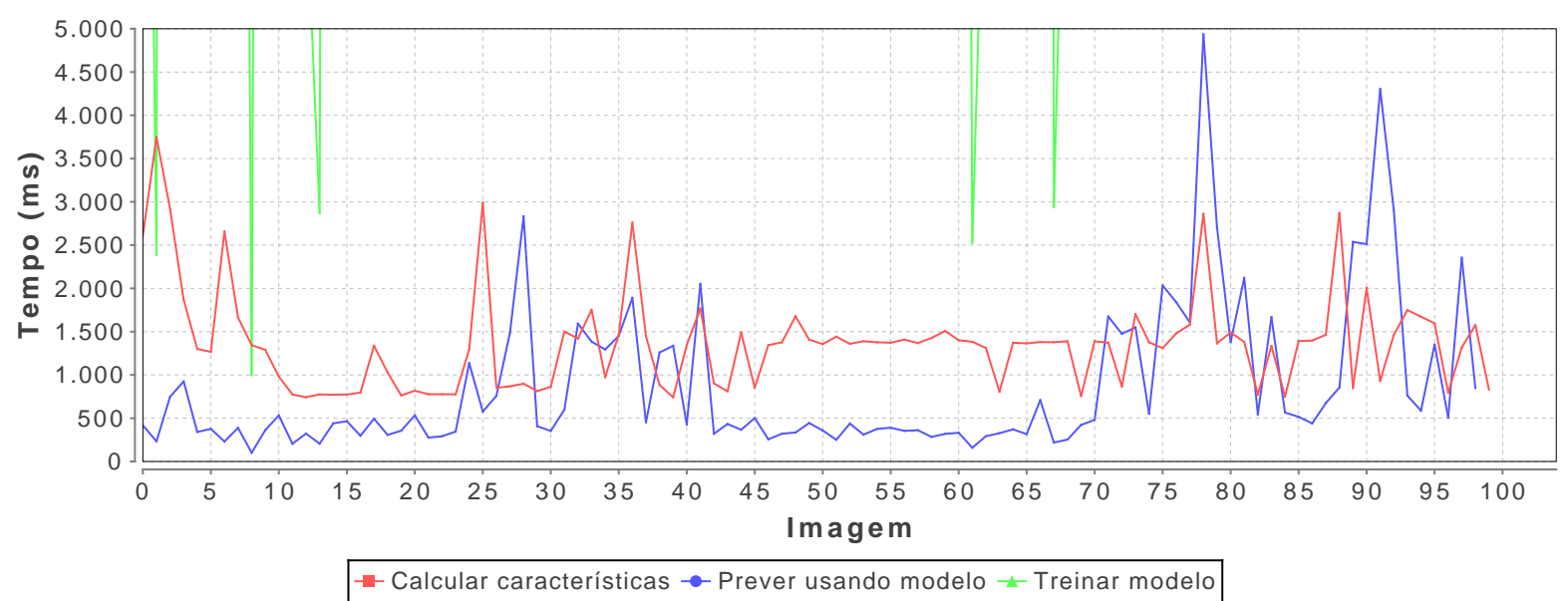

(b) Detalhe do tempo de processamento no intervalo de 0 a 5 segundos

Figura 6.1: Tempo de processamento para o lote "Borboletas".

\subsection{Coerência entre operações global e locais}

O método proposto resulta em uma partição inicial contida em uma hierarquia adaptada de uma hierarquia inicial. Após esse passo inicial, feito automaticamente, o usuário pode executar as operações desejadas para refinar a partição obtida. Como descrito no Capítulo 4, a operação de seleção de limiar pode desfazer o efeito de operações anteriores. Se um usuário utilizar tal operação, a partição selecionada pelo método proposto é potencialmente desfeita, pois dificilmente corresponde a um limiar das hierarquias existentes. Dessa forma, o uso da operação de seleção de limiar pode anular o efeito da redução de esforço de interação desejado. 


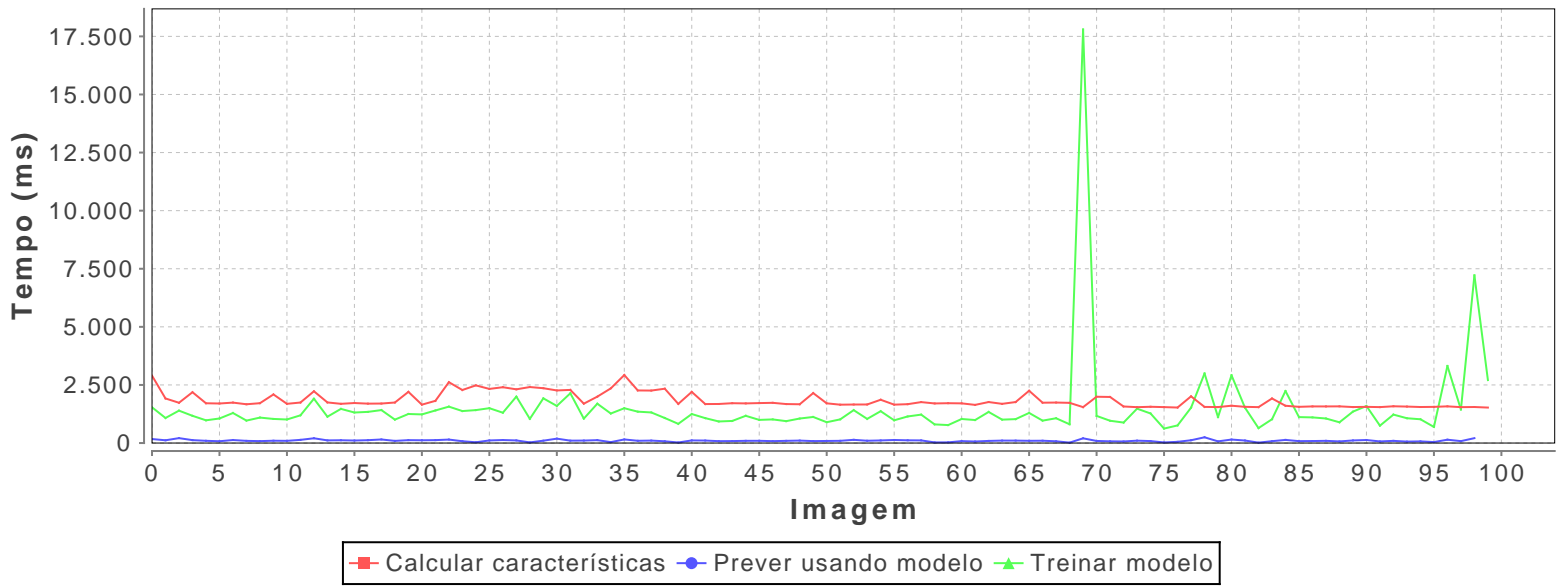

Figura 6.2: Tempo de processamento para o lote "Fitoplâncton".

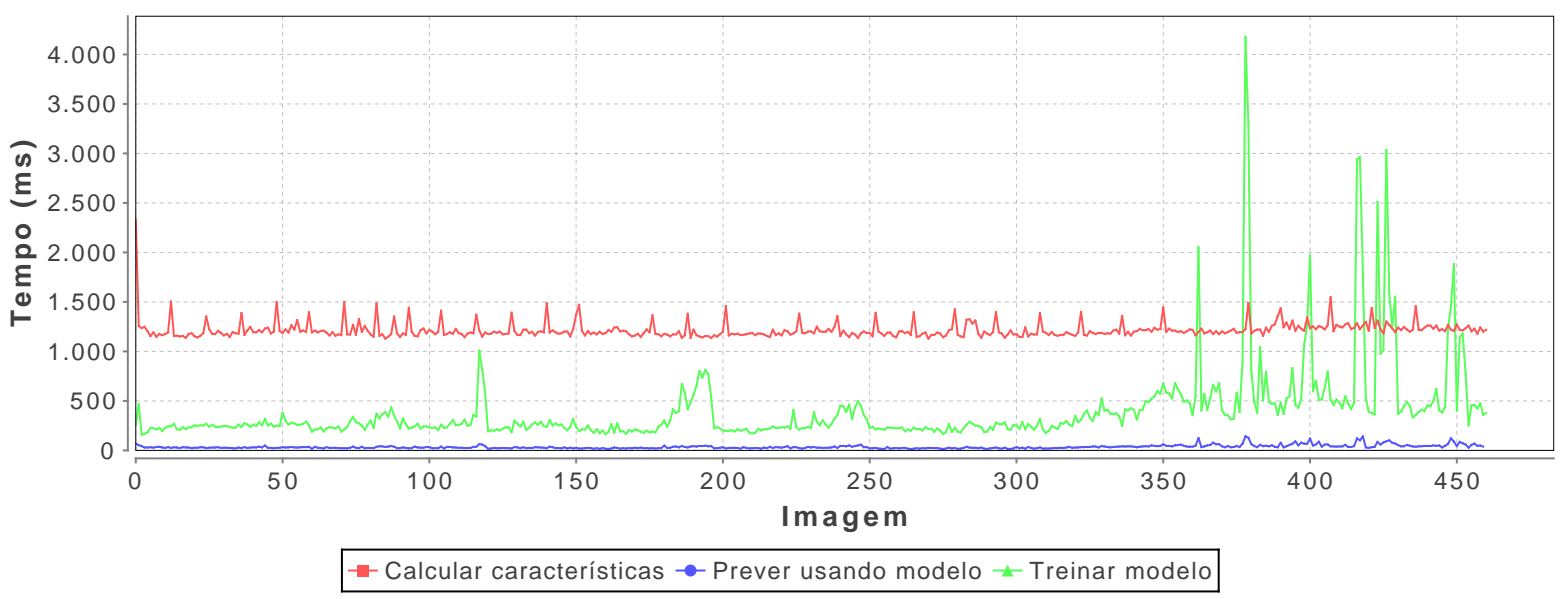

Figura 6.3: Tempo de processamento para a sequência "Pedras".

Intuitivamente, ao diminuir o limiar da hierarquia, é esperado que a partição atual seja apenas refinada, isto é, que somente novas bordas sejam acrescentadas. Da mesma forma, ao aumentar o limiar da hierarquia, é esperado que nenhuma borda seja acrescentada, somente removida. Porém, isto não ocorre, a não ser que a partição inicialmente selecionada corresponda a um limiar da hierarquia. Isto pode ser percebido como uma incoerência pelos usuários.

Para evitar tal incoerência, uma possibilidade é limitar a utilização da operação de seleção de limiar aos passos iniciais do processo de segmentação, como proposto no modelo de interação descrito no Capítulo 4. Entretanto, a operação de seleção de limiar é muito conveniente pra explorar a estrutura da hierarquia e não há razão para supor que tal exploração deva ser limitada aos passos iniciais. De fato, nos experimentos descritos na 


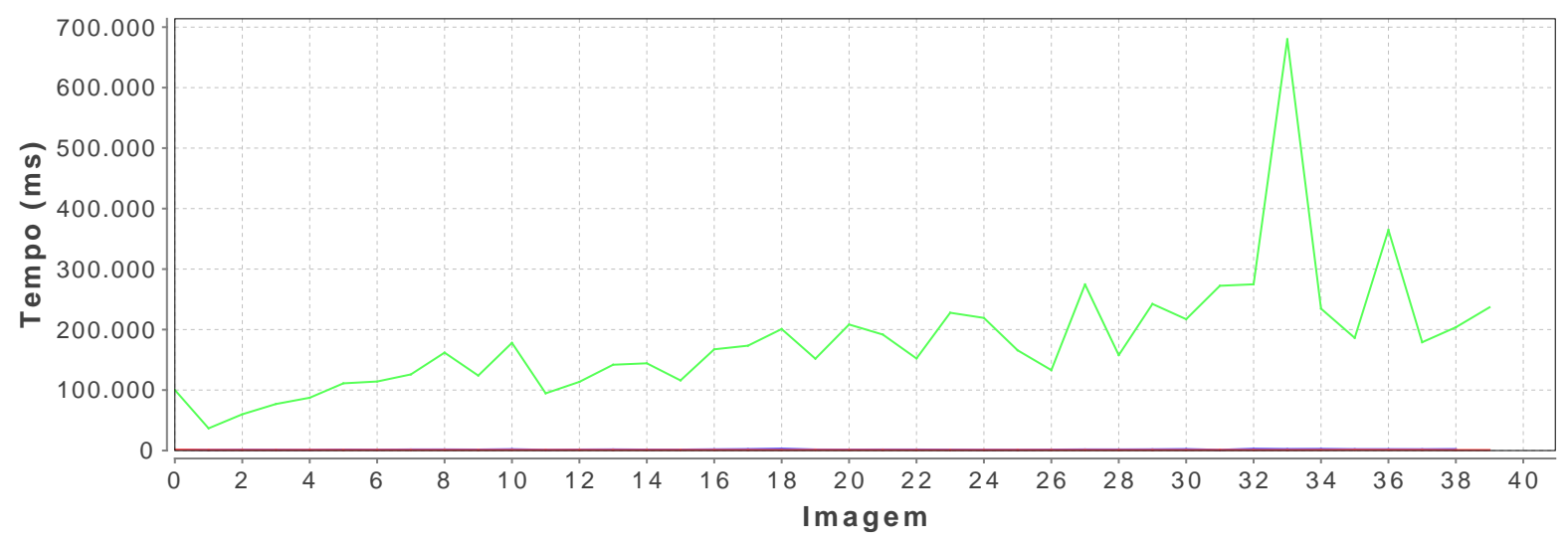

- Calcular características - - Prever usando modelo $₫$ Treinar modelo

(a)

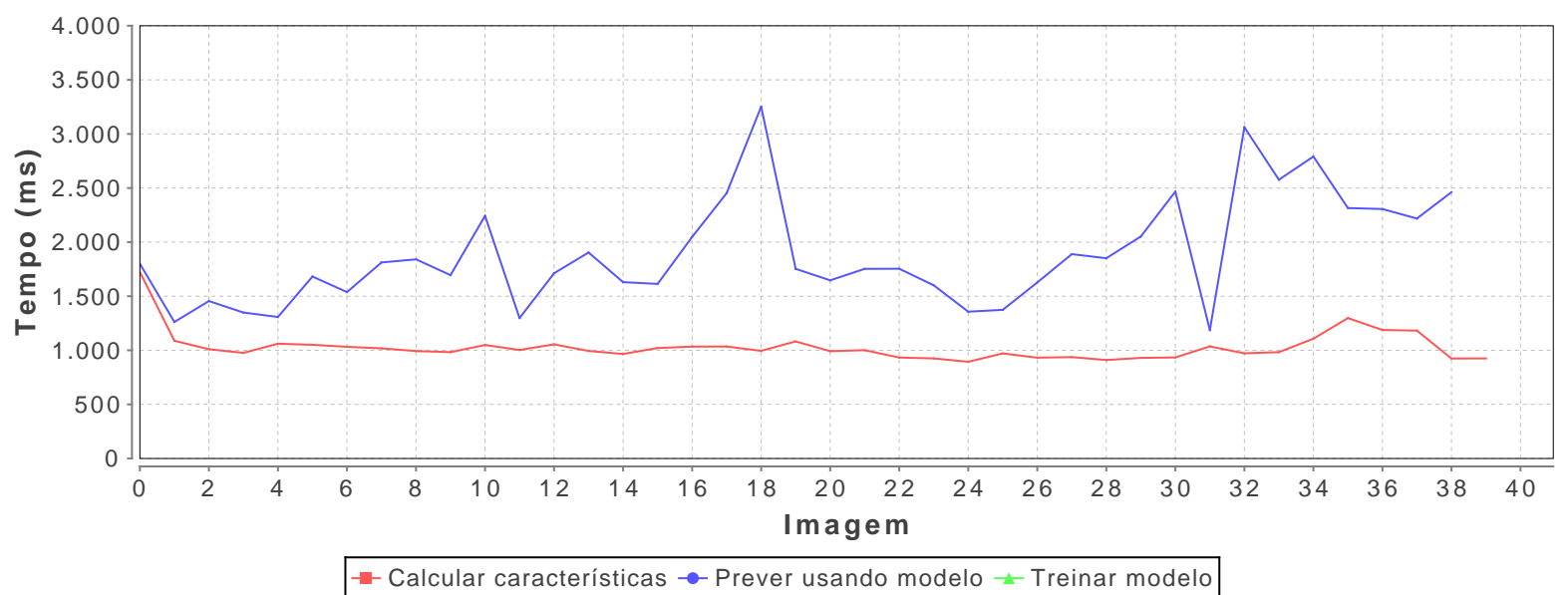

(b) Detalhe do tempo de processamento no intervalo de 0 a 4 segundos

Figura 6.4: Tempo de processamento para a sequência "CT".

Seção 4.2, os usuários utilizaram a operação de seleção de limiar após operações locais em 16, $5 \%$ das tarefas de segmentação, mesmo tendo sido explicitamente alertados a respeito dessa restrição.

A seguir, é proposto um método para manter a coerência entre a operação de seleção de limiar e as demais operações, com o objetivo de:

- ao aumentar o limiar, somente fusões de regiões da partição atual devem ocorrer;

- ao diminuir o limiar, somente divisões de regiões da partição atual devem ocorrer.

Com isso, o uso da operação de seleção de limiar não fica restrito aos passos iniciais 
do processo de segmentação e, em particular, viabiliza a utilização de tal operação para refinar a partição selecionada automaticamente pelo método proposto no Capítulo 3.

\subsubsection{Representação de hierarquias através de dendrogramas}

Hierarquias de partições podem ser representadas por dendrogramas, que são diagramas de árvores utilizados para ilustrar a disposição e relacionamentos entre as regiões das partições da hierarquia. Na Figura 6.5 exibimos uma hierarquia de partições, sua representação através de um dendrograma e como as operações sobre a hierarquia podem ser representadas como cortes sobre o dendrograma da hierarquia. As partições obtidas a cada operação descrita na Figura 6.5 são exibidas na Figura 6.6.

Suponha, por exemplo, que um usuário realizou as operações exibidas na Figura 6.5. Se, após a segunda operação de divisão local, o usuário desejar dividir a região K em F e $\mathrm{G}$, ao invés de utilizar a operação de divisão local, ele pode diminuir o limiar, para o valor 10, por exemplo, de forma a obter as bordas desejadas. Porém, dessa forma, as regiões A e H serão fundidas. Isto não é coerente com o comportamento esperado ao diminuir o limiar, cujo efeito deveria ser somente a divisão de regiões.

\subsubsection{Adaptação dos pesos da hierarquia}

Para manter a coerência entre as operações global e locais, a estrutura da hierarquia deve ser atualizada dinamicamente de forma a conter, a cada passo do processo de segmentação, a partição gerada no passo anterior. Tal atualização deve ser feita de forma a manter as relações entre os nós da hierarquia e seus filhos, condição necessária para que as operações locais continuem compatíveis com a métrica utilizada na construção da hierarquia.

Para tal, propomos esticar verticalmente o dendrograma da hierarquia ao redor dos nós afetados a cada operação local executada, como descrito abaixo.

Retomando o exemplo anterior, na Figura 6.5 (e) é exibido que uma sequência de operações sobre a hierarquia pode resultar em um corte arbitrário no respectivo dendrograma. Um maneira simples de se obter as características desejadas é mover todos os nós que estão acima da linha de corte para que fiquem acima do nó mais alto entre os nós abaixo do corte. Por exemplo, na Figura 6.5 (d), o nó mais alto entre os nós abaixo do corte é o nó K. Então, os nós acima do corte (J, L e M) devem ser movidos pra cima do limiar do nó K, como exibido na Figura 6.7. Uma maneira simples de garantir isto é deslocar os nós acima do corte com o valor correspondente ao nó mais alto abaixo da linha de corte. No exemplo, o valor correspondente ao nó mais alto, K, é 14. Então, ao adicionar o valor 14 aos pesos dos nós J, L e M, obtemos a hierarquia exibida na Figura 6.7. Dessa forma, a linha de corte que separa os dois conjuntos de nós (nós acima e nós abaixo da linha de 

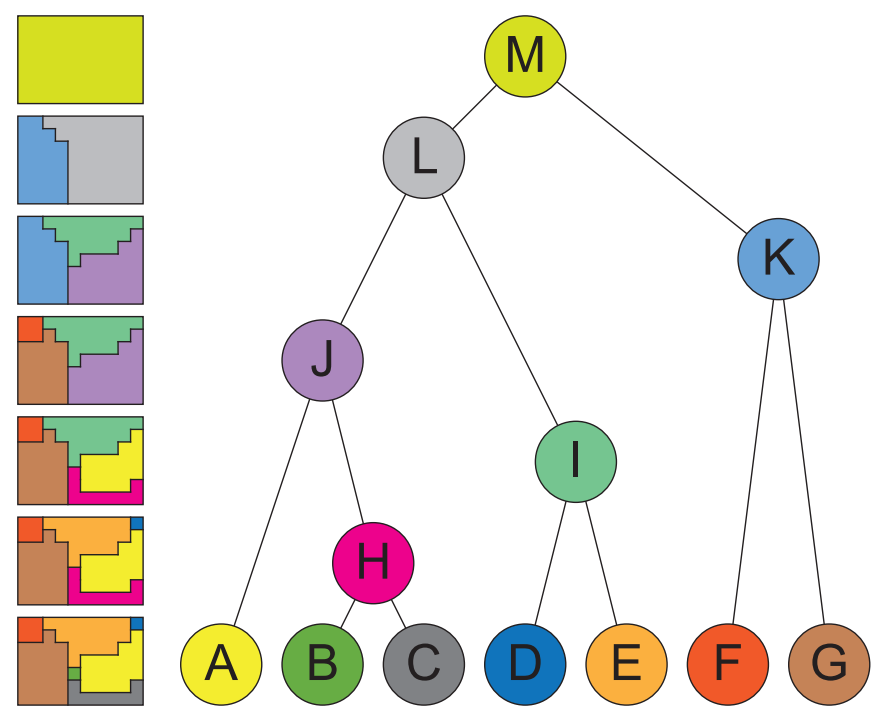

(a) Hierarquia e ALC

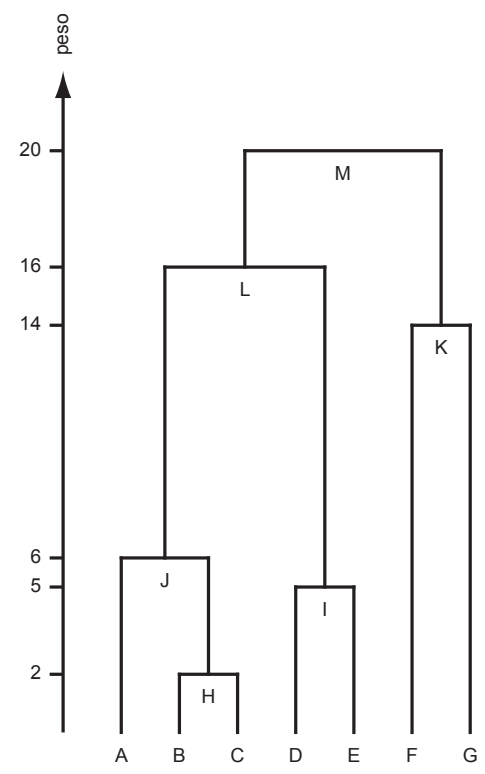

(b) Dendrograma

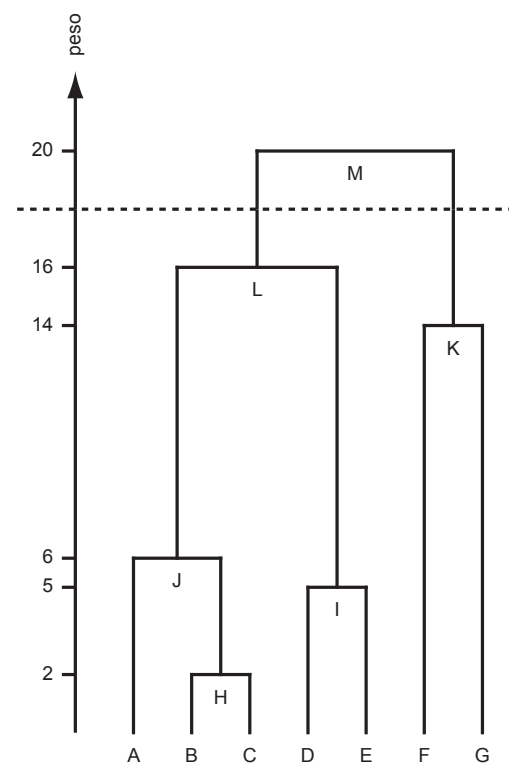

(c) Seleção de limiar

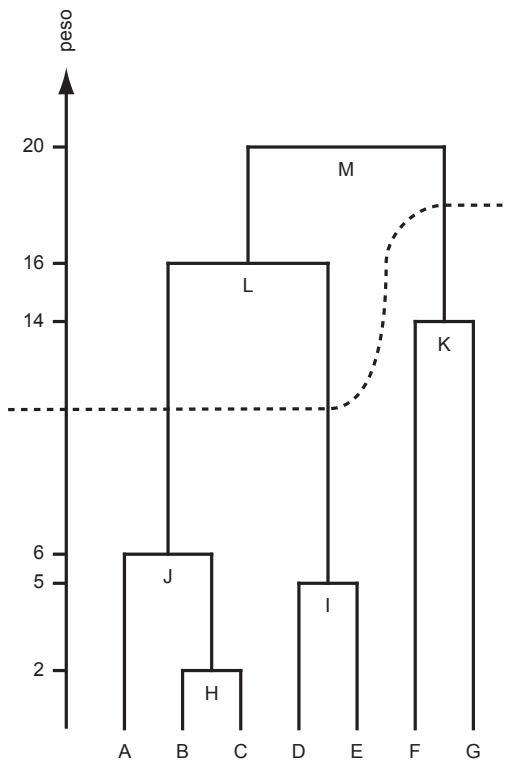

(d) Divisão local

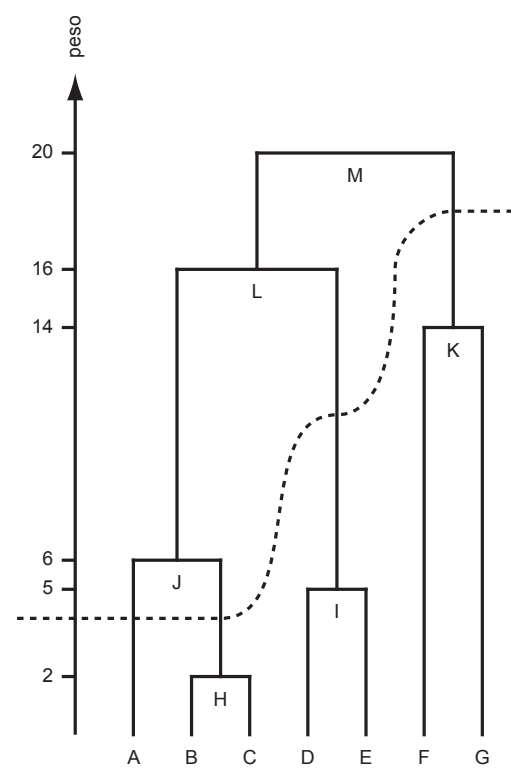

(e) Outra divisão local

Figura 6.5: Uma hierarquia de partições representada por um dendrograma e operações sobre a hierarquia representadas por cortes (linhas tracejadas) no dendrograma: (a) Hierarquia de partições e sua ALC. (b) Dendrograma da hierarquia de (a). (c) Uma operação de seleção de limiar corresponde a um corte por todo o dendrograma, no valor correspondente ao peso da métrica utilizada na construção da hierarquia. Ao selecionar o limiar 18, a partição formada pelas regiões L e K é selecionada. (d) Uma divisão local (região L dividida em seus filhos J e I) faz o corte que representa a partição selecionada ir abaixo do peso que formou a região L. (e) Outra operação de divisão local, dividindo J em A e H. 


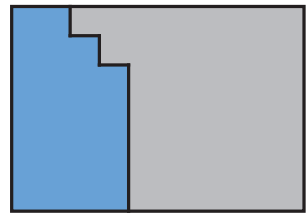

(a)

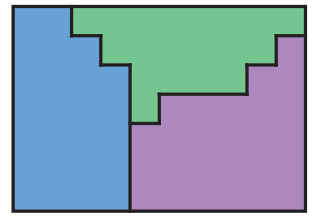

(b)

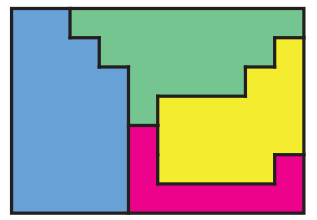

(c)

Figura 6.6: Partições obtidas através de operações hierárquicas: (a) Partição correspondente à operação de seleção de limiar da Figura 6.5(c). (b) Partição correspondente à operação de divisão local da Figura 6.5(d). (c) Partição correspondente à operação de divisão local da Figura 6.5(e). Note que esta partição não corresponde a nenhuma das partição da Figura 6.5(a), isto é, tal partição não pode ser obtida usando somente operações de seleção de limiar, mas pode ser obtida através de operações de divisão local.

corte) pode ser desenhada como uma reta horizontal, cuja altura corresponde a um limiar da hierarquia adaptada.

Esta adaptação dos pesos dos nós da hierarquia pode ser implementada por um algoritmo baseado em uma busca em largura, exibido no Algoritmo 1. Ao adaptar os pesos da hierarquia com este algoritmo, o corte que representa qualquer partição selecionada na hierarquia pode sempre ser desenhada como uma linha horizontal, ou seja, pode sempre ser selecionada na hierarquia utilizando uma operação de seleção de limiar. A altura do corte horizontal corresponde ao último limiar utilizado numa operação de seleção de limiar (caso tal operação tenha sido utilizada).

A operação de seleção de limiar original seleciona um valor para a métrica utilizada na construção da hierarquia. Os nós acima do limiar selecionado, isto é, os nós cujos pesos estão acima do limiar, não estão ativos na partição atual (na partição correspondente ao limiar selecionado). Para cada caminho a partir de uma folha da hierarquia (uma bacia primitiva) até a raiz da hierarquia, somente um nó é selecionado: o nó mais alto cujo peso é menor ou igual ao limiar selecionado. Com a adaptação dos pesos proposta, um valor adicional para o peso é armazenado em cada nó interno da hierarquia. A operação de seleção de limiar, então, deve ser executada comparando-se o limiar selecionado com o peso total dos nós da hierarquia, peso dado pela métrica original acrescentado do peso delta. Outra possibilidade seria somar o valor delta diretamente ao peso original dos nós acima da linha de corte que representa a partição selecionada, porém, tal abordagem faria os pesos dos nós crescerem indefinidamente ao longo de processos interativos de segmentação, o que podia levar a problemas de implementação se os limites máximo dos tipos das variáveis utilizadas fosse atingido. Ao recalcular e reajustar o peso delta necessário a cada operação local utilizada, garantimos que o valor do peso dos nós fica limitado (o peso delta é sempre 


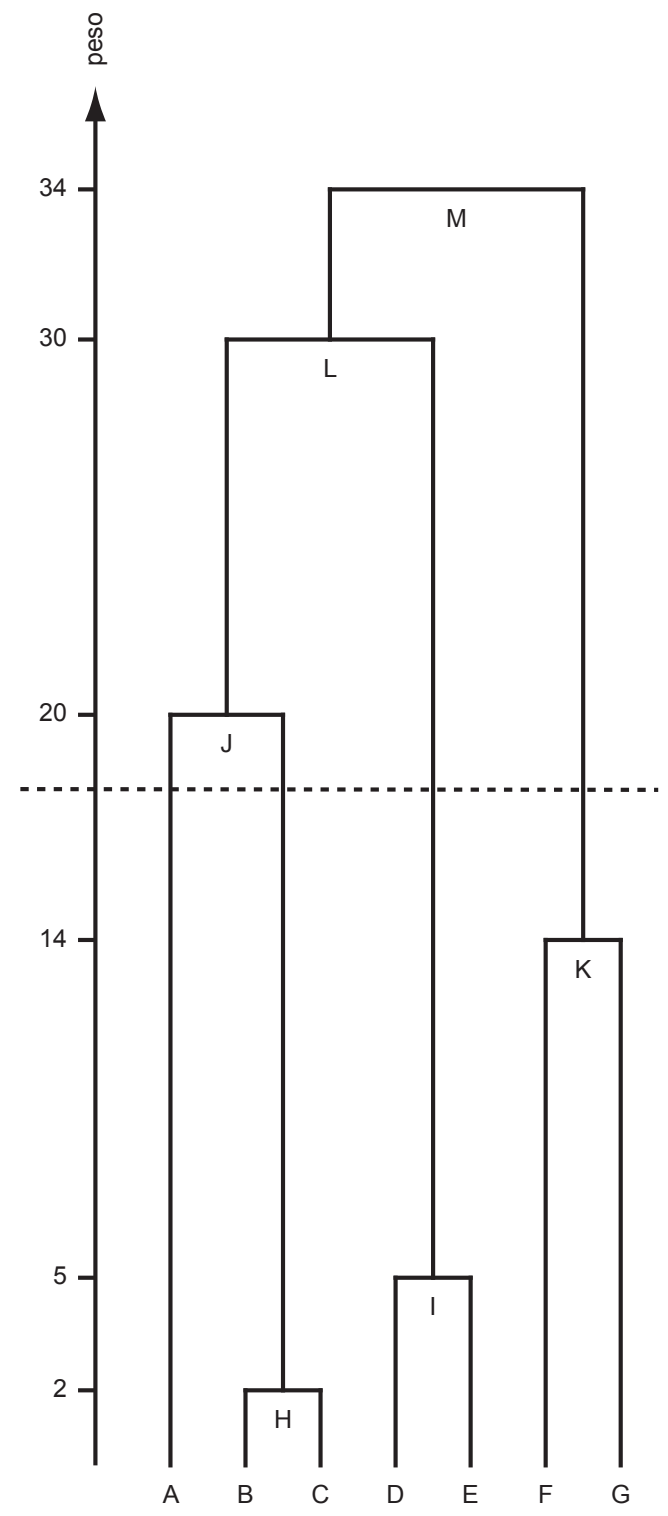

Figura 6.7: Adaptação dos pesos do dendrograma da Figura 6.5 (e) de forma que o corte arbitrário é coerente com a operação de seleção de limiar. O limiar correspondente ao nó mais alto entre os nós abaixo do corte $(\mathrm{K})$ é 14 . Ao somar este valor aos pesos dos nós acima do corte (J, L e M), a linha de corte que separa os nós pode ser desenhada como uma linha horizontal na altura 18, valor que corresponde ao último valor de limiar utilizado numa operação de seleção de limiar (na Figura 6.5 (c)). 


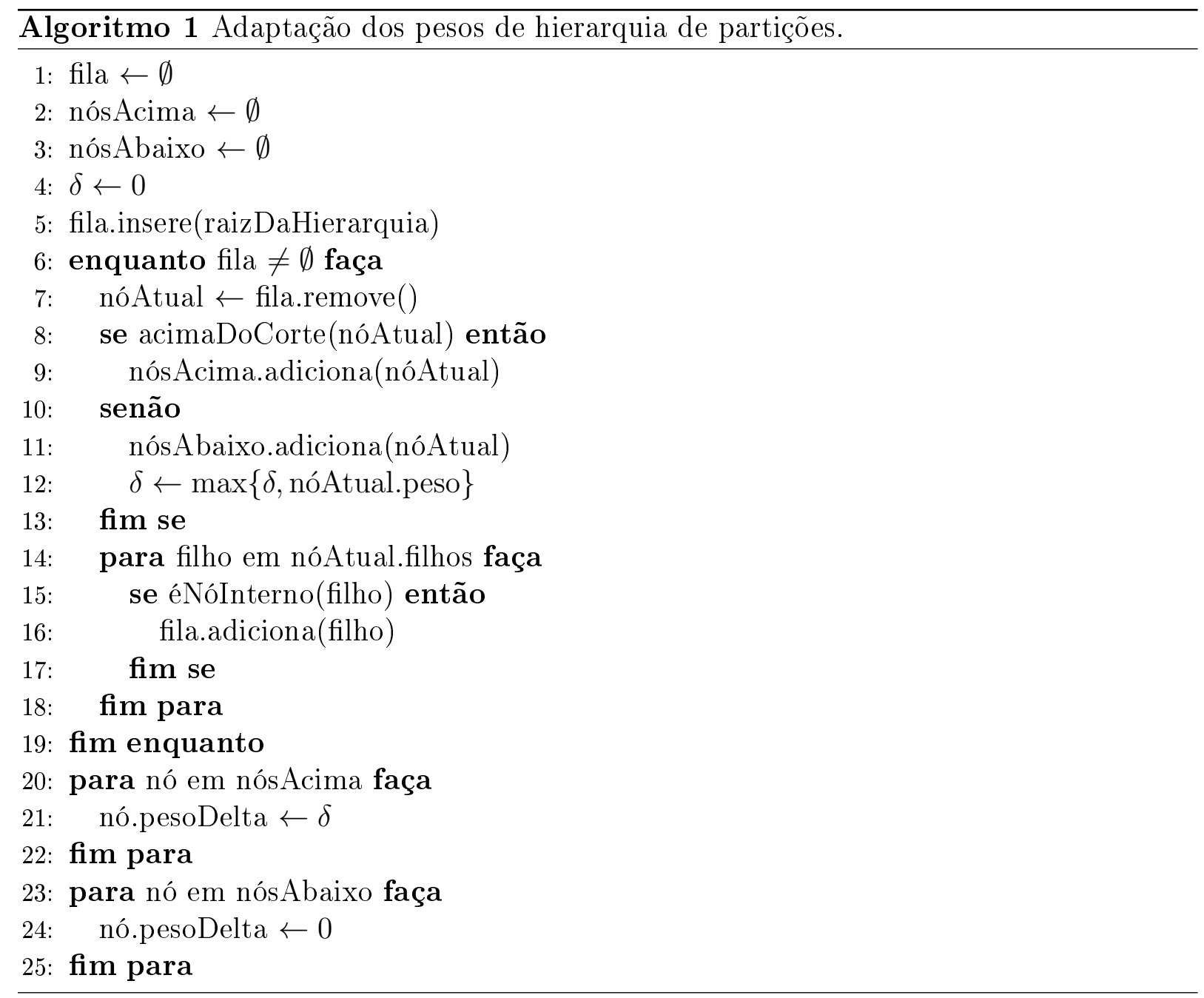

menor ou igual ao valor máximo da métrica utilizada na construção da hierarquia). 


\section{Considerações finais}

Esta tese de doutorado apresentou um método, baseado em aprendizado supervisionado, para reduzir o esforço de interação no contexto de segmentação hierárquica de imagens.

Para avaliar o método proposto e possibilitar a automatização de testes que dependem da manipulação de uma hierarquia de partições, um modelo inédito para simulação de interação no contexto de segmentação hierárquica foi proposto. Simulações desse modelo foram utilizados para estimar os esforços de interação, cujos resultados foram discutidos num artigo apresentado na IEEE International Conference on Image Processing (Klava e Hirata, 2014).

Os experimentos realizados mostram que reduções de esforço significativos são obtidos com o método proposto. Em particular, foram observadas reduções entre $13 \%$ e $84 \%$ para os 4 lotes de imagens avaliadas. Portanto, o método proposto é útil para adaptar hierarquias existentes de forma que o esforço de interação necessário é reduzido.

As hierarquias existentes exigem muito esforço de interação e o método proposto pode ser utilizado para reduzir tal esforço. Com isso, o método proposto abre possibilidade para a criação de hierarquias mais representativas, de forma que a estrutura das hierarquias obtidas se aproximem mais das relações semânticas entre os componentes do conteúdo de imagens digitais.

Apesar do trabalho ter considerado a redução de esforço no uso de hierarquias de partições, o método proposto pode ser estendido para o contexto de segmentação baseada em marcadores bastando, nesse caso, analisar a redução do esforço de interação em termos das operações possíveis para manipular os marcadores das regiões de interesse de uma partição (estender, criar, apagar e unir marcadores).

O método proposto é flexível de forma que diversos de seus componentes, como o classificador utilizado, características para representação dos dados de entrada e métrica para 
a construção da hierarquia, podem ser customizados para obter melhores resultados em domínios de aplicação específicos. Em particular, é possível incorporar novos componentes ao método proposto:

- utilização de novas hierarquias, baseada em outras características como nível de cinza ou cores médias das regiões da partições, entre outras;

- utilização de hierarquias derivadas a partir do máximo, mínimo e outras combinações entre as hierarquias existentes;

- utilização de técnicas baseadas em casamento de grafos (Noma et al., 2011), apropriadas para ampliar as possibilidades do método para incluir, por exemplo, informação estrutural e melhorar os resultados obtidos.

Novos métodos devem ser divulgados e acessíveis abertamente à comunidade acadêmica/científica para expandir as possibilidades de novos trabalhos. Com esse intuito, a ferramenta SegmentIt, distribuída como software livre, terá seu desenvolvimento continuado, de forma a incorporar o método proposto e novas possibilidades, como por exemplo:

- integrar o método proposto ao SegmentIt, com as considerações práticas feitas no Capítulo 6;

- integração das abordagens do watershed de forma mais transparente no SegmentIt, de forma que seja possível utilizar marcadores e hierarquia sem ficar alternando entre os modos de visualização específicos para cada abordagem;

- em segmentação de vídeo, comparar os resultados do método proposto com técnicas de propagação de marcadores (Flores e Lotufo, 2010) e casamento de grafos e integrálas ao SegmentIt;

- implementar a hierarquia de valor médio (Apêndice B) para utilizar cores (atualmente está restrita para imagens em níveis de cinza);

- implementar uma operação em que o usuário segmente uma pequena região da imagem e a partição obtida seja expandida para o resto do domínio espacial da imagem, com base nas semelhanças entre os objetos contidos na imagem;

- implementar uma operação de divisão manual de regiões, análoga a operação de fusão manual de regiões, através da qual os usuários poderão indicar explicitamente quais regiões devem ser divididas (não sendo limitada à estrutura da hierarquia). 


\section{Tarefas de segmentação dos experimentos}

Neste apêndice é apresentado o conjunto de tarefas de segmentação utilizados nos experimentos descritos no Capítulo 4. Cada uma das 20 tarefas é formada por uma imagem de entrada, uma descrição textual explicando quais objetos devem ser segmentados e um ground truth. 
Tarefa 1: Segmentar cada uma das 4 asas. Dividir cada asa em 2 partes, separando a maior região central com outra cor.

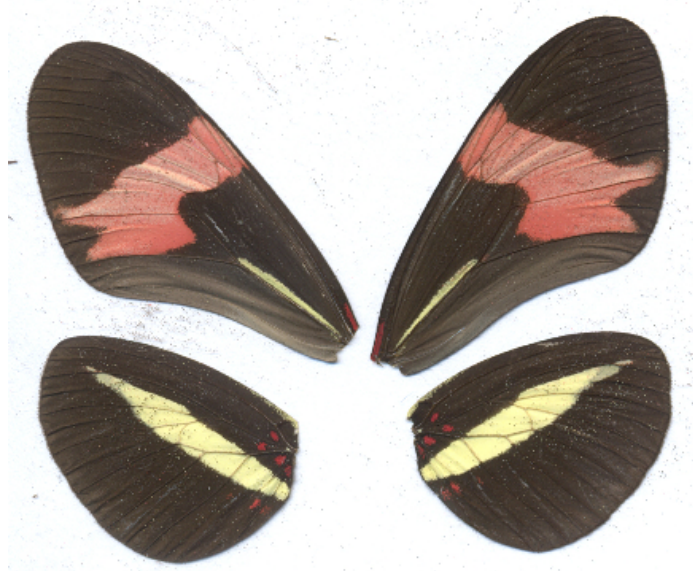

(a) Imagem de entrada

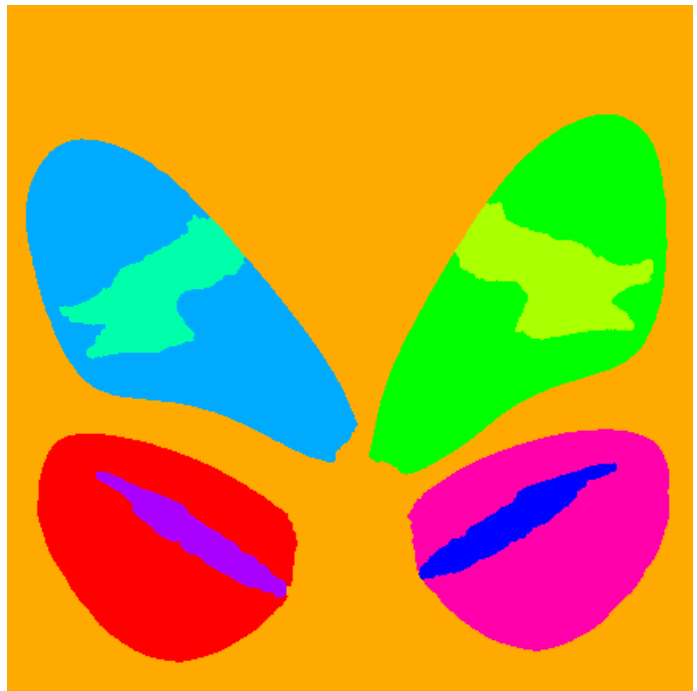

(b) Ground truth

Figura A.1: Tarefa 1.

Tarefa 2: $\quad$ Segmentar cada uma das células.

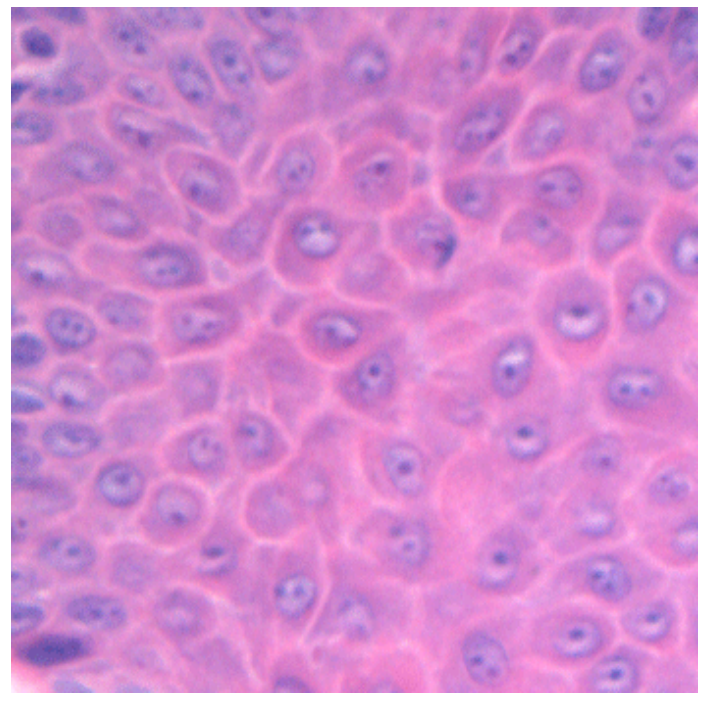

(a) Imagem de entrada

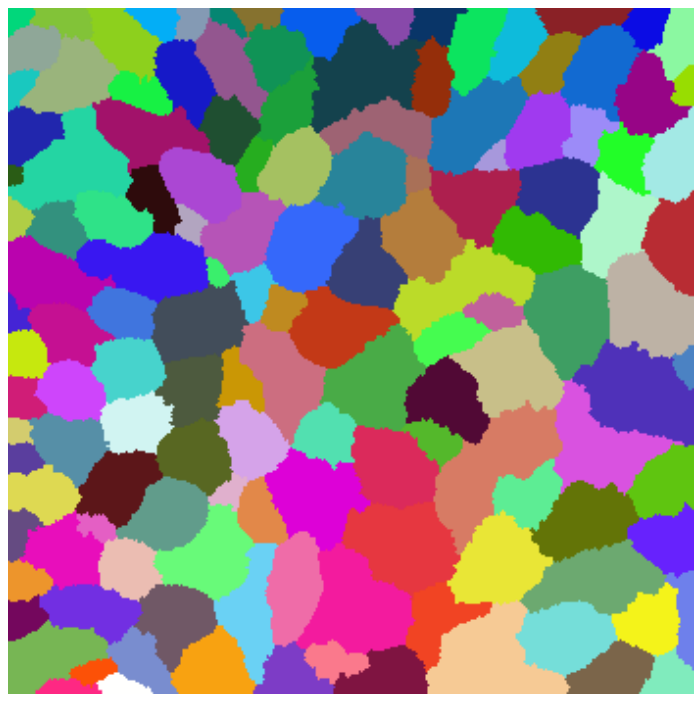

(b) Ground truth

Figura A.2: Tarefa 2. 
Tarefa 3: Segmentar cada um dos 6 morangos. Incluir as sépalas (folhas) e os pedúnculos (cabos). Não incluir as sombras no fundo.

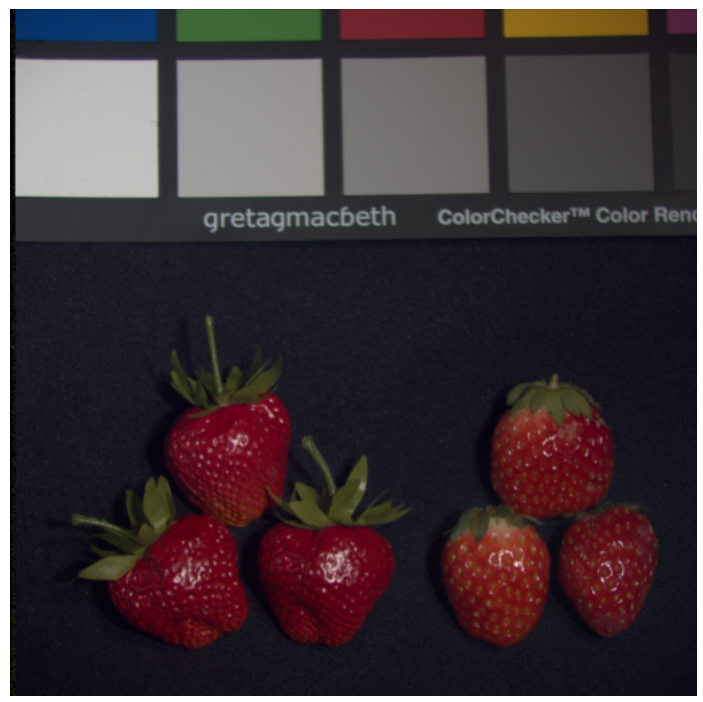

(a) Imagem de entrada

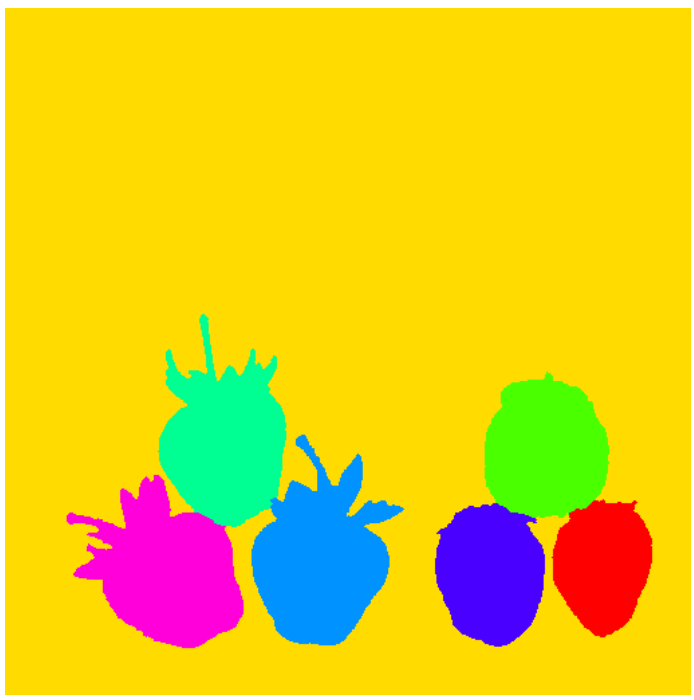

(b) Ground truth

Figura A.3: Tarefa 3.

Tarefa 4: Segmentar cada um dos 4 planos da imagem (céu e 3 montanhas).

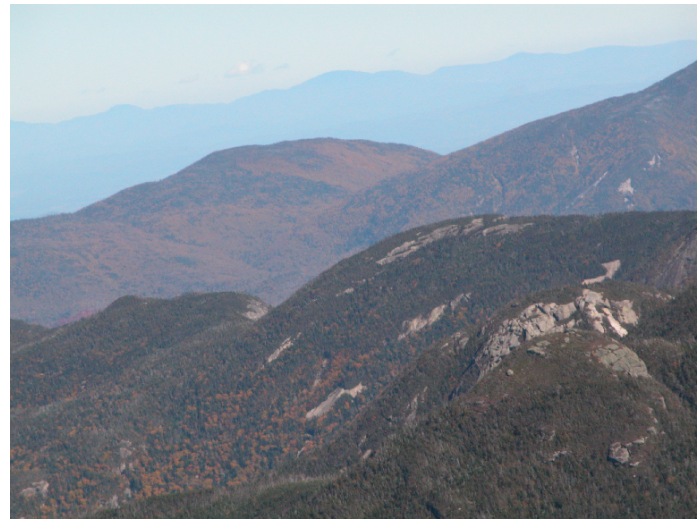

(a) Imagem de entrada

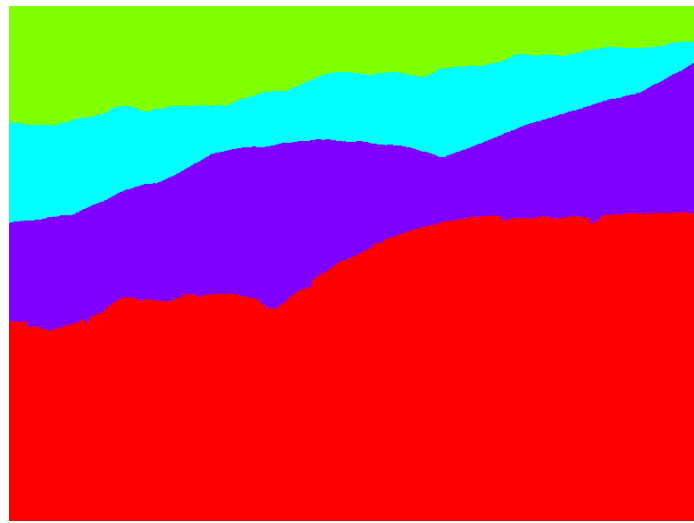

(b) Ground truth

Figura A.4: Tarefa 4. 
Tarefa 5: Segmentar as regiões de água, grama e céu, separando-as das demais regiões.

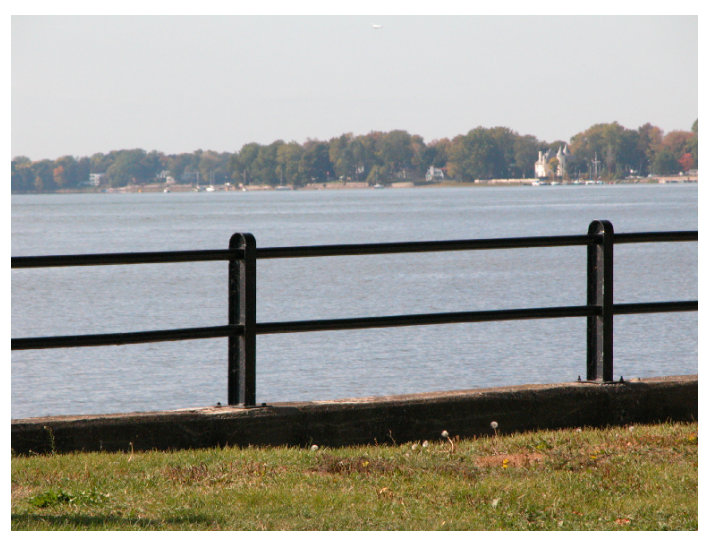

(a) Imagem de entrada

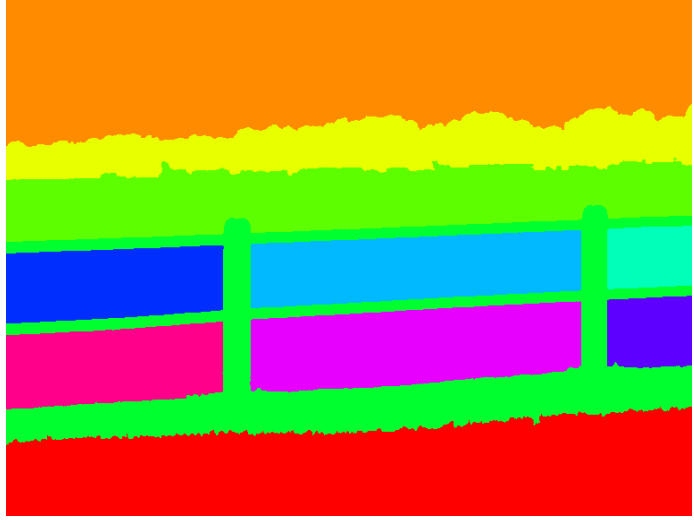

(b) Ground truth

Figura A.5: Tarefa 5.

Tarefa 6: Segmentar os quadrados da textura. Manter o restante (fundo) em uma única região.

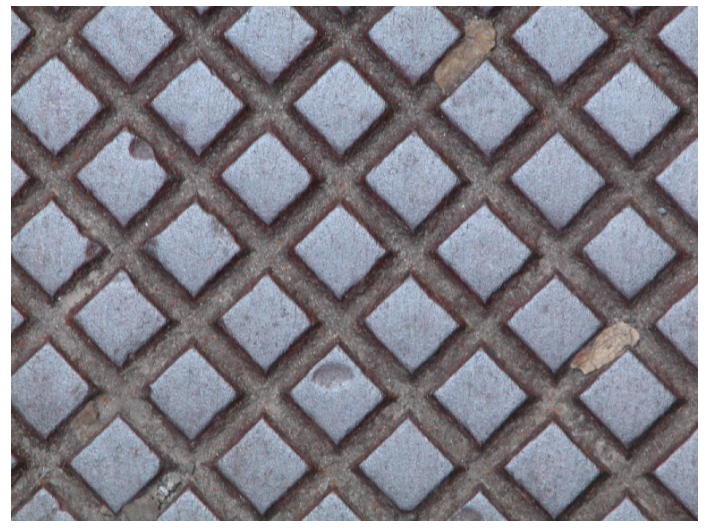

(a) Imagem de entrada

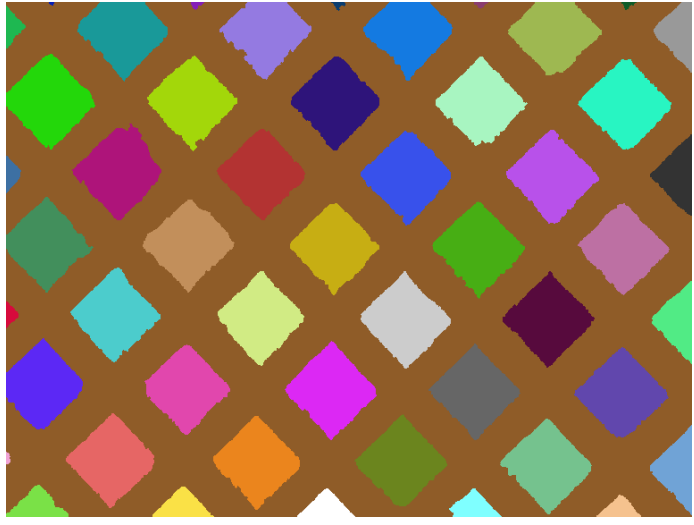

(b) Ground truth

Figura A.6: Tarefa 6 . 
Tarefa 7: Segmentar cada um dos balões. Manter os 2 bicos que aparecem na imagem conectados ao seu balão. Não incluir pedaços do fundo.

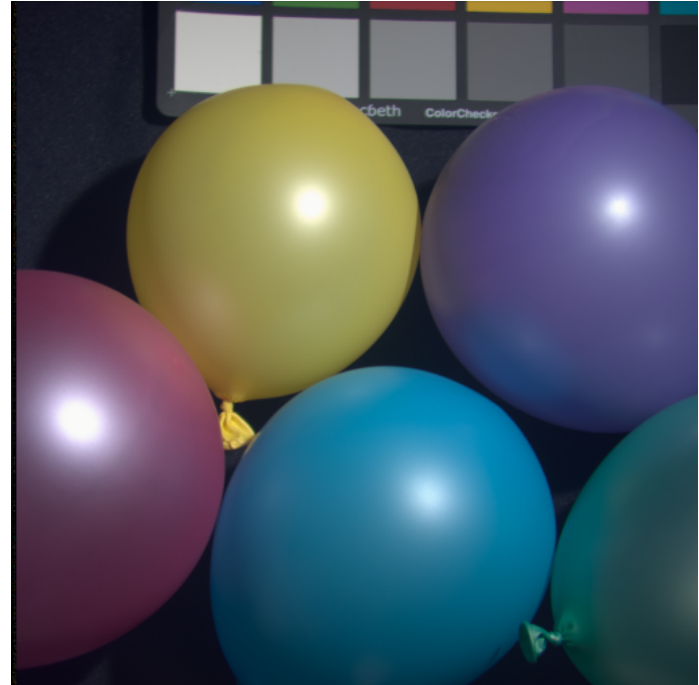

(a) Imagem de entrada

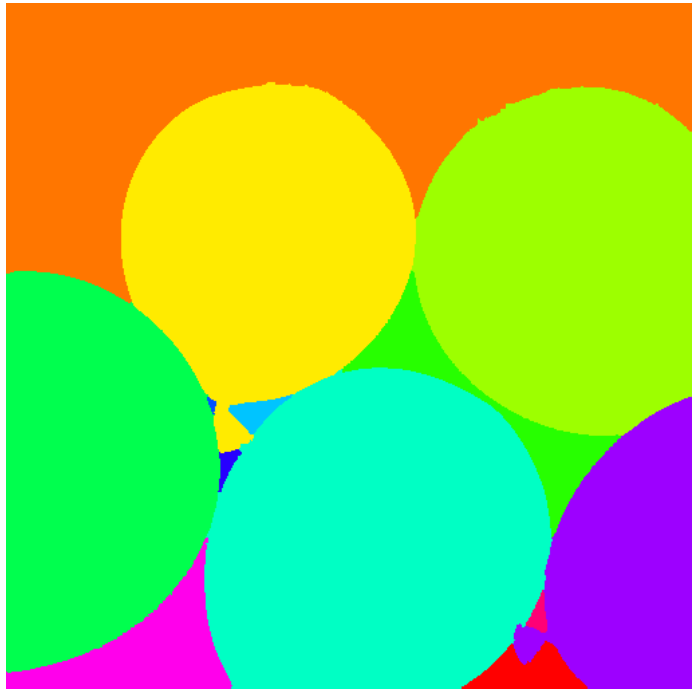

(b) Ground truth

Figura A.7: Tarefa 7.

Tarefa 8: Segmentar cada uma das células.

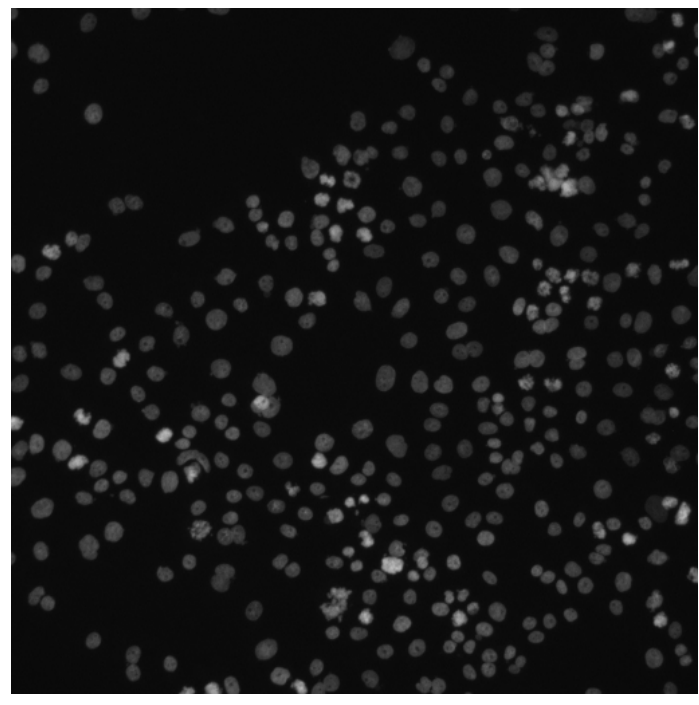

(a) Imagem de entrada

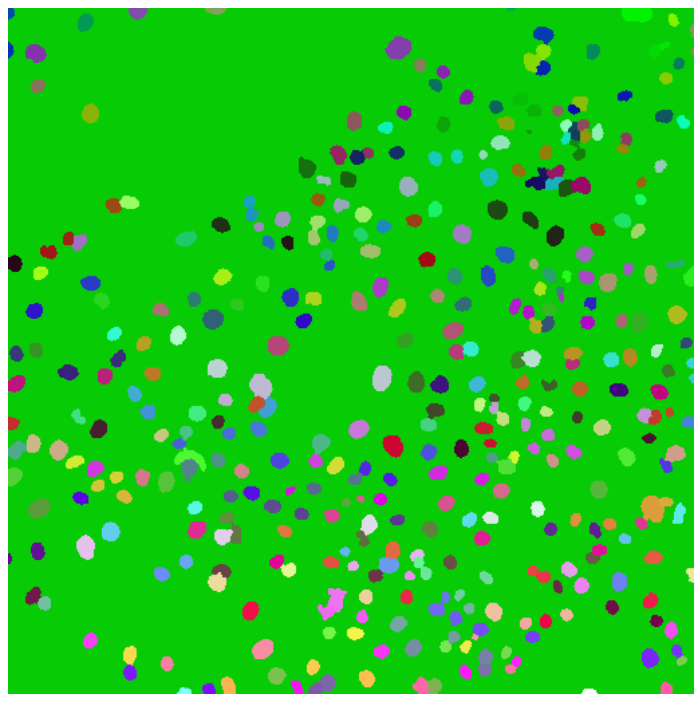

(b) Ground truth

Figura A.8: Tarefa 8. 
Tarefa 9: Segmentar as letras "T", "i", "d" e "e" da maior embalagem. Segmente isoladamente o pingo do "i" e os buracos nas letras "d" e "e".

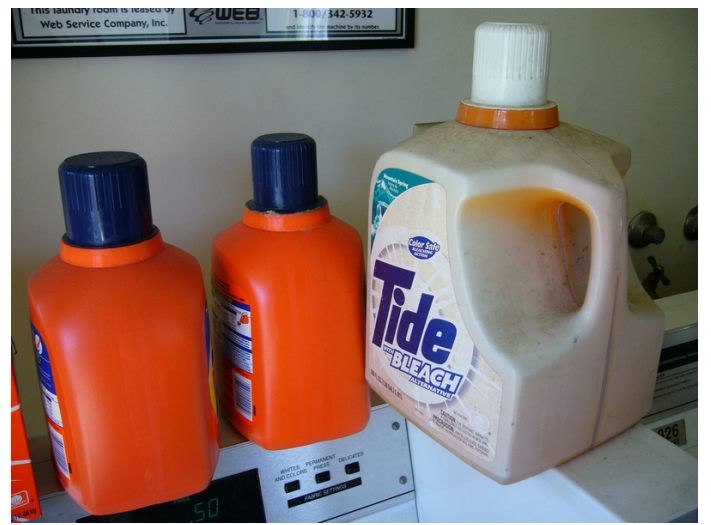

(a) Imagem de entrada

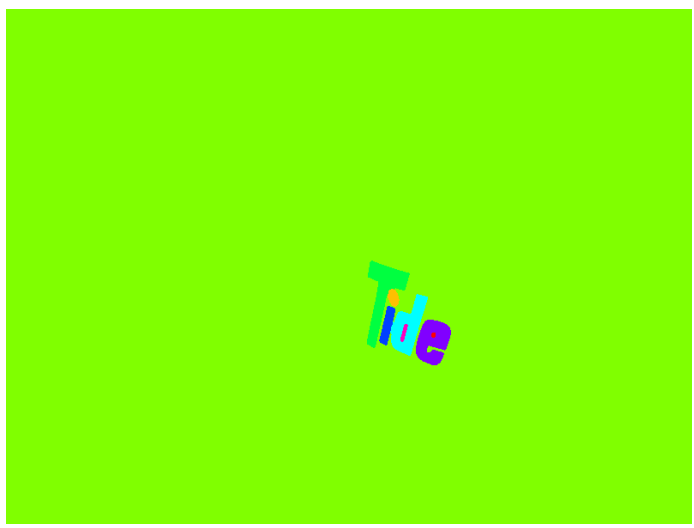

(b) Ground truth

Figura A.9: Tarefa 9.

Tarefa 10: Segmentar o homem e cada lanterna. Considerar apenas a parte amarela com inscrição de cada lanterna (não incluir a parte vermelha).

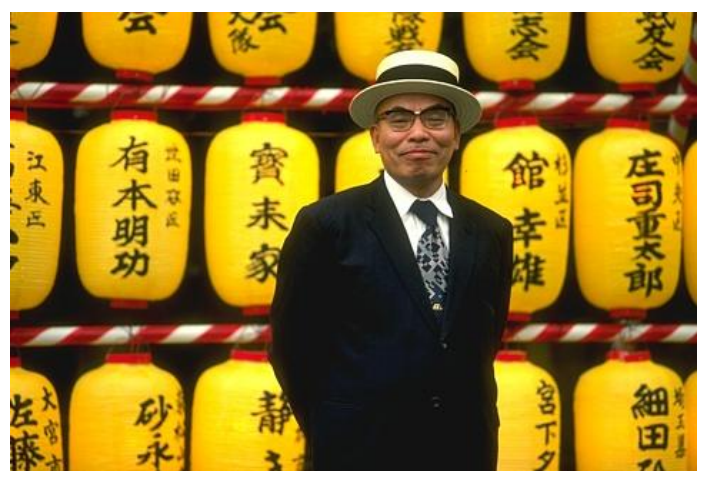

(a) Imagem de entrada

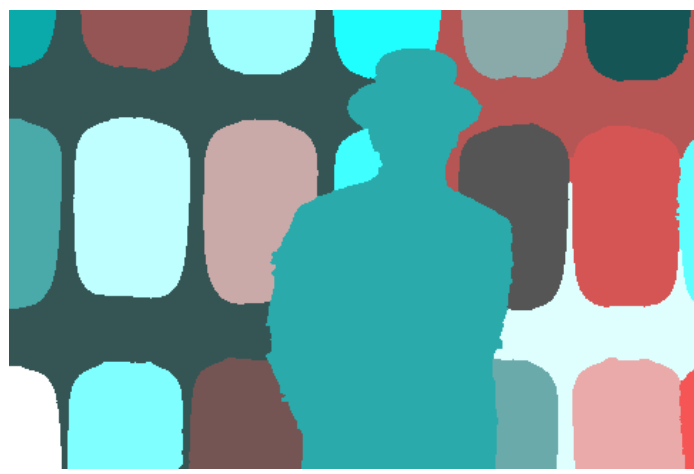

(b) Ground truth

Figura A.10: Tarefa 10. 
Tarefa 11: Segmentar cada um dos 10 espelhos.

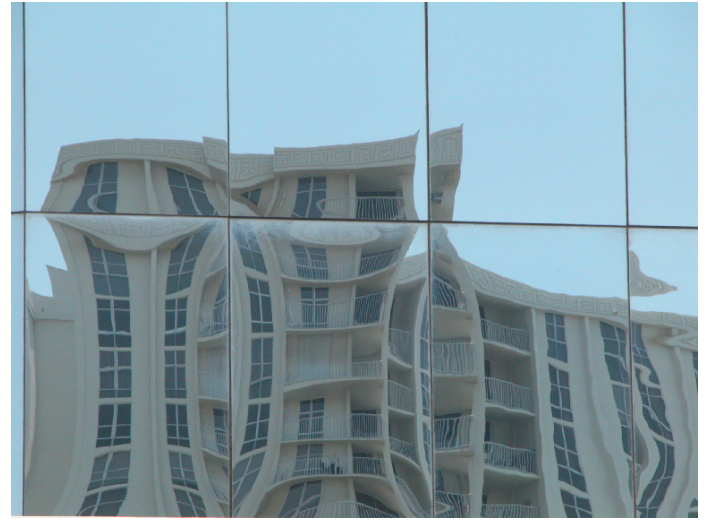

(a) Imagem de entrada

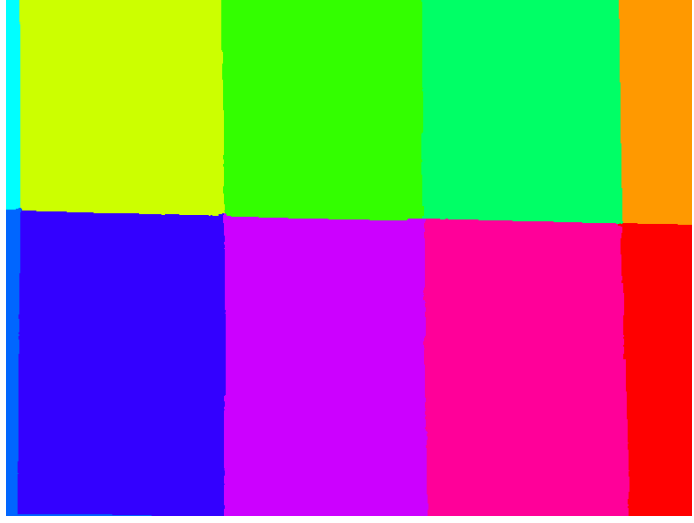

(b) Ground truth

Figura A.11: Tarefa 11.

Tarefa 12: Segmentar cada um dos pimentões. Incluir os pedúnculos (cabos). Não incluir as sombras no fundo.

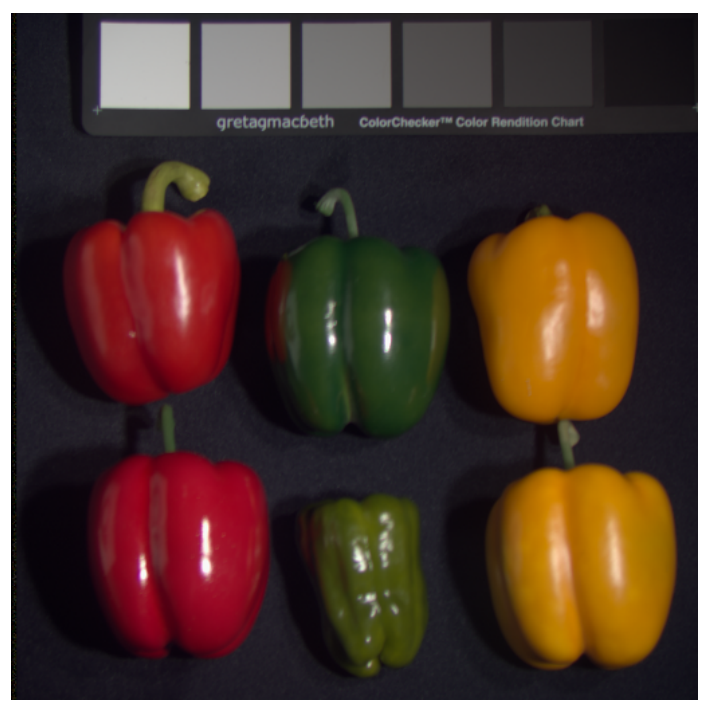

(a) Imagem de entrada

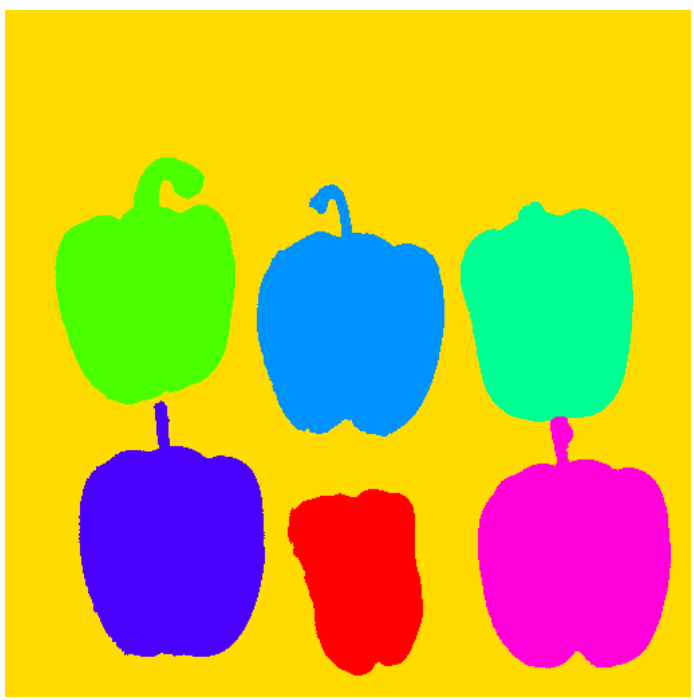

(b) Ground truth

Figura A.12: Tarefa 12. 
Tarefa 13: Segmentar o objeto da imagem, separando cada uma das faces visíveis do poliedro.

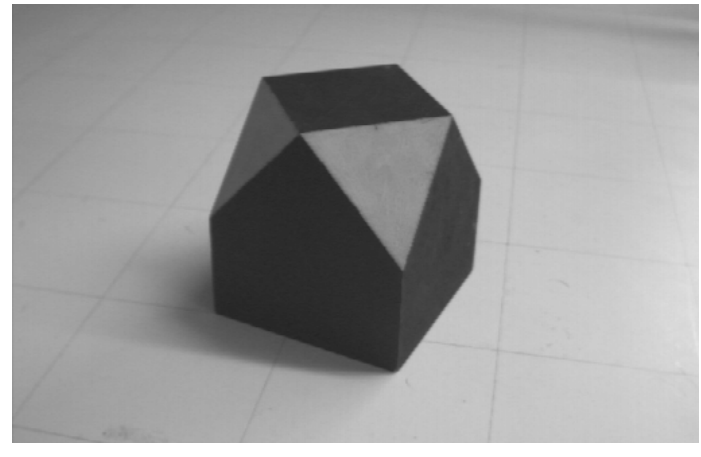

(a) Imagem de entrada

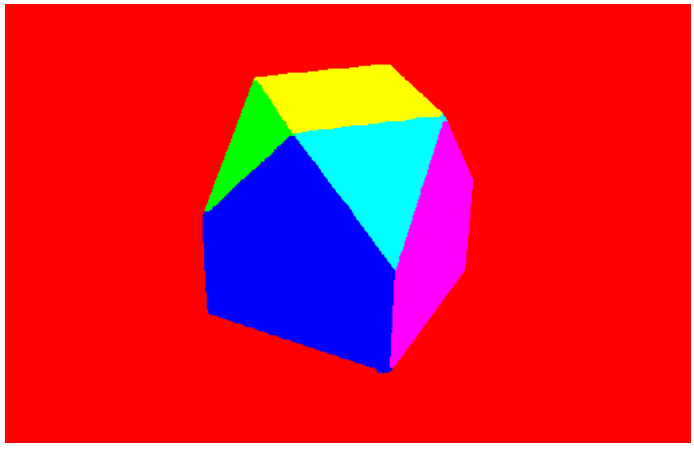

(b) Ground truth

Figura A.13: Tarefa 13.

Tarefa 14: Segmentar o cogumelo.

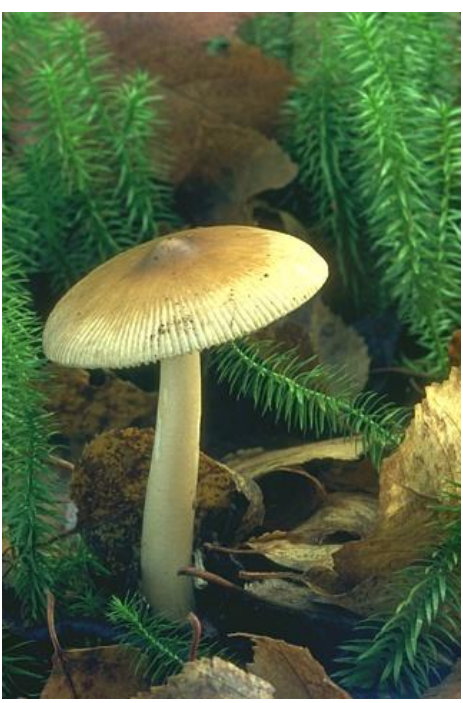

(a) Imagem de entrada

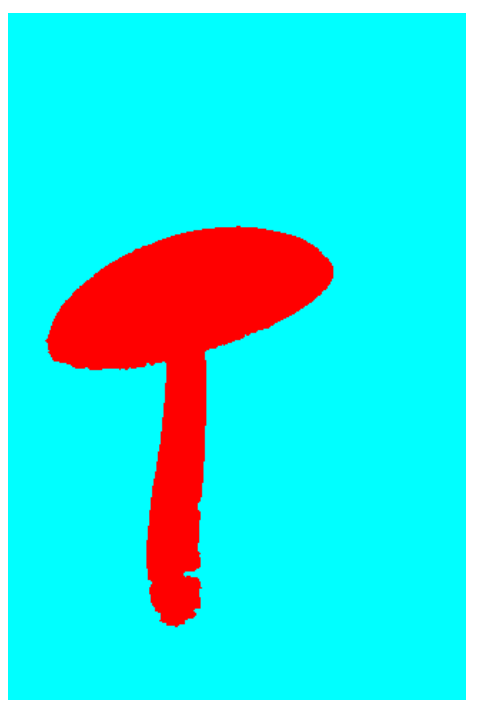

(b) Ground truth

Figura A.14: Tarefa 14. 
Tarefa 15: Segmentar a flor, separando individualmente cada uma das pétalas e a região dos estames (parte central).

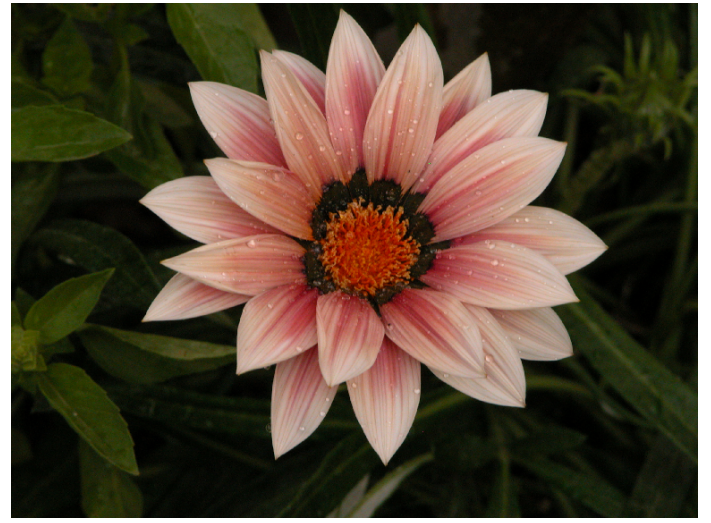

(a) Imagem de entrada

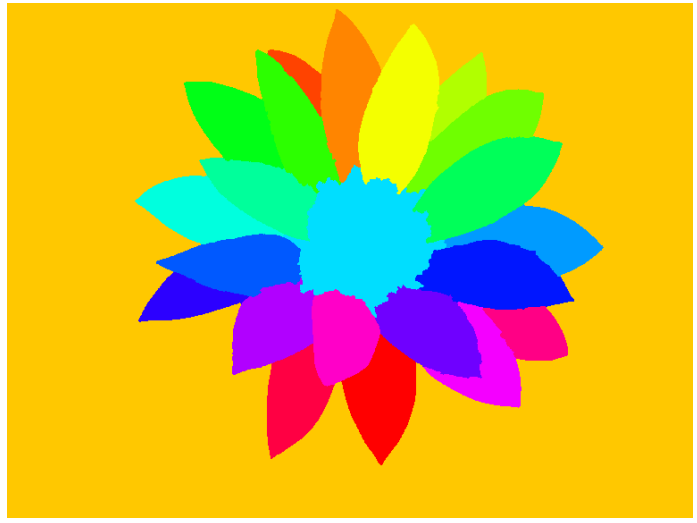

(b) Ground truth

Figura A.15: Tarefa 15.

Tarefa 16: Segmentar cada uma das bolinhas. Não incluir as sombras no fundo.

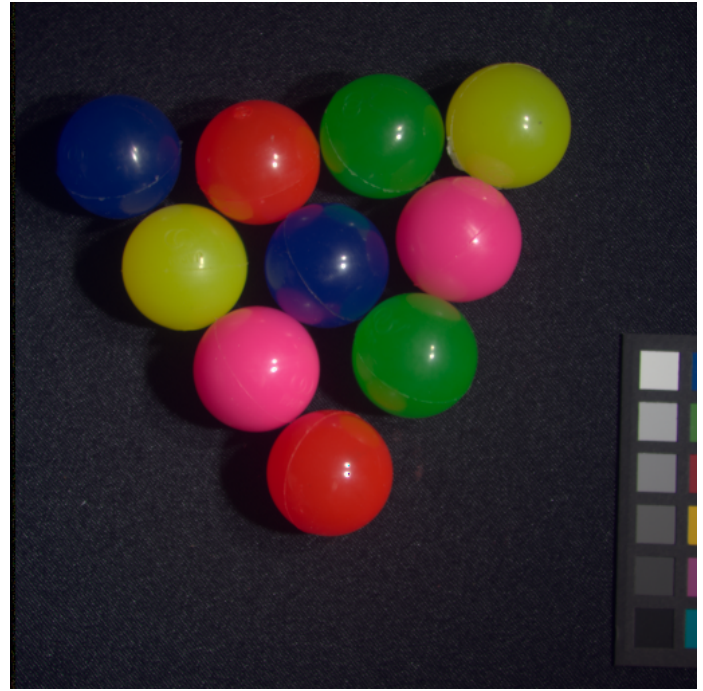

(a) Imagem de entrada

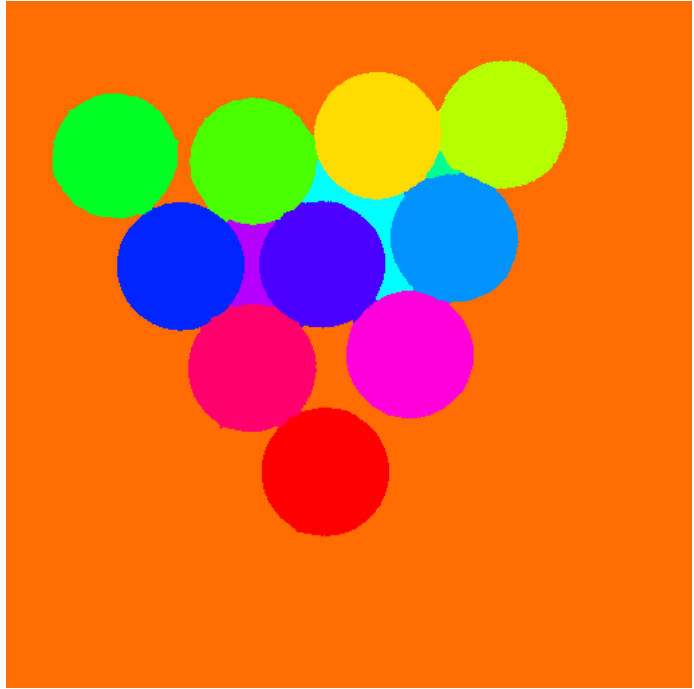

(b) Ground truth

Figura A.16: Tarefa 16. 
Tarefa 17: Segmentar cada um dos vermes. Não incluir pedaços do fundo.

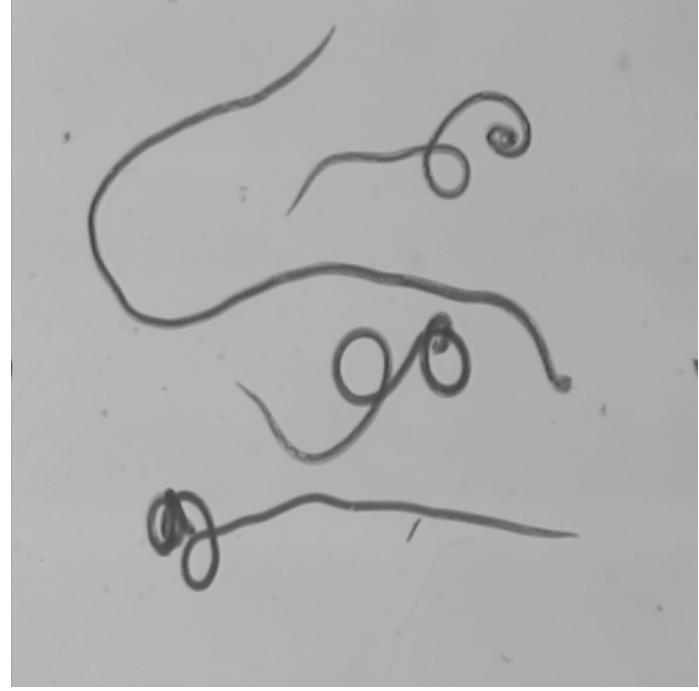

(a) Imagem de entrada

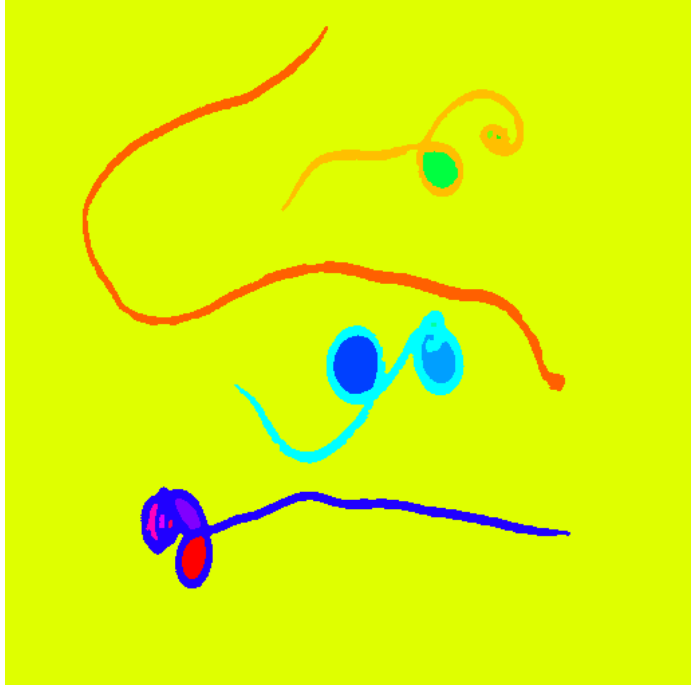

(b) Ground truth

Figura A.17: Tarefa 17.

Tarefa 18: Segmentar a flor, juntando todas as pétalas em uma única região. Não incluir pedaços do fundo.

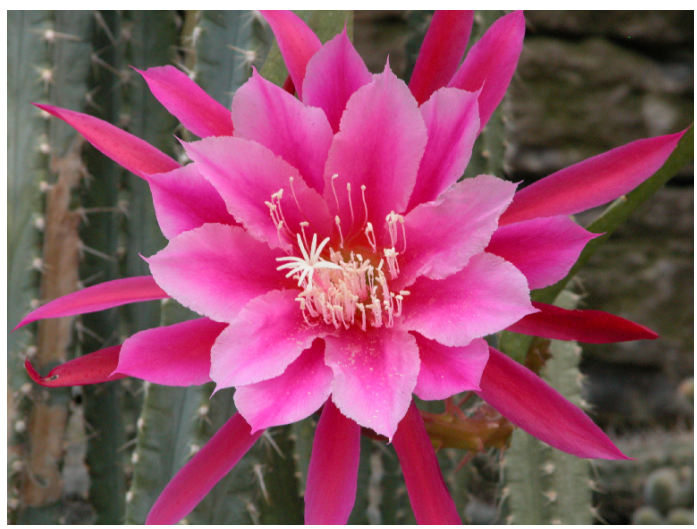

(a) Imagem de entrada

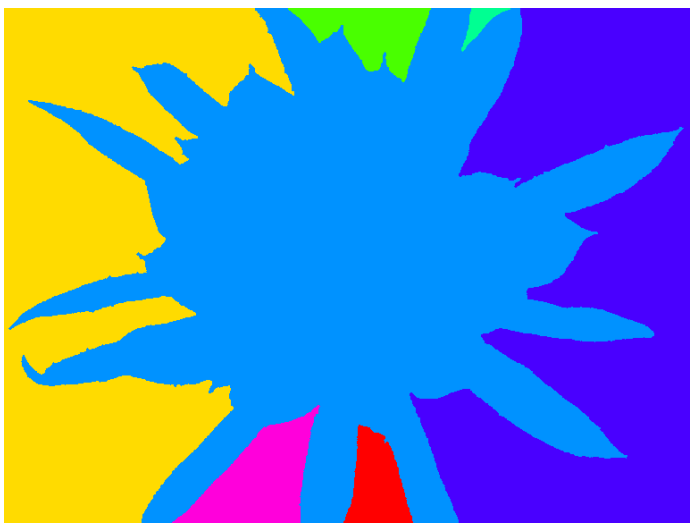

(b) Ground truth

Figura A.18: Tarefa 18. 
Tarefa 19: Segmentar cada um dos carretéis.

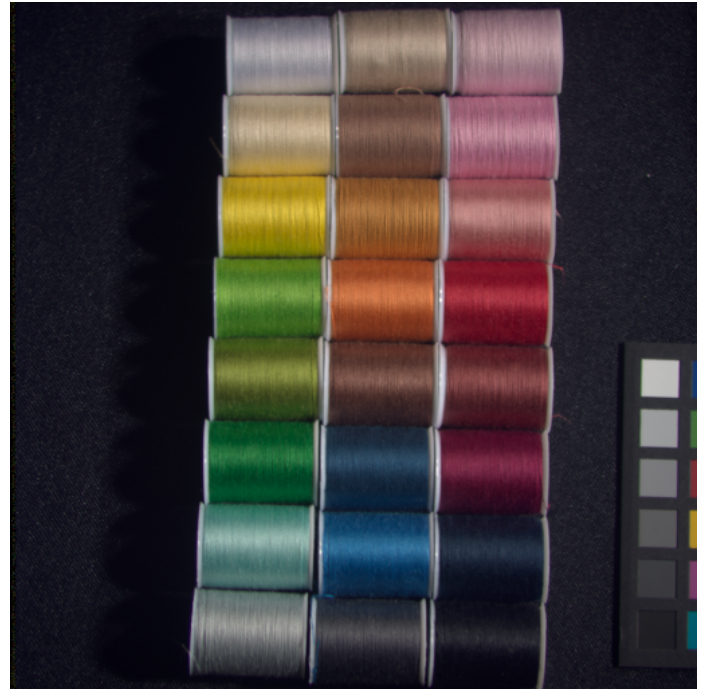

(a) Imagem de entrada

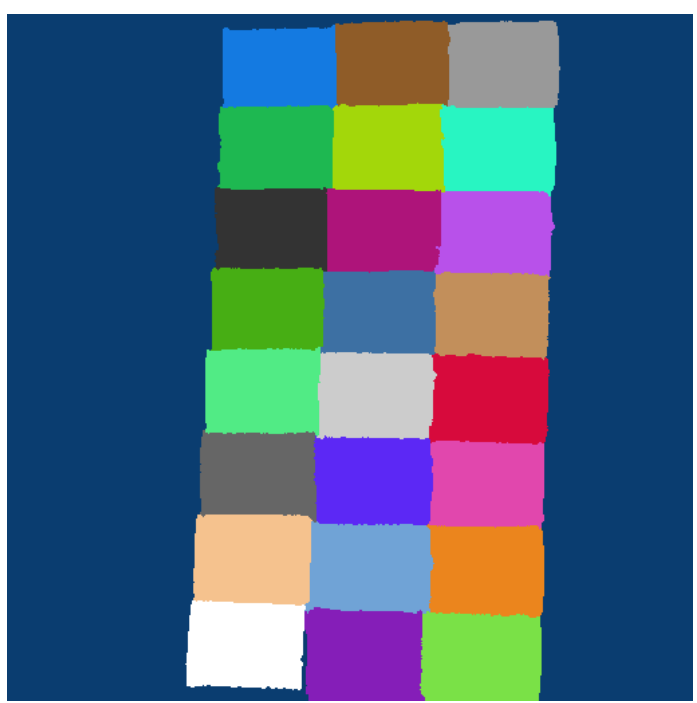

(b) Ground truth

Figura A.19: Tarefa 19.

Tarefa 20: Segmentar a imagem em 3 regiões: a laranja mais a direita isolada, as demais laranjas numa mesma região e o restante da imagem em outra região.

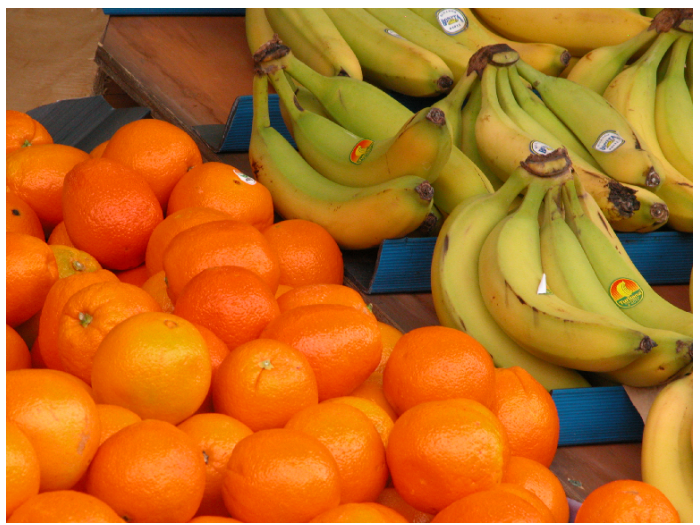

(a) Imagem de entrada

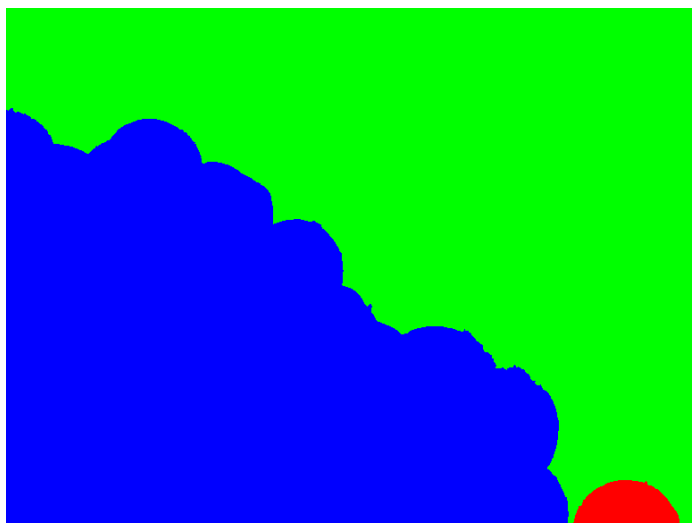

(b) Ground truth

Figura A.20: Tarefa 20. 


\section{Hierarquia de valor médio}

Como foi observado na Seção 4.5, o modelo de interação proposto no Capítulo 4 não é restrito às hierarquias gerada pelo watershed hierárquico. Qualquer hierarquia de partições de imagens representada por uma árvore binária (como a ALC) pode ser manipulada através das operações descritas na Subseção 2.1.3. Nesses casos, o modelo proposto também pode ser utilizado para a simulação de interação utilizando tais hierarquias.

Algoritmos para clustering SAHN $^{1}$ (Jain e Dubes, 1988) podem ser utilizados para gerar hierarquias utilizando alguma métrica definida sobre regiões conexas numa imagem $I:$

- considere uma partição inicial $P_{0}$ da imagem $I$;

- crie um cluster para cada região de $P_{0}$ (tais clusters serão as folhas da hierarquia);

- compute a métrica associada a cada um dos clusters iniciais a partir de alguma métrica bem definida sobre os pixels pertencentes a cada cluster;

- enquanto não houver um único cluster englobando todos os pixels da imagem $I$, faça:

- para cada par $\left\{C_{i}, C_{j}\right\}$ de clusters vizinhos ${ }^{2}$, tais que $C_{i}$ e $C_{j}$ sejam clusters órfãos (sem pai na hierarquia), compute a distância entre as métricas de $C_{i} \mathrm{e}$ $C_{j}$;

- seja $\left\{C_{1}, C_{2}\right\}$ o par de clusters com menor distância entre suas métricas;

\footnotetext{
${ }^{1}$ SAHN: do inglês Sequential, Agglomerative, Hierarchical, Nonoverlapping.

${ }^{2} \mathrm{Um}$ cluster $C_{i}$ é vizinho do cluster $C_{j}$ se e somente se existem pixels $p_{i}$ e $p_{j}$, tais que $p_{i} \in C_{i}, p_{j} \in C_{j}$ e $\left\{p_{i}, p_{j}\right\}$ é um par de pixels adjacentes em $I$.
} 
- crie um novo cluster $C_{3}$, formado pela fusão de $C_{1}$ e $C_{2}\left(C_{3}\right.$ é o pai de $C_{1}$ e $C_{2}$ na hierarquia);

- compute a métrica de $C_{3}$ a partir das métricas de $C_{1}$ e $C_{2}$;

- o último cluster construído, que engloba todos os pixels da imagem $I$, é a raiz da hierarquia.

Em relação aos algoritmos de clustering SAHN descritos em Jain e Dubes (1988), acrescentamos a restrição de que, para formar um novo cluster, o par de clusters a serem fundidos devem ser vizinhos. Essa restrição é necessária para que cada cluster seja formado por uma região conexa na imagem. Dessa forma, a estrutura hierárquica de clusters obtida tem as mesmas propriedades que uma ALC, e todas as operações que aplicamos sobre a ALC também podem ser aplicadas sobre esta hierarquia.

A partição mais fina $P_{0}$ define a granularidade das partições que podem ser obtidas na hierarquia. Podemos usar, por exemplo, a partição gerada pelo watershed clássico.

Uma métrica que pode ser utilizada nesta abordagem de clustering é o valor médio dos níveis de cinza dos pixels de cada cluster, correspondendo ao método UPGMA ${ }^{3}$ dos algoritmos de clustering SAHN. Com esta métrica podemos gerar uma hierarquia de partições que pode demandar menos esforço de interação do que as hierarquias do watershed hierárquico, conforme o exemplo exibido na Figura B.1.

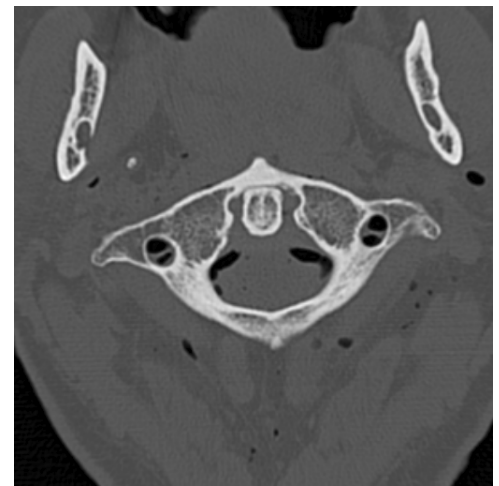

(a) Imagem de entrada

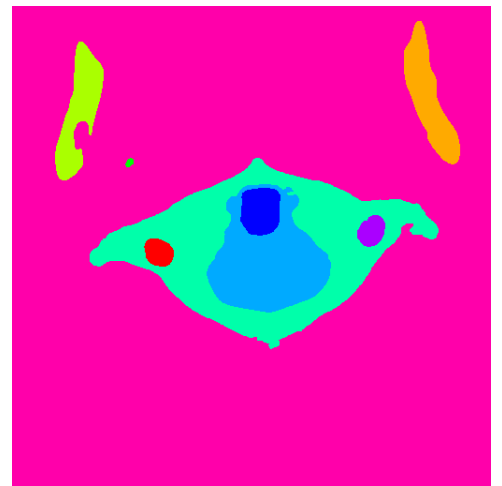

(b) Partição desejada

\begin{tabular}{|l|c|}
\hline Critério & Esforço \\
\hline Profundidade & 200 \\
\hline Área & 165 \\
\hline Volume & 141 \\
\hline Valor médio & 130 \\
\hline
\end{tabular}

(c) Esforço necessário

Figura B.1: Imagem segmentada mais facilmente usando a hierarquia de valor médio: o esforço necessário para segmentar a imagem exibida em (a), de forma a obter a partição exibida em (b), é menor para a hierarquia de valor médio, comparando com o esforço necessário para se obter a mesma partição com as hierarquias do watershed hierárquico, conforme a medida definida na Seção 5.1.

\footnotetext{
${ }^{3}$ UPGMA: do inglês Unweighted Pair Group Method using arithmetic Averages.
} 
A seguir exibimos os níveis mais altos da hierarquia de valor médio para a imagem da Figura B.1. A hierarquia construída com essa métrica gera partições que podem ser mais interessante para certas imagens.
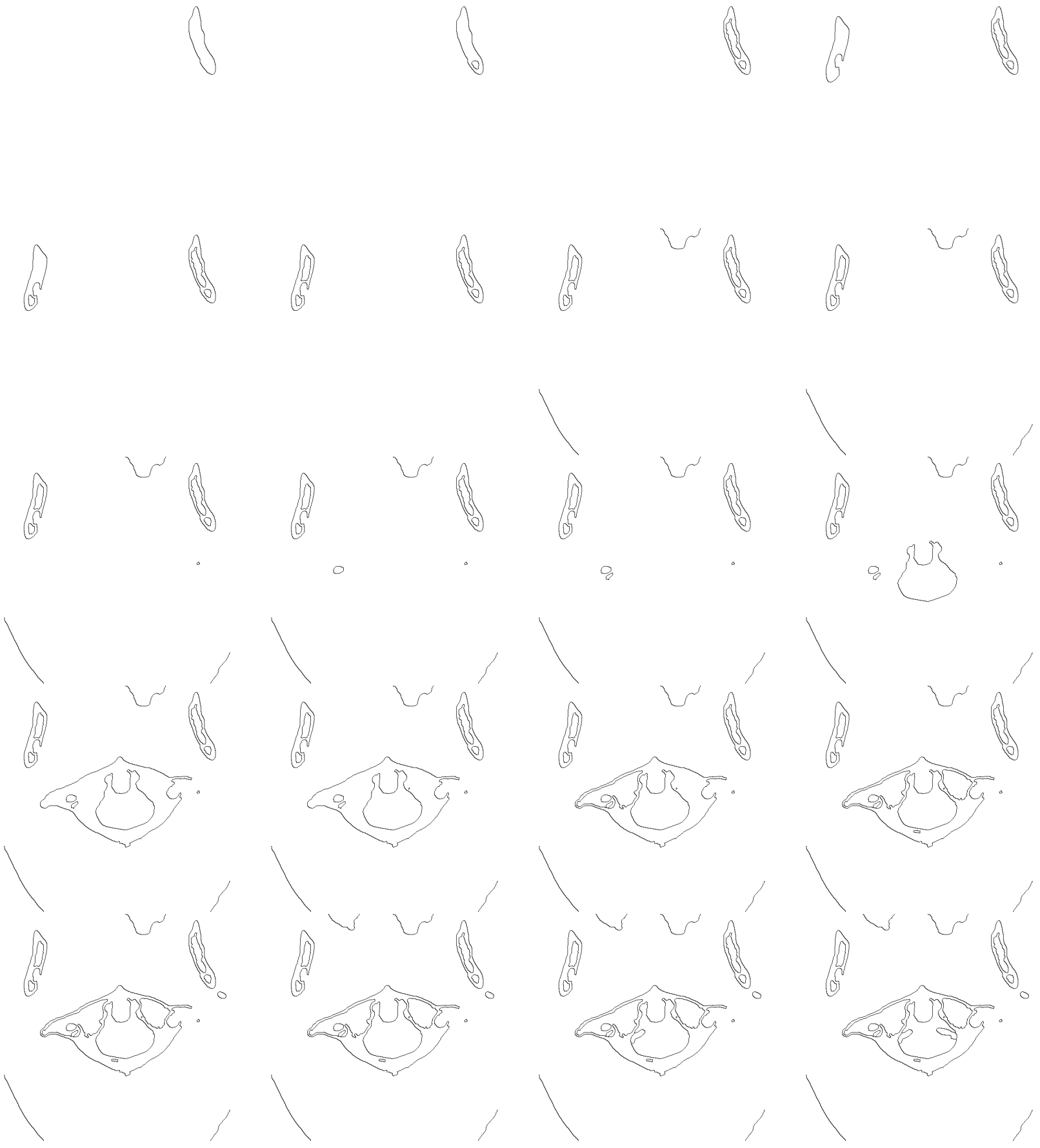


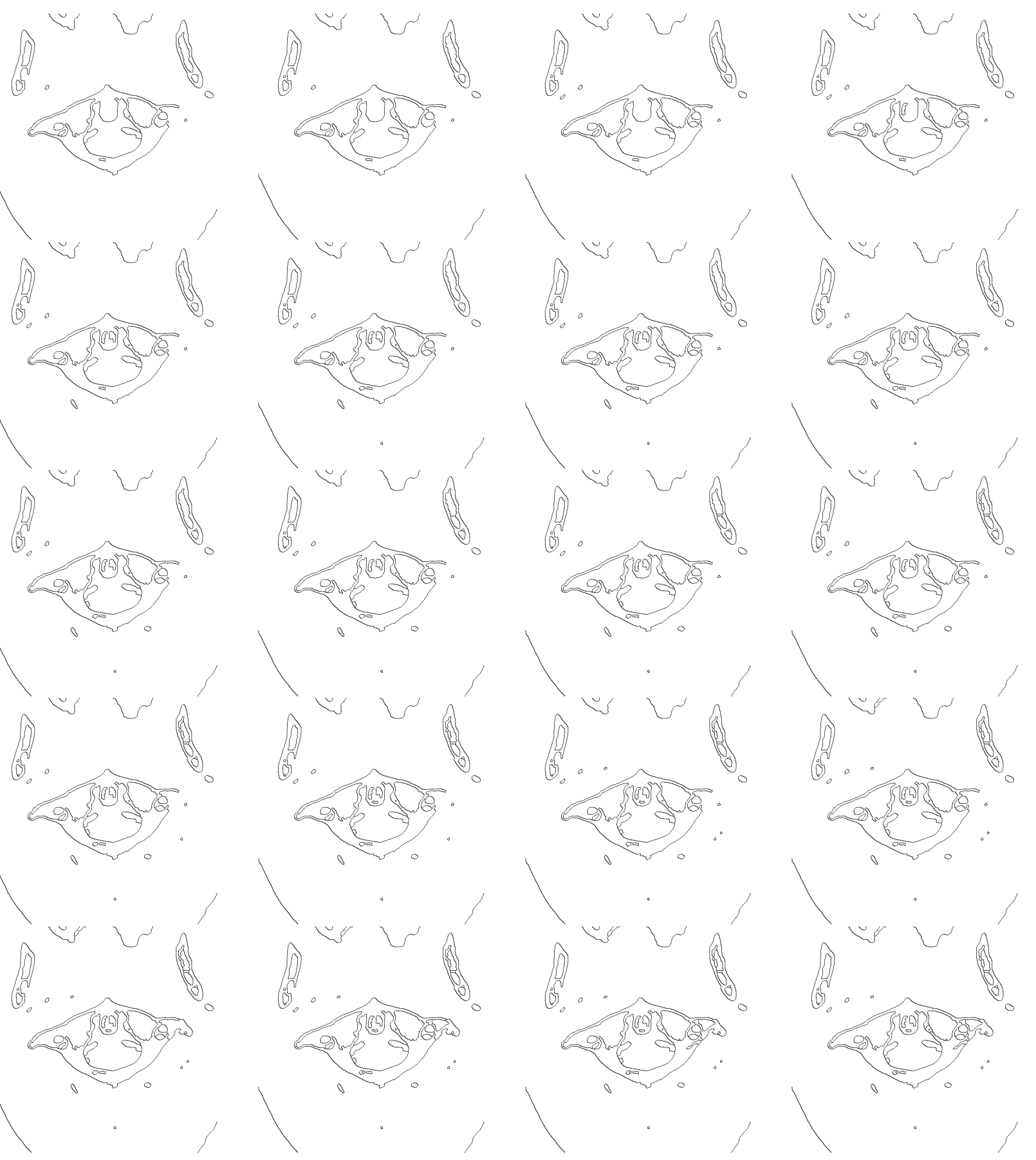




\section{Referências Bibliográficas}

Audigier e Lotufo(2007) Romaric Audigier e Roberto Lotufo. Seed-relative segmentation robustness of watershed and fuzzy connectedness approaches. Em SIBGRAPI '0\%: Proceedings of the XX Brazilian Symposium on Computer Graphics and Image Processing, páginas 61-70, Washington, DC, USA. IEEE Computer Society. ISBN 07695-2996-8. doi: http://dx.doi.org/10.1109/SIBGRAPI.2007.38. Citado na pág. 9, 15

Beucher e Meyer(1993) S. Beucher e F. Meyer. Mathematical Morphology in Image Processing, chapter The Morphological Approach to Segmentation: The Watershed Transformation, páginas 433-481. Marcel Dekker. Citado na pág. 2

Beucher e Lantuejoul(1979) Serge Beucher e Christian Lantuejoul. Use of watersheds in contour detection. Em Proceedings of the International Workshop on Image Processing: Real-Time Edge and Motion Detection/Estimation. Citado na pág. 7

Blake et al.(2004) Andrew Blake, Carsten Rother, M. Brown, Patrick Pérez e Philip H. S. Torr. Interactive image segmentation using an adaptive GMMRF model. Em Tomás Pajdla e Jiri Matas, editors, ECCV (1), volume 3021 of Lecture Notes in Computer Science, páginas 428-441. Springer. URL http://dblp.uni-trier.de/db/conf/eccv/ eccv2004-1.html\#BlakeRBPT04. Citado na pág. 2

Cates et al.(2005) Joshua E. Cates, Ross T. Whitaker e Greg M. Jones. Case study: an evaluation of user-assisted hierarchical watershed segmentation. Medical Image Analysis, 9(6):566-578. Citado na pág. 2

Chang e Lin(2011) Chih-Chung Chang e Chih-Jen Lin. LIBSVM: A library for support vector machines. ACM Transactions on Intelligent Systems and Technology, 2:27:1- 
27:27. Software available at http://www.csie.ntu.edu.tw/ ${ }^{c j l i n / l i b s v m . ~ C i t a d o ~ n a ~}$ pág. 51

Falcão et al.(1998) Alexandre X. Falcão, Jayaram K. Udupa, Supun Samarasekera, Shoba Sharma, Bruce Elliot Hirsch e Roberto de A. Lotufo. User-steered image segmentation paradigms: Live wire and live lane. Graphical Models and Image Processing, 60(4):233 - 260. ISSN 1077-3169. doi: http://dx.doi.org/10.1006/gmip.1998.0475. URL http: //www.sciencedirect.com/science/article/pii/S1077316998904750. Citado na pág. 2

Falcão et al.(2004) Alexandre X. Falcão, Jorge Stolfi e Roberto de Alencar Lotufo. The image foresting transform: Theory, algorithms, and applications. IEEE Trans. Pattern Anal. Mach. Intell., 26(1):19-29. ISSN 0162-8828. doi: http://dx.doi.org/10.1109/ TPAMI.2004.1261076. Citado na pág. 10

Flores e Lotufo(2010) Franklin César Flores e Roberto de Alencar Lotufo. Watershed from propagated markers: An interactive method to morphological object segmentation in image sequences. Image Vision Comput., 28(11):1491-1514. ISSN 0262-8856. doi: 10.1016/j.imavis.2009.06.015. URL http://dx.doi.org/10.1016/j.imavis.2009.06. 015. Citado na pág. 82

Gerstmayer et al.(2011) Michael Gerstmayer, Yll Haxhimusa e Walter G. Kropatsch. Hierarchical interactive image segmentation using irregular pyramids. Em Proceedings of the 8th international conference on Graph-based representations in pattern recognition, GbRPR'11, páginas 245-254. Springer-Verlag. ISBN 978-3-642-20843-0. URL http: //dl.acm.org/citation. cfm?id=2009206.2009235. Citado na pág. 2

Gonzalez e Woods(2002) Rafael C. Gonzalez e Richard E. Woods. Digital Image Processing. Prentice Hall, 2nd edição. Citado na pág. 26

Hahn e Peitgen(2003) Horst K. Hahn e Heinz-Otto Peitgen. Iwt-interactive watershed transform: a hierarchical method for efficient interactive and automated segmentation of multidimensional gray-scale images, 2003. URL http://dx.doi.org/10.1117/12. 481097. Citado na pág. 2

Jain e Dubes(1988) Anil K. Jain e Richard C. Dubes. Algorithms for clustering data. Prentice-Hall, Inc., Upper Saddle River, NJ, USA. ISBN 0-13-022278-X. Citado na pág. 95, 96

Klava(2009) Bruno Klava. Segmentação interativa de imagens via transformação watershed. Dissertação de Mestrado, Instituto de Matemática e Estatística da Universidade de São Paulo. Citado na pág. 3, 7, 16

Klava e Hirata(2009) Bruno Klava e Nina Sumiko Tomita Hirata. Interactive image segmentation with integrated use of the markers and the hierarchical watershed approaches. 
Em Proceedings of the Fourth International Conference on Computer Vision Theory and Applications, volume 1, páginas 186-193. ISBN 978-989-8111-69-2. Citado na pág. 2, 13

Klava e Hirata(2014) Bruno Klava e Nina Sumiko Tomita Hirata. A model for simulating user interaction in hierarchical segmentation. Em Proceedings of IEEE International Conference on Image Processing (ICIP 2014). Citado na pág. 81

Kohli et al.(2012) Pushmeet Kohli, Hannes Nickisch, Carsten Rother e Christoph Rhemann. User-centric learning and evaluation of interactive segmentation systems. Int. J. Comput. Vision, 100(3):261-274. Citado na pág. 3

McGuinness e O'Connor(2010) Kevin McGuinness e Noel E. O'Connor. A comparative evaluation of interactive segmentation algorithms. Pattern Recogn., 43(2):434-444. Citado na pág. 3

McGuinness e O'Connor(2011) Kevin McGuinness e Noel E. O'Connor. Toward automated evaluation of interactive segmentation. Computer Vision and Image Understanding, 115(6):868 - 884. ISSN 1077-3142. doi: 10.1016/j.cviu.2011.02.011. URL http: //www.sciencedirect.com/science/article/pii/S1077314211000889. Citado na pág. 3, 4,29

Meilă(2007) Marina Meilă. Comparing clusterings - an information based distance. Journal of Multivariate Analysis, 98(5):873 - 895. Citado na pág. 17

Meyer(1986) F. Meyer. Sequential algorithms cell segmentation: maximum efficiency? Em Proceedings of the International Symposium on Clinical Cytometry and Histometry. Citado na pág. 7, 9

Meyer(2001a) F. Meyer. An overview of morphological segmentation. International Journal of Pattern Recognition and Artificial Intelligence (IJPRAI), 15(7):1089-1118. Citado na pág. 7

Meyer e Beucher(1990) F. Meyer e S. Beucher. Morphological segmentation. Journal of Visual Communication and Image Representation, 1(1):21-46. Citado na pág. 2, 7

Meyer(1996) Fernand Meyer. The dynamics of minima and contours. Em P. Maragos, R. W. Schafer e M. A. Butt, editors, Mathematical Morphology and its Applications to Image and Signal Processing, páginas 329-336. Kluwer Academic Publishers. Citado na pág. 11

Meyer(2001b) Fernand Meyer. Hierarchies of partitions and morphological segmentation. Em Scale-Space '01: Proceedings of the Third International Conference on Scale-Space and Morphology in Computer Vision, páginas 161-182, London, UK. Springer-Verlag. ISBN 3-540-42317-6. Citado na pág. 13 
Mortensen e Barrett(1998) Eric N. Mortensen e William A. Barrett. Interactive segmentation with intelligent scissors. Graphical Models and Image Processing, 60 (5):349 - 384. doi: http://dx.doi.org/10.1006/gmip.1998.0480. URL http://www . sciencedirect.com/science/article/pii/S1077316998904804. Citado na pág. 2

Moschidis e Graham(2010) Emmanouil Moschidis e Jim Graham. A systematic performance evaluation of interactive image segmentation methods based on simulated user interaction. Em Proceedings of the 2010 IEEE International Conference on Biomedical imaging: from Nano to Macro, ISBI'10, páginas 928-931. Citado na pág. 4

Ning et al.(2010) Jifeng Ning, Lei Zhang, David Zhang e Chengke Wu. Interactive image segmentation by maximal similarity based region merging. Pattern Recogn., 43(2):445456. ISSN 0031-3203. doi: 10.1016/j.patcog.2009.03.004. URL http://dx.doi.org/10. $1016 / j$. patcog.2009.03.004. Citado na pág. 2

Noma et al.(2011) Alexandre Noma, Alvaro Pardo e Roberto M. Cesar, Jr. Structural matching of 2D electrophoresis gels using deformed graphs. Pattern Recogn. Lett., 32: 3-11. ISSN 0167-8655. doi: http://dx.doi.org/10.1016/j.patrec.2010.02.016. URL http: //dx.doi.org/10.1016/j.patrec.2010.02.016. Citado na pág. 82

Pont-Tuset e Marqués(2013) Jordi Pont-Tuset e Ferran Marqués. Measures and metameasures for the supervised evaluation of image segmentation. Em CVPR, páginas 2131-2138. Citado na pág. 3, 17

Rodgers e Nicewander(1988) J. L. Rodgers e W. A. Nicewander. Thirteen ways to look at the correlation coefficient. The American Statistician, 42:59-66. Citado na pág. 41

Shotton et al.(2009) Jamie Shotton, John Winn, Carsten Rother e Antonio Criminisi. TextonBoost for image understanding: Multi-class object recognition and segmentation by jointly modeling texture, layout, and context. Int. J. Comput. Vision, 81:2-23. ISSN 0920-5691. doi: 10.1007/s11263-007-0109-1. URL http://portal .acm.org/citation . cfm?id=1487450.1487516. Citado na pág. 26

Unnikrishnan et al.(2007) Ranjith Unnikrishnan, Caroline Pantofaru e Martial Hebert. Toward objective evaluation of image segmentation algorithms. IEEE Trans. Pattern Anal. Mach. Intell., 29(6):929-944. URL http://dblp.uni-trier.de/db/journals/ pami/pami29.html\#UnnikrishnanPH07. Citado na pág. 3

Zanoguera et al.(1999) F. Zanoguera, B. Marcotegui e F. Meyer. A toolbox for interactive segmentation based on nested partitions. Em Proceedings of the International Conference on Image Processing, volume 1, páginas 21-25. Citado na pág. 2, 11

Zhao et al.(2011) Yibiao Zhao, Xiaohan Nie, Yanbiao Duan, Yaping Huang e Siwei Luo. A benchmark for interactive image segmentation algorithms. Em Person-Oriented Vision 
(POV), 2011 IEEE Workshop on, páginas 33-38. doi: 10.1109/POV.2011.5712366. Citado na pág. 4 